Meylí Valin Fernández

\title{
DESENVOLVIMENTO DA MICROSCOPIA HOLOGRÁFICA DIGITAL POR REFLEXÃO PARA AVALIAÇÃO 3D DE SUPERFICIES.
}

São Paulo 
Meylí Valin Fernández

\section{DESENVOLVIMENTO DA MICROSCOPIA HOLOGRÁFICA DIGITAL POR REFLEXÃO PARA AVALIAÇÃO 3D DE SUPERFICIES.}

Tese apresentada à Escola Politécnica da Universidade de São Paulo para obtenção do título de Doutora em Ciências.

Área de Concentração: Engenharia Mecânica e de Projetos de Fabricação

Orientador: Prof. Dr. Edison Gonçalves

São Paulo

2017 
Este exemplar foi revisado e corrigido em relação à versão original, sob responsabilidade única do autor e com a anuência de seu orientador.

São Paulo, de de

Assinatura do autor:

Assinatura do orientador:

Catalogação-na-publicação

Fernández, Meylí

Desenvolvimento da microscopia holográfica digital por reflexão para avaliação 3D de superfícies. / M. Fernández -- versão corr. -- São Paulo, 2017. $149 \mathrm{p}$.

Tese (Doutorado) - Escola Politécnica da Universidade de São Paulo. Departamento de Engenharia Mecatrônica e de Sistemas Mecânicos.

1.Holografia Digital 2.Microscopia Holográfica Digital 3.Rugosidade Superficial I.Universidade de São Paulo. Escola Politécnica. Departamento de Engenharia Mecatrônica e de Sistemas Mecânicos II.t. 


\section{Agradecimentos}

Este não é o trabalho de uma pessoa só, sinto a obrigação de expressar aqui o meu infinito agradecimento a todos aqueles que colaboraram na realização desta tese e que em todo momento ofereceram a sua desinteressada ajuda.

Agradeço ao meu orientador Prof. Dr. Edison Gonçalves, pela possibilidade que me ofereceu de compartilhar estes anos, pela sua constante orientação e permanente incentivo para o desenvolvimento deste trabalho.

Agradeço ao Professor Dr. Jorge Octavio Ricardo Pérez, pela ajuda oferecida, troca de ideias, orientação no desempenho experimental e orientação teórica.

Aos professores Mikiya Muramatsu e Oswaldo Horikawa pelas indicações que deram abertura à iniciativa que fortaleceu este trabalho.

Agradeço ao Professor Dr. Marcos Roberto da Rocha Gesualdi, pela colaboração acadêmica que pemitiu o desempenho deste trabalho.

Agradeço a Francisco Palacios pela colaboração com o programa Holodig.

Agradeço aos meus amigos, em especial a Alexander Alfonso. A modéstia é para o mérito o que as sombras são para um quadro, dão-lhe forma e relevo. Você com sua modéstia sempre me guiou pelo caminho da sabedoria, obrigada meu amigo. Agradeço também à minha amiga Adriane Lopes do laboratório CEFCON, pelos momentos que compartilhamos juntas. A Leandro Ticlia do Instituto Oceanográfico, pela ajuda na programação no Matlab.

Agradeço aos professores Angelo Fernando Padilha e Eduardo Monlevade, e ao Técnico Responsável Rafael Rocha Maia, do Laboratório de Caracterização Microestrutural do Departamento de Engenharia Metalúrgica e de Materiais, pela atenção, orientação e disposição para o uso das instalações e equipamentos.

Agradeço aos técnicos da oficina do Departamento de Mecatrônica, Cisero, Carlos, Fidel e Rafael, pela ajuda na elaboração das amostras. Ao técnico Casio, do Laboratório de Fenômenos de Superfície (LFS), pela assessoria nas medições no Perfilômetro óptico 3D sem contacto CCI MP.

Agradeço à minha família. Aos que estão, e aqueles que não estão mais conosco, as lembranças do seu apoio, força e motivação me ajudaram a nunca perder o foco do que eu queria no meu caminho profissional.

"O sonho de cada família é poder viver junta e feliz, num lar tranquilo e pacífico, em que os pais têm oportunidade de criar os filhos da melhor maneira possível, ou de orientá-los e ajudar a escolher as suas carreiras, dando-lhes o amor e carinho que desenvolverá neles um sentimento de segurança e de autoconfiança". Sou abençoada por ter isso na minha vida, obrigada pai, obrigada mãe, obrigada irmã! Este trabalho é para vocês! 


\section{Resumo}

Dentre dos procedimentos geradores de perfil óptico encontra-se a microscopia holográfica digital. Esta ferramenta interferométrica surgiu da ideia inicial proposta por D. Gabor sobre holografia, a qual permite mediante o registro da interferência de campos ópticos coerentes, guardar e extrair informações de imagens. A microscopia holográfica digital permite a análise de objetos com resoluções transversais semelhantes às obtidas por microscopia óptica, e ainda, possui a vantagem pela natureza da holografia de permitir realizar análises através do acesso a valores quantitativos de fase. Apresentam-se neste trabalho os conceitos básicos da holografia digital e da microscopia holográfica digital, com o objetivo, de introduzir o desenvolvimento de uma metodologia para a implementação da microscopia holográfica digital por reflexão para o controle dimensional de objetos e determinação da rugosidade superficial de amostras de aço. Os hologramas são obtidos mediante uma instalação óptica, que consiste em um interferômetro de Michelson por reflexão com o uso de uma lente objetiva de microscópio e uma câmera CCD sem lente. Para a reconstrução das imagens de contraste de fase são utilizadas técnicas numéricas que capacitam à microscopia holográfica digital para a supressão do termo de ordem zero, controle da resolução de pixel, desmodulação da fase óptica, determinação dos mapas de intensidades e fase, filtragem e compensação de aberrações dos hologramas obtidos. As reconstruções numéricas dos feixes objeto e referência são realizadas utilizando o método de dupla propagação. Foi desenvolvido um algoritmo que apresenta a imagem de contraste de fase com base num critério de distância a partir de um único holograma. Desta forma o programa utilizado permite a realização de medições quantitativas das dimensões dos objetos e da rugosidade superficial de amostras de aço, assim como, a representação em $3 \mathrm{D}$ da imagem de fase reconstruída com resultados validados através de um perfilômetro óptico 3D sem contacto modelo CCI-MP.

Palavras-chave: Holografia digital, Microscopia Holográfica Digital, Rugosidade Superficial. 


\section{Abstract}

Among the procedures generating optical profile is the digital holographic microscopy. This interferometric tool arose from the initial idea proposed by D. Gabor on holography, which allows by recording the interference of coherent optical fields, save and extract information from images. Digital holographic microscopy allows the analysis of objects with transversal resolutions similar to those obtained by optical microscopy, and also has the advantage of the nature of holography to allow to perform analyzes through the access to quantitative phase values. This paper presents the basic concepts of digital holography and digital holographic microscopy, with the objective of introducing the development of a methodology for the implementation of digital holographic microscopy by reflection for the dimensional control of objects and determination of surface roughness of samples of steel. The holograms are obtained by means of an optical installation consisting of a Michelson interferometer by reflection using an objective microscope lens and a lensless CCD camera. For the reconstruction of phase contrast images, numerical techniques are used that enable digital holographic microscopy to suppress the zero-order term, control pixel resolution, optical phase demodulation, determination of intensity and phase maps, filtering and compensation of aberrations of the obtained holograms. Numerical reconstructions of the object and reference beams are performed using the double propagation method. An algorithm has been developed that presents the phase contrast image based on a distance criterion from a single hologram. In this way the program used allows the realization of quantitative measurements of the object dimensions and the surface roughness of steel samples, as well as the 3D representation of the reconstructed phase image with results validated through a $3 \mathrm{D}$ contactless optical profilometer model CCI- MP.

Keywords: Digital holography; Digital holographic microscopy, Surface roughness. 


\section{Sumário}

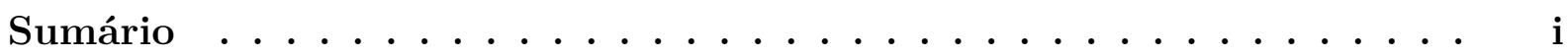

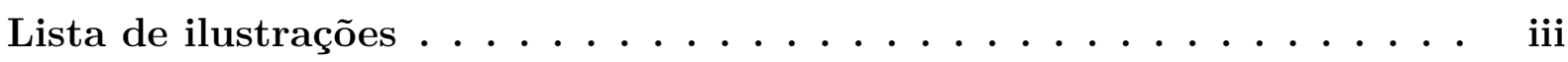

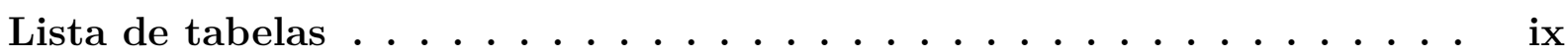

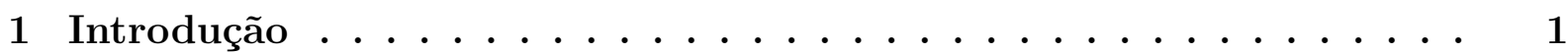

1.1 Considerações Iniciais . . . . . . . . . . . . . . . . . . . . . 1

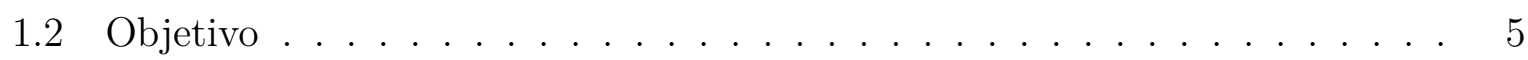

1.3 Relevância e Justificativa da Tese . . . . . . . . . . . . . . . . . . 6

1.4 Escopo do Trabalho . . . . . . . . . . . . . . . . 7

2 Fundamentos da Holografia $\ldots \ldots \ldots \ldots \ldots \ldots$

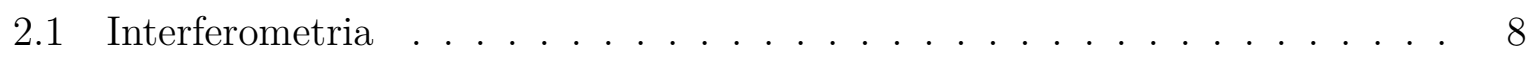

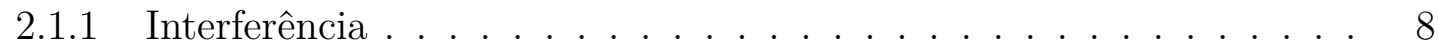

2.1.2 Interferômetro de Michelson . . . . . . . . . . . . . . . . . 9

2.1.3 Diferença de fase e interferência . . . . . . . . . . . . . . . 10

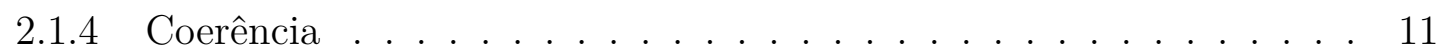

2.1.4.1 Coerência temporal . . . . . . . . . . . . . . . 11

2.1.4.2 Coerência espacial . . . . . . . . . . . . . . . 13

2.2 Holografia Digital . . . . . . . . . . . . . . . . . . . 14

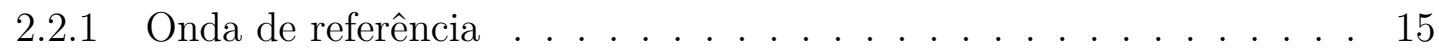

2.2 .2 Reconstrução numérica da imagem . . . . . . . . . . . . . 16

2.2 .3 Supressão do termo ordem zero . . . . . . . . . . . . . 18

2.2 .4 Desmodulação . . . . . . . . . . . . . . . . . . . . . 20

2.3 Microscopia Holográfica Digital _ . . . . . . . . . . . . . . . . 22

2.3 .1 Resolução Lateral . . . . . . . . . . . . . . . . . . . . . . . 23

2.3 .2 Profundidade de campo . . . . . . . . . . . . . . . . 24

2.3 .3 Iluminação do laser . . . . . . . . . . . . . . . . . . 25

2.3.4 Reconstrução em Microscopia Holográfica Digital (DHM) . . . . . . 25

2.3.5 Método de Dupla Propagação como método numérico de reconstrução holográfica . . . . . . . . . . . . . . 26

3 Técnica proposta para análise da rugosidade superficial . . . . . . 31

3.1 Técnica . . . . . . . . . . . . . . . . . 31

3.2 Processamento das imagens $\ldots \ldots \ldots \ldots \ldots \ldots \ldots$

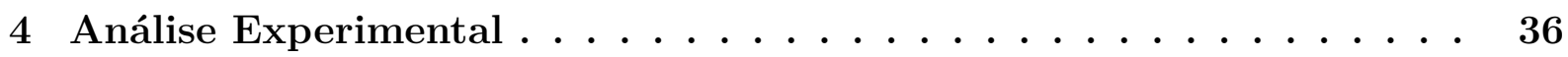

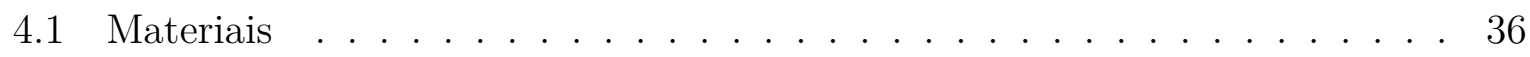

4.2 Métodos . . . . . . . . . . . . . . . . . . . . . 39

4.2.1 Preparação das amostras de objetos para a análise dimensional. . . 39 
4.2.2 Metodologia para captura e processamento dos hologramas, reconstrução numérica e análise dimensional. . . . . . . . . . . . . . 39

4.2 .3 Resultados preliminares. . . . . . . . . . . . . . . 46

5 Análise da rugosidade superficial . . . . . . . . . . . . 51

5.1 Fundamentos da Rugosidade Superficial . . . . . . . . . . . . . . . . . 51

5.1 .1 Erros macrogeométricos . . . . . . . . . . . . . 52

5.1 .2 Erros microgeométricos . . . . . . . . . . . . . . . 52

5.1 .3 Sistemas de medição da rugosidade . . . . . . . . . . . . . . . 53

5.1 .4 Sistema "E" . . . . . . . . . . . . . . . . . . . 53

5.1 .5 Sistema " $M$ " o da linha média . . . . . . . . . . . . 53

5.1 .6 Parâmetros de rugosidade . . . . . . . . . . . . . . . 55

5.1.7 Sistemas com base na profundidade da rugosidade. Rugosidade média aritmética $(R a) \ldots \ldots \ldots \ldots$

5.1 .8 Utilização do parâmetro Ra . . . . . . . . . . . . . . . . 58

5.2 Técnica para medir rugosidade superficial através da microscopia holográfica digital por reflexão. . . . . . . . . . . . . . . . . . . . . 59 59

5.2.1 Elaboração e preparação das amostras. . . . . . . . . . . . . . . . 62

5.3 Execução das medições. . . . . . . . . . . . . . . . . . . . 64

5.4 Algoritmo e metodologia para medição da Ra . . . . . . . . . . . . . . . 64

5.5 Perfilômetro óptico 3D sem contato modelo CCI MP. . . . . . . . . . . . 66

5.6 Resultados da análise da rugosidade superficial. . . . . . . . . . . . . . . 67

5.7 Análise Estatística. . . . . . . . . . . . . . . . . . . . . . . 79

6 Conclusões e Recomendações . . . . . . . . . . . . . . . . . 90

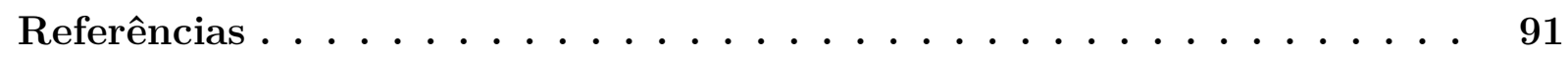

Apêndices $\quad 95$

APÊNDICE A Algoritmo para o cálculo da rugosidade superficial Ra. 96 APÊNDICE B Resultados da rugosidade superficial do Perfilometro óptico 3D sem contacto CCI. . . . . . . . . . 99

APÊNDICE C Resultados dos valores da (Ra) por amostras e suas respectivas regiões. .............. 130

APÊNDICE D Resultados da Análise Estatística. . . . . . . . . 145 


\section{Lista de ilustrações}

Figura 2.1 - Configuração básica do interferômetro de Michelson. . . . . . . . . . . 9

Figura 2.2 - Geometria de reconstrução para a holografia de Fresnel sem lentes. . 16

Figura 2.3 - Reconstrução de uma imagem sem ordem zero. . . . . . . . . . . . . . 20

Figura 2.4 - Diagrama dos métodos tradicionais de reconstrução de imagem no DHM. 26

Figura 2.5 - Reconstrução da onda de distribuição õ $(u, v)$ no plano de reconstrução $(u-v)$ com uma distância $z=D$ (primeira propagação). . . . . . . . 27

Figura 2.6 - Reconstrução da frente de onda óptico $o\left(x^{\prime}, y^{\prime} ; d^{\prime}\right)$ no plano imagem a partir do plano $(u-v)$ (segunda propagação). . . . . . . . . . . . . . 28

Figura 4.1 - (a) Parafuso M3 sem cabeça com sextavado interior, (b) Parafuso sem fim. . . . . . . . . . . . . . . . . . 36

Figura 4.2 -Engrenagem . . . . . . . . . . . . . . . . . . . . . . 36

Figura 4.3 - Configuração experimental. . . . . . . . . . . . . . . . . . 37

Figura 4.4 - Escala padrão para calibração . . . . . . . . . . . . . . . . . . . . 38

Figura 4.5 - Janela principal do HOLODIG. . . . . . . . . . . . . . . . . . . . . 40

Figura 4.6 - Acesso à janela de Captura. . . . . . . . . . . . . . . . . . . . . . . . . 40

Figura 4.7 - Janela de Captura. . . . . . . . . . . . . . . . . . . . . . . . . . . . . 40

Figura 4.8 - Escala padrão de 1 milímetro para calibração. . . . . . . . . . . . . . . 41

Figura 4.9 - Holograma capturado com seu padrão de interferência definido. . . . . . 41

Figura 4.10-Espectro de Fourier do Holograma. . . . . . . . . . . . . . . . . . . . . 42

Figura 4.11-Seleção da área para a reconstrução. . . . . . . . . . . . . . . . . . . . 42

Figura 4.12-Imagem obtida sem nenhum processo. . . . . . . . . . . . . . . . . 43

Figura 4.13-Resultado após a desmodulação. . . . . . . . . . . . . . . . . . . . . . 43

Figura 4.14-Resultado final do processo de reconstrução. . . . . . . . . . . . . . . . 44

Figura 4.15-Imagem de contraste de fase em 3D . . . . . . . . . . . . . . . . 44

Figura 4.16-Medição do passo do parafuso. . . . . . . . . . . . . . . . . . . . . . . . 45

Figura 4.17-Barra de ferramentas do ImageJ. . . . . . . . . . . . . . . . . . . . . . 45

Figura 4.18-Medição do passo do parafuso. . . . . . . . . . . . . . . . . . . 45

Figura 4.19-Resultados das medições. . . . . . . . . . . . . . . . . . . . . . 46

Figura 4.20-Imagem de distribuição do contraste de fase reconstruída do parafuso

M3 cabeça hexagonal. . . . . . . . . . . . . . . . . . . 46

Figura 4.21-Representação em 3D da imagem reconstruída do parafuso M3 cabeça hexagonal . . . . . . . . . . . . . . . . . . 4 47

Figura 4.22-Imagem de distribuição de contraste de fase reconstruída de uma seção do parafuso M3 sem cabeça com sextavado interno . . . . . . . . . . . 47

Figura 4.23-Representação em 3D da imagem reconstruída do parafuso M3 sem cabeça com sextavado interno. . . . . . . . . . . . . . . . . . . . . 48 
Figura 4.24-Imagem de distribuição de contraste de fase reconstruída de uma seção do parafuso sem fim . . . . . . . . . . . . . . . . . 48

Figura 4.25-Representação em 3D da imagem reconstruída do parafuso sem fim. . . 49

Figura 4.26-Imagem de distribuição de contraste de fase reconstruída de uma seção de uma engrenagem . . . . . . . . . . . . . . . . . . . . . . . 49

Figura 4.27-Representação em 3D da imagem reconstruída do parafuso sem fim. . . 50

Figura 5.1 - Características de uma superfície . . . . . . . . . . . . . . 51

Figura 5.2 - Compartimento de uma amostra com uma linha média traçada . . . . 54

Figura 5.3 - Traçado sem exclusão da ondulação . . . . . . . . . . . . . . . . . . 54

Figura 5.4 - Módulos de medição . . . . . . . . . . . . . . . . . . . . 55

Figura 5.5 - Extensão da amostra e divisões . . . . . . . . . . . . . . . . . 55

Figura 5.6 - Rugosidade média aritmética Ra . . . . . . . . . . . . . . . 56

Figura 5.7 - Amostra ou corpo de prova . . . . . . . . . . . . . . . . . 60

Figura 5.8-Microscópio Eletrônico de Varredura (SEM), Jeol Intouch Scope/JSM-6010La. . . . . . . . . . . . . . . . 6 60

Figura 5.9 - Superfície do corpo de prova obtida pelo Microscópio Eletrônico . . . 61

Figura 5.10-Análise química do corpo de prova . . . . . . . . . . . . . . 61

Figura 5.11-Amostras após preparação metalográfica. . . . . . . . . . . . . . 63

Figura 5.12-Amostra No.10 após processo de polido. . . . . . . . . . . . . . . 63

Figura 5.13-Regiões onde foram realizadas as medições de Ra. . . . . . . . . . . . . 64

Figura 5.14-Várias medições de Ra para uma região de uma amostra. . . . . . . . . 65

Figura 5.15-Resultados de Ra obtidos. . . . . . . . . . . . . . . . . . . 66

Figura 5.16-Perfilômetro óptico 3D sem contato modelo CCI MP . . . . . . . . . . 67

Figura 5.17-Exemplo de medição com uma amostra de Aço 1010. . . . . . . . . . . 67

Figura 5.18-Imagem reconstruída em 3D da Amostra No.1 Região 1. . . . . . . . . 68

Figura 5.19-Imagem reconstruída em 3D da Amostra No.1 Região 2. . . . . . . . . 68

Figura 5.20-Imagem reconstruída em 3D da Amostra No.1 Região 3. . . . . . . . . 68

Figura 5.21-Imagem reconstruída em 3D da Amostra No.2 Região 1. . . . . . . . . 69

Figura 5.22-Imagem reconstruída em 3D da Amostra No.2 Região 2. . . . . . . . . 69

Figura 5.23-Imagem reconstruída em 3D da Amostra No.2 Região 3. . . . . . . . . 69

Figura 5.24-Imagem reconstruída em 3D da Amostra No.3 Região 1. . . . . . . . . 70

Figura 5.25-Imagem reconstruída em 3D da Amostra No.3 Região 2. . . . . . . . . 70

Figura 5.26-Imagem reconstruída em 3D da Amostra No.3 Região $3 . . . . .70$

Figura 5.27-Imagem reconstruída em 3D da Amostra No.4 Região 1. . . . . . . . . 71

Figura 5.28-Imagem reconstruída em 3D da Amostra No.4 Região 2. . . . . . . . . 71

Figura 5.29-Imagem reconstruída em 3D da Amostra No.4 Região 3. . . . . . . . . 71

Figura 5.30-Imagem reconstruída em 3D da Amostra No.5 Região 1. . . . . . . . . 72

Figura 5.31-Imagem reconstruída em 3D da Amostra No.5 Região 2. . . . . . . . . 72

Figura 5.32-Imagem reconstruída em 3D da Amostra No.5 Região 3. . . . . . . . . 72 
Figura 5.33-Imagem reconstruída em 3D da Amostra No.6 Região 1. . . . . . . . . 73

Figura 5.34-Imagem reconstruída em 3D da Amostra No.6 Região 2. . . . . . . . . 73

Figura 5.35-Imagem reconstruída em 3D da Amostra No.6 Região 3. . . . . . . . . 73

Figura 5.36-Imagem reconstruída em 3D da Amostra No.7 Região 1. . . . . . . . . 74

Figura 5.37-Imagem reconstruída em 3D da Amostra No.7 Região 2. . . . . . . . . 74

Figura 5.38-Imagem reconstruída em 3D da Amostra No.7 Região 3. . . . . . . . . 74

Figura 5.39-Imagem reconstruída em 3D da Amostra No.8 Região 1. . . . . . . . . 75

Figura 5.40-Imagem reconstruída em 3D da Amostra No.8 Região 2. . . . . . . . . 75

Figura 5.41-Imagem reconstruída em 3D da Amostra No.8 Região 3. . . . . . . . . 75

Figura 5.42-Imagem reconstruída em 3D da Amostra No.9 Região 1. . . . . . . . . 76

Figura 5.43-Imagem reconstruída em 3D da Amostra No.9 Região 2. . . . . . . . . 76

Figura 5.44-Imagem reconstruída em 3D da Amostra No.9 Região $3 . \quad$. . . . . . . 76

Figura 5.45-Imagem reconstruída em 3D da Amostra No.10 Região 1. . . . . . . . . 77

Figura 5.46-Imagem reconstruída em 3D da Amostra No.10 Região 2 . . . . . . . . 77

Figura 5.47-Imagem reconstruída em 3D da Amostra No.10 Região 3. . . . . . . . . 77

Figura 5.48-Comportamento da rugosidade Ra segundo o tipo da lixa utilizado por amostra. . . . . . . . . . . . . . . . . . 79

Figura 5.49-Variação dos picos e vales da Ra segundo o número da lixa. . . . . . . . 79

Figura 5.50-Gráfico da dispersão de Ra obtidos através dos dois métodos. . . . . . 81

Figura 5.51-Diagrama de extremos e quartis de DHM e CCI. . . . . . . . . . . . . . 81

Figura $5.52-$ Modelo ajustado . . . . . . . . . . . . . . . . . . 84

Figura 5.53-Gráfico da Dispersão por Nível. . . . . . . . . . . . . . . . . . . . . 87

Figura 5.54 -Diagrama de extremos e quartis. . . . . . . . . . . . . . . . . . 87

Figura 5.55-Modelo ajustado. . . . . . . . . . . . . . . . . . . . . . . . . 89

Figura B.1-Amostra 1 Região 1 Perfil da Superfície. . . . . . . . . . . . . . . . . 100

Figura B.2-Relação dos parâmetros obtidos da Amostra 1 Região 1. . . . . . . . . 100

Figura B.3-Amostra 1 Região 1 Resultados em 3D . . . . . . . . . . . . . . . . . . 100

Figura B.4-Amostra 1 Região 2 Perfil da Superfície. . . . . . . . . . . . . . . . . . 101

Figura B.5-Relação dos parâmetros obtidos da Amostra 1 Região 2. . . . . . . . . 101

Figura B.6-Amostra 1 Região 2 Resultados em 3D . . . . . . . . . . . . . . . . . . 101

Figura B.7-Amostra 1 Região 3 Perfil da Superfície. . . . . . . . . . . . . . . . . . 102

Figura B.8-Relação dos parâmetros obtidos da Amostra 1 Região 3. . . . . . . . . 102

Figura B.9-Amostra 1 Região 3 Resultados em 3D . . . . . . . . . . . . . . . . . . 102

Figura B.10-Amostra 2 Região 1 Perfil da Superfície. . . . . . . . . . . . . . . . . . 103

Figura B.11-Relação dos parâmetros obtidos da Amostra 2 Região 1. . . . . . . . . 103

Figura B.12-Amostra 2 Região 1 Resultados em 3D . . . . . . . . . . . . . . . . . . 103

Figura B.13-Amostra 2 Região 2 Perfil da Superfície. . . . . . . . . . . . . . . . . . 104

Figura B.14-Relação dos parâmetros obtidos da Amostra 2 Região 2. . . . . . . . . 104

Figura B.15-Amostra 2 Região 2 Resultados em 3D. . . . . . . . . . . . . . . . . . 104 
Figura B.16-Amostra 2 Região 3 Perfil da Superfície. . . . . . . . . . . . . . . . . . 105

Figura B.17-Relação dos parâmetros obtidos da Amostra 2 Região 3. . . . . . . . . 105

Figura B.18-Amostra 2 Região 3 Resultados em 3D. . . . . . . . . . . . . . . . . 105

Figura B.19-Amostra 3 Região 1 Perfil da Superfície. . . . . . . . . . . . . . . . . 106

Figura B.20-Relação dos parâmetros obtidos da Amostra 3 Região 1. . . . . . . . . 106

Figura B.21-Amostra 3 Região 1 Resultados em 3D . . . . . . . . . . . . . . . . 106

Figura B.22-Amostra 3 Região 2 Perfil da Superfície. . . . . . . . . . . . . . . . . 107

Figura B.23-Relação dos parâmetros obtidos da Amostra 3 Região 2. . . . . . . . . 107

Figura B.24-Amostra 3 Região 2 Resultados em 3D. . . . . . . . . . . . . . . . . 107

Figura B.25-Amostra 3 Região 3 Perfil da Superfície. . . . . . . . . . . . . . . . . 108

Figura B.26-Relação dos parâmetros obtidos da Amostra 3 Região 3. . . . . . . . . 108

Figura B.27-Amostra 3 Região 3 Resultados em 3D. . . . . . . . . . . . . . . . . 108

Figura B.28-Amostra 4 Região 1 Perfil da Superfície. . . . . . . . . . . . . . . . . . 109

Figura B.29-Relação dos parâmetros obtidos da Amostra 4 Região 1. . . . . . . . . 109

Figura B.30-Amostra 4 Região 1 Resultados em 3D. . . . . . . . . . . . . . . . . . . 109

Figura B.31-Amostra 4 Região 2 Perfil da Superfície. . . . . . . . . . . . . . . . . . 110

Figura B.32-Relação dos parâmetros obtidos da Amostra 4 Região 2. . . . . . . . . 110

Figura B.33-Amostra 4 Região 2 Resultados em 3D. . . . . . . . . . . . . . . . . 110

Figura B.34-Amostra 4 Região 3 Perfil da Superfície. . . . . . . . . . . . . . . . . . 111

Figura B.35-Relação dos parâmetros obtidos da Amostra 4 Região 3. . . . . . . . . 111

Figura B.36-Amostra 4 Região 3 Resultados em 3D . . . . . . . . . . . . . . . . . 111

Figura B.37-Amostra 5 Região 1 Perfil da Superfície. . . . . . . . . . . . . . . . . . 112

Figura B.38-Relação dos parâmetros obtidos da Amostra 5 Região 1. . . . . . . . . 112

Figura B.39-Amostra 5 Região 1 Resultados em 3D . . . . . . . . . . . . . . . . . . 112

Figura B.40-Amostra 5 Região 2 Perfil da Superfície. . . . . . . . . . . . . . . . 113

Figura B.41-Relação dos parâmetros obtidos da Amostra 5 Região 2. . . . . . . . . 113

Figura B.42-Amostra 5 Região 2 Resultados em 3D. . . . . . . . . . . . . . . . 113

Figura B.43-Amostra 5 Região 3 Perfil da Superfície. . . . . . . . . . . . . . . . . . 114

Figura B.44-Relação dos parâmetros obtidos da Amostra 5 Região 3. . . . . . . . . 114

Figura B.45-Amostra 5 Região 3 Resultados em 3D. . . . . . . . . . . . . . . . . 114

Figura B.46-Amostra 6 Região 1 Perfil da Superfície. . . . . . . . . . . . . . . . . . 115

Figura B.47-Relação dos parâmetros obtidos da Amostra 6 Região 1. . . . . . . . . 115

Figura B.48-Amostra 6 Região 1 Resultados em 3D . . . . . . . . . . . . . . . . . 115

Figura B.49-Amostra 6 Região 2 Perfil da Superfície. . . . . . . . . . . . . . . . 116

Figura B.50-Relação dos parâmetros obtidos da Amostra 6 Região 2. ...... 116

Figura B.51-Amostra 6 Região 2 Resultados em 3D . . . . . . . . . . . . . . . 116

Figura B.52-Amostra 6 Região 3 Perfil da Superfície. . . . . . . . . . . . . . . . . 117

Figura B.53-Relação dos parâmetros obtidos da Amostra 6 Região 3. . . . . . . . . 117

Figura B.54-Amostra 6 Região 3 Resultados em 3D. . . . . . . . . . . . . . . . 117 
Figura B.55-Amostra 7 Região 1 Perfil da Superfície. . . . . . . . . . . . . . . . . 118

Figura B.56-Relação dos parâmetros obtidos da Amostra 7 Região 1. . . . . . . . . 118

Figura B.57-Amostra 7 Região 1 Resultados em 3D . . . . . . . . . . . . . . . 118

Figura B.58-Amostra 7 Região 2 Perfil da Superfície. . . . . . . . . . . . . . . . . . 119

Figura B.59-Relação dos parâmetros obtidos da Amostra 7 Região 2. ....... 119

Figura B.60-Amostra 7 Região 2 Resultados em 3D. . . . . . . . . . . . . . . . . . 119

Figura B.61-Amostra 7 Região 3 Perfil da Superfície. . . . . . . . . . . . . . . . . . 120

Figura B.62-Relação dos parâmetros obtidos da Amostra 7 Região 3. . . . . . . . . 120

Figura B.63-Amostra 7 Região 3 Resultados em 3D. . . . . . . . . . . . . . . . . . . 120

Figura B.64-Amostra 8 Região 1 Perfil da Superfície. . . . . . . . . . . . . . . . . . 121

Figura B.65-Relação dos parâmetros obtidos da Amostra 8 Região 1. . . . . . . . . 121

Figura B.66-Amostra 8 Região 1 Resultados em 3D . . . . . . . . . . . . . . . . . . 121

Figura B.67-Amostra 8 Região 2 Perfil da Superfície. . . . . . . . . . . . . . . . . . 122

Figura B.68-Relação dos parâmetros obtidos da Amostra 8 Região 2. . . . . . . . . 122

Figura B.69-Amostra 8 Região 2 Resultados em 3D . . . . . . . . . . . . . . . . . . 122

Figura B.70-Amostra 8 Região 3 Perfil da Superfície. . . . . . . . . . . . . . . . . . 123

Figura B.71-Relação dos parâmetros obtidos da Amostra 8 Região 3. . . . . . . . . 123

Figura B.72-Amostra 8 Região 3 Resultados em 3D. . . . . . . . . . . . . . . . . . 123

Figura B.73-Amostra 9 Região 1 Perfil da Superfície. . . . . . . . . . . . . . . . . . 124

Figura B.74-Relação dos parâmetros obtidos da Amostra 9 Região 1. . . . . . . . . 124

Figura B.75-Amostra 9 Região 1 Resultados em 3D. . . . . . . . . . . . . . . . . 124

Figura B.76-Amostra 9 Região 2 Perfil da Superfície. . . . . . . . . . . . . . . . . . 125

Figura B.77-Relação dos parâmetros obtidos da Amostra 9 Região 2. . . . . . . . . 125

Figura B.78-Amostra 9 Região 2 Resultados em 3D . . . . . . . . . . . . . . . . . 125

Figura B.79-Amostra 9 Região 3 Perfil da Superfície. . . . . . . . . . . . . . . . . 126

Figura B.80-Relação dos parâmetros obtidos da Amostra 9 Região 3. . . . . . . . . 126

Figura B.81-Amostra 9 Região 3 Resultados em 3D . . . . . . . . . . . . . . . . . 126

Figura B.82-Amostra 10 Região 1 Perfil da Superfície. . . . . . . . . . . . . . . . . 127

Figura B.83-Relação dos parâmetros obtidos da Amostra 10 Região 1. . . . . . . . . 127

Figura B.84-Amostra 10 Região 1 Resultados em 3D. . . . . . . . . . . . . . . . . 127

Figura B.85-Amostra 10 Região 2 Perfil da Superfície. . . . . . . . . . . . . . . . . . 128

Figura B.86-Relação dos parâmetros obtidos da Amostra 10 Região 2. . . . . . . . . 128

Figura B.87-Amostra 10 Região 2 Resultados em 3D. . . . . . . . . . . . . . . . . . 128

Figura B.88-Amostra 10 Região 3 Perfil da Superfície. . . . . . . . . . . . . . . . . . 129

Figura B.89-Relação dos parâmetros obtidos da Amostra 10 Região 3. . . . . . . . . 129

Figura B.90-Amostra 10 Região 3 Resultados em 3D. . . . . . . . . . . . . . . . . . 129

Figura C.1-Rugosidade superficial Amostra 1 Região 1. . . . . . . . . . . . . . . 135

Figura C.2-Rugosidade superficial Amostra 1 Região 2. . . . . . . . . . . . . . . . 135

Figura C.3-Rugosidade superficial Amostra 1 Região 3. . . . . . . . . . . . . . . 135 
Figura C.4-Rugosidade superficial Amostra 2 Região 1. . . . . . . . . . . . . . . 136

Figura C.5-Rugosidade superficial Amostra 2 Região 2. . . . . . . . . . . . . . 136

Figura C.6-Rugosidade superficial Amostra 2 Região 3. . . . . . . . . . . . . . . 136

Figura C.7-Rugosidade superficial Amostra 3 Região 1. . . . . . . . . . . . . . . 137

Figura C.8-Rugosidade superficial Amostra 3 Região 2. . . . . . . . . . . . . . 137

Figura C.9-Rugosidade superficial Amostra 3 Região $3 . . . . . .137$

Figura C.10-Rugosidade superficial Amostra 4 Região 1. . . . . . . . . . . . . . . 138

Figura C.11-Rugosidade superficial Amostra 4 Região 2. . . . . . . . . . . . . . . . 138

Figura C.12-Rugosidade superficial Amostra 4 Região 3. . . . . . . . . . . . . . . 138

Figura C.13-Rugosidade superficial Amostra 5 Região 1. . . . . . . . . . . . . . . 139

Figura C.14-Rugosidade superficial Amostra 5 Região 2. . . . . . . . . . . . . . . 139

Figura C.15-Rugosidade superficial Amostra 5 Região $3 . . . . . .139$

Figura C.16-Rugosidade superficial Amostra 6 Região 1. . . . . . . . . . . . . . . . 140

Figura C.17-Rugosidade superficial Amostra 6 Região 2. . . . . . . . . . . . . . . . 140

Figura C.18-Rugosidade superficial Amostra 6 Região 3. . . . . . . . . . . . . . . . 140

Figura C.19-Rugosidade superficial Amostra 7 Região 1. . . . . . . . . . . . . . . . 141

Figura C.20-Rugosidade superficial Amostra 7 Região 2. . . . . . . . . . . . . . . . 141

Figura C.21-Rugosidade superficial Amostra 7 Região 3. . . . . . . . . . . . . . . . 141

Figura C.22-Rugosidade superficial Amostra 8 Região 1. . . . . . . . . . . . . . . . 142

Figura C.23-Rugosidade superficial Amostra 8 Região $2 . . . . . . . .142$

Figura C.24-Rugosidade superficial Amostra 8 Região 3. . . . . . . . . . . . . . . 142

Figura C.25-Rugosidade superficial Amostra 9 Região 1. . . . . . . . . . . . . . . . 143

Figura C.26-Rugosidade superficial Amostra 9 Região 2. . . . . . . . . . . . . . . . 143

Figura C.27-Rugosidade superficial Amostra 9 Região 3. . . . . . . . . . . . . . . 143

Figura C.28-Rugosidade superficial Amostra 10 Região 1. . . . . . . . . . . . . . . . 144

Figura C.29-Rugosidade superficial Amostra 10 Região 2. . . . . . . . . . . . . . . . 144

Figura C.30-Rugosidade superficial Amostra 10 Região 3. . . . . . . . . . . . . . . . 144 


\section{Lista de tabelas}

Tabela 4.1 - Relação dos resultados obtidos pelo programa Holodig e o ImageJ. . 50

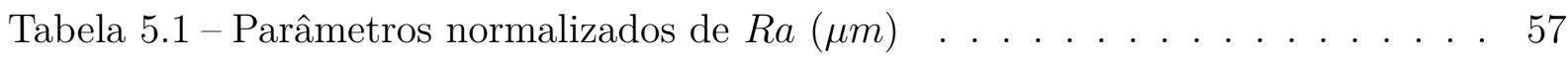

Tabela 5.2 - Relação longitude de medição e rugosidade média . . . . . . . . . . . . 58

Tabela 5.3 -Graus dos valores de $R a \ldots \ldots$. . . . . . . . . . . . . 59

Tabela 5.4 - Composição química do material . . . . . . . . . . . . . . . . 61

Tabela 5.5 - Processo de lixamento para as amostras de Aço 1010 . . . . . . . . . . 62

Tabela 5.6 - Valores da Rugosidade Superficial. . . . . . . . . . . . . . . . . . 78

Tabela 5.7 - Estatística resumida . . . . . . . . . . . . . . . . 80

Tabela 5.8 - Anova . . . . . . . . . . . . . . . . . . . 80

Tabela 5.9 - Tabela das Médias com 95,0 \% de intervalos LSD . . . . . . . . . . . 82

Tabela 5.10 -Verificação da Variação . . . . . . . . . . . . . . . . . . . 82

Tabela 5.11-Coeficientes . . . . . . . . . . . . . . . . . . 83

Tabela $5.12-$ Análise de Variância . . . . . . . . . . . . . . . . . . . 83

Tabela 5.13-Código na análise estatística. . . . . . . . . . . . . . . . . . 84

Tabela 5.14-Estatísticas resumidas da Ra. . . . . . . . . . . . . . . . . . 85

Tabela 5.15-Assimetria e Kurtosis. . . . . . . . . . . . . . . . . . . . 86

Tabela 5.16-ANOVA para Ra por Processo ou número de lixa. . . . . . . . . . . . . 86

Tabela 5.17-Coeficientes . . . . . . . . . . . . . . . . . . . . . 88

Tabela $5.18-$ Análise de Variância . . . . . . . . . . . . . . . . . . . . 88

Tabela C.1-Resultados de Ra da Amostra 1. . . . . . . . . . . . . . . . . . 130

Tabela C.2-Resultados de Ra da Amostra 2. . . . . . . . . . . . . . . . . . 130

Tabela C.3-Resultados de Ra da Amostra 3. . . . . . . . . . . . . . . . . . . . . . 131

Tabela C.4-Resultados de Ra da Amostra 4. . . . . . . . . . . . . . . . . . . 131

Tabela C.5-Resultados de Ra da Amostra 5. . . . . . . . . . . . . . . . . . . 132

Tabela C.6-Resultados de Ra da Amostra 6. . . . . . . . . . . . . . . . . . . . . . 132

Tabela C.7-Resultados de Ra da Amostra 7. . . . . . . . . . . . . . . . . . . . 133

Tabela C.8-Resultados de Ra da Amostra 8. . . . . . . . . . . . . . . . . . . . 133

Tabela C.9-Resultados de Ra da Amostra 9. . . . . . . . . . . . . . . . . . . . . . 134

Tabela C.10-Resultados de Ra da Amostra 10. . . . . . . . . . . . . . . . . . . . . . 134

Tabela D.1-Método: 95,0 \% LSD. . . . . . . . . . . . . . . . . . . . 145

Tabela D.2-Testes de alcance múltiplo para Ra por Processo ou número de lixa. . . 146

Tabela D.3-Testes de alcance múltiplo para Ra por Processo ou número de lixa. . . 147

Tabela D.4-Resultados da Ra $(\mu m) \ldots \ldots$. . . . . . . . . . . . . . . . . . . . .

Tabela D.5-Cpmparação de modelos alternativos . . . . . . . . . . . . . . . . 149 


\section{Introdução}

\subsection{Considerações Iniciais}

No ano 1947 o físico Húngaro Dennis Gabor, desenvolveu os princípios teóricos da holografia, ele procurava um método para melhorar a resolução e definição do microscópio eletrônico. Compensando por meios ópticos as deficiências da imagem, propõe a utilização de um processo de registro fotográfico de imagens ao qual chamou de holografia. O nome Holografia vem do grego "holos" (todo, inteiro) e "grafos" (sinal, escrita), pois é um método de registro "integral"da informação com relevo e profundidade.

O método foi idealizado contendo dois passos. O primeiro passo consiste na captura do padrão de interferência a partir da superposição de uma onda proveniente do objeto, transmitida ou refletida por este, e uma onda de referência, gerando a interferência e desta maneira o holograma. O segundo passo resulta a reconstrução da imagem a partir desse holograma, iluminado mediante uma onda igual à da referência ou a sua conjugada complexa e o padrão difratado pelo holograma nestas condições da imagem reconstruída, [GABOR, 1949].

Anos depois pesquisadores como Leith e Upatnieks buscavam um método para registrar e mostrar a forma da onda de sinais de radar usando técnicas ópticas. Sem perceber, com seu trabalho tinham descoberto a holografia de Gabor. A partir desse momento, seus objetivos foram aperfeiçoar o método eliminando o principal problema da holografia de Gabor, onde não se produzia apenas uma imagem, o que provocava uma imagem difusa [LEITH; UPATNIEKS, 1962], [LEITH; UPATNIEKS, 1963], [LEITH; UPATNIEKS, 1964].

Com o surgimento do laser, inventado por Maiman em 1959, Leith e Upatnieks desenvolveram a holografia fora do eixo. Depois disto foram criando-se por todas as partes do mundo diferentes técnicas a partir das que se produziram hologramas como: os hologramas de transmissão, hologramas de reflexão, hologramas de Fourier, Fresnel e Fraunhofer, etc. [VÁZQUEZ, 1996].

Em 1962, Denisyuk realizou pela primeira vez hologramas de reflexão utilizando emulsões. Benton, em 1976 realiza hologramas "imagem", conhecidos também como hologramas arco-íris. Estes se tornaram atrativos, pois não precisavam de uma fonte coerente monocromática para reconstruí-los, apenas se requeria iluminar o holograma com luz branca [BENTON, 1976].

O processo holográfico considera a interferência de duas ondas luminosas, assim como seu registro, que na holografia convencional inclui uma transparência que contém o registro codificado de um padrão de interferência. O registro tem lugar mediante um padrão 
de interferência, e a reconstrução se realiza através de processos de difração. O poder de resolução do material de registro deve ser elevado, pois as franjas de interferência costumam ter separação de $1 \mu \mathrm{m}$. Estas ordens exigem a ausência total de movimentos e vibrações dos elementos que intervêm na formação do holograma [VÁZQUEZ, 1996].

Esta holografia, feita com luz incoerente abre as possibilidades em vários campos da ciência. O uso da propriedade de que cada objeto incoerente está composto de muitas fontes pontuais, cada uma delas auto coerente espacialmente e capaz de gerar um padrão de interferência com luz procedente de sua imagem especular, constitui o principio geral sob o qual são gerados os hologramas de Fresnel, sendo que pela existência destas fontes pontuais teremos a informação necessária do objeto, [COCHRAN, 1966], [PETERS, 1966].

Uma melhora significativa foi obtida pela introdução da holografia digital (DH, em inglés) no sentido de que os hologramas não são mais gravados em chapas holográficas de alta resolução, emulsões como antes, mas capturadas eletronicamente por um dispositivo acoplado de carga (CCD, em inglês) ou óxido de metal complementar matrizes de semicondutores (CMOS, em inglês) [LOPEZ, 2012].

A característica fundamental da holografia digital é a capacidade de realizar o registro da informação da frente de onda de um objeto, de forma que possa ser reconstruída posteriormente através da observação de duas grandezas físicas relacionadas à frente de onda, que são a intensidade e a fase. A imagem de um objeto observada por meio de um filme fotográfico convencional corresponde ao registro de intensidade, sem a percepção espacial oferecida para um objeto observado por meio de um filme holográfico, holograma. Na holografia clássica, temos o registro da informação qualitativa, restrita à observação dos parâmetros físicos, também se têm uma informação quantitativa, mas que resulta muito mais difícil de extrair. A Holografia Digital, por outro lado, permite que um holograma obtido de uma amostra, após processamento numérico, forneça informação numérica dos parâmetros físicos, possibilitando a realização da análise quantitativa. É possível assim, realizar reconstruções separadas em intensidade ou fase [LOPEZ, 2012].

A holografia digital utiliza dispositivos eletrônicos de captura de imagens, realizando a digitalização através de um sensor denominado, Dispositivo de Carga Acoplada (CCD). O holograma é conformado pelo registro digital da interferência entre feixes objeto e referência. A captura e processamentos de hologramas em um computador, efetuado por Schars e Juptner, assim como o desenvolvimento de computadores e dispositivos de gravação digital, CCD e CMOS, permitiram que a holografia digital superasse alguns problemas da holografia clássica [SCHNARS; JUPTNER, 1994], [SCHNARS; JUPTNER, 1996].

Os sensores CCD disponíveis comercialmente têm suas limitações, como por exemplo, uma menor resolução de pixels e uma área de detecção menor que o sensor analógico. Esta baixa resolução restringe o ângulo entre os feixes objeto e referência, a apenas alguns graus [MONTEIRO, 2012]. 
No ano 1887, Albert Abraham Milchelson, criou o que se conhece hoje como o interferômetro de Michelson e que permite medir distâncias com uma precisão muito alta. Seu funcionamento tem base na divisão de um feixe de luz coerente em dois feixes que percorrem caminhos diferentes para posteriormente convergir novamente em um ponto. Conhecendo o comprimento de onda da luz utilizada, este interferômetro pode ser utilizado para medir distâncias pequenas na trajetória óptica analisando as interferências produzidas. Esta técnica se utiliza para medir o contorno da superfície de espelhos de telescópios, o índice de refração de uma substância calculando o deslocamento nas franjas de interferência. Desta maneira é muito utilizado na área da metrologia.

A expansão da holografia digital no campo da visualização e a metrologia, permite fazer uso de ferramentas numéricas e computacionais na Microscopia Holográfica Digital (DHM, em inglês), [TAVIO et al., 2017]. Esta técnica pode ser implementada em uma configuração de um microscópio óptico, como também pode ser encontrada em configurações experimentais onde é combinada a microscopia com a interferometria através da inclusão de um interferômetro de Michelson ou de Mach-Zehnder. Estes tipos de configurações aportam varias características interessantes, como por exemplo, uma profundidade focal melhorada e a possibilidade de gerar imagens tridimensionais ou de contraste de fase.

A holografia digital apresenta numerosas vantagens como o acesso direto à informação da fase, a correção numérica de aberrações ópticas e a capacidade de enfoque numérico a partir de um só holograma. Como método interferométrico, oferece um enfoque sem contato para trabalhos com objetos muito frágeis, com flexibilidade e uma alta sensibilidade a quantidades geométricas tais como espessuras e deslocamentos. Estas características permitem sua utilização para solução de diversos problemas de imagem e medição, como a inspeção e caracterização de sistemas microeletromecânicos (MEMS/MEOMS) inspeção e caracterização, [MATRECANO et al., 2014]. Ela nos permite também, caracterizar a fase de um campo de luz e a intensidade e, portanto, todo o campo de onda pode ser medido e armazenado em um computador. Suas aplicações tem se tornado uma ferramenta científica e tecnológica com as possibildades para medir a amplitude e a fase das ondas do objeto, deslocamento e forma tridimensional, distribuições e movimentos de partículas, caracterização do índice de refração de tecidos biológicos, e análise de vibração. [SANG et al., 2011]

Na microscopia a DH tornou-se uma ferramenta interferométrica na metrologia óptica com a melhora dos sensores das câmeras e o aparecimento de programas com capacidade de processar as imagens adquiridas. Isto permitiu a investigação de superfícies manipuladas em microescala como sistemas microeletromecânicos (MEMS). As ferramentas numéricas realizam a reconstrução do campo de onda o que permite a recuperação da intensidade do campo de onda adquirido e a distribuição de fase [PAGLIARULO et al., 2015].

Por outro lado, a Microscopia Holográfica Digital (DHM), que surge anos após a DH, tem sido considerada como um melhor teste não invasivo e ferramenta metrológica. Muitas 
aplicações que utilizam DHM foram propostas mostrando a sua capacidade de focagem numérica. Entre essas aplicações a análise de MEMS e MOEMS exige maior precisão da resolução topográfica. As aberrações em DHM são principalmente produzidas pela lente objetiva do microscópio. Para remover estas aberrações se aplicam métodos de processamento e software [GESUALDI et al., 2013], [PALACIOS et al., 2011].

As técnicas holográficas têm sido amplamente utilizadas em microscopia, geração de contornos, análise de vibração, medição de deformação, ensaios não destrutivos e armazenamento de dados. Na interferometría holográfica convencional, a fase reconstruída é usualmente calculada a partir de três ou mais interferogramas com deslocamento de fase. No entanto, esta técnica requer esforços experimentais. Computadores e sensores digitais com resolução reduzida tornaram possível a gravação digital de um holograma e o processamento numérico para a reconstrução da sua imagem [GESUALDI et al., 2013].

Consequentemente surgiram publicações contemporâneas sobre metrologia holográfica digital e microscopia. Goodman, Lauren e Kronrod foram os primeiros a usar um computador para reconstruir a imagem holográfica codificada no holograma. A difração da ordem zero e as duas imagens conjugadas sobrepõem-se na configuração em linha. Na holografia clássica, a influência da imagem conjugada foi superada pela geometria fora do eixo inventada por Leith e Upatnieck fora do eixo. Ao usar o conceito de onda de referência digital, podemos obter uma onda de objeto (amplitude e fase) que é reconstruída na região central do plano de observação, [ABDELSALAM et al., 2012].

Os hologramas fora dos eixos gravados com uma imagem ampliada de objetos microscópicos são recosntruídos numéricamente em amplitude e fase, através da aproximação de Fresnel. O método de reconstrução envolve a computação de uma réplica digital da onda de referência. Para correção de aberrações da fase Cuche apresenta que a resolução transversal é igual ao limite de difração do sistema da imagem, dentro da microscopia holográfica, [CUCHE et al., 1999].

Por outro lado, Colomb introduz lentes de aumento no arranjo óptico para acessar um campo de visão microscópico. Uma eliminação do ruído também poderia ser conseguida, em particular pelo desenvolvimento de um arranjo óptico onde os objetos de difração poderiam ser eliminados. Desenvolve assim, uma aplicação da holografia digital à microscopia óptica. A microscopia holográfica digital (DHM) é caracterizada pelo fato de que a frente de onda é reconstruída através de um algoritmo numérico, diretamente a partir de um holograma capturado e digitalizado com uma câmera. Os dados de fase, em particular, trazem informações exclusivas sobre a morfologia, que podem ser usadas para a apresentação do objeto microscópico [COLOMB. et al., 2002].

Uma aplicação da DHM tem lugar na biologia para a transmissão de contraste da fase de células vivas em cultivo. A resolução para medições de espessura depende do índice de refração da amostra, de uma resolução de aproximadamente 30 nanômetros de altura e aproximadamente a metade de uma micra de largura [DEPEURSINGE et al., 
2002]. A aquisição neste caso se realiza com um único holograma obtido a partir de um interferômetro Mach-Zender ou Michelson.

Um dos problemas que afeta na holografia a interpretação dos mapas de fase, tem a ver com a origem de alterações que não sempre são provocadas pelo objeto. Estas alterações ocorrem devido à geometria da configuração experimental ou de aberrações dos sistemas de magnificação usados. Com o fim de compensar e corrigir estas alterações na fase das frentes de onda refletidos pelos objetos, é implementada uma estratégia numérica para que a medida do relevo que se obtenha corresponda à medida real.

A metrologia, por outro lado, é uma das ferramentas que caracteriza a indústria da manufatura. Sem processos de metrologia não é possível alcançar os padrões necessários na indústria aeroespacial, automotriz, médica, de geração de energia e moldes entre outras. É um requisito sem o qual não poderia se garantir a qualidade, confiabilidade e precisão das peças manufaturadas pelos milhares de indústrias que existem no mundo. Nestas indústrias, a metrologia se converte no processo chave para dar uma prova objetiva da qualidade de um processo e produto, que dependem de medições confiáveis mediante equipamentos de medição.

Na grande maioria das indústrias a inspeção se realiza por máquinas de medição por coordenadas, capazes de executar medições programadas, ou dispositivos como os perfilômetros que medem o acabamento das superfícies usinadas. Estes equipamentos pelas suas características e precisão são muito caros e de uma acessibilidade restrita pelos cuidados que se requerem para seu uso.

Neste trabalho, se utiliza um arranjo de microscopia holográfica digital com base num interferômetro de Michelson, com o objetivo de realizar uma análise dimensional de objetos de pequeno tamanho e a medição da rugosidade superficial de aço 1010 utilizando um algoritmo numérico que realiza as medições através da imagem de contraste de fase em 3D.

\subsection{Objetivo}

Desenvolver uma metodologia que possibilite a análise microscópica dos aspectos tridimensionais das superfícies, abarcando tanto a geometria como a rugosidade superficial, através da microscopia holográfica digital por reflexão utilizando uma configuração experimental com base num interferômetro de Michelson.

Para atingir este objetivo, foi necessário o desenvolvimento das seguintes tarefas específicas:

- Desenvolvimento de um algoritmo que permita medir a rugosidade superficial através da imagem de contraste de fase 3D reconstruída. 
- Montagem e calibração da instalação de microscopia holográfica digital por reflexão com base num interferômetro de Michelson, utilizando objetos de contornos definidos.

- Seleção e preparação das amostras para controle da sua rugosidade superficial.

- Medição da rugosidade superficial a partir da captura e armazenamento dos hologramas e sua reconstrução numérica através do programa Holodig.

- Medição da rugosidade superficial através do Perfilômetro óptico 3D sem contato CCI MP.

- Análise estatística dos resultados da rugosidade superficial obtidos pela metodologia proposta neste trabalho com os resultados obtidos pelo Perfilômetro óptico 3D sem contato CCI MP.

\subsection{Relevância e Justificativa da Tese}

O presente trabalho propõe uma metodologia para análise dimensional de objetos de contorno definido e avaliação de superfícies. Para alcançar estes resultados foi desenvolvido um algoritmo que permite medir mudanças na superfície através da imagem de contraste de fase em 3D.

A metodologia desenvolvida tem seu sentido inovador pelo uso de uma configuração experimental de microscopia holográfica digital por reflexão, com base num interferômetro de Michelson. Não foram encontrados trabalhos anteriores a este utilizando uma metodologia que permita medir diretamente a partir da imagem de contraste de fase as diferenças na superfície de objetos refletivos.

O mérito do trabalho reside no algoritmo desenvolvido que permitiu a medição da rugosidade superficial a patir das diferenças de contraste de fase em 3D. Este algoritmo apresenta a imagem de contraste de fase com base num critério de distância a partir de um único holograma.

A obtenção dos hologramas foi realizada através de uma configuração experimental simples. O armazenamento e a reconstrução destes conseguiou-se de uma forma rápida e em tempo real.

O método proposto, comparado com os métodos tradicionais de medição de superfícies, garante resultados confiáveis, a um menor custo. A avaliação é realizada em uma superfície que apresenta imperfeições em uma escala da ordem dos micrômetros.

Os objetos utilizados para a parte de controle dimensional são parafusos e uma engrenagem; para a medição da rugosidade superficial foi escolhido um aço 1010. 


\subsection{Escopo do Trabalho}

No Capítulo I, se faz uma breve indicação do tema abordado no trabalho, seus objetivos, relevância e justificativa como pesquisa científica. Em seguida, no Capítulo II, tratam-se os conceitos básicos da holografia digital e da microscopia holográfica digital. No Capítulo III é proposta uma técnica que permitirá medir a rugosidade superficial utilizando a microscopia holográfica digital por reflexão e com a utilização de um algoritmo desenhado para o processamento das imagens. No Capítulo IV, são apresentados os materiais, equipamentos utilizados no desenvolvimento da pesquisa, o método que permitiu a captura, armazenamento dos hologramas digitais, a reconstrução da imagem de contraste de fase e a análise dimensional de objetos de contorno definido com seus resultados preliminares. No Capítulo V são abordados conceitos básicos da rugosidade superficial, a técnica desenvolvida para medir o parâmetro utilizando a microscopia holográfica digital por reflexão, o material usado e as amostras preparadas, a metodologia para a sua obtenção, os resultados obtidos e a sua comparação com os resultados do perfilômetro óptico 3D sem contacto CCI MP através de uma análise estatística. No Capítulo VI, citam-se as conclusões do trabalho em base aos resultados e recomendações para possíveis futuras pesquisas. 


\section{Fundamentos da Holografia}

Neste capítulo se apresentam conceitos de interferometria, holografia digital e microscopia holográfica digital. Estes conceitos foram essenciais no desenvolvimento deste trabalho.

\subsection{Interferometria}

A seguir apresentam-se aspectos importantes da interferência óptica e a sua relação com a metrologia através de técnicas de interferência holográfica. Pretende-se fazer uma abordagem detalhada do fenómeno da interferência entre ondas.

\subsubsection{Interferência}

A luz é uma onda eletromagnética constituída por campos elétricos e magnéticos que oscilam periodicamente no tempo e no espaço perpendiculares entre eles [WALBORN, 2015]. A interferência da luz consiste na redistribuição espacial da intensidade luminosa condicionada pela diferença de fase. A interferência entre ondas tem sido estudada ao longo dos tempos encontrando aplicações na deformação de objetos, espessuras, comprimentos de onda, índices de refração, entre outros [MONTEIRO, 2012].

Em 1801, Thomas Young provou experimentalmente a sua teoria sobre que a luz é uma onda através do conhecido experimento de interferência de dupla fenda de Young. O efeito de duas ou mais ondas ao se encontrarem em um ponto do espaço, em certo instante, é determinado pelo princípio de superposição. Se elas se encontram em fase, ou seja, se os máximos das ondas coincidem elas produzem uma onda resultante cuja amplitude é igual à soma das amplitudes de cada uma, o que neste caso se denomina como interferência construtiva das ondas. Por outro lado, se as ondas ao se encontrarem estão fora de fase, ou seja, se o máximo de uma coincide com o mínimo da outra, ocorre interferência destrutiva e a amplitude da onda produzida é igual à diferença entre as amplitudes das duas. Os pontos em que as ondas se reforçam formam franjas claras e os pontos em que se cancelam formam as denominadas franjas escuras. [HALLIDAY et al., 2013], [WALBORN, 2015]. A intensidade luminosa em cada ponto depende da diferença entre as distâncias $\Delta l$, percorridas pelos raios que chegam a um ponto determinado.

Para que uma figura de interferência apareça numa tela é preciso que a diferença de fase entre as ondas que chegam a um ponto qualquer não varie com o tempo. Quando a 
diferença de fase permanece constante em todos os pontos do espaço dizemos que os raios são totalmente coerentes.

A interferência da luz se utiliza em diversos meios de medição, onde o sistema de medição interferométrico é essencialmente constituído por uma fonte de luz, um sistema óptico (interferómetro) e um detector que converte as variações de intensidade luminosa num sinal mensurável.

\subsubsection{Interferômetro de Michelson}

Em 1881 o físico Albert A. Michelson desenvolveu o interferômetro que mais tarde levaria seu nome. A sua configuração básica se apresenta na Fig. 2.1.

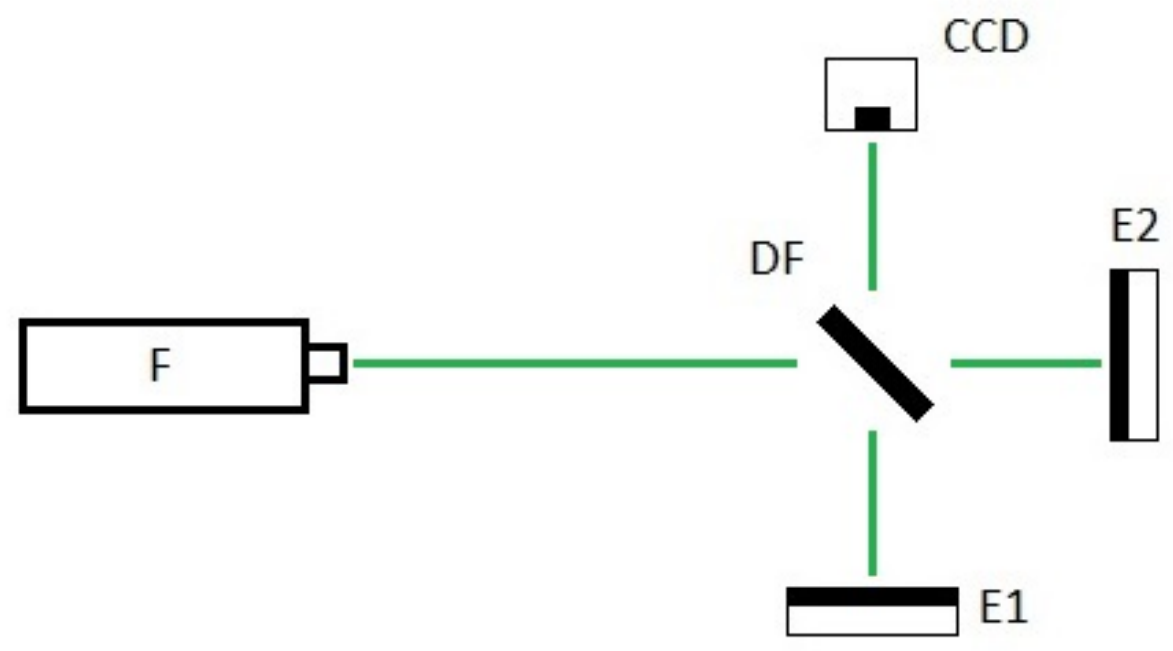

Figura 2.1 - Configuração básica do interferômetro de Michelson.

A luz que provê de uma fonte $(\mathrm{F})$ é dividida nos feixes de referência e o feixe objeto por um divisor de feixe (DF). O feixe de referência é refletido pelo espelho (E2) e refaz seu caminho sendo refletido pelo DF em direção à câmera (CCD). O feixe objeto é refletido pela superfície especular do objeto do espelho (E1), cujo deslocamento pretende se medir. Os dois feixes são recombinados, usando o DF, sobre o sensor da CCD. Se a diferença de comprimento do caminho óptico entre os campos de referência e o objeto é zero ou um inteiro múltiplo do comprimento de onda, a interferência é construtiva. Se a diferença de comprimento do caminho óptico é múltiplo de fase, a interferência é destrutiva.

Uma frente de onda separada em duas partes, percorre caminhos ópticos diferentes designados como braços do interferômetro. Na saída, estas duas ondas são novamente recombinadas dando origem ao denominado padrão de interferência. 


\subsubsection{Diferença de fase e interferência}

Uma onda senoidal pode ser entendida como um movimento circular que se propaga ao longo de um eixo, o qual pode representar uma distância ou tempo. A relação desse movimento com um ponto de referência é chamada de fase.

Quando duas ondas são superpostas suas amplitudes são somadas algebricamente e a onda resultante desta soma depende da fase. Assim, duas ondas de mesma frequência $f$ e amplitude A começando seus ciclos em zero grau, quer dizer em fase, vão resultar numa onda com a mesma frequência $f$ e amplitude igual a duas vezes A. Mas se essas ondas estiverem defasadas, essa relação de amplitude é modificada. Para duas ondas de mesma frequência e amplitude, mas defasadas em $180^{\circ}$, as amplitudes estão exatamente opostas, cancelando-se totalmente. Dizemos assim que diferenças de fase entre duas ondas geram interferências construtivas ou destrutivas.

O campo elétrico de uma onda de luz linearmente polarizada varia no tempo e pode ser descrito por:

$$
V(t)=\int_{0}^{\infty} a(\nu) \cdot e^{[-i \phi(\nu)]} \cdot e^{[i 2 \pi \nu t]} d \nu
$$

onde $a(\nu)$ é a amplitude, $\phi(\nu)$ é a fase de uma componente com frequência $\nu$. Para ondas de luz de uma única frequência, luz monocromática, a Eq. 2.1 se reduz a:

$$
V(t)=|a(\nu)| \cdot e^{(-i \phi)} \cdot e^{(i 2 \pi \nu t)}
$$

onde o fator $a=|a| \cdot e^{(-i \phi)}$ representa a amplitude complexa da onda gerada.

A intensidade luminosa $I$ num ponto determinado se define como a média temporal da quantidade de energia [MONTEIRO, 2012] gerada por unidade de tempo perpendicular ao fluxo de energia. Pode ser calculada através da multiplicação da amplitude complexa pelo seu complexo conjugado:

$$
I=|a|^{2}=a a^{*}
$$

Para qualquer ponto a amplitude complexa se obtém somando a amplitude complexa das ondas individuais:

$$
\begin{aligned}
I & =\left|a_{1}+a_{2}\right|^{2}=\left|a_{1}\right|^{2}+\left|a_{2}\right|^{2}+a_{1} a_{2}^{*}+a_{1}^{*} a_{2} \\
& =I_{1}+I_{2}+2 \sqrt{I_{1} I_{2}} \cos \left(\varphi_{1}-\varphi_{2}\right)
\end{aligned}
$$


A Eq. 2.4 descreve um padrão de franjas em que a distribuição espacial da intensidade é modulada pela diferença de fase $\left(\varphi_{1}-\varphi_{2}\right)$.

A visibilidade ou contraste das franjas pode ser determinado como:

$$
V=\frac{\left(I_{\max }-I_{\min }\right)}{\left(I_{\max }+I_{\min }\right)}=2 \frac{\sqrt{I_{1} I_{2}}}{\left(I_{1}+I_{2}\right)}
$$

Se duas ondas, paralelas polarizadas e de igual intensidade interferem, tem-se o máximo contraste de $V=1$ e o mínimo de contraste $V=0$ em uma superposição incoerente.

A Eq. 2.4 pressupõe que as ondas são polarizadas e com os vectores elétricos paralelos. Se os dois vectores elétricos formarem entre sim um ângulo $\Psi$, a intensidade resultante no padrão de interferência toma a seguinte forma:

$$
I=I_{1}+I_{2}+2 \sqrt{I_{1} I_{2}} \cos \psi \cos \left(\varphi_{1}-\varphi_{2}\right)
$$

O contraste das franjas diminui com o aumento do ângulo $\Psi$, sendo igual a zero para $\Psi=\pi / 2$.

\subsubsection{Coerência}

A característica que possuem as ondas luminosas para interferir entre elas é chamada de coerência. Precisamente, Kreis descreve a correlação entre ondas de luz individuais e a medida da correlação entre as fases medidas em diferentes pontos de uma onda. Os dois aspectos gerais da coerência espaço-temporal são, a coerência temporal e a coerência espacial, [KREIS, 2005].

\subsubsection{Coerência temporal}

A coerência temporal descreve a correlação de uma onda de luz entre ela mesma como seu comportamento em diferentes instantes de tempo [KREIS, 2005].

O interferômetro de Michelson permite um melhor entendimento. Nele, o padrão de ondas que chega ao divisor de feixe é dividido em duas partes com uma divisão nomeada de divisão de amplitude.

Deixando as ondas como $E_{1}$ e $E_{2}$ para um ponto fixo na tela temos:

$$
E_{2}(t)=E_{1}(t+\tau) \text { ou } E_{1}(t)=E_{2}(t+\tau)
$$


onde

$$
\tau=\frac{2 d}{c}
$$

No ponto de observação temos a superposição:

$$
E(t)=E_{1}(t)+E_{2}(t)=E_{1}(t)+E_{1}(t+\tau)
$$

e a intensidade:

$$
\begin{aligned}
I & =\left\langle E E^{*}\right\rangle \\
& =\left\langle E_{1} E_{1}^{*}\right\rangle+\left\langle E_{2} E_{2}^{*}\right\rangle+\left\langle E_{2} E_{1}^{*}\right\rangle+\left\langle E_{1} E_{2}^{*}\right\rangle \\
& =2 I_{1}+2 R_{e}\left(\left\langle E_{1} E_{2}^{*}\right\rangle\right)
\end{aligned}
$$

Define-se a parte complexa de coerência como:

$$
\begin{aligned}
\Gamma(\tau) & =\left\langle E_{1}^{*} E_{1}(t+\tau)\right\rangle \\
& =\int_{-T_{m} / 2}^{T_{m} / 2} E_{1}^{2}(t) E_{1}(t+\tau) d t
\end{aligned}
$$

que é a autocorrelação de $E_{1}(t)$. A quantidade normalizada:

$$
\gamma(\tau)=\frac{\Gamma(\tau)}{\Gamma(0)}
$$

define os graus de coerência. Desde que $\Gamma(0)=I_{1}$ é sempre um valor real e máximo de $|\Gamma(\tau)|$, vamos ter:

$$
\begin{gathered}
|\gamma(\tau)| \leq 1 \\
I(\tau)=2 L_{1}(1+\operatorname{Re} \gamma(\tau))
\end{gathered}
$$

Os graus de coerência ou de auto-coerência não são diretamente mensuráveis, mas para o contraste $V$, que pode ser facilmente calculado temos:

$$
V(\tau)=|\gamma(\tau)|
$$


Podemos deduzir que para luz coerente $|\gamma(\tau)|=1$, e luz incoerente para $|\gamma(\tau)|=0$. Muitas vezes o contraste $V$ diminui monotonamente em $\tau$. O tempo de coerência $\tau$ se define como a mudança do tempo em que o contraste é reduzido a $1 / e$. A mudança de tempo em interferômetros é realizada pela diferença de trajetórias, assim pode ser definido o comprimento de coerência como:

$$
l_{c}=c \tau_{c}
$$

\subsubsection{Coerência espacial}

A coerência espacial descreve a medida da correlação da fase da onda luminosa em diferentes pontos na direção transversal à direção de propagação. Ela nos diz quão uniforme é a fase da frente de onda.

A medição da coerência espacial pode ser feita a partir do experimento de fendas duplas de Young. Este experimento consiste em fazer um feixe de luz passar por duas fendas. O padrão exibido como resultado da interferência permite medir a coerência espacial.

O padrão de franjas oferece informação da semelhança da frente de onda $E\left(r_{1}, t\right)$ e $E\left(r_{2}, t\right)$ nas aberturas em $r_{1}$ e $r_{2}$ sem a mudança do tempo. Esta semelhança pode ser expressa pela função da coerência espacial, [KREIS, 2005]:

$$
\Gamma\left(r_{1}, r_{2}, 0\right)=\Gamma_{12}(0)=\left\langle E\left(r_{1}, t\right) E^{*}\left(r_{2}, t\right)\right\rangle
$$

O espaço temporal da função coerência agora resulta:

$$
\begin{aligned}
\Gamma(\tau) & =\Gamma_{12}\left(t_{2}-t_{1}\right)=\Gamma(\tau) \\
& =\left\langle E\left(r_{1}, t+\tau\right) E^{*}\left(r_{2}, t\right)\right\rangle
\end{aligned}
$$

Que pode ser normalizada para dar o grau de coerência mutua:

$$
\gamma_{12}(\tau)=\frac{\Gamma_{12}(\tau)}{\sqrt{\Gamma_{11}(0) \Gamma_{22}(0)}}
$$

onde $\Gamma_{11}(0)$ é a intensidade em $r_{1}, \Gamma_{2}(0)$ é a intensidade em $r_{2}$. 


\subsection{Holografia Digital}

A holografia digital (DH) é uma ferramenta útil em diversas aplicações. Dentro das vantagens que oferece, destaca-se a capacidade de gerar informação numérica sobre a fase do campo óptico transmitido ou refletido por um objeto [MONTEIRO, 2012]. Também é um método de imagem no qual o holograma é gravado no sensor de uma câmara (CCD) e depois a imagem é reconstruída numericamente simulando o processo de reconstrução óptica da holografia analógica [KREIS, 2005].

Um dos problemas que afetam a interpretação dos mapas de fase está relacionado com as distorções que aparecem no campo de medida. Estas ocorrem devido à geometria da montagem óptica ou às aberrações dos sistemas de ampliação, [MONTEIRO, 2012]. Com o fim de compensar ou corrigir tais alterações, têm sido desenvolvidas varias técnicas [MONTEIRO, 2012]. , como por exemplo, o cálculo numa máscara de fase polinomial diretamente do holograma onde os parâmetros de fase são computados automaticamente sem conhecimento de valores físicos, como vetores de ondas, distâncias focais ou distâncias [COLOMB. et al., 2002]; a compensação da aberração através da gravação de um holograma de referência, demonstrando que o holograma da amostra pode ser usado para calibrar a configuração do arranjo, onde, a resolução da fase axial é avaliada em uma sequência medindo o desvio padrão da fase em torno da amostra [COLOMB. et al., 2002]; a decomposição da fase em um conjunto de valores variáveis não correlacionados chamados de componentes principais e, em seguida, a extração dos termos de aberração do primeiro componente principal obtido, [ZHANG et al., 2012]; a remoção da curvatura da frente de onda introduzida pelo objetivo de imagem da microscopia holográfica digital, compensando a curvatura indesejada pela avaliação de uma frente de onda corretiva no plano do holograma [FERRARO et al., 2003].

O holograma consiste num registro digital do padrão de interferência gerado pela coerência da onda objeto e da onda de referência. A frequência espacial do padrão de interferência é determinada pelo ângulo entre os dois campos ondulatórios interferentes. A reconstrução digital da onda complexa (amplitude de fase) correspondente à imagem do objeto é baseada na integral de difração.

As relativas baixas resoluções dos CCD restringem o ângulo $(\theta)$ entre os feixes objeto e referência a apenas alguns graus. Usualmente o sensor de $N \times M$ pixels e distâncias $\Delta \xi$ e $\Delta \eta$ entre os pixels na direção $x$ e a direção $y$ para obter uma boa qualidade de reconstrução, na gravação digital a frequência espacial no padrão ou holograma $f$, deve satisfazer o teorema da amostragem Nyquist, [KREIS, 2005], que implica:

$$
f<\frac{2}{\lambda} \sin \left(\frac{\theta_{\max }}{2}\right)
$$


A distância mínima requerida entre o objeto e o sensor CCD deve cumprir a seguinte regra:

$$
d>d_{0} \frac{\Delta \xi}{\lambda}
$$

sendo $d_{0}$ a largura máxima do objeto.

A reconstrução óptica dos campos ondulatórios correspondentes a um objeto a partir do seu holograma produz simultaneamente uma imagem real e uma virtual. A imagem real corresponde à convergência da frente de onda para uma imagem nítida, entanto a imagem virtual pertence à frente de onda divergente que parece ser emitida a partir do objeto como ele foi localizado durante a gravação do holograma [KREIS, 2005]. A reconstrução numérica na holografia digital se realiza pela multiplicação do holograma com o campo da onda de referência.

\subsubsection{Onda de referência}

Em holografia digital os arranjos CCD registram a distribuição de intensidade produzida pela superposição coerente de um campo de ondas de um objeto e outro campo de ondas, de referência.

A reconstrução é realizada pela multiplicação da distribuição de intensidade digital armazenada (holograma) pelo modelo digital da onda de referência e, subsequentemente, a determinação do campo difratado em um plano imagem definido.

A onda de referência é de fácil uso em processamentos numéricos onde a onda plana, que não é outra que aquela onda de frequência constante e quais frentes de onda são planos paralelos de amplitude constante normal ao vetor velocidade de fase, quer dizer, aquela que se propaga em uma só direção ao longo do espaço; se encontra normal ao arranjo CCD.

$$
\begin{aligned}
& k=\frac{2 \pi}{\lambda}(0, \sin \theta, \cos \theta) \quad r=(\xi, \eta, z) \\
& r(\xi, \eta)=E_{r} \cdot e^{i(k \cdot r+\phi)} \\
& =E_{r} \cdot e^{i\left(\frac{2 \pi}{\lambda} \eta \sin \theta+\frac{2 \pi}{\lambda} z \cos \theta+\phi\right)} \\
& =E_{r} \cdot e^{i\left(\frac{2 \pi}{\lambda} z \cos \theta+\phi\right)} e^{\frac{2 \pi i}{\lambda} \eta \sin \theta}
\end{aligned}
$$


Para casos onde a onda não é plana pôde-se reconstruir com ondas de referência divergente. Multiplicando com a onda de referência conjugada se reconstrói um campo de onda convergindo à imagem real no plano imagem.

\subsubsection{Reconstrução numérica da imagem}

A ferramenta teórica para reconstrução numérica é a teoria de difração escalar. Aqui se concentram autores como Fresnel, Kirchhoff e a utilização do teorema de convolução onde a propagação da luz é tomada como um sistema linear [MONTEIRO, 2012].

A geometria para descrição numérica de Fresnel se apresenta na Figura. 2.2 onde a superfície aproximadamente plana significa que $z$ em $b(x, y, z)$ é constante. A distância $d$ à parte desde a superfície do objeto onde temos o médio de gravação, o plano do holograma ou alvo CCD. O plano do médio de gravação possui as coordenadas $(\xi, \eta)$.

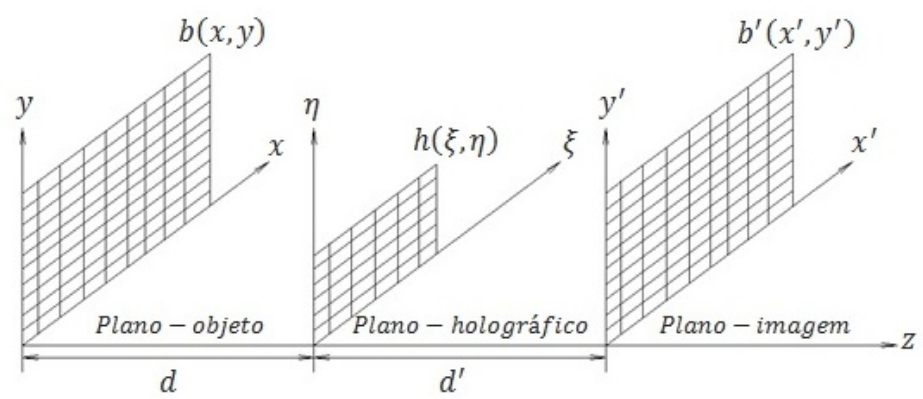

Figura 2.2 - Geometria de reconstrução para a holografia de Fresnel sem lentes.

Na distância $d^{\prime}$ a partir do plano do holograma temos o plano imagem ou também conhecido como plano de observação, onde a imagem real pode ser reconstruída. As coordenadas deste plano são $(x, y)$.

O objeto se encontra em $b(x, y)$ e o plano do holograma é $h(\xi, \eta)$. A superposição com o campo de onda de referência $r(\xi, \eta)$ pela interferência produz um campo ondulatório com distribuição de intensidade $h(\xi, \eta)$ gravado pela CCD. Após a gravação da distribuição real, $h(\xi, \eta)$ é armazenado em um computador. A avaliação numérica permite calcular a distribuição complexa do campo elétrico no plano $b^{\prime}\left(x^{\prime}, y^{\prime}\right)$ a qual representa a imagem reconstruída.

Em geral o número de pixels $N, M$ e distância entre pixels $\Delta \xi, \Delta \eta$ são dados pelo fabricante do CCD [KREIS, 2005].

$$
\begin{array}{cc}
\xi=n \Delta \xi & n=1, \ldots, N \\
\eta=m \Delta \eta & m=1, \ldots, M
\end{array}
$$


Com os parâmetros dados no plano objeto, temos as larguras do passo:

$$
\Delta x=\frac{1}{N \Delta v}=\frac{\lambda d}{N \Delta \xi} \quad \Delta y=\frac{1}{M \Delta u}=\frac{\lambda d}{M \Delta \eta}
$$

A difração de uma onda plana no holograma é descrita pela integral de Fresnel-Kirchhoff. A distância d entre o holograma e a imagem real se assume como maior que a máxima dimensão do sensor da câmera CCD [KREIS, 2005].

$$
d^{2} \gg \frac{\pi}{4 \lambda}\left[(x-\xi)^{2}+(x-\eta)^{2}\right]_{\max }^{2}
$$

A aproximação de Fresnel pode ser utilizada para calcular a amplitude complexa da onda difratada no plano da imagem real [MONTEIRO, 2012].

$$
\begin{gathered}
\Gamma(\xi, \eta)=\frac{i a}{\lambda d} \exp \left[-i \frac{\pi}{\lambda d}\left(\xi^{2}+\eta^{2}\right)\right] \\
\times \iint_{-\infty}^{+\infty} t(x, y) \exp \left[-i \frac{\pi}{2 d}\left(x^{2}+y^{2}\right)\right] \times \exp \left[i \frac{2 \pi}{\lambda d}(x \xi+y \eta)\right] d x d y
\end{gathered}
$$

Onde $(\xi, \eta)$ e $\left(x^{\prime}, y^{\prime}\right)$ são as coordenadas no plano do holograma e no plano da imagem real, $t(x, y)$ é o coeficiente de transmissão do holograma, a é a amplitude da onda incidente reconstrutora.

A função $\Gamma(\xi, \eta)$ pode ser digitalizada se a transmissão do holograma $t(x, y)$ é amostrada segundo uma matriz de $N \times M$ pontos, com passos $\Delta x$ e $\Delta y$ ao longo das coordenadas, $\xi$ e $\eta$ são substituídos por $n \Delta \xi$ e $m \Delta \eta$, sendo $n$ e $m$ números inteiros.

A representação discreta da equação fica:

$$
\begin{gathered}
\Gamma(m, n)=\exp \left[i \pi \lambda d\left(\frac{m^{2}}{M^{2} \Delta x^{2}}+\frac{n^{2}}{N^{2} \Delta y^{2}}\right)\right] \\
\times \sum_{k=0}^{N-1} \sum_{k=0}^{N-1} t(k, l) \exp \left[-i \frac{\pi}{\lambda d}\left(k^{2} \Delta x^{2}+l^{2} \Delta y^{2}\right)\right] \times \exp \left[i 2 \pi\left(\frac{k m}{N}+\frac{l m}{N}\right)\right]
\end{gathered}
$$

sendo $\Gamma(\xi, \eta)$ uma matriz de $N \times N$ pontos que descreve o campo da onda no plano imagem real. As dimensões dos pixels na imagem reconstruída são $\Delta \xi$ e $\Delta \eta$, tendo as relações entre $\Delta x, \Delta y$ e $\Delta \xi, \Delta \eta$ :

$$
\Delta \xi=\frac{\lambda d}{N \Delta x}, \quad \Delta \eta=\frac{\lambda d}{N \Delta y}
$$

A equação Eq. 2.29 constitui o método de cálculo discreto com base na transformada discreta inversa de Fourier para a reconstrução do campo ondulatório codificado em um 
holograma digital. A representação numérica $\Gamma(m, n)$ do campo complexo do plano da imagem real, a intensidade e distribuição de fase podem ser determinadas [KREIS, 2005].

$$
I(\xi, \eta)=\left|\Gamma(\xi, \eta)^{2}\right|=\operatorname{Re}^{2}|\Gamma(\xi, \eta)|+\operatorname{Im}^{2}|\Gamma(\xi, \eta)|
$$

onde $R e$ é a parte real e Im a parte imaginária.

A fase pode ser determinada:

$$
\phi(\xi, \eta)=\arctan \frac{\operatorname{Im}[\Gamma(\xi, \eta)]}{\operatorname{Re}[\Gamma(\xi, \eta)]}
$$

Se

$$
\begin{aligned}
& \operatorname{Re}[\Gamma(\xi, \eta)]<0= \\
& \phi(\xi, \eta)=\arctan \frac{\operatorname{Im}[\Gamma(\xi, \eta)]}{\operatorname{Re}[\Gamma(\xi, \eta)]}+\operatorname{sgn}[\operatorname{Im}[\Gamma(\xi, \eta)]]
\end{aligned}
$$

$v \phi(\xi, \eta)$ Assume alores entre - $\pi$ e $\pi$ como resultado da função arctan. Este campo de fase é nomeado como modulador no intervalo $[-\pi, \pi]$.

\subsubsection{Supressão do termo ordem zero}

O termo de ordem zero ou componente contínuo da imagem, não tem qualquer utilidade prática, a sua forte amplitude o transforma em um elemento que perturba a gama dinâmica de representação da imagem e restringe a área de visualização do objeto. Os procedimentos para sua eliminação estão divididos em procedimentos numéricos e técnicas experimentais de salto de fase [MONTEIRO, 2012], [LIANG et al., 2005], [ZHANG et al., 2012].

Entre os métodos numéricos um considerado muito eficaz na eliminação do termo zero é o da Transformada de Fresnel. Este tem como base a subtração do termo médio da intensidade em cada holograma. Este pode ser interpretado como o equivalente à aplicação de um filtro passa alto, onde só o termo da ordem zero é eliminado. Uma maneira rápida de implementar este filtro consiste no cálculo do valor médio por convolução da imagem na vizinhança $3 \times 3$ do pixel e subtração ao holograma original:

$$
h^{\prime}((k, l))=h(k, l)-(k, l) \otimes M
$$


onde a janela da média esta dada por:

$$
M=\left(\begin{array}{lll}
1 & 1 & 1 \\
1 & 1 & 1 \\
1 & 1 & 1
\end{array}\right)
$$

Eliminando a componente contínua se consegue a visualização da imagem do objeto sobre um fundo completamente escuro, conseguindo-se melhoria do contraste.

O método da média considera a formação do holograma. A correspondente equação pode ser escrita considerando as definições de $R$ e $O$ e multiplicando os termos:

$$
I(x, y)=r(x, y)^{2}+o(x, y)^{2}+2 r(x, y) o(x, y) \cos \left(\varphi_{O}-\varphi_{R}\right)
$$

onde:

$O$ - é a intensidade da onda objeto

$R$ - é a intensidade da onda de referência

Os primeiros dois termos conduzem à ordem zero no processo de reconstrução. Para poder ver as imagens real e virtual devem ser eliminados.

O terceiro termo varia estatisticamente entre $\pm 2 r(x, y) o(x, y)$. A intensidade média de todos os pixels da matriz do holograma:

$$
=\frac{1}{N^{2}} \sum_{k=0}^{N-1} \sum_{k=0}^{N-1} I(k \Delta x, l \Delta y)
$$

$r^{2}+o^{2}$ agora pode ser suprimido mediante subtração desta intensidade média do holograma Im.

$$
I^{\prime}(k \Delta x, l \Delta y)=I(k \Delta x, l \Delta y)-\operatorname{Im}(k \Delta x, l \Delta y)
$$

para $k=0, \ldots, N-1 \quad ; l=0, \ldots, N-1$

A reconstrução de $I^{\prime}(x, y)$ resulta em uma imagem livre da ordem zero. O método não implica novas medições. No seguinte esquema apresenta-se a reconstrução de $I^{\prime}(x, y)$ sem ordem zero: 


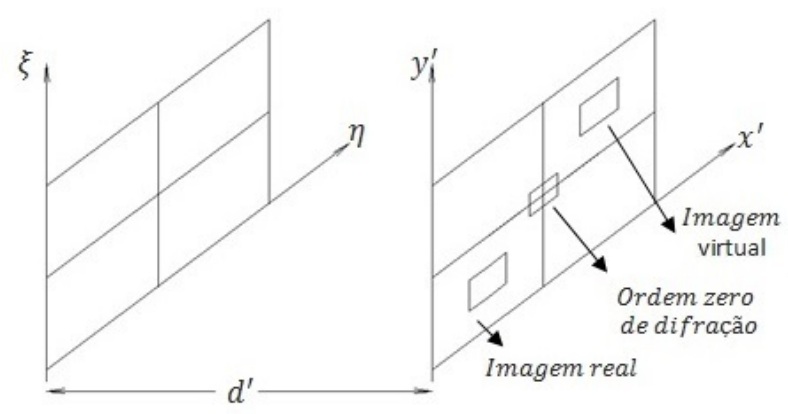

Figura 2.3 - Reconstrução de uma imagem sem ordem zero.

\subsubsection{Desmodulação}

A fase de uma função complexa é exclusivamente definida na faixa do principal valor. Recuperar os valores de fase a partir de valores originais principais é um problema de processamento de sinais clássico, muitas vezes conhecido como desmodulação ou desembrulhar a fase.

Este problema tem origem em aplicações como: mapeamentos de campos magnéticos em ressonâncias, distorção de frente de onda, etc.

Devido à natureza senoidal da função da onda usada em interferometria, o termo de fase $\delta($ ou $\varphi, \phi)$ a ser medido esta modulado sobre si mesmo com um período $2 \pi$. Em holografia digital a origem desse problema reside em que a frente de onda complexa $b^{\prime}(x, y)$ é reconstruída numericamente mediante um processo onde a fase $\delta(x, y, m)$ aparece como o argumento de uma função harmônica (coseno) o qual é uma função periódica:

$$
\cos (\delta)=\cos (s \delta+N 2 \pi), \quad s \epsilon[-1,1], \quad N \epsilon Z
$$

A fase em cada pixel $(x, y)$ entende-se como:

$$
\begin{gathered}
\Phi(x, y)=\operatorname{arctg} \frac{\operatorname{Im}\left[b^{\prime}(x, y)\right]}{\operatorname{Re}\left[b^{\prime}(x, y)\right]}, \quad \text { se } \operatorname{Re}\left[b^{\prime}(x, y)\right]>0 \\
\Phi(x, y)=\operatorname{arctg} \frac{\operatorname{Im}\left[b^{\prime}(x, y)\right]}{\operatorname{Re}\left[b^{\prime}(x, y)\right]}+\pi \operatorname{sgn}\left[\operatorname{Im}\left[b^{\prime}(x, y)\right]\right], \quad \text { se } \operatorname{Re}\left[b^{\prime}(x, y)\right]<0
\end{gathered}
$$

O valor de fase varia entre $-\pi \leq \Phi(x, y) \leq \pi$ razão pela qual denomina-se modulada. A correção da segunda equação é feita automaticamente pelo programa Holodig, o qual possui algoritmos específicos para fazer uma serie de correções e cálculos predeterminados. 
A função "arctg" tem os seus valores principais entre $-\pi / 2$ e $\pi / 2$. No programa Matlab usa-se a função "atan" e o resultado se encontra dentro do intervalo $(-\pi, \pi)$ radianos.

Para o caso em que o objeto tenha dimensões maiores que o comprimento de onda na direção z, os valores da fase também estão neste intervalo, por isso é necessário um algoritmo que elimine os saltos de fase $2 \pi$. Este processo é denominado "desmodulação", ele lineariza a fase para estabelecer a relação fase-propriedade física.

Qualquer mapa de fase envolvido é definido pelo seu valor principal, variável no intervalo:

$$
0 \leq \varphi_{w}(r)<2 \pi
$$

A fase real $\varphi(r)$ mede as quantidades físicas reais, tais como espessura, mapa de potencial, temperatura, campo de deformação, etc. Consequentemente tem que realizar-se o desenvolvimento da fase antes de qualquer reconstrução da quantidade física a partir do mapa de fase.

Matematicamente a desmodulação se expressa:

$$
\varphi_{w}(r)+2 \pi k(r)=\varphi(r)+n(r)
$$

onde $k(r)$ é a solução do campo de números inteiros o qual transforma a equação anterior numa identidade; $n(r)$ função de ruído experimental.

A desmodulação da fase leva à principal dificuldade e limitação de todos os procedimentos de aplicação da DH. A chave da desmodulação de fase é a identificação das descontinuidades reais $2 \pi$ em cada pixel da imagem. A continuação seguem algoritmos para a desmodulação:

1. Desmodulação espacial: Uma condição importante para sua identificação é que as fases nos pontos vizinhos satisfazem a condição:

$$
-\pi \leq \Delta_{i} \delta(x, y)<\pi \quad \operatorname{com} \quad \Delta_{i} \delta(x, y)=\delta(x, y)-\delta(x-1, y)
$$

Os algoritmos de desmodulação que substituem esta condição espacial dos pontos (pixels) vizinhos por uma temporal são mais robustos em caso de objetos complexos, eles são algoritmos conhecidos como: desmodulação temporal.

2. Desmodulação temporal: O procedimento de desmodulação temporal elimina a condição espacial e faz a desmodulação de cada pixel por separado ao longo de um eixo temporal. 
3. Desenvolvimento hierárquico multilambda: No método multilambda, os comprimentos de onda $\lambda_{i j}$ são selecionados de forma tal que o correspondente comprimento de onda sintético seja:

$$
\lambda_{i, j}^{k}=\frac{\lambda_{i} \lambda_{j}}{\left(\lambda_{i}-\lambda_{j}\right)}
$$

Em cada passo sucessivo $(k+1)$ tem que assegurar-se, considerando a tolerância da fase $\epsilon$, que:

$$
\lambda^{k+1}(1-4 \varepsilon) \geq \Lambda^{k} 4 \varepsilon
$$

Neste método se precisam só quatro passos para o desenvolvimento do mapa de fase complexo modulo $2 \pi$.

Para realizar o processo de desmodulação tem se desenvolvidos algoritmos baseados na solução da equação de Poisson com condições de fronteiras de Newmann, algoritmos baseados no método dos mínimos quadrados [GHIGLIA et al., 1987], e o algoritmo de Soille o qual usa técnicas de processamentos de imagens morfológicas [SOILLE, 1999].

\subsection{Microscopia Holográfica Digital}

O microscópio é o instrumento insígnia no estudo histológico que permite a compreensão da estrutura microscópica de diversos materiais que podem ser biológicos ou não, como no caso dos materiais metálicos, resinas, etc. A evolução do conhecimento depende fundamentalmente do progresso tecnológico alcançado. Os numerosos descobrimentos tem ajudado com que o ser humano consiga ver muito mais das suas capacidades, observando tanto aqueles objetos que estão muito longe, como também os que pelo reduzido tamanho escapa da capacidade do olho humano para formar uma imagem dos mesmos. O funcionamento de muitos microscópios tem sido interpretado de uma maneira mais efetiva ao entender o processo da visão e formação das imagens, estabelecendo diferenças entre o que é o objeto que se observa e a imagem que se forma a partir dele quando este é iluminado.

Para produzir uma imagem se requer: Primeiro, o objeto em estudo sob o qual deve incidir algum tipo de luz e segundo, um meio de formação da imagem, o sistema óptico que permitirá produzir a imagem. O tamanho da imagem formada pode ser menor, igual ou maior que o tamanho do objeto a partir do qual foi produzido. 
O Microscópio Holográfico Digital surge nos anos seguintes ao surgimento da holografia digital, pertencendo a uma área composta respectivamente pela conjugação de holografia digital com a microscopia óptica [JUNIOR, 2014]. Tem como finalidade estudos e aplicações baseadas na apropriação das vantagens da disponibilidade da amplitude e fase das imagens microscópicas armazenadas digitalmente, ampliando bastante as possibilidades de análise e testes em várias áreas de conhecimento [TAVIO et al., 2017], [GESUALDI et al., 2013], [JUNIOR, 2014], [LOPEZ, 2012].

Na microscopia holográfica digital, o holograma geralmente é obtido mediante uma instalação óptica, que consiste em um interferômetro de Mach-Zender para hologramas de transmissão e reflexão, ao qual está acoplado um microscópio óptico em um dos seus braços, [TAVIO et al., 2017]. Outro interferômetro como instalação óptica é o interferômetro de Michelson, para hologramas de reflexão, como o que se apresentam neste trabalho.

Como fonte de luz se utiliza um feixe linearmente polarizado de um laser. O feixe é filtrado por um filtro espacial, depois dividido nos dois braços do interferômetro. No microscópio óptico as lentes objetivas possuem aumento e apertura numérica segundo as necessidades e características do objeto em estudo, produzindo um aumento do mesmo. Para melhores resultados pode ser utilizado também um condensador para focar a iluminação do objeto. A seguir são descritos aspectos teóricos necessários para o trabalho com DHM.

\subsubsection{Resolução Lateral}

Os fundamentos do microscópio foram estabelecidos por Erns Abbe entre os anos 1873 a 1884. Ele demostrou como a difração da luz pelo objeto e pelas lentes objetivas determina a resolução da imagem; definindo as condições necessárias para desenhar lentes qual resolução fosse de difração limitada e estabelecer a função das aperturas numéricas (NA) do objetivo e o condensador, [LOPEZ, 2012].

$$
d_{\text {min }}=\frac{1.22 \lambda_{0}}{N A_{o b j}+N A_{\text {cond }}}
$$

onde $d_{\text {min }}$ é o espaçamento mínimo em uma rede de difração periódica e se expressa como a distância lateral no espaço da amostra; $\lambda_{0}$ o comprimento de onda no vazio e $N A_{o b j}$ e $N A_{\text {cond }}$ são as aperturas numéricas das lentes objetivo e condensador respectivamente. $N A$ é o produto do seno da metade do ângulo $(\alpha)$ do cone de luz aceitável pela lente objetiva ou emergindo da lente condensadora e os índices de refração $(\eta)$ do meio entre o objeto e as lentes objetiva e condensador, [LOPEZ, 2012].

A Eq. 2.47 demonstra que, além do comprimento de onda e da $N A$ da lente objetiva, a $N A$ do condensador também afectam a resolução da imagem no microscópio. Para objetos 
que são iluminados coerentemente por completo, o espaçamento lateral mínimo resolvível aumenta por um fator de 2 comparado ao caso quando o íris do condensador está aberto tanto que $N A_{\text {cond }}=N A_{o b j}$. Como o íris do condensador está aberto e $N A_{\text {cond }}$ torna-se maior, a iluminação torna-se progressivamente menos coerente e a resolução aumenta, [PAWLEY, 2006].

Um método complementar de definição do limite de resolução utiliza objetos pontuais em vez de grades de linha. A imagem em foco, de um objeto luminoso infinitamente pequeno é em si mesmo não infinitamente pequena, mas é um circulo de Airy de imagem de difração com um disco central brilhante, e escuras concêntricas progressivamente mais fracas e mais brilhantes. O raio $r_{\text {Airy }}$ do primeiro círculo escuro ao redor do disco central Airy da imagem de difração de $\lambda$ e $N A$ da objetiva, [PAWLEY, 2006].

$$
r_{\text {Airy }}=0.61 \frac{\lambda_{0}}{N A_{o b j}}
$$

onde $r_{\text {Airy }}$ está expressado como a distância no plano do objeto.

Quando existem dois pontos de luz separados por uma pequena distância $d$ no plano do objeto, suas imagens de difração ficam lado a lado no plano da imagem. Diz-se que as imagens de dois pontos igualmente brilhantes são resolvidas se $d$ é igual ou maior que o raio do disco de Airy. Este é o critério de Rayleigh, e baseia-se na suposição de que as duas fontes pontuais irradiam incoerentemente. Se as duas fontes pontuais emitem luz de forma coerente, deve-se considerar sua amplitude em vez de sua distribuição de intensidade na imagem, e a sua resolução geralmente diminui, [PAWLEY, 2006].

A distribuição precisa da energia na luz de formação da imagem acima e abaixo do foco especialmente para lentes objetivas de $N A$ alta, não pode ser deduzida por traçado do raio geométrico, mas deve ser derivada da óptica da onda, [PAWLEY, 2006].

A distância do centro do padrão de difração 3D ao primeiro mínimo axial (em dimensões do espaço do objeto) é dada por:

$$
z_{\text {min }}=\frac{2 \lambda_{0} \eta}{\left(N A_{o b j}\right)^{2}}
$$

onde $\eta$ é o índice refrativo do meio do objeto. $z_{\text {min }}$ corresponde à distância pela qual temos de elevar o objetivo do microscópio para focalizar o primeiro mínimo de intensidade observado ao longo do eixo do padrão de difração 3D em vez do padrão central, [PAWLEY, 2006]. Como limite de resolução lateral do microscópio óptico se pode usar $z_{\text {min }}$.

\subsubsection{Profundidade de campo}


A profundidade de campo é um efeito que descreve até que ponto os objetos que estão mais ou menos perto do plano do foco aparentam estar nítidos. A atual profundidade tem sido determinada experimentalmente e a contribuição de vários fatores que afeta a medição tem sido explorado por Berek (1927).

De acordo com Berek, a profundidade de campo é afetada por: (1) a geometria e espalhamento de difração limitada acima e abaixo do plano do foco do feixe de luz que surge a partir de um único ponto na amostra (objeto); (2) o ponto de observação; (3) a magnificação final da imagem.

A profundidade de campo depende da abertura do diafragma e da proximidade que se está do objeto. O diafragma regula a intensidade de luz, ela afeta a nitidez entre os planos, ou seja, a profundidade de campo. A abertura do diafragma pode variar entre fechado e aberto, dependendo somente da objetiva utilizada. Outro fator que afeta a profundidade de campo é a distância focal da objetiva a ser utilizada. Quanto maior a distância focal, maior será a área desfocada e vice-versa [PAWLEY, 2006].

\subsubsection{Iluminação do laser}

Uma aplicação prática dos lasers na microscopia está no seu uso como uma intensa, fonte monocromática de luz. Os lasers podem ter feixes de luz com alto grau de monocromaticidade e polarização empregando um alto grau de coerência. Alguns lasers também geram feixes com alta intensidade. Desse modo, um laser apropriado poderia constituir uma valiosa fonte de luz nesses modos da microscopia onde a monocromaticidade, alta intensidade e um alto grau de coerência e polarização são indispensáveis, [PAWLEY, 2006].

Para usar o laser como uma fonte efetiva de luz para microscopia três condições devem ser satisfeitas, [PAWLEY, 2006]:

- Tanto o campo de visão do microscópio como a abertura do condensador deve ser adequadamente preenchido.

- O comprimento de coerência do feixe do laser deve ser reduzida para eliminar a interferência causada por defeitos do foco externo.

- A coerência no plano da imagem deve ser reduzida para eliminar o "speckle"do laser e para maximizar a resolução da imagem.

\subsubsection{Reconstrução em Microscopia Holográfica Digital (DHM)}

Existem diferentes métodos de reconstrução de imagens em $D H M$ como a Simples Transformada de Fourier (SFTF, em inglês), o algoritmo de convolução (CV) e algoritmo 
com base no espectro angular (ASA). Outros métodos têm sido desenvolvidos para eliminar as distorções de campo características do processo de captura e reconstrução da imagem [PALACIOS et al., 2004].

Um método para a reconstrução da imagem que sim consegue a correção do campo reconstruído se conhece como o algoritmo de Dupla Propagação (DPA). Seu principio resulta em realizar uma propagação do campo até o plano focal da lente objetiva e logo a partir deste, se realiza uma segunda propagação até o plano imagem eliminando limitações dos métodos tradicionais.

O algoritmo DPA é utilizado neste trabalho para a reconstrução numérica das imagens, por isso se apresenta a continuação uma descrição deste.

\subsubsection{Método de Dupla Propagação como método numérico de reconstrução holográfica}

No microscópio digital holográfico, o campo produzido pela lente objetiva pode ser reconstruído em qualquer plano ao longo da direção do campo de propagação. Tradicionalmente, o campo óptico $\psi\left(x^{\prime}, y^{\prime}\right)$ no plano imagem $\left(x^{\prime}-y^{\prime}\right)$ é calculado pela propagação da frente de onda $\psi(\xi, \eta)$, uma distância $z=d^{\prime}$ a partir do plano do holograma $\psi(\xi-\eta)$, como se apresenta na Figura. 2.4, [PALACIOS et al., 2011].

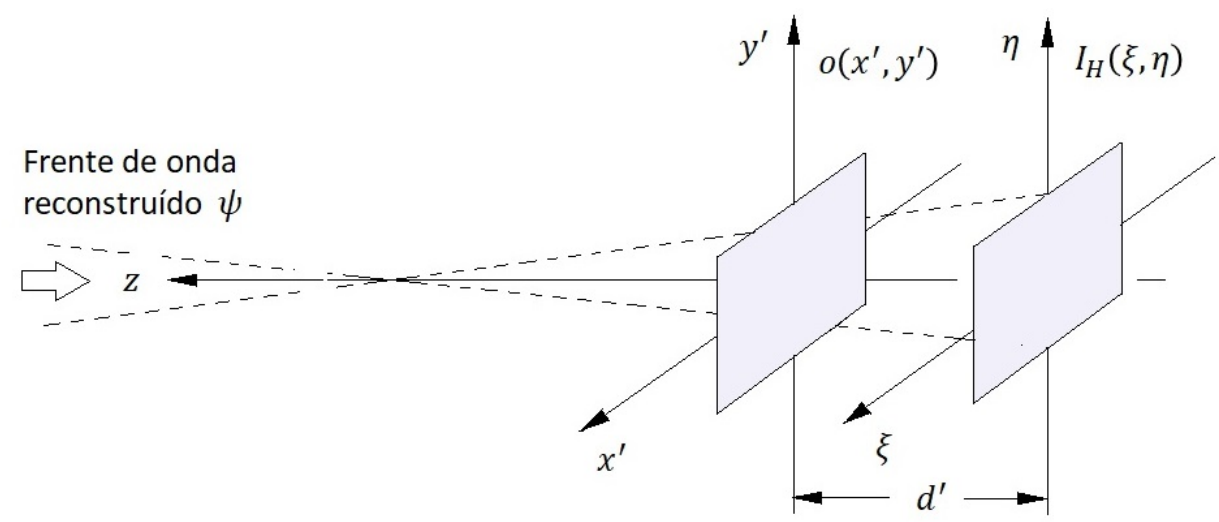

Figura 2.4 - Diagrama dos métodos tradicionais de reconstrução de imagem no DHM.

Em nossa abordagem, a reconstrução da onda complexa de distribuição õ $\left(x^{\prime}, y^{\prime}\right)=$ $\psi\left(x^{\prime}, y^{\prime} ; z=d^{\prime}\right)$ basicamente consiste de dois estágios que envolve duas frentes de ondas de progação. No primeiro estágio, Figura. 2.5, se reconstrói a distribuição da onda õ $(u, v)$ no $(u-v)$ plano de reconstrução com uma distância $z=D$ (primeira propagação). 


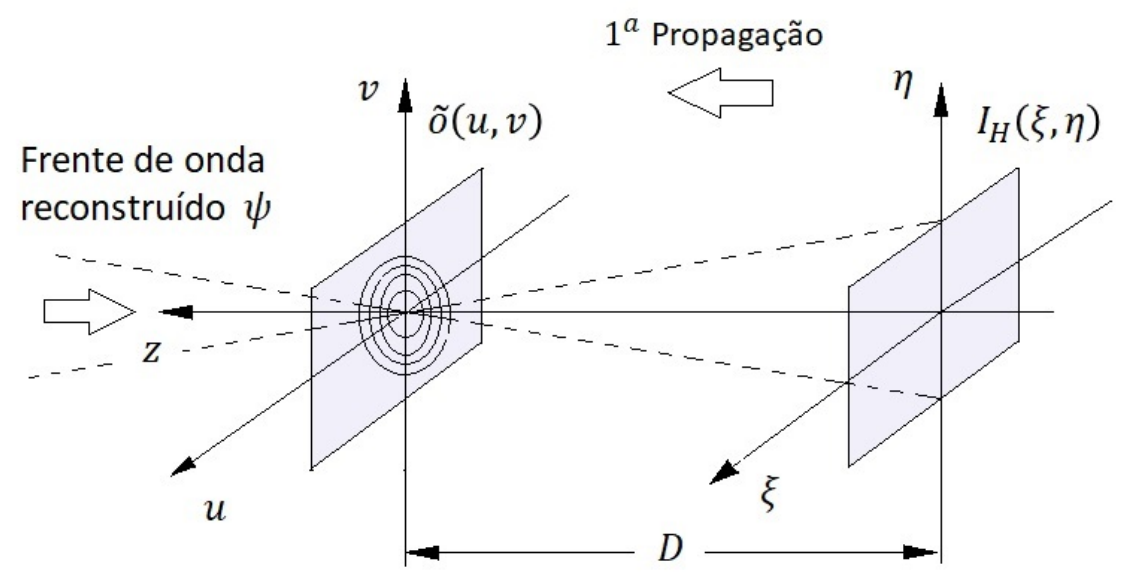

Figura 2.5 - Reconstrução da onda de distribuição õ $(u, v)$ no plano de reconstrução $(u-v)$ com uma distância $z=D$ (primeira propagação).

A distância $D$ tem sido calculada, a primeira propagação é realizada por meio do método de aproximação de Fresnel, especificamente pela simples transformada de Fourier (SFTF).

$$
\psi_{S F T F}(u, v ; z)=A \exp \left[\frac{i \pi}{\lambda z}\left(u^{2}+v^{2}\right)\right] \Im\left\{I_{H}(\xi, \eta) \exp \left[\frac{i \pi}{\lambda z}\left(\xi^{2}+\eta^{2}\right)\right]\right\}
$$

Onde $z$ é a distância de reconstrução, $\Im$ um operador que denota a transformada de Fourier, $A=\exp (i 2 \pi / \lambda) /(i \pi \lambda)$ é considerado a onda do plano de referência com uma força unitária perpendicular ao plano de gravação.

Em $z=D$, o campo de ondas reconstruido consiste de uma ordem zero e duas imagens gêmeas (real e a conjugada). O campo de ondas complexo filtrado $\psi_{S F T F}^{f}(u, v ; z=D)$ pode ser expressado pela Eq. 2.51 reemplazando a especimen do holograma $I_{H}(\xi, \eta)$ com o holograma filtrado $I_{H} I_{H}^{f}(\xi, \eta)=R O$ contendo somente os componentes espaciais da imagem real [CUCHE et al., 2000].

$$
\psi_{S F T F}^{f}(u, v ; z=D)=A \exp \left[\frac{i \pi}{\lambda z}\left(u^{2}+v^{2}\right)\right] \Im\left\{I_{H}^{f}(\xi, \eta) \exp \left[\frac{i \pi}{\lambda z}\left(\xi^{2}, \eta^{2}\right)\right]\right\}
$$

O campo complexo $\psi_{S F T F}^{f}(u, v ; z=D)$ é equivalente à distribuição com o campo complexo õ $(u, v)$ no plano focal traseiro da lente objetivo. O plano focal traseiro pode ser representado pela expressão:

$$
\psi_{S F T F}^{f}(u, v ; z=D) \cong \tilde{o}(u, v)=S_{\phi}(u, v) \Im\left[o\left(x_{0}, y_{0}, \lambda f\right)\right]
$$


onde $\Im\left[o\left(x_{0}, y_{0}, \lambda f\right)\right]$ é a Transformada de Fourier da distribuição da onda objeto no plano $(u-v)$, com $o\left(x_{0}, y_{0}\right)$, a amplitude da transmitância do objeto.

$$
\Im\left[o\left(x_{0}, y_{0}, \lambda f\right)\right]=\iint o\left(x_{0}, y_{0}\right) \exp \left[-i \frac{2 \pi}{\lambda f}\left(x_{0} u+y_{0} v\right)\right] d x_{0} d y_{0}
$$

e $S_{\phi}(u, v)$ é um fator de fase quadrático,

$$
S_{\phi}(u, v)=\frac{i}{\lambda f} \exp \left[-i k\left(S_{o}+f\right)\left[\frac{i k}{2 f}\left(u^{2}+v^{2}\right)\left(1-\frac{S_{o}}{f}\right)\right]\right]
$$

onde $S_{o}$ é a distância a partir do objeto até as lentes, $f$ é a distância focal das lentes, $\lambda$ é o comprimento de onda da onda plana incidente.

A partir da teoria de formação da imagem, depois das lentes objetivas produzirem o padrão de interferência do objeto no seu plano focal posterior, uma segunda transformação de Fourier é realizada sobre o padrão de difração que está associado com a imagem objeto. Consequentemente toda a informação sobre o campo de onda da imagem no plano do holograma está contida na frente de onda complexa $o(u, v)$ no plano focal posterior, por esse motivo a reconstrução do campo de onda óptico $o\left(x^{\prime}, y^{\prime} ; d^{\prime}\right)$ pode ser realizada a partir do plano $(u-v)$, em vez do tradicionalmente plano do holograma $(\xi, \eta)$, Figura. 2.6.

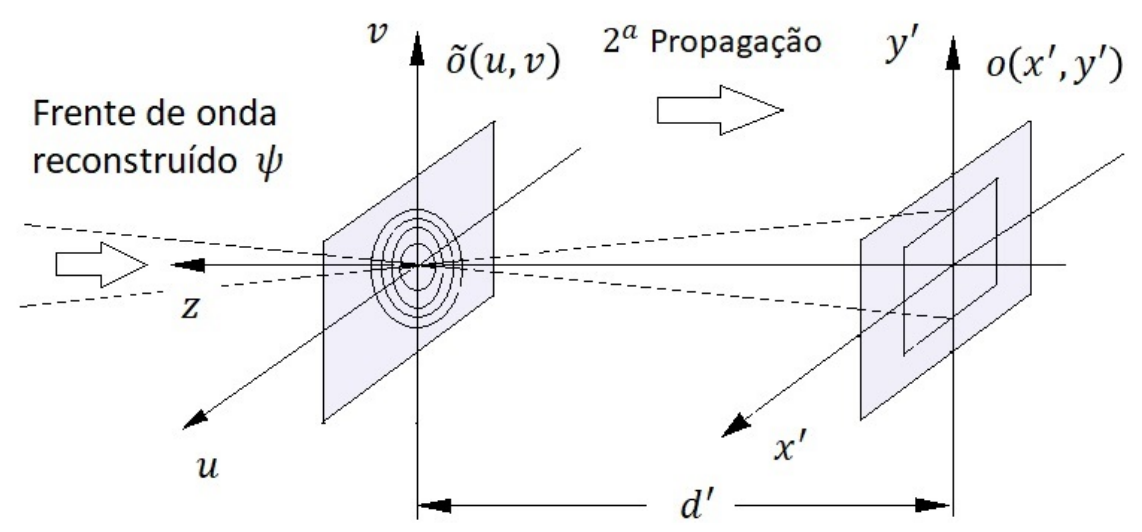

Figura 2.6 - Reconstrução da frente de onda óptico $o\left(x^{\prime}, y^{\prime} ; d^{\prime}\right)$ no plano imagem a partir do plano $(u-v)$ (segunda propagação).

Na segunda etapa do método, a frente de onda complexa $\psi\left(x^{\prime}, y^{\prime} ; d^{\prime}\right)$ em uma distância arbitraria pode ser obtida pela propagação da frente de onda õ $(u, v)$ através da distância 
$d^{\prime}$ e o resultado resulta como a transformada de Fourier inversa:

$$
\psi\left(x^{\prime}, y^{\prime} ; d^{\prime}\right)=\Im^{-1}\left[\psi_{S F T F}^{f}(u, v ; z=D) \exp \left(i d^{\prime} \sqrt{k^{2}+k_{u}^{2}+k_{v}^{2}}\right)\right]
$$

onde $\Im^{-1}$ simboliza a Transformada de Fourier Inversa, $k=2 \pi / \lambda, k_{u}$ e $k_{o}$ são as correspondentes frequencias espaciais de $u$ e $v$ respectivamente. A implementação numérica da Eq. 2.55, que se denota como o algoritmo de Dupla propagação (DPA), está dado por:

$$
\begin{gathered}
\psi\left(m, n ; d^{\prime}\right)= \\
F F T^{-1}\left\{\psi_{S F T F}^{f}(l, j ; z=D) \times \exp \left[2 \pi i d^{\prime} \sqrt{(1 / \lambda)^{2}+(l / N \Delta \eta)^{2}+(j / M \Delta \eta)^{2}}\right]\right\}
\end{gathered}
$$

onde $j, l, m, n$ são inteiros $(-M / 2<j, l<M / 2),(-N / 2<m, n<N / 2)$ e $\psi_{S F T F}^{f}(l, j ; z=D)$ resulta a formulação discreta da Eq. 2.52. A partir da Eq. 2.56 pode ser obtida a imagem de intensidade $I_{D P A}\left(x^{\prime}, y^{\prime} ; d^{\prime}\right)$ pelo cálculo de $\left|\psi_{D P A}\left(m, n ; d^{\prime}\right)^{2}\right|$ e da imagem de fase $\phi_{D P A}\left(x^{\prime}, y^{\prime} ; d^{\prime}\right)$ pelo cálculo da $\arg \left[\psi_{D P A}\left(m, n ; d^{\prime}\right)\right]$.

Em resumo, o seguinte passo a passo descreve o procedimento geral do método de reconstrução alternativo:

- Determinar a distância $D$.

- Calcular $\psi_{S F T F}(u, v ; z=D)$ utilizando a Eq. 2.50 isto é, as amplitudes complexas da frente de onda em $z=D$.

- Obter $\psi_{\text {SFTF }}(u, v ; z=D)$ pelo filtrado das componentes espaciais que correspondem às amplitudes complexas da transformada de Fourier dos objetos.

- Calcular $\psi_{D P A}\left(m, n ; d^{\prime}\right)$, utilizando a Eq. 2.56, em uma distância arbitraria $d^{\prime}$.

- Determinar a imagem de intensidade ou a imagem de fase pelo cálculo dos módulos dos quadrados ou o argumento da Eq. 2.56.

A Eq. 2.56 garante que a imagem reconstruída mantem seu tamanho independente da profundidade $d^{\prime}$, a compensação da curvatura da fase pode ser feito facilmente através das técnicas de subtração do fundo da imagem.

A amplitude e fase do holograma correspondente são obtidos através das seguintes expressões:

$$
I\left(x^{\prime}, y^{\prime}, d_{j}\right)=\left|\operatorname{Re}\left[O\left(x^{\prime}, y^{\prime}, d_{j}\right)\right]\right|^{2}+\left|\operatorname{Im}\left[O\left(x^{\prime}, y^{\prime}, d_{j}\right)\right]\right|^{2}
$$




$$
\alpha\left(x^{\prime}, y^{\prime}, d_{j}\right)=\arctan \frac{\operatorname{Im}\left[O\left(x^{\prime}, y^{\prime}, d_{j}\right)\right]}{\operatorname{Re}\left[O\left(x^{\prime}, y^{\prime}, d_{j}\right)\right]}
$$

Quando $d_{j}=0$ a imagem está focalizada sobre o plano do holograma, e se $d_{j} \neq 0$ ela é focalizada fora do plano do holograma. 


\section{Técnica proposta para análise da rugosidade superficial}

A análise de superfícies, ou metrologia nas superfícies é um campo que analisa as texturas e medição de características como ondulação, rugosidade e arredondamento dos materiais e objetos. Estes estudos têm como objetivo entender a origem e historia de um objeto, como por exemplo, os processos de fabricação e desgaste que tem influenciado na sua textura e como isto afetará as suas interações com outros componentes e materiais. As medições precisas e reproduzíveis de diferenciação e correlação da textura são essenciais uma vez que dão origem às propriedades fundamentais como a aderência, abrasão, atrito e estética superficial [GONZÁLEZ; VÁZQUEZ, 1995].

Para avaliar as variações na textura da superfície, a metrologia utiliza técnicas ou métodos que podem ser qualitativos, de observação tátil ou visual, com ou sem óptica. Os métodos de medição quantitativos como os rugosímetros, trabalham mediante acionamento mecânico, elétrico ou eletrônico. Existem diferentes tipos de rugosímetros como os capacitivos, indutivos e piezoelétricos. A principal diferença encontra-se na forma em que geram o sinal elétrico a partir do movimento mecânico da agulha. A agulha geralmente está fabricada com materiais como o diamante ou carburo de tungstênio, e a sua forma e seu raio influenciam nos resultados. Também existem os rugosímetros a laser, não possuem um apalpador físico, este se substitui por um laser. A medição é baseada na luz refletida e espalhada pela superfície [GONZÁLEZ; VÁZQUEZ, 1995].

\subsection{Técnica}

O interesse no desenvolvimento de uma técnica e metodologia para medir a rugosidade superficial utilizando microscopia holográfica digital por reflexão tem sua origem, na necessidade de uma técnica que permita a obtenção de resultados de uma maneira rápida e que por sua vez seja de baixo custo, garantindo precisão nos valores obtidos.

Por tanto, na realização deste trabalho a primeira etapa foi dedicada à análise das metodologias que atualmente são utilizadas, com o objetivo de avaliar o método de campo adequado. Procurou-se um método com diferentes aplicações, sem ficar restringido à analise de apenas um parâmetro. Assim, o novo método permitirá medir a rugosidade superficial e realizar também, por exemplo, a sua análise dimensional. Sua execução e posteriormente seu uso, será de baixo custo, possibilitando o estudo de parâmetros sem um equipamento excessivamente sofisticado, porém, caro. 
A dificuldade do desenvolvimento reside em que os métodos sem contato na análise de superfícies que não são planas, apresentam inconvenientes devido à coerência. Seu uso depende das condições específicas de campo, dependendo das zonas de medição. Neste caso, onde a geometria da superfície interfere nas medições, deve ser considerado um tratamento desta. Assim diminui o problema da coerência e não se afetam as medições conseguindo uma adequada aproximação dos resultados aos valores reais.

\subsection{Processamento das imagens}

A microscopia holográfica digital por reflexão é uma técnica que captura, armazena e processa as imagens obtidas do objeto em estudo. O processamento das imagens depende do material em estudo, geometria e dos parâmetros desejados a analisar. Para isto é necessário o conhecimento de alguns dos conceitos básicos para o processamento destas.

Uma imagem, pode ser representada por uma função bidimensional da forma $f(x, y)$, onde o valor ou amplitude de $f$ nas coordenadas espaciais $(x, y)$ é igual à intensidade da imagem nesse ponto. A imagem gerada a partir de um processo físico possui valores proporcionais à energia irradiada pela fonte física. Como consequência $f(x, y)$, deve ser diferente de zero e finita [FOLEY et al., 1996], [GONZALEZ; WOODS, 2002] e [BERND, 2005].

$$
0<f(x, y)<\infty
$$

A função $f(x, y)$ se caracteriza por duas componentes:

1. Iluminação: A quantidade de luz incidente procedente da fonte sob a cena.

2. Reflectância: A quantidade de luz refletida pelos objetos da cena.

As duas se combinam para formar:

$$
f(x, y)=i(x, y) r(x, y)
$$

onde:

$$
0<i(x, y)<\infty
$$

e

$$
0<r(x, y)<1
$$


A Eq. 3.4 indica que a Reflectância está limitada entre 0 (absorção total) e 1 (reflexão total). A natureza de $i(x, y)$ está determinada pela fonte de iluminação, e a de $r(x, y)$, pelas características dos objetos.

Níveis de cinzas e escala de cinzas

A intensidade de uma imagem monocromática $f$ nas coordenadas $(x, y)$ se denomina "níveis de cinza" da imagem nesse ponto [FOLEY et al., 1996], [GONZALEZ; WOODS, 2002] e [BERND, 2005].

$$
I=f\left(x_{0}, y_{0}\right)
$$

Das equações anteriores segue-se que $I$ está no intervalo:

$$
L_{\text {mín }}<=I<=L_{m a ́ x}
$$

O intervalo $\left[L_{m i ́ n}, L_{m a ́ x}\right]$ se denomina "escala de cinzas". Uma prática habitual consiste em deslocar esse intervalo até $[0, L]$, onde $I=0$ se considera preto e $I=L-1$ se considera branco (todos os valores intermédios são tons de cinzas) [FOLEY et al., 1996], [GONZALEZ; WOODS, 2002] e [BERND, 2005].

\section{Amostragem e quantificação}

Existem diferentes formas de adquirir imagens, mas o nosso objetivo é gerar imagens digitais desde dados detectados com sensores, como por exemplo, os de uma câmera CCD. Para obter uma imagem digital, precisamos converter os dados detectados de forma digital, o que envolve processos de amostragem e quantificação.

Uma imagem pode ser contínua tanto em relação a suas coordenadas $x$ e $y$, como a sua amplitude. Para convertê-la à forma digital, deve ser digitalizada em dois aspectos (espacialmente e em amplitude).

A digitalização das coordenadas espaciais $(x, y)$ se denomina "amostragem" da "imagem" e a digitalização da sua amplitude se conhece como quantificação. O método de amostragem está determinado pela ordem dos sensores utilizados para gerar a imagem. A qualidade é determinada em grande parte pelo número de amostras e níveis de cinza utilizados na amostragem e quantificação [FOLEY et al., 1996], [GONZALEZ; WOODS, 2002] e [BERND, 2005].

Representação das imagens digitais 
A saída da amostragem e quantificação é uma matriz de números reais. Estes serão apresentados de duas formas.

Uma imagem contínua $f(x, y)$ descreve-se de forma aproximada por uma serie de amostras igualmente espaçadas que se encontram organizadas em forma de matriz $N \times M$, como se indica na Eq. 3.7, onde cada elemento da matriz é uma quantidade discreta [FOLEY et al., 1996], [GONZALEZ; WOODS, 2002] e [BERND, 2005].

$$
\left[\begin{array}{cccc}
f(0,0) & f(0,1) & \cdots & f(0, N-1) \\
f(1,0) & f(1,1) & \cdots & f(1, N-1) \\
\vdots & \vdots & \vdots & \vdots \\
f(M-1,0) & f(M-1,1) & \cdots & f(M-1, N-1)
\end{array}\right]
$$

Cada um dos seus elementos é um "elemento da imagem", o pixel. Algumas vezes se apresenta como uma notação de matrizes mais tradicional.

$$
\left[\begin{array}{cccc}
a_{0,0} & a_{0,1} & \cdots & a_{0, N-1} \\
a_{1,0} & a_{1,1} & \cdots & a_{1, N-1} \\
\vdots & \vdots & \vdots & \vdots \\
a_{M-1,0} & a_{M-1,1} & \cdots & a_{M-1, N-1}
\end{array}\right]
$$

Não se requer um valor espacial de $M$ e $N$, exceto que sejam inteiros positivos. Para o caso do número de níveis de cinza, este é usualmente uma potência inteira de 2, [FOLEY et al., 1996], [GONZALEZ; WOODS, 2002] e [BERND, 2005].

$$
L=2^{k}
$$

O número de bits necessários para armazenar uma imagem digitalizada se representa como:

$$
b=N \times M \times k
$$

Quando $M=N$ então:

$$
b=N^{2} k
$$


Resolução espacial e resolução em níveis de cinza

A amostragem é o principal fator para determinar a "resolução espacial" de uma imagem sendo o grau de detalhe discernível em uma imagem. A "resolução" de "nível de cinza" refere-se à mais pequena mudança discernível em nível de cinza, embora, medir estas mudanças de intensidade resulta um processo subjetivo [FOLEY et al., 1996], [GONZALEZ; WOODS, 2002] e [BERND, 2005].

A potência de 2 que determina o número de níveis de cinza usualmente é de 8 bits, ou seja, 256 diferentes níveis de cinza. Algumas aplicações utilizam 16 bits. Usualmente se expressa como uma imagem digital de tamanho $M \times N$, com $L$ níveis de cinza tem uma "resolução espacial" de $M \times N$ pixels e uma "resolução de níveis de cinza" de $L$ níveis [FOLEY et al., 1996], [GONZALEZ; WOODS, 2002] e [BERND, 2005].

Conhecendo estes princípios temos a base para elaborar um algoritmo que permitirá a transformação dos valores da imagem que se encontrará em forma matricial em pixels, a valores reais com magnitude de $(\mu m)$. Este será apresentado no Capítulo 5 do texto. 


\section{Análise Experimental}

Para o desenvolvimento deste trabalho, além dos conhecimentos teóricos, foram necessários toda uma série de elementos que permitiram a sua concretização. A seguir, são apresentados os materiais e a metodologia que permitiram o desenvolvimento da holografia digital como uma ferramenta para a análise de objetos de pequena dimensão.

\subsection{Materiais}

- Objetos de pequeno tamanho

Para a análise dimensional foram utilizadas peças de pequenas dimensões como parafusos e engrenagens, apresentadas na Fig. 4.1 e Figura. 4.2. Estas peças foram embutidas, lixadas, polidas e atacadas quimicamente.

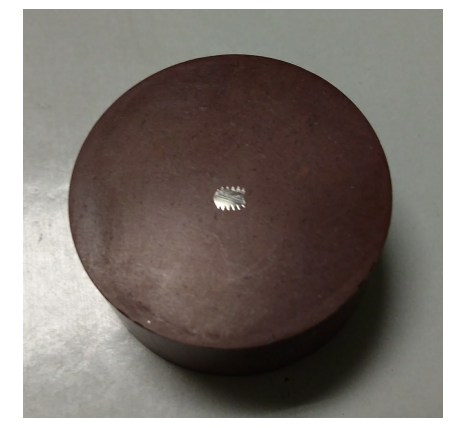

(a)

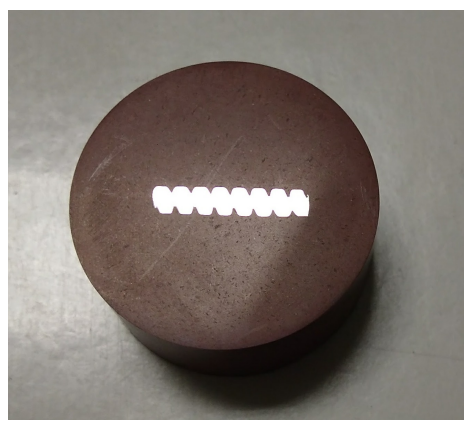

(b)

Figura 4.1 - (a) Parafuso M3 sem cabeça com sextavado interior, (b) Parafuso sem fim.

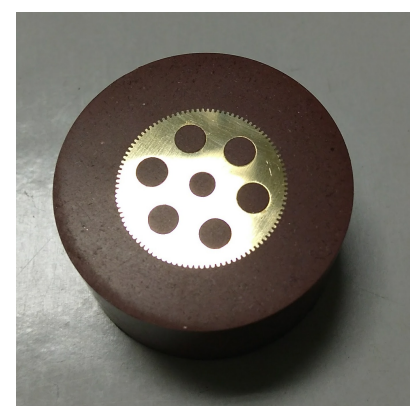

Figura 4.2 - Engrenagem 
- Configuração experimental

Para a captura dos hologramas foi utilizada uma instalação que tem como base o interferômetro de Michelson. A instalação consta com uma adaptação de microscopia holográfica, possuindo duas lentes plano convexa de $250 \mathrm{~mm}$ de distância focal (L), uma utilizada como lente condensador (C), uma lente objetiva 10X/0,25 monocromática e correção infinita (LO). Uma fonte de luz Laser Excelsior $532 \mathrm{~nm}$ 150mW. (FL) Modelo: EXLSR-532-150-CDRH, um atenuador (A), um filtro espacial Melles Griot (FE), um diafragma (D), um divisor de feixe $(\mathrm{BS})$, o objeto $(\mathrm{O})$, um polarizador $(\mathrm{P})$, um espelho $(\mathrm{E})$, uma lente biconvexa de $50 \mathrm{~mm}$ de distância focal (L) e um dispositivo de carga acoplada (CCD), como se apresenta na Figura. 4.3 .

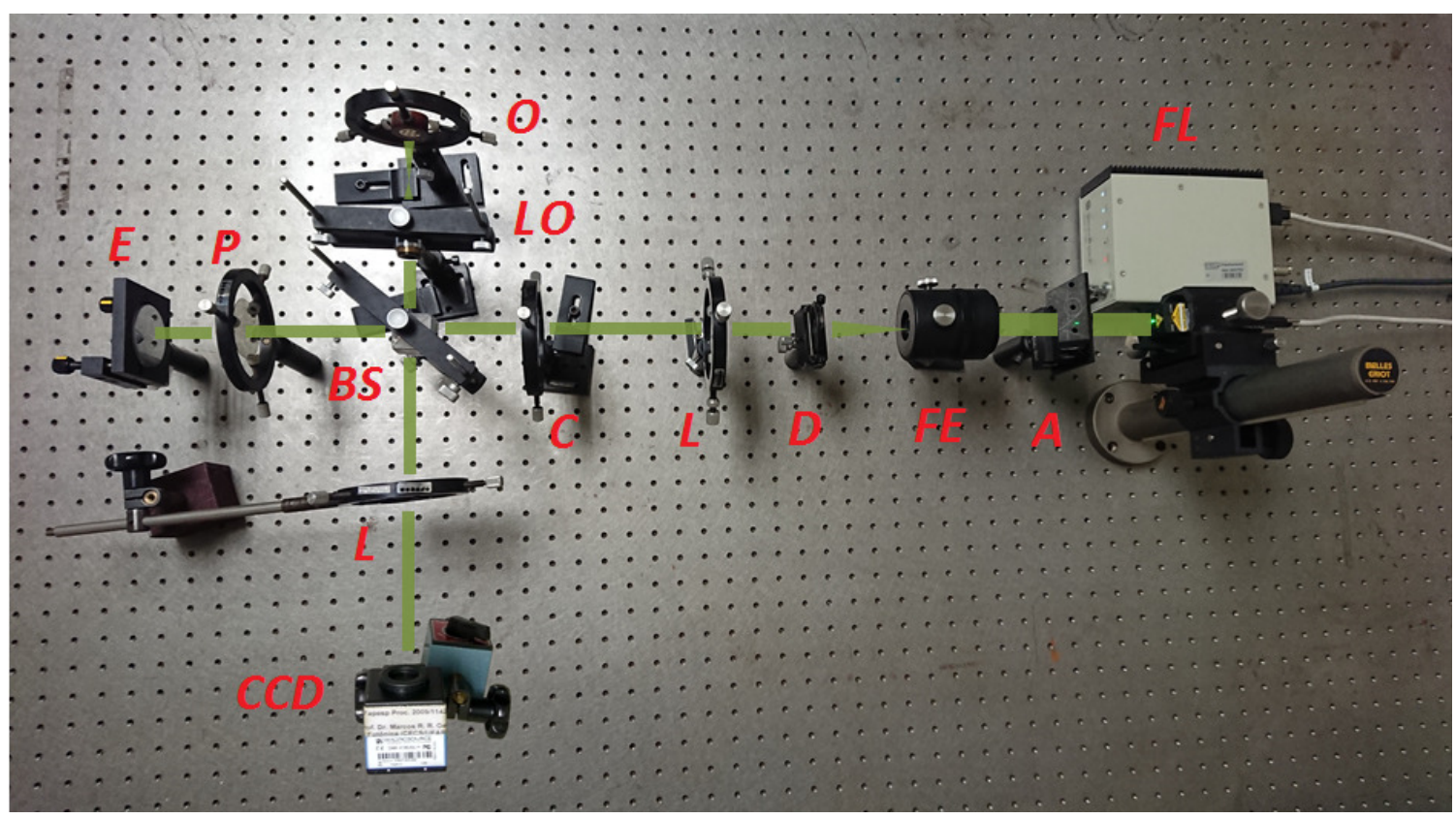

Figura 4.3 - Configuração experimental.

A luz do laser é expandida e filtrada pelo filtro espacial, o paralelismo é corrigido pela lente condensadora $(\mathrm{C})$. O (BS) divide o feixe em dois, o feixe objeto e referência. $\mathrm{O}$ primeiro passa pela lente objetiva (LO) até o objeto, o segundo passa pelo polarizador (P) até o espelho (E). As intensidades de cada feixe se controlam mediante o polarizador $(\mathrm{P})$ e o atenuador (A). Ambos feixes voltam pelo mesmo caminho até o (BS) que os conduz até o sensor da câmera CCD, na qual chegam orientados corretamente criando o padrão de interferência. 
- Escala Padrão para Calibração

A escala padrão para calibração possui escala $1 \mathrm{~mm} / 100$ divisões com 0,01 precisão, Figura. 4.4.

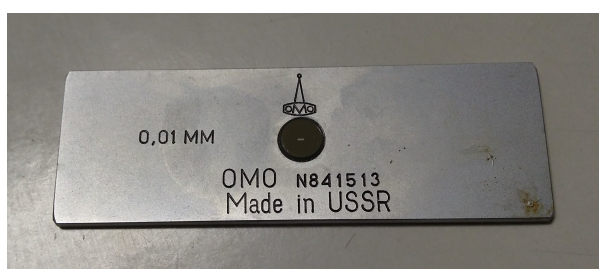

Figura 4.4 - Escala padrão para calibração

Para o processamento das imagens, foram utilizados dois programas que se apresentam em seguida.

- Sistema de Captura dos Hologramas, Reconstrução da Imagem e a Análise Dimensional, HOLODIG.

HOLODIG é um sistema suportado pelo MATLAB e encontra-se programado para o processo de captura da imagem holográfica. O programa encontra-se desenhado para realizar captura de hologramas e a reconstrução das imagens de intensidade e fase.

- ImageJ

Para a validação das medições foi utilizado um programa de processamento de imagens digitais de domínio público programado em Java e desenvolvido por Wayne Rasband. ImageJ tem uma arquitetura aberta que proporciona extensibilidade via plug-ins e macros graváveis. Suas características fazem possível resolver muitos problemas de processamento e análise de imagens radiológicas, comparações de múltiplos dados de sistema de imagem até sistemas automáticos de hematologia. Sua arquitetura e entorno de desenvolvimento integrado tem convertido ao ImageJ em uma plataforma popular [DOMINGUEZ C.; HERAS, 2017], [GILLES et al., 2017], [PIEDRAHITA-QUINTERO P.; GARCIA-SUCERQUIA, 2017], [SOKOLOV et al., 2017], [LOPEZ, 2012], [ALVAREZ, 2015], [DAVIM et al., 2007]. 


\subsection{Métodos}

\subsubsection{Preparação das amostras de objetos para a análise dimensional.}

A seguir se apresentam as diferentes etapas da preparação das amostras.

- Embutimento metalográfico

No processo de embutimento metalográfico a quente foi utilizado baquelite em uma embutidora metalográfica EM30D com molde de 30mm no diâmetro. O processo de embutimento foi realizado para as amostras dos parafusos.

- Lixamento

Foram utilizadas lixas de água, fixadas em discos rotativos. Com granulometria entre 180 e 1200.

\section{- Polimento}

A etapa de polimento foi executada foi executado com panos especiais colados em pratos giratórios, sobre os quais foram depositadas pequenas quantidades de abrasivos de pasta de diamante com tamanhos de grão de 6, 3 e $1 \mu \mathrm{m}$ respectivamente. Durante este processo a amostra é refrigerada com a utilização de álcool.

- Ataque químico

O ataque químico foi realizado pela imersão da amostra durante um período de três (3) segundos em Nital (ácido nítrico e álcool). Após o ataque químico são passadas por água para retirar o ácido da superfície, secadas e guardadas num saco plástico para evitar a oxidação da mesma.

\subsubsection{Metodologia para captura e processamento dos hologramas, reconstrução numérica e análise dimensional.}

Os elementos utilizados para a captura dos hologramas e a reconstrução da imagem de fase foram parafusos de pequenas dimensões e uma engrenagem, apresentados nas Fig. 4.1 e Figura. 4.2.

Os hologramas foram capturados através do programa HOLODIG, armazenados em um computador e posteriormente realizado o processo de reconstrução numérica. A continuação 
se apresenta a sequencia de passos para captura dos hologramas e reconstrução da imagem de fase. Na Figura. 4.5 se apresenta a janela principal de programa HOLODIG.

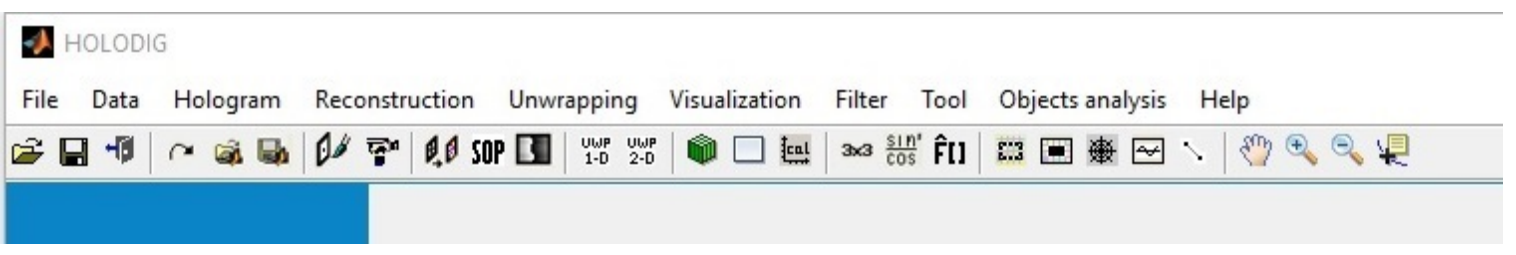

Figura 4.5 - Janela principal do HOLODIG.

Para realizar a captura, entramos pela opção "Holograma" e depois "Capture", como se apresenta na Figura. 4.6 .

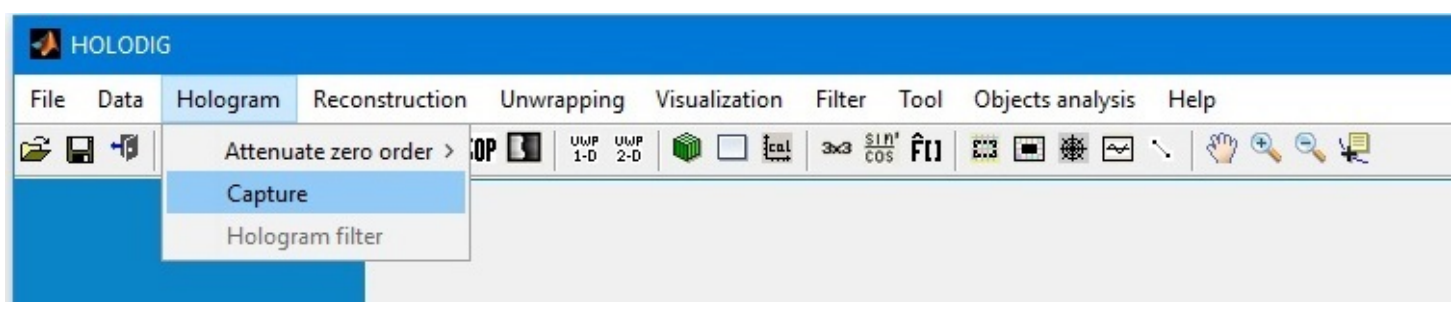

Figura 4.6 - Acesso à janela de Captura.

A Figura. 4.7 apresenta a janela de captura. Nesta se tem a imagem que chega à câmera CCD. Quando desejado para captar a imagem basta ir à opção "Save Frame".

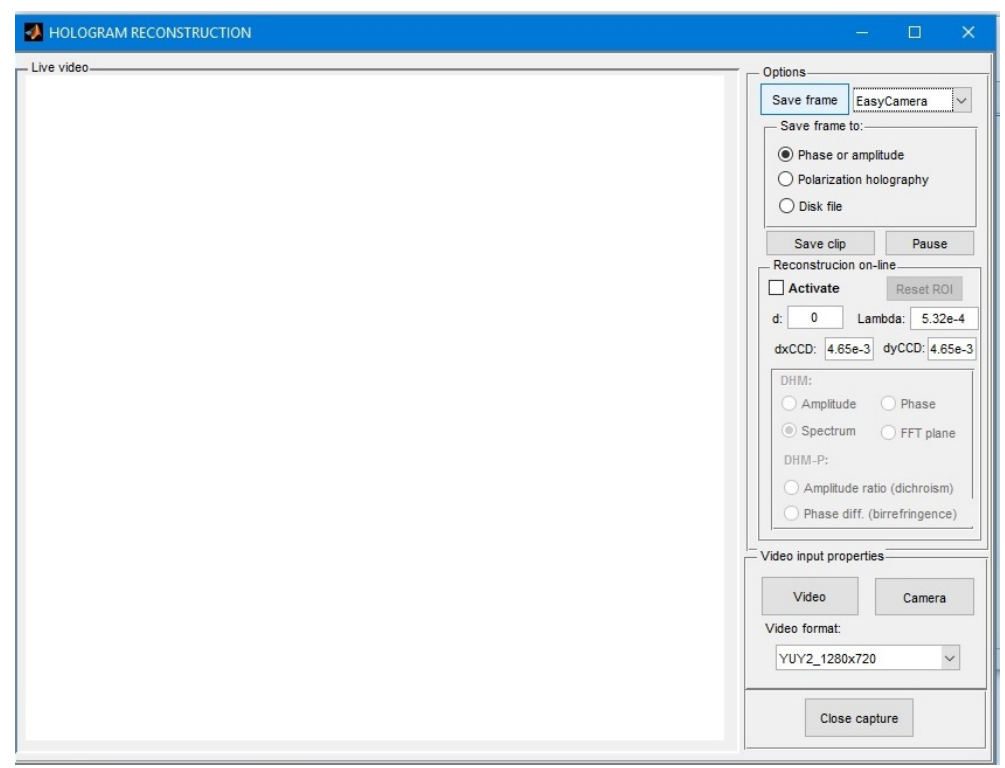

Figura 4.7 - Janela de Captura. 
Antes de começar a captura das imagens holográficas o arranjo deve ser calibrado. Para isto foi utilizada uma escala padrão de calibração de um milímetro (1 mm) ou mil micras $(1000 \mu \mathrm{m})$ como se apresenta na Figura. 4.8. A calibração é guardada no programa e com isto a configuração possui as condições necessárias para a captura dos hologramas.

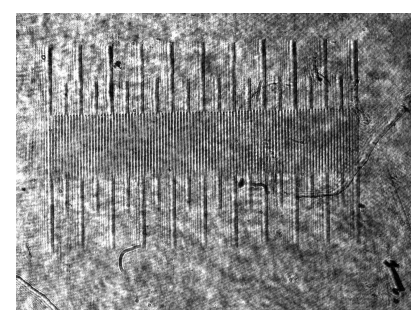

Figura 4.8 - Escala padrão de 1 milímetro para calibração.

Para realizar o processo de captura o objeto é colocado na frente da objetiva até se conseguir o foco adequado que permita ver com clareza a geometria do objeto. Este processo é realizado com o feixe de referência coberto para garantir que no sensor da câmera CCD chegue só o feixe objeto, garantindo assim a qualidade do mesmo. Posteriormente se deixa passar o feixe de referência para que ambos feixes coincidam no sensor da CCD. O holograma será considerado pronto para captura só quando na imagem apareça o padrão de interferência e este seja deslocado para um dos extremos, como se apresenta na Figura. 4.9. Para processar a imagem se definem parâmetros como os tamnhos do pixel da câmera CCD tanto na vertical como na horizontal. O valor do comprimento de onda $\lambda\left(5.32 \times 10^{-4}\right)$, o tipo de reconstrução (Reconstrução de fase) e o algoritmo (Dupla propagação).

Depois de selecionados todos os parâmetros se obtêm o espectro de Fourier através do "Plano focal" selecionando a área correspondente.

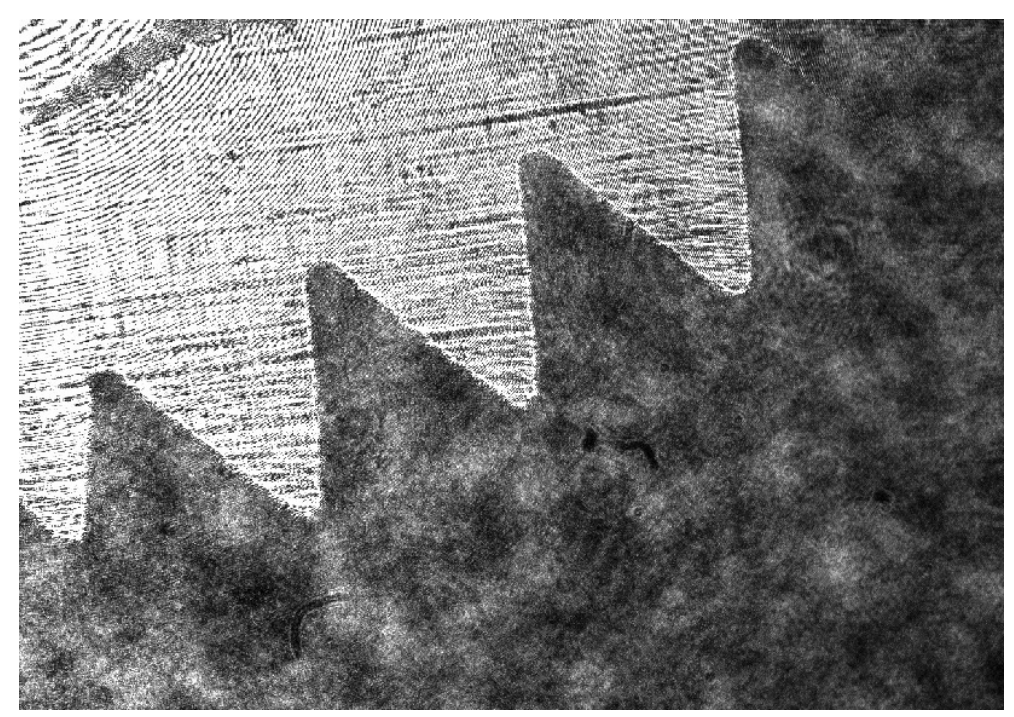

Figura 4.9 - Holograma capturado com seu padrão de interferência definido. 


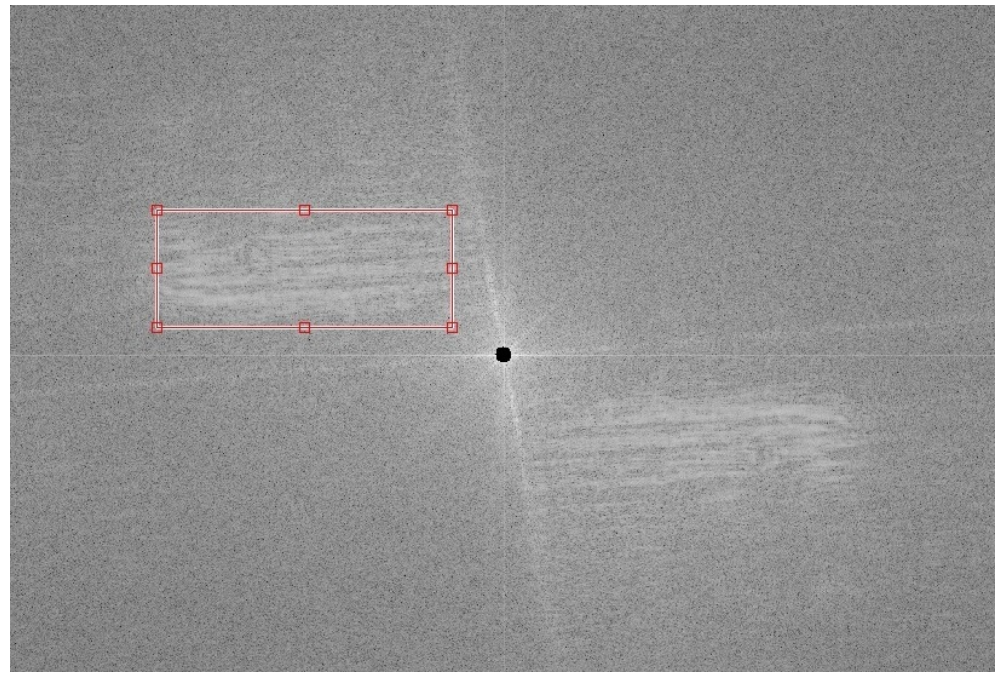

Figura 4.10 - Espectro de Fourier do Holograma.

O programa faz o processamento procurando o máximo dentro do espectro e gerando a distancia do plano focal. Selecionando a área próxima ao redor do ponto obtido se obterá a imagem reconstruída, conforme a Figura. 4.11.

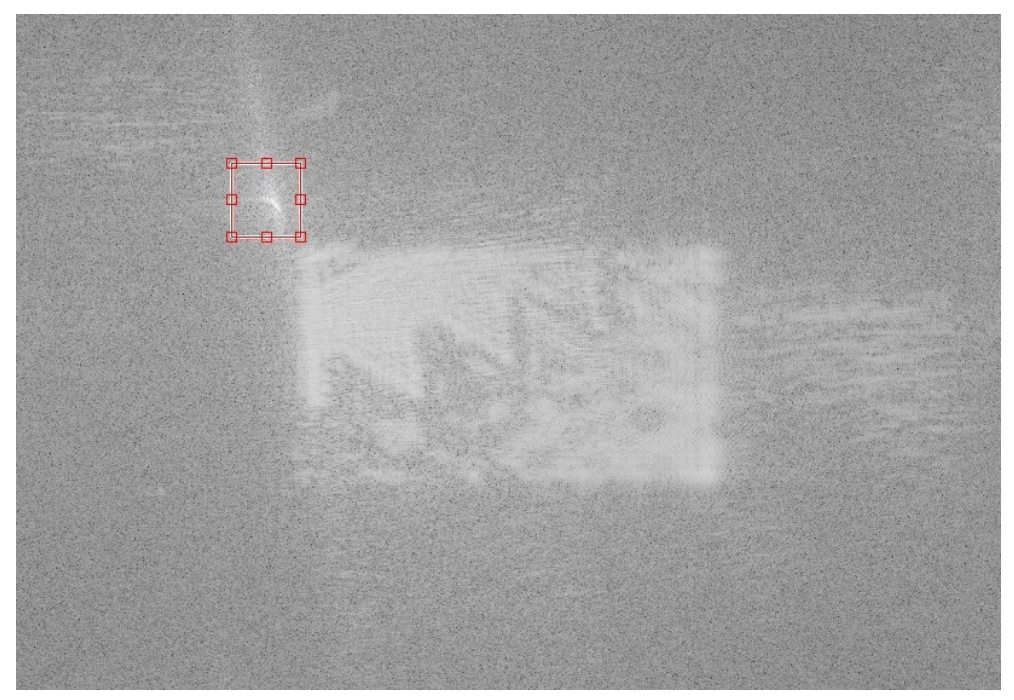

Figura 4.11 - Seleção da área para a reconstrução.

A imagem reconstruída, Figura. 4.12, passa então por uma série de processos para aperfeiçoar as condições da imagem, como por exemplo, filtragem, desmodulação da fase e subtração do fundo. 


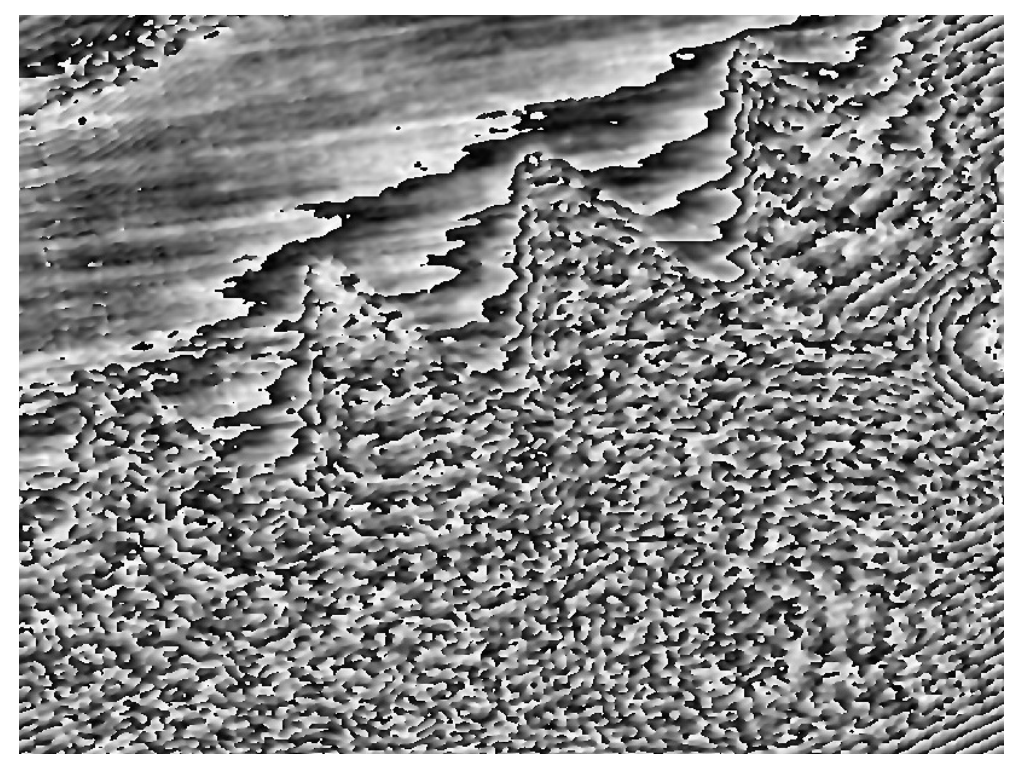

Figura 4.12 - Imagem obtida sem nenhum processo.

O programa oferece três tipos de filtro. Foi utilizado o filtro da "Median"(Média), com valores que variam dependendo das características de cada imagem. Geralmente são usados valores de sete (7) no tamanho da janela tanto na horizontal como na vertical. O processo de desmodulação pelo qual o valor absoluto de fase de uma função contínua se estende por um intervalo maior que $2 \pi$ é recuperado como se apresenta na Figura. 4.13.

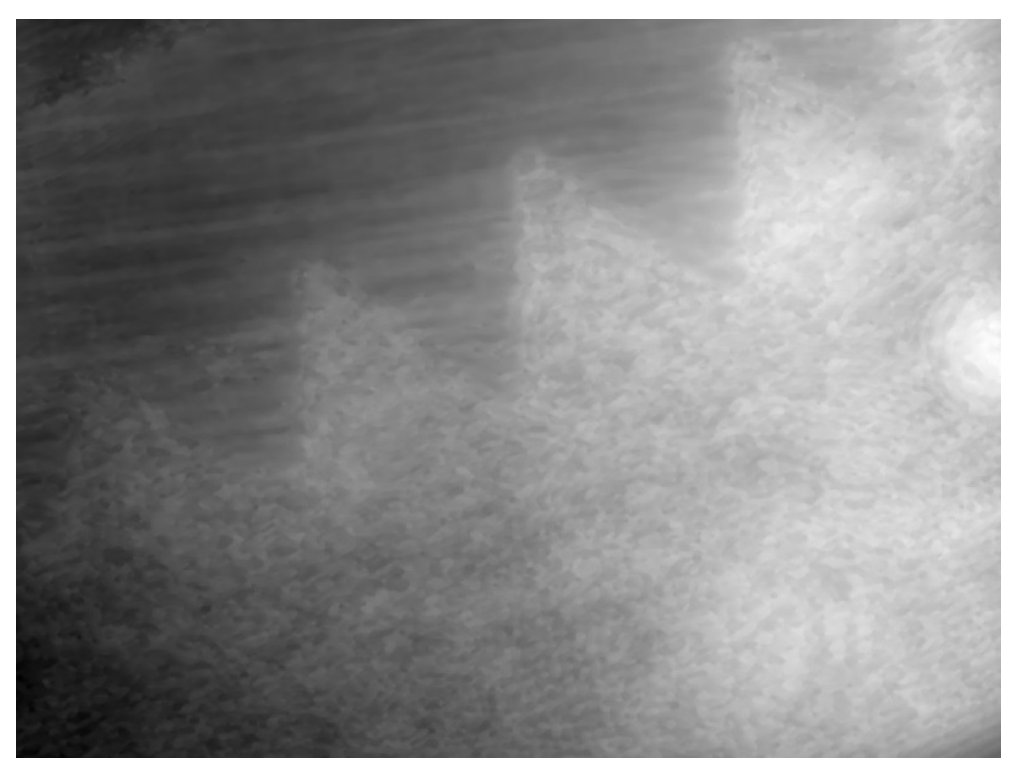

Figura 4.13 - Resultado após a desmodulação.

Por último, através da opção "Tool"(Ferramentas), se subtrai o fundo da imagem em "Background subtraction". Na Figura. 4.14 se apresenta a imagem reconstruída. A partir de esta podemos obter a imagem de contraste de fase em $3 \mathrm{D}$ como pode ser observado na Figura. 4.15 . 


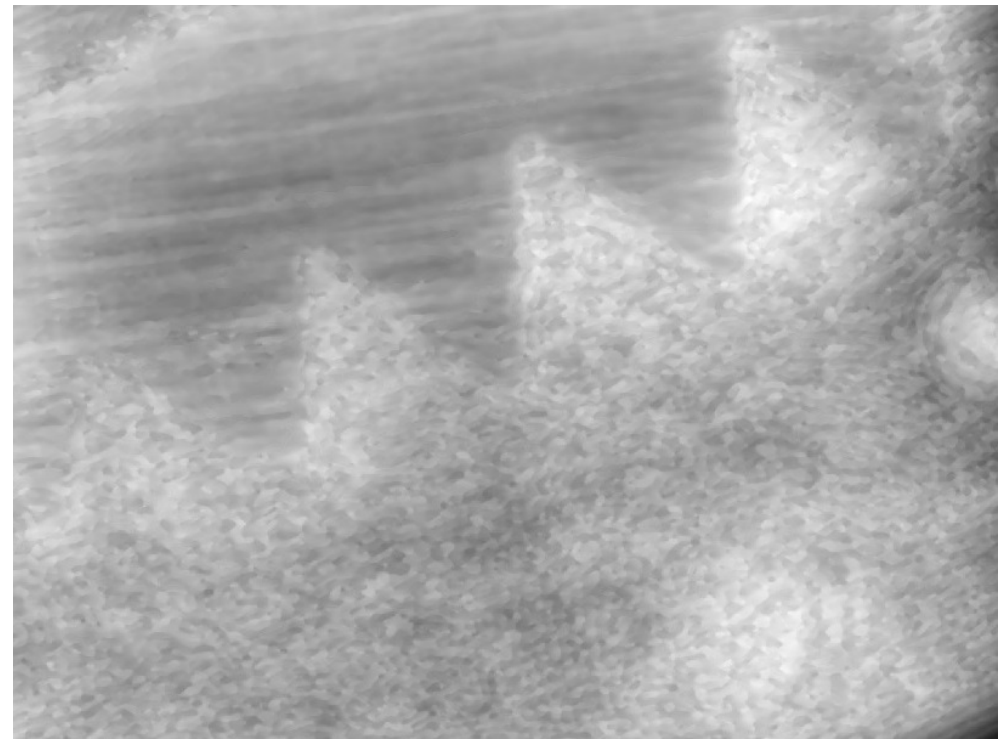

Figura 4.14 - Resultado final do processo de reconstrução.

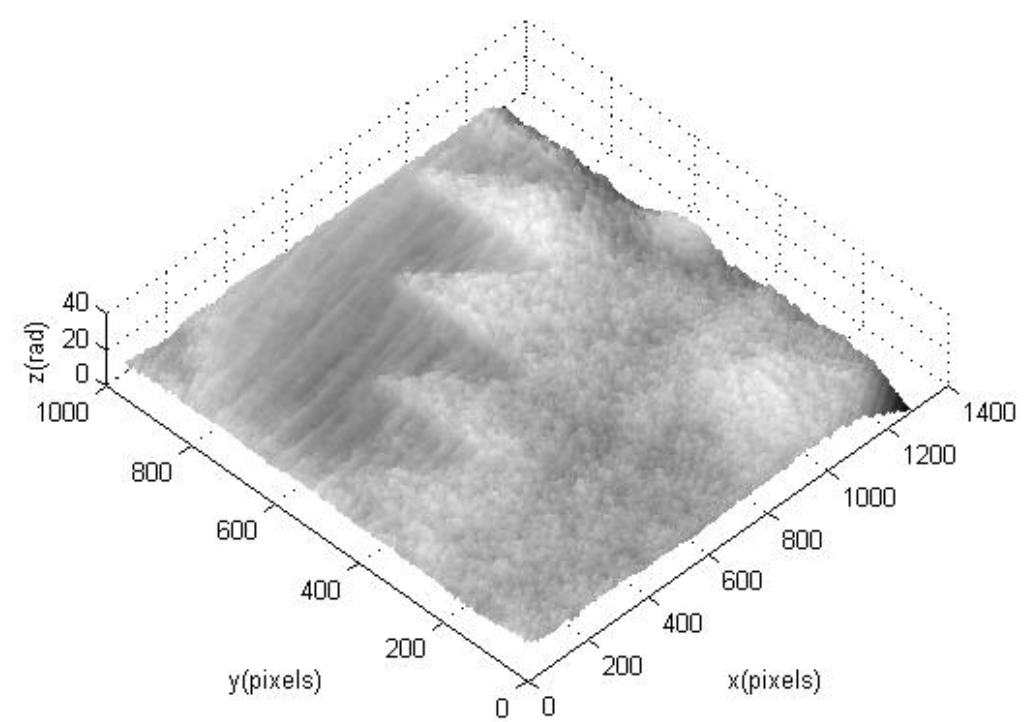

Figura 4.15 - Imagem de contraste de fase em 3D

Para a análise dimensional, a escala de calibração é colocada na imagem e se procura a opção "medir". A continuação se apresentam na Figura. 4.16 um exemplo das medições realizadas a partir de um dos hologramas obtidos através do programa Holodig. 


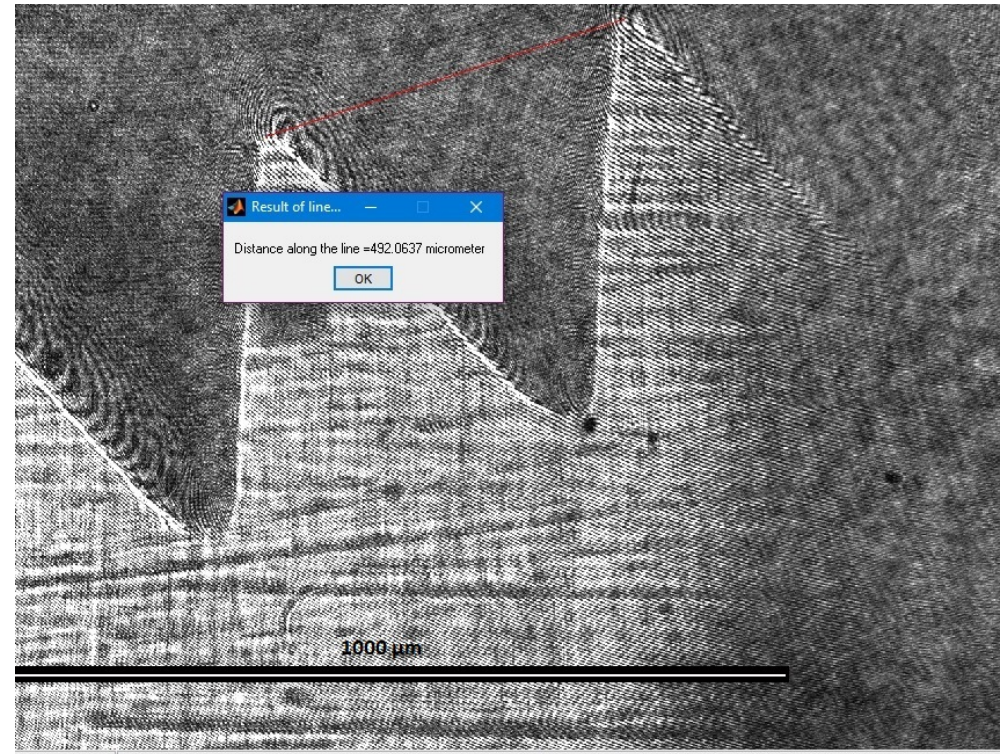

Figura 4.16 - Medição do passo do parafuso.

Da mesma forma o procedimento para realizar as medições com o programa Image J é apresentado em seguida.

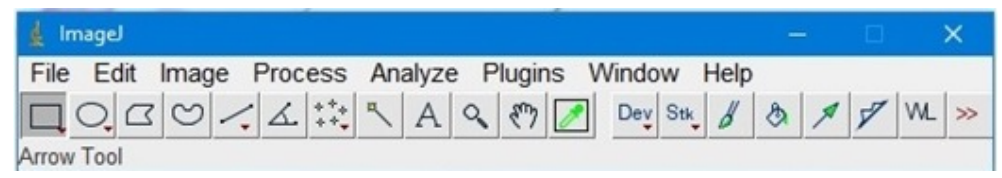

Figura 4.17 - Barra de ferramentas do ImageJ.

Com o programa aberto, se carrega através da barra de ferramentas da Figura. 4.18 a imagem objeto de estudo. Na opção "Analyse" se seleciona "Measure" e são realizadas as medições traçando uma reta na imagem.

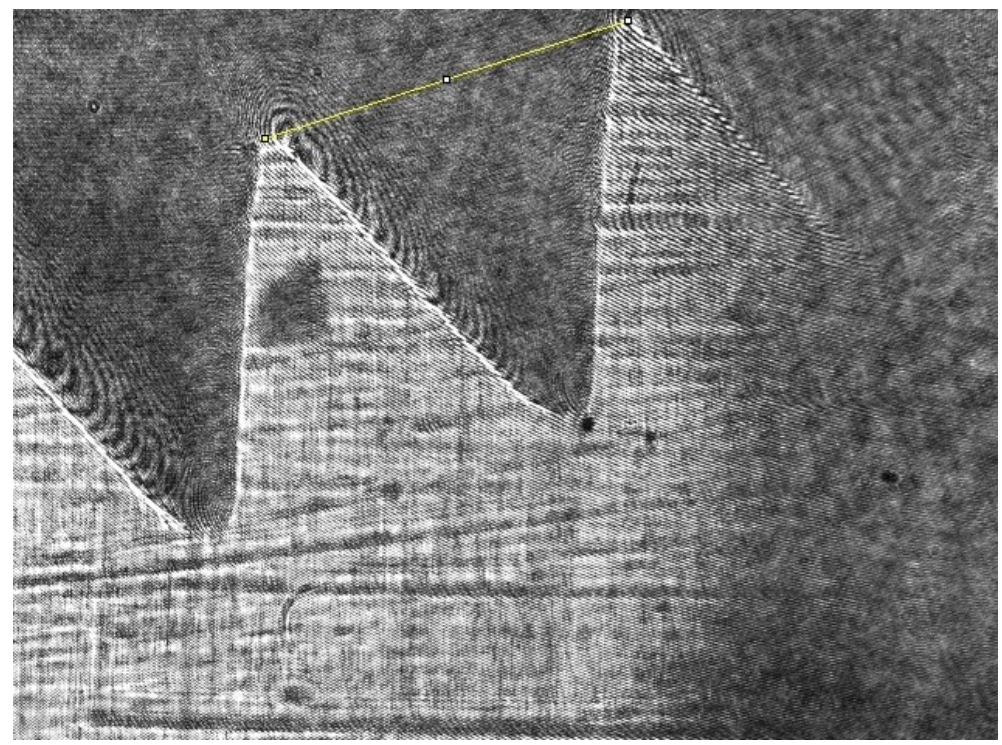

Figura 4.18 - Medição do passo do parafuso. 
O programa oferece os resultados em uma nova janela segundo se apresenta na Figura. 4.19 .

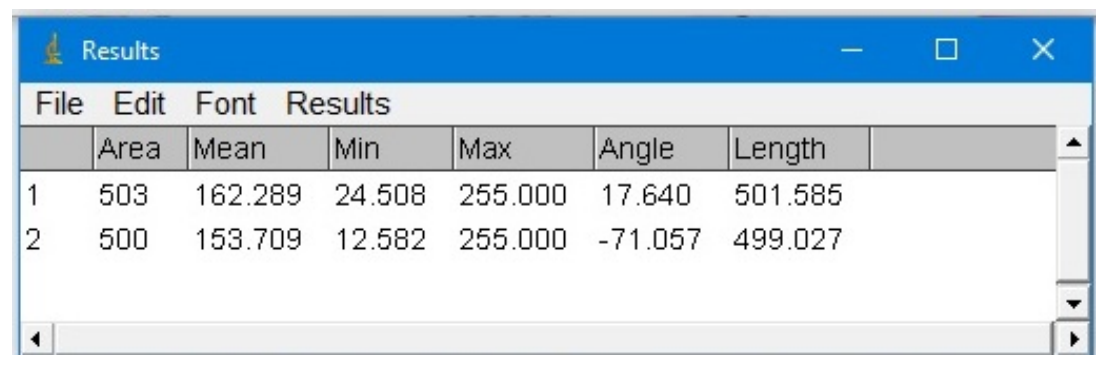

Figura 4.19 - Resultados das medições.

\subsubsection{Resultados preliminares.}

A continuação se apresentam as imagens de contraste de fase e a imagem em 3D de cada objeto. O primeiro objeto utilizado é um parafuso M3 cabeça hexagonal, Figura. 4.20 e Figura. 4.21.

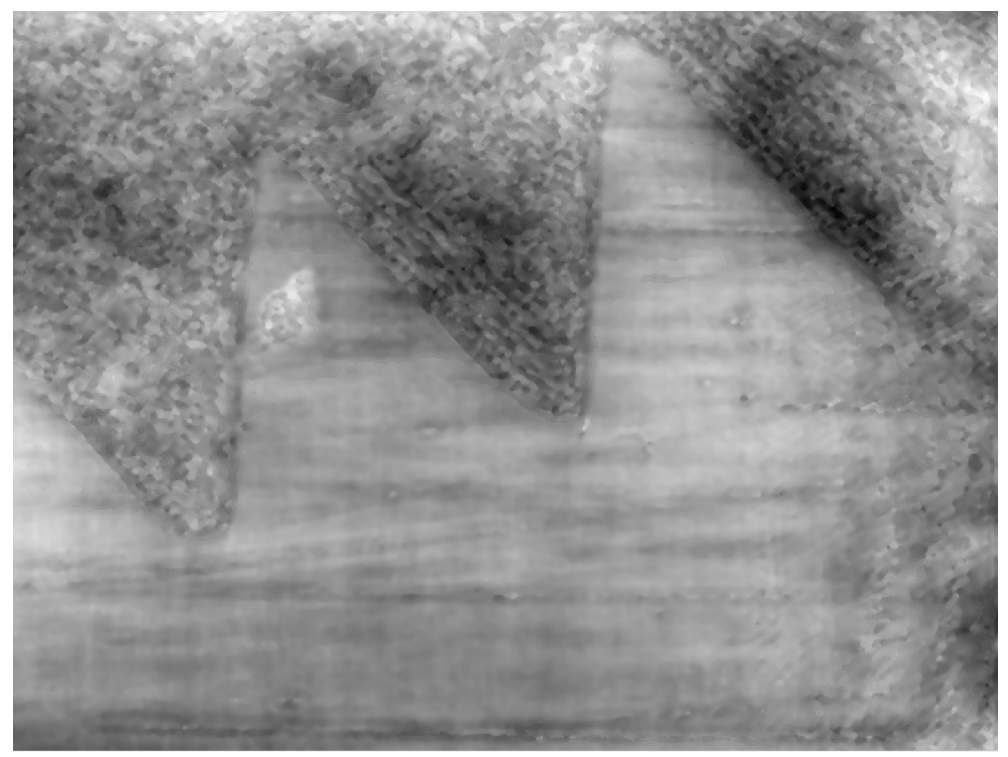

Figura 4.20 - Imagem de distribuição do contraste de fase reconstruída do parafuso M3 cabeça hexagonal. 


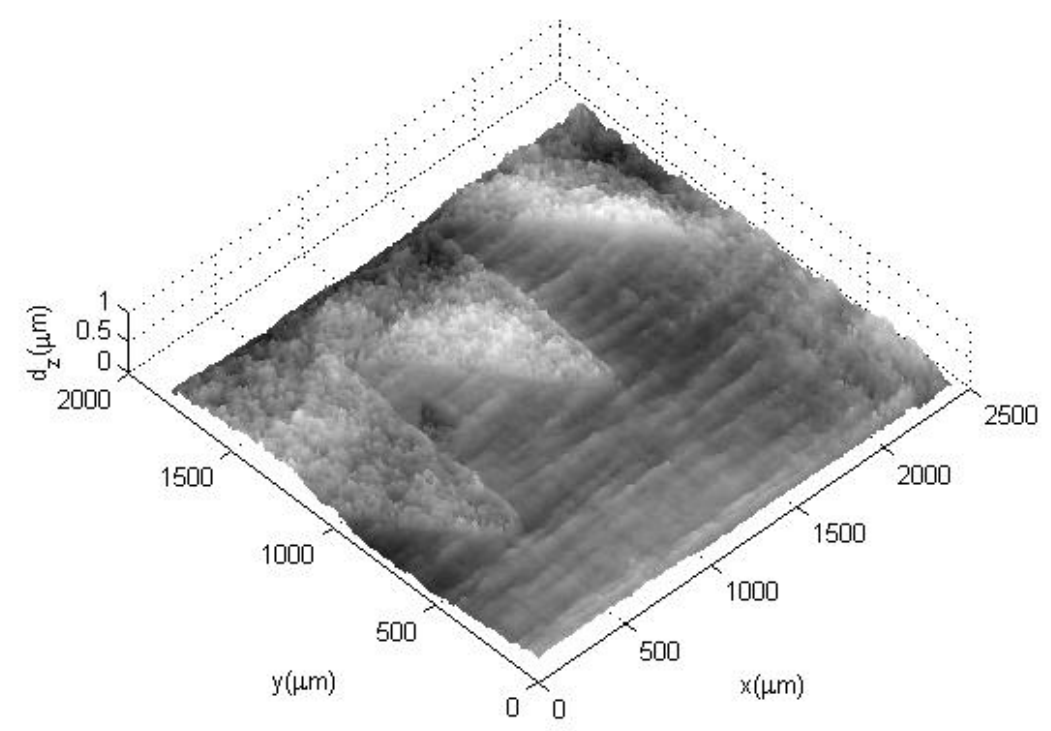

Figura 4.21 - Representação em 3D da imagem reconstruída do parafuso M3 cabeça hexagonal

O segundo objeto utilizado é um parafuso M3 sem cabeça com sextavado interno Sua imagem de contraste de fase e a imagem em 3D se apresentam na Figura. 4.22 e Figura. 4.23.

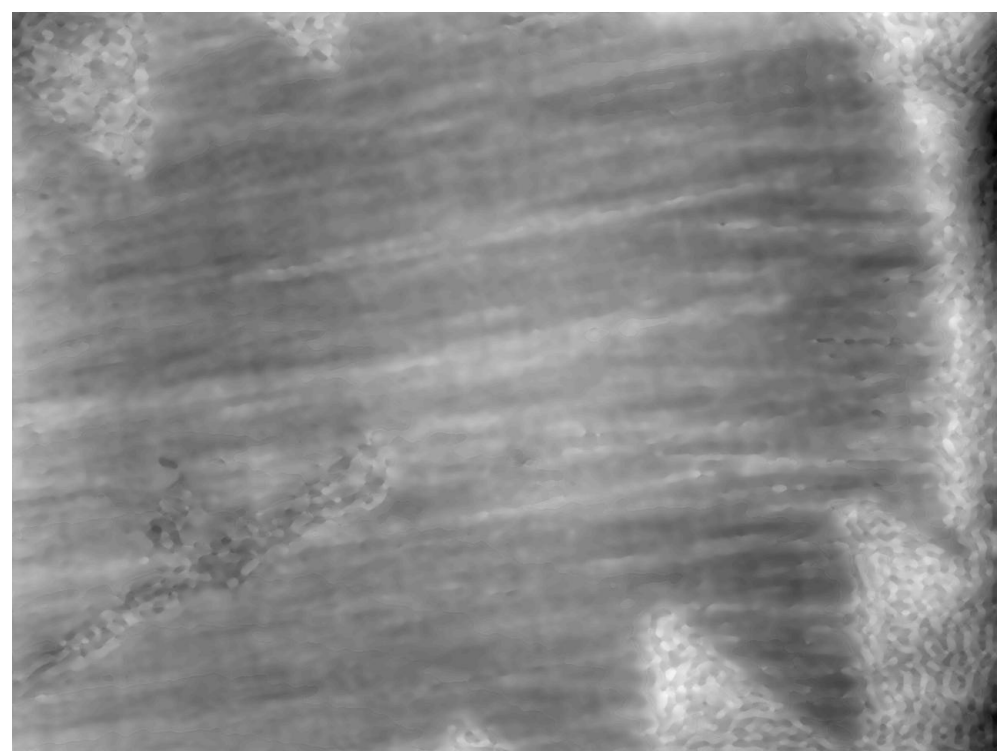

Figura 4.22 - Imagem de distribuição de contraste de fase reconstruída de uma seção do parafuso M3 sem cabeça com sextavado interno 


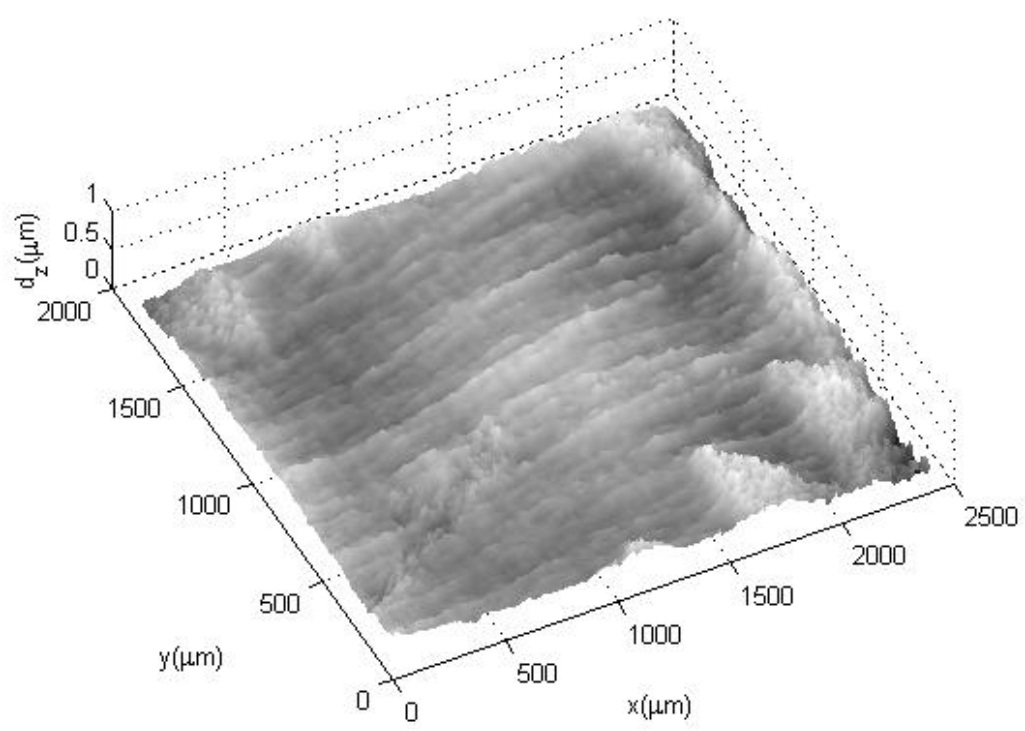

Figura 4.23 - Representação em 3D da imagem reconstruída do parafuso M3 sem cabeça com sextavado interno.

O terceiro objeto utilizado é um parafuso sem fim, do qual se apresentam a continuação sua imagem de contraste de fase e a imagem em 3D, Figura. 4.24 e Figura. 4.25.

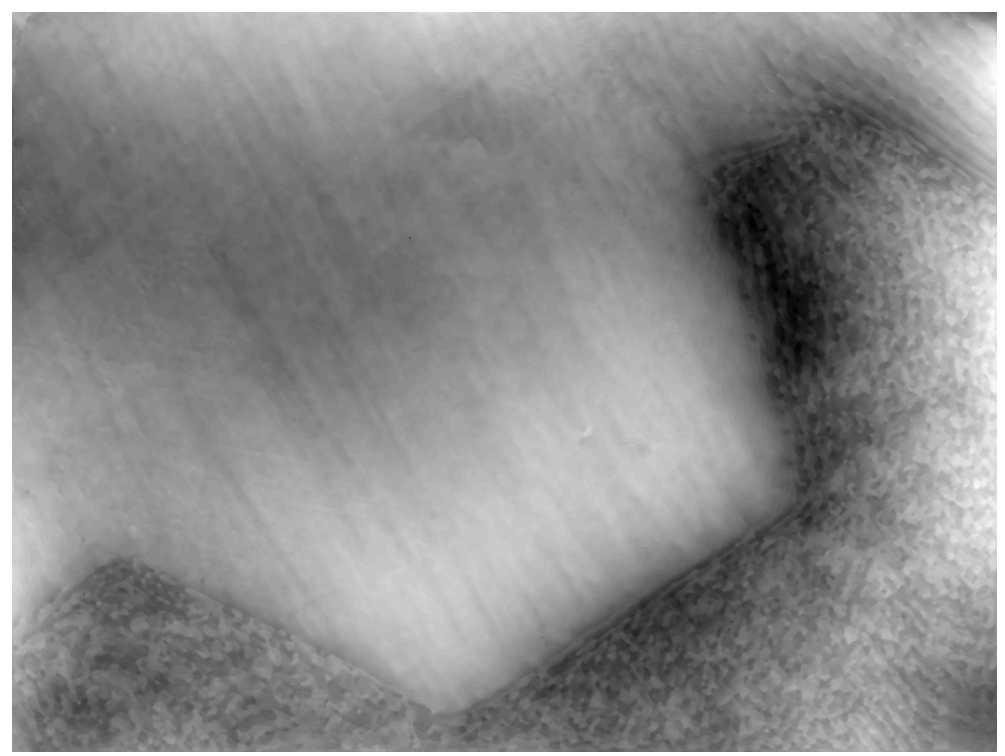

Figura 4.24 - Imagem de distribuição de contraste de fase reconstruída de uma seção do parafuso sem fim 


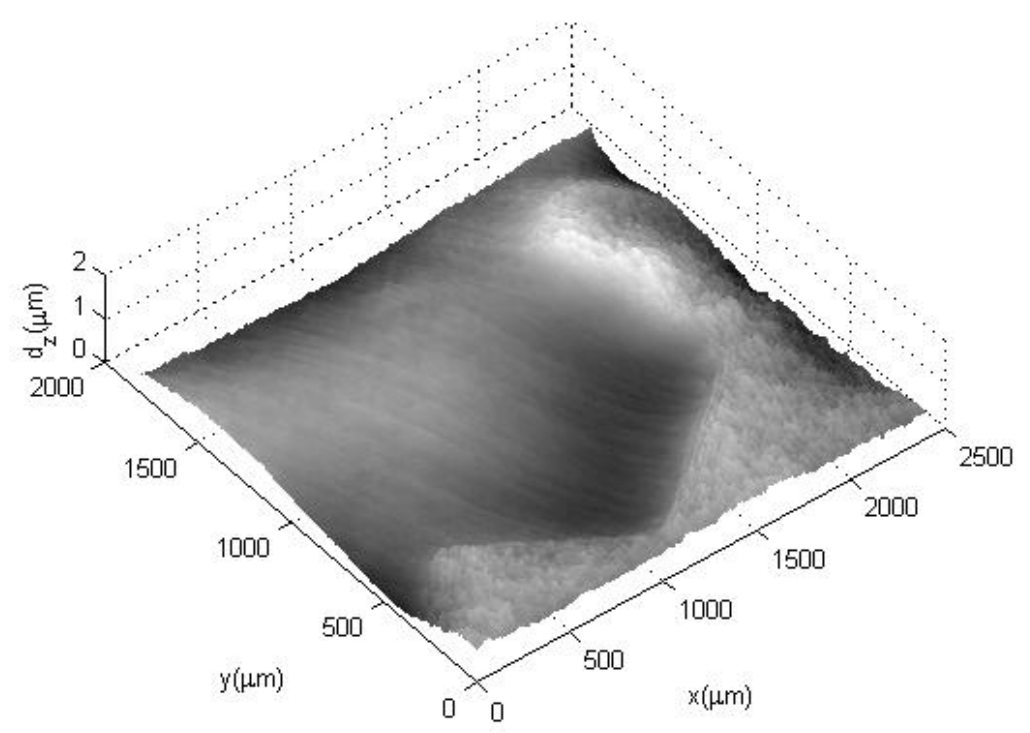

Figura 4.25 - Representação em 3D da imagem reconstruída do parafuso sem fim.

O quarto objeto utilizado é uma engrenagem, do qual se apresentam a continuação sua imagem de contraste de fase e a imagem em 3D, Figura. 4.26 e Figura. 4.27.

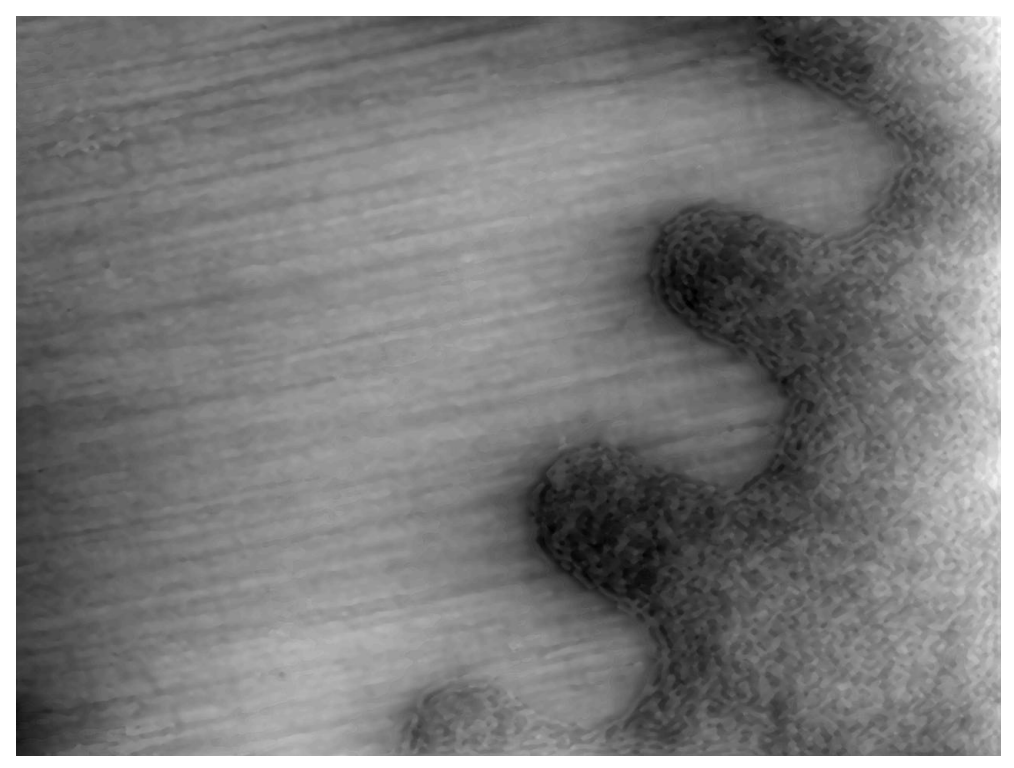

Figura 4.26 - Imagem de distribuição de contraste de fase reconstruída de uma seção de uma engrenagem 


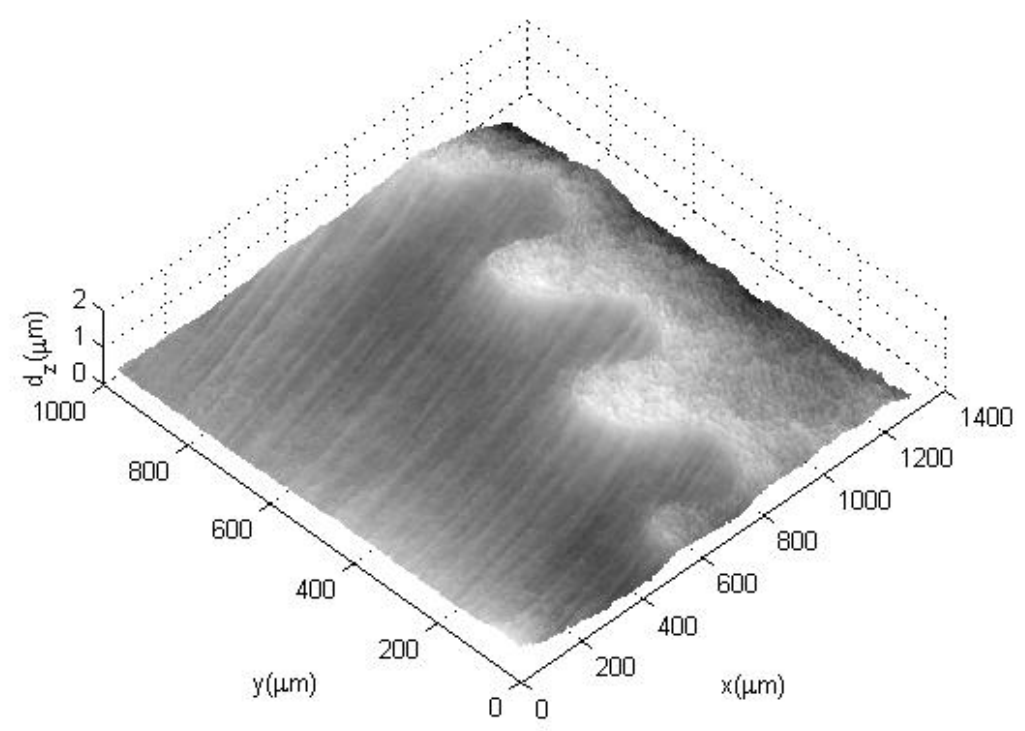

Figura 4.27 - Representação em 3D da imagem reconstruída do parafuso sem fim.

Os valores dos resultados da análise dimensional de todos os objetos sao apresentados na Tabela. 4.1.

Tabela 4.1 - Relação dos resultados obtidos pelo programa Holodig e o ImageJ.

\begin{tabular}{lcccc}
\hline \multicolumn{1}{c}{ Objeto } & Medida & $\begin{array}{c}\text { Holodig } \\
{[\mu \mathrm{m}]}\end{array}$ & $\begin{array}{c}\text { ImageJ } \\
{[\mu \mathrm{m}]}\end{array}$ & $\begin{array}{c}\Delta \\
\%\end{array}$ \\
\hline Parafuso M3 cabeça hexagonal & Passo & 492,06 & 492,06 & 0 \\
\hline Parafuso M3 cabeça hexagonal & Altura do dente & 483,10 & 483,39 & 0,06 \\
\hline $\begin{array}{l}\text { Parafuso M3 sem cabeça com } \\
\text { sextavado interno }\end{array}$ & Passo & 551,13 & 551,59 & 0,08 \\
\hline $\begin{array}{l}\text { Parafuso M3 sem cabeça com } \\
\text { sextavado interno }\end{array}$ & Altura do dente & 506,27 & 506,12 & 0,03 \\
\hline $\begin{array}{l}\text { Parafuso M3 sem cabeça com } \\
\text { sextavado interno }\end{array}$ & Trinca & 577,55 & 576,64 & 0,15 \\
\hline Parafuso sem fim & Passo & 1097,71 & 1095,6 & 0,19 \\
\hline Parafuso sem fim & Altura do dente & 418,22 & 418,82 & 0,14 \\
\hline Engrenagem & Passo & 357,32 & 357,75 & 0,12 \\
\hline Engrenagem & Raio & 113,64 & 113,87 & 0,20 \\
\hline
\end{tabular}




\section{Análise da rugosidade superficial}

\subsection{Fundamentos da Rugosidade Superficial}

O constante progresso na área industrial exige métodos cada vez mais eficientes para a obtenção de produtos cada vez mais sofisticados. O projeto de novos mecanismos exige uma perfeição crescente e as tolerâncias de fabricação cada dia são menores.

Superfícies reais, por mais perfeitas que sejam apresentam particularidades que são uma marca do método utilizado para sua obtenção, por exemplo; torneado, fresado, retificado, etc. As superfícies assim produzidas, apresentam um conjunto de irregularidades como o, espaçamento regular ou irregular que tende a formar um padrão ou textura característica em sua extensão. Nesta textura superficial distinguem-se dois componentes diferentes: rugosidade e ondulação [GONZÁLEZ; VÁZQUEZ, 1995].

A rugosidade ou textura primaria, está formada por entalhes ou marcas deixadas pelos agentes que atacam a superfície no processo de usinagem (ferramenta, partículas abrasivas, ação química, etc.) e se encontra superposta ao perfil de ondulação. Os espaços entre picos variam entre 4 e 50 vezes a profundidade da depressão.

A ondulação ou textura secundária é o conjunto de irregularidades repetidas em ondas de passo muito maior que a amplitude e que podem acontecer por vibrações da maquina-ferramenta, deformação por tratamento térmico, tensões residuais de forjamento ou fundição, etc. Os espaçamentos entre ondas (compressões de ondulação) podem ser de 100 a 1000 vezes sua amplitude.

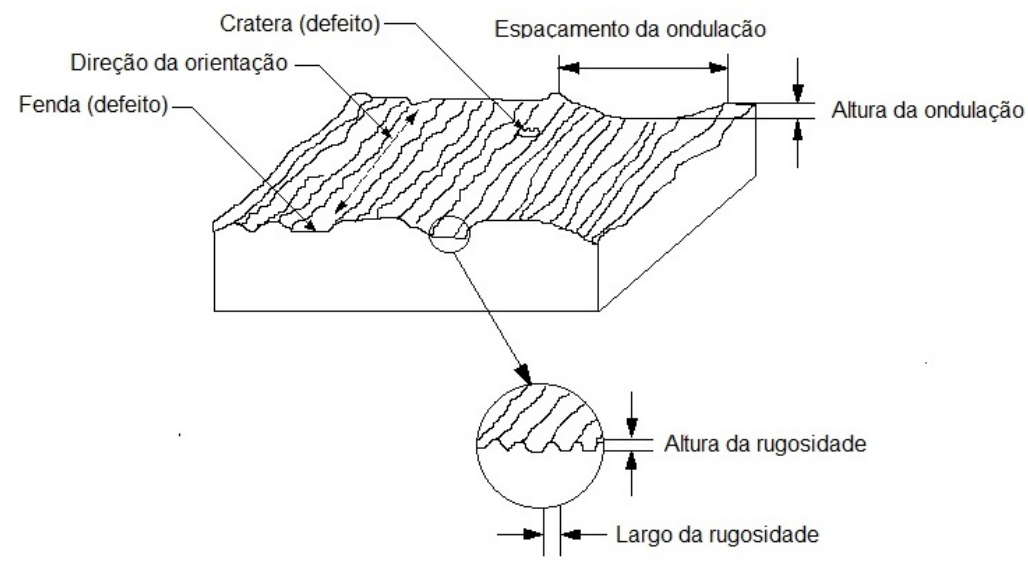

Figura 5.1 - Características de uma superfície 
Como se apresenta na Fig. 5.1 uma superfície exibe erros de diferentes magnitudes e sua definição é possível através de meios ou técnicas também diferentes, por isso, para facilitar seu estudo, dividem-se em dois grandes grupos: erros macrogeométricos e erros microgeométricos.

\subsubsection{Erros macrogeométricos}

Conhecidos também como erros de forma ou de textura secundária que incluem entre eles divergências de ondulação, ovalização, múltiplas facetas, conicidade, cilindricidade, etc., e são possíveis de medir através de instrumentos convencionais como micrómetros, comparadores, projetores de perfil, etc.

\subsubsection{Erros microgeométricos}

Conhecidos como erros de rugosidade ou de textura primária. Seu perfil está formado por entalhes, ou marcas deixadas pelos processos de usinagem durante a fabricação. Sua medição só resulta possível devido ao progresso na eletrônica que com auxilio de circuitos eletrônicos desenvolveram equipamentos baseados em sistemas que utilizam uma pequena agulha de ponta muito aguda para percorrer uma amostra da superfície e definir numericamente ou graficamente seu perfil.

No estudo e avaliação do estado das superfícies é necessário conhecer previamente conceitos que permitem criar uma linguagem apropriada, assim temos: superfície ideal, perfil real, perfil ideal, perfil efetivo, superfície real e perfil de rugosidade.

A superfície ideal por definição não possui erros, é perfeita. O perfil ideal é aquele resultado do corte de uma superfície ideal por um plano perpendicular, em algumas normas esta característica se denomina como perfil nominal. A superfície real é aquela que limita o corpo e o separa do meio ambiente. Perfil real é o resultado de cortar uma superfície real por um plano definido em relação à superfície ideal, limitando a seção material e separando-a do meio ambiente, incluído a ondulação. O perfil efetivo é a imagem aproximada de um perfil real obtido por meio da avaliação ou medição, função das características geométricas e físicas do instrumento de medição e da técnica utilizada para sua avaliação. Sua diferença com o perfil real é certa deformação causada pela imprecisão do equipamento. Finalmente o perfil de rugosidade se obtém a partir do perfil efetivo por um instrumento de avaliação com sistema de filtrado (filtrado das ondas) para excluir outras irregularidades (ondulação, por exemplo) [GONZÁLEZ; VÁZQUEZ, 1995].

Em correspondência às definições apresentadas, o perfil de rugosidade esta superposto ao perfil de ondulação, por isso a necessidade de ter um sistema que permita excluir este 
último para evitar a medição de influencias não desejadas.

\subsubsection{Sistemas de medição da rugosidade}

A definição de medição de textura superficial é realizada em forma geométrica diante da impossibilidade de uma definição funcional. As definições geométricas são bastante abstratas porque estão baseadas em uma linha de referência que existe somente em teoria. Os resultados ainda sofrem algumas distorções pela utilização de filtros para excluir a ondulação quando se pretende definir a rugosidade. Por este motivo, foram desenvolvidos dois sistemas de referência: O sistema " $E$ " ou da envolvente e o sistema " $M$ " ou da linha média.

\subsubsection{Sistema "E"}

Este sistema tem por base as linhas envolventes descritas pelos centros de dois círculos, de raio $R$ (normalmente $25 \mathrm{~mm}$ ), que rolam sobre o perfil efetivo.

A linha envolvente pode ser colocada de maneira de obter a igualdade de áreas do perfil situadas por cima e por baixo delas. Obtém-se uma linha correspondente à linha média do sistema $M$, a partir da qual podem ser calculados os parâmetros $R a$ (rugosidade média aritmética) e $R q$ (rugosidade média quadrática). De maneira semelhante, deslocando a linha envolvente até tocar o ponto mais baixo do perfil se obtém a linha $E E$ que permite a medição do parâmetro Rmax (rugosidade máxima).

Por este método, a linha de referência é obtida através da envolvente do círculo e sua maior dificuldade reside na definição do perfil geométrico, que deve ser ampliado por igual em ambas as direções.

\subsubsection{Sistema " $M "$ o da linha média}

Dentro da metrologia de superfícies não se mede a dimensão de um corpo (isso corresponde à metrologia dimensional), mas sim os desvios em relação a uma forma ideal (forma perfeitamente plana, por exemplo). Desta maneira, se tem que usar como linha de referência uma forma ideal (ou uma forma próxima a esta).

No sistema $M$, a linha de referência utilizada é a linha média que se define como a linha localizada na parte média do perfil de rugosidade, com a mesma forma que do perfil geométrico, disposto paralelo à direção geral do perfil, dentro dos limites compreendidos como base de medição, de modo que com a soma das áreas por cima de esta, sejam exatamente iguais à soma das áreas que estão por baixo. 
Pode ser definida também como a linha que ficaria se as cristas fossem niveladas para compensar os vales.

A linha média é traçada para cada compartimento da amostra, se a ondulação fosse excluída, a forma de cada compartimento da amostra formaria uma linha reta e interrompida, como se apresenta na Figura. 5.2 .

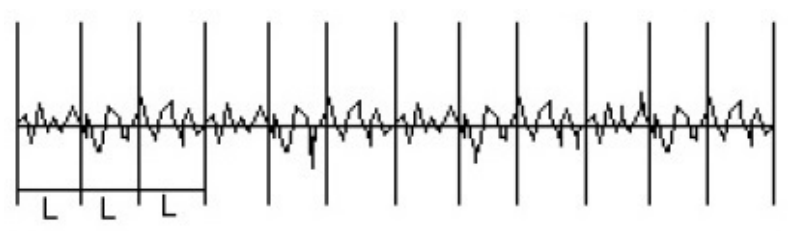

Figura 5.2 - Compartimento de uma amostra com uma linha média traçada

Se a ondulação não fosse excluída, a forma de traçado acompanharia a forma geral do perfil, teria a inclinação diferente e poderia ser interrompida para cada compartimento da amostra, como pode ser observado na Figura. 5.3 .

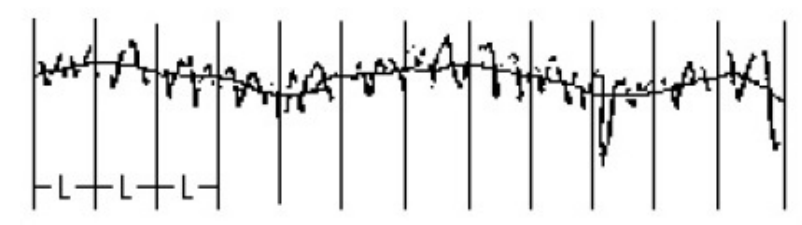

Figura 5.3 - Traçado sem exclusão da ondulação

Dentro de cada compartimento da amostra ou módulo de medição a linha média é teoricamente reta, no em tanto, sua inclinação em relação à forma nominal da superfície depende da ondulação, desta forma quando a Linha Média está determinada graficamente, ela poderá ser tratada como uma linha reta. Quando a Linha Média estiver determinada por meio de filtros, poderá ser curva, mas isso não causará variações significativas nos resultados das medições.

A longitude dos módulos de medição deve ser suficiente para poder avaliar a rugosidade, isto é, deve conter todos os detalhes representativos da rugosidade e excluir aqueles inerentes à ondulação.

É de grande importância que esses módulos de medição sejam corretamente definidos em relação ao tipo de rugosidade. De forma tal que se uma linha média fosse traçada para cada comprimento posteriormente alinhada, como resultado teremos o perfil original com uma ondulação filtrada. 
Um módulo muito pequeno não será representativo da superfície, dando erro ao avaliar a rugosidade. Os resultados de medições repetidas, realizadas nessas condições darão certa dispersão, como se apresenta na Figura. 5.4.

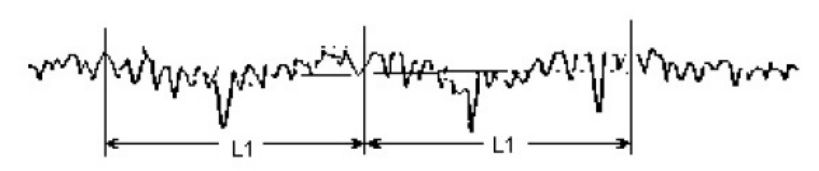

Figura 5.4 - Módulos de medição

O módulo de medição é conhecido também como "Cut-Off" e não deve ser confundido com a longitude de medição. Sua função é a de atuar como filtro e normas internacionais, como por exemplo, a norma DIN, estabelecem cinco vezes o módulo como mínimo para realizar uma avaliação da rugosidade de uma superfície.

Existem modernos equipamentos para medição de rugosidade através de apalpadores de agulha que consideram a seção inicial e final da carreira total de apalpado, cuja única finalidade é a de permitir o amortecimento das oscilações do sistema, em especial as oscilações iniciais, como pode ser obsevado na Figura. 5.5 .

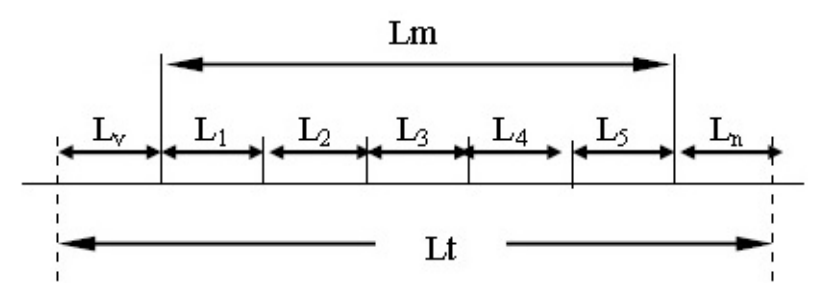

Figura 5.5 - Extensão da amostra e divisões

sendo:

$L_{1}=L_{2}=L_{3}=L_{4}=L_{5}$ - Extensão da amostra (Cut - off)

$L_{v}=$ Longitude inicial

$L_{n}=$ Longitude final

$L_{m}=L_{1}+L_{2}+L_{3}+L_{4}+L_{5}$ - Longitude de medição

$L_{t}=L_{v}+L_{m}+L_{n}$

\subsubsection{Parâmetros de rugosidade}

Os parâmetros de medição de rugosidade, baseados na Linha Média "M" são agrupados em três classes: 
- Os que têm base na medida da profundidade da rugosidade

- Os que têm base nas medidas horizontais

- Os que têm base nas medidas proporcionais

\subsubsection{Sistemas com base na profundidade da rugosidade. Rugosidade média aritmética $(R a)$}

Conhecido também como CLA (Média da linha central, de Inglaterra), AA (Média aritmética dos Estados Unidos) e hm (termo usado pelas normas IRAM). Está definido como a média aritmética dos valores absolutos das coordenadas dos pontos do perfil de rugosidade em relação à Linha Média dentro da longitude de medição $L_{m}$, Fig. 5.6 .

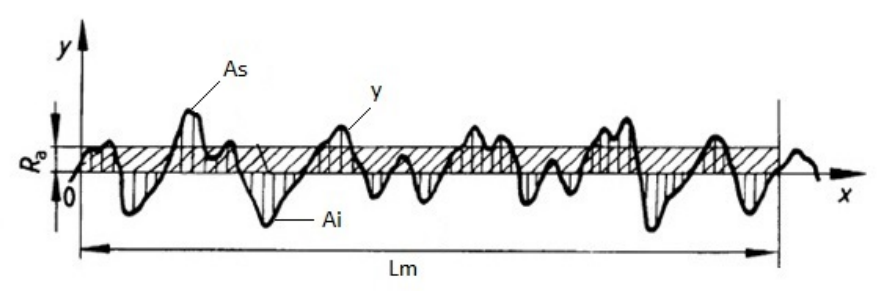

Figura 5.6 - Rugosidade média aritmética Ra

sendo:

$A_{s}$ - Áreas superiores

$A_{i}$ - Áreas inferiores

$A_{g}$ - Área total

$$
\sum A_{s}=\sum A_{i}
$$

$$
A_{g}=\sum A_{s}+\sum A_{i}
$$


Esta medida pode ser definida também como: sendo (a) a altura de um retângulo qual área seja igual à soma absoluta das áreas delimitadas entre o perfil de rugosidade e a linha média, sendo a longitude de medição $L_{m}$

$$
R_{a}=\frac{1}{L_{m}} \int_{0}^{L_{m}}|y| d x
$$

Por aproximação pode-se determinar o valor de $R_{a}$ por meio de um determinado número de ordenadas de pontos do perfil.

$$
R_{a}=\frac{1}{n} \sum_{i=1}^{n}|y|
$$

sendo:

$y=$ ordenada

$n=$ número de ordenadas consideradas

O valor de " $n$ " é prefixado de acordo com o tipo de equipamento. A medida do valor de $R_{a}$ pode ser expressa em $\mu m$ ou $\mu$ in (sistema métrico ou em polegadas respetivamente). A fim de racionalizar a quantidade de valores do parâmetro a serem utilizados em desenhos e especificações, a norma recomenda os que se indicam na Tabela. 5.1, [GONZÁLEZ; VÁZQUEZ, 1995].

Tabela 5.1 - Parâmetros normalizados de $R a(\mu m)$

\begin{tabular}{llllll}
\hline 0,008 & 0,040 & 0,20 & 1,00 & 5,0 & 25,0 \\
0,010 & 0,050 & 0,25 & 1,25 & 6,0 & 32,0 \\
0,012 & 0,063 & 0,32 & 1,60 & 8,0 & 40,0 \\
0,016 & 0,080 & 0,40 & 2,00 & 10,0 & 50,0 \\
0,020 & 0,100 & 0,50 & 2,50 & 12,5 & 63,0 \\
0,025 & 0,125 & 0,63 & 3,20 & 16,0 & 80,0 \\
0,032 & 0,160 & 0,80 & 4,00 & 20,0 & 100,0 \\
\hline
\end{tabular}

A determinação do módulo de medição $(C u t$ - off $)$ e a longitude de medição estão ligados à rugosidade média que se deseja medir, segundo a Tabela. 5.2. 
Tabela 5.2 - Relação longitude de medição e rugosidade média

\begin{tabular}{|c|c|c|}
\hline $\begin{array}{c}\text { Rugosidade Ra } \\
{[\mu \mathrm{m}]}\end{array}$ & $\begin{array}{c}\text { Cut }- \text { Off } \\
{[\mathrm{mm}]}\end{array}$ & $\begin{array}{c}\text { Longitude de medição } \\
{[\mathrm{mm}]}\end{array}$ \\
\hline até 0,1 & 0,25 & 1,25 \\
\hline 0,1 a 2 & 0,8 & 4 \\
\hline 2 a 10 & 2,5 & 12,5 \\
\hline 10 & 8 & 40 \\
\hline
\end{tabular}

A utilização deste parâmetro vem dada pelas características da peça, processo ou necessidades específicas do estudo.

\subsubsection{Utilização do parâmetro Ra}

A utilização deste parâmetro vem dada pelas características da peça, processo ou necessidades específicas do estudo.

- No controle da rugosidade em forma contínua em linhas de produção, devido à facilidade da obtenção do resultado.

- Superfícies onde o acabamento apresenta os entalhes de usinagem bem orientados (torneado, fresado)

- Superfícies retificadas, lapidadas.

A medição da rugosidade Ra tem as seguintes vantagens, [GONZÁLEZ; VÁZQUEZ, 1995].

- É o parâmetro mais utilizado no mundo todo.

- É um parâmetro aplicável à maioria dos processos de fabricação.

- Devido a sua grande utilização, quase a totalidade dos equipamentos apresentam este parâmetro, em forma analógica ou digital.

- As marcas inerentes ao processo de usinagem não alteram substancialmente seu valor. 
A norma DIN 4769, para uma maior facilidade de especificação e controle, divide em graus os diferentes valores de $R a$ em $\mu m$ como se observa na Tabela. 5.3, [GONZÁLEZ; VÁZQUEZ, 1995].

Tabela 5.3 - Graus dos valores de $R a$

\begin{tabular}{|c|c|}
\hline$R a[\mu m]$ & $N^{\circ}$ de Grau de Rugosidade \\
\hline 50 & $\mathrm{~N} 12$ \\
\hline 25 & $\mathrm{~N} 11$ \\
\hline 12,5 & $\mathrm{~N} 10$ \\
\hline 6,3 & $\mathrm{~N} 9$ \\
\hline 3,2 & $\mathrm{~N} 8$ \\
\hline 1,6 & $\mathrm{~N} 7$ \\
\hline 0,8 & $\mathrm{~N} 6$ \\
\hline 0,4 & $\mathrm{~N} 5$ \\
\hline 0,2 & $\mathrm{~N} 4$ \\
\hline 0,1 & $\mathrm{~N} 3$ \\
\hline 0,05 & $\mathrm{~N} 2$ \\
\hline 0,025 & $\mathrm{~N} 1$ \\
\hline
\end{tabular}

Desta maneira conhecemos os conceitos básicos para o trabalho e a determinação da rugosidade superficial. Assim, se deu inicio à realização dos diferentes processos que darão lugar ao desenvolvimento de uma nova técnica para medir a rugosidade superficial através da microscopia holográfica digital por reflexão.

\subsection{Técnica para medir rugosidade superficial através da microscopia holográfica digital por reflexão.}

Para realizar a análise da rugosidade superficial segundo acabamento obtido por processo de lixado e polido, primeiramente, foi necessário escolher o material a ser utilizado. Procurou-se um material com baixo teor de carbono que facilitasse o processo de preparação das amostras ou corpos de prova.

Desta maneira foi cortado um pedaço de uma barra de aço de baixo carbono e foram realizados dois processos para a determinação das características dele. O primeiro processo foi um ensaio de dureza, o qual reportou que o material possui uma dureza de 120 Vickers, Fig. 5.7. 


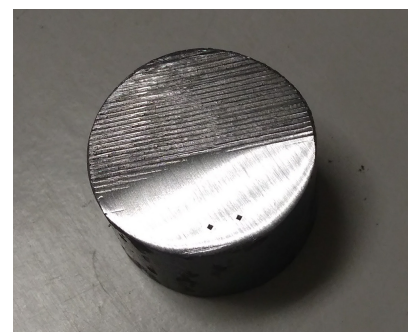

Figura 5.7 - Amostra ou corpo de prova

O segundo processo, foi uma análise química realizada no Microscópio Eletrônico de Varredura (SEM), apresentado na Figura. 5.8. O microscópio da marca JEOL USA Inc., modelo IntouchScope/JSM-6010LA, possui uma resolução de $4 \mathrm{~nm} @ 20 \mathrm{kV}$; magnificação de $5 \mathrm{X}$ a 300,000 X; tamanho de espécimen de até $150 \mathrm{~mm}$ de diâmetro; tensão de aceleração de $500 \mathrm{~V}$ a $20 \mathrm{kV}$; modos de imagem de alto vácuo SE (elétron secundário) e BSE (elétron de retrodispersão), baixo vácuo (pressão variável): BSE, baixo vácuo: SE (opcional) e campo de visão de até $25,4 \mathrm{~mm}$.

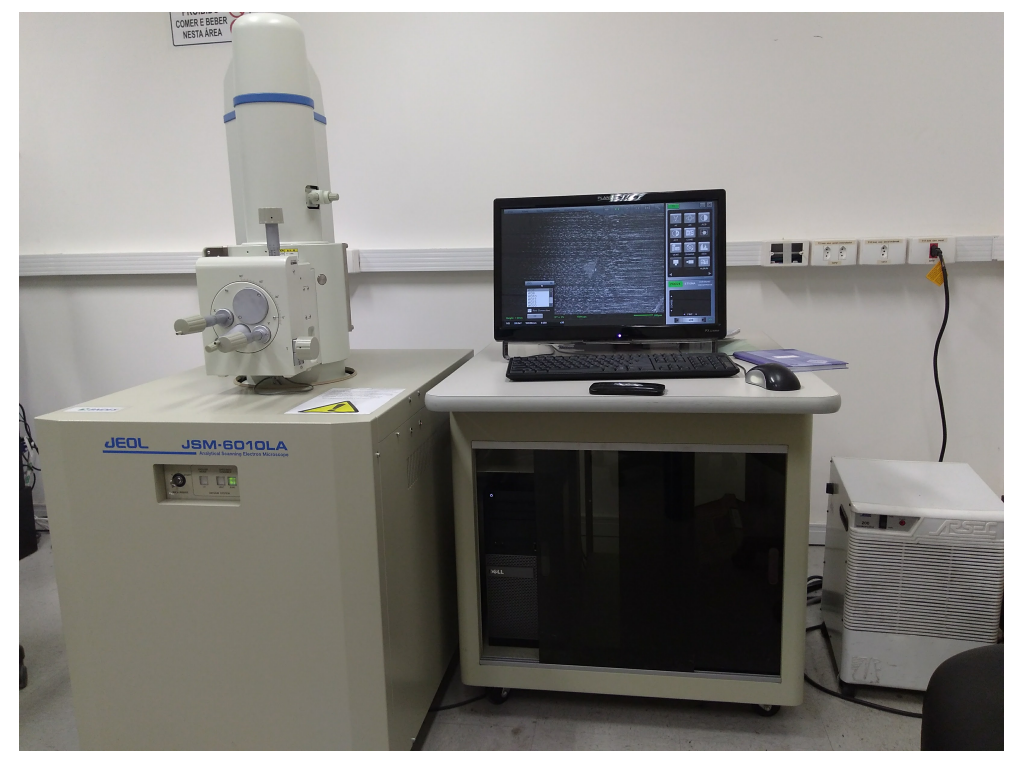

Figura 5.8 - Microscópio Eletrônico de Varredura (SEM), Jeol Intouch Scope/JSM-6010La.

Os resultados obtidos através da análise realizada pelo SEM, Figura. 5.8, se apresentam nas Figuras. 5.9 e 5.10. Os valores do carbono não se encontram na análise química realizada, mas pela concentração dos outros componentes como o Fe, Mn, Si, P, se conclui que o material corresponde a um Aço 1010 segundo a norma AISI-SAE, Tabela. 5.4. Nesta norma o primeiro número especifica a liga principal, o segundo a porcentagem aproximada do elemento principal e com os dois últimos se conhece a quantidade de carbono presente na liga. 


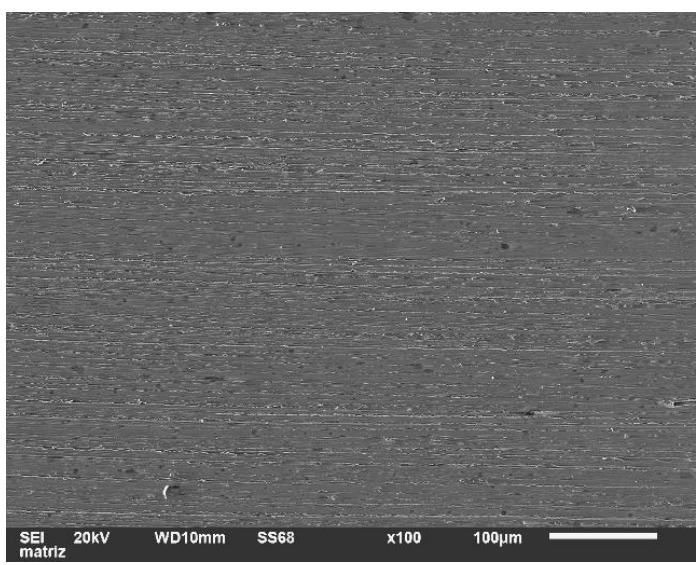

Figura 5.9 - Superfície do corpo de prova obtida pelo Microscópio Eletrônico

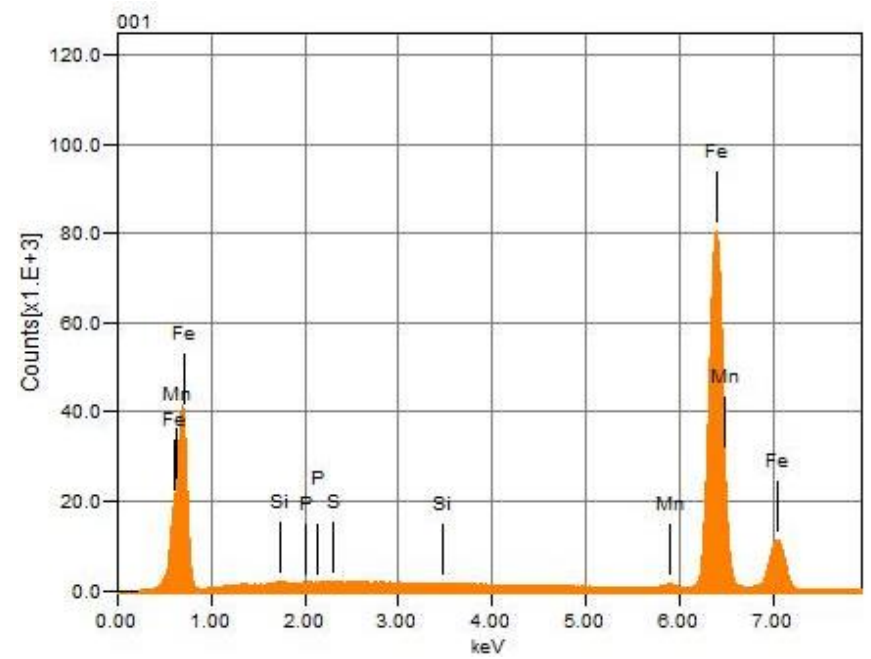

Figura 5.10 - Análise química do corpo de prova

Tabela 5.4 - Composição química do material

\begin{tabular}{ccccccc}
\hline $\begin{array}{c}\text { Fórmula } \\
\text { química }\end{array}$ & $\begin{array}{c}\text { Massa } \\
{[\%]}\end{array}$ & $\begin{array}{c}\text { Atom } \\
{[\%]}\end{array}$ & Sigma & Net & RadioK & Linha \\
Si* $^{*}$ & 0,18 & 0,36 & 0,01 & 19378 & 0,0011312 & $\mathrm{~K}$ \\
$\mathrm{P}^{*}$ & 0,05 & 0,09 & 0,01 & 5076 & 0,0042009 & $\mathrm{~K}$ \\
$\mathrm{~S}^{*}$ & 0,00 & 0,00 & 0,00 & 30 & 0,00000219 & $\mathrm{~K}$ \\
$\mathrm{Mn}^{*}$ & 1,03 & 1,05 & 0,01 & 65658 & 0,1214644 & $\mathrm{~K}$ \\
$\mathrm{Fe}^{*}$ & 98,74 & 98,51 & 0,05 & 5559095 & 11,8948421 & $\mathrm{~K}$ \\
Total & 100,00 & 100,00 & & & & \\
\hline
\end{tabular}


Conhecendo o material foram cortadas com dimensões de $17 \mathrm{~mm}$ de altura e $20 \mathrm{~mm}$ de diâmetro, as amostras para a análise da rugosidade superficial, sendo um total de 10 amostras.

\subsubsection{Elaboração e preparação das amostras.}

- Corte

A amostra a ser analisada foi cortada de forma que não sofresse alterações na estrutura devido ao corte. Em frio, foi utilizado uma serra de cinta e farta de refrigeração.

Foram utilizadas lixas de água, fixadas em discos rotativos. Com granulometria entre 180 e 2500. Para obter diferentes tipos de acabamento da superfície, o processo foi diferente para cada amostra, como se apresenta na Tabela. 5.5.

Tabela 5.5 - Processo de lixamento para as amostras de Aço 1010

\begin{tabular}{|c|c|c|c|c|c|c|c|c|c|}
\hline \multirow{2}{*}{ Amostra } & \multicolumn{7}{|c|}{ Granulometria das lixas } \\
\hline & 180 & 240 & 360 & 600 & 1200 & 1500 & 2000 & 2500 & Polido \\
\hline 1 & \multicolumn{7}{|c|}{ Não passou por lixamento } \\
\hline 2 & $\mathrm{X}$ & & & & & & & & \\
\hline 3 & $\mathrm{X}$ & $\mathrm{X}$ & & & & & & & \\
\hline 4 & $\mathrm{X}$ & $\mathrm{X}$ & $\mathrm{X}$ & & & & & & \\
\hline 5 & $\mathrm{X}$ & $\mathrm{X}$ & $\mathrm{X}$ & $\mathrm{X}$ & & & & & \\
\hline 6 & $\mathrm{X}$ & $\mathrm{X}$ & $\mathrm{X}$ & $\mathrm{X}$ & $\mathrm{X}$ & & & & \\
\hline 7 & $\mathrm{X}$ & $\mathrm{X}$ & $\mathrm{X}$ & $\mathrm{X}$ & $\mathrm{X}$ & $\mathrm{X}$ & & & \\
\hline 8 & $\mathrm{X}$ & $\mathrm{X}$ & $\mathrm{X}$ & $\mathrm{X}$ & $\mathrm{X}$ & $\mathrm{X}$ & $\mathrm{X}$ & & \\
\hline 9 & $\mathrm{X}$ & $\mathrm{X}$ & $\mathrm{X}$ & $\mathrm{X}$ & $\mathrm{X}$ & $\mathrm{X}$ & $\mathrm{X}$ & $\mathrm{X}$ & \\
\hline 10 & $\mathrm{X}$ & $\mathrm{X}$ & $\mathrm{X}$ & $\mathrm{X}$ & $\mathrm{X}$ & $\mathrm{X}$ & $\mathrm{X}$ & $\mathrm{X}$ & $\mathrm{X}$ \\
\hline
\end{tabular}

As amostras após a preparação metalográfica por processo de desbaste são apresentadas na Figura. 5.11. 

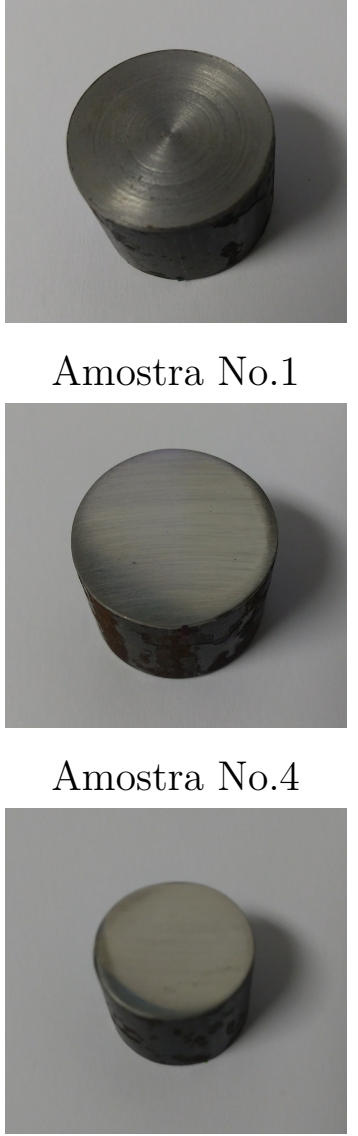

Amostra No.7

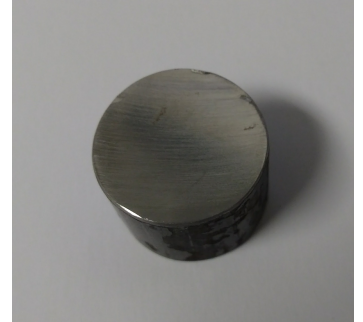

Amostra No.2

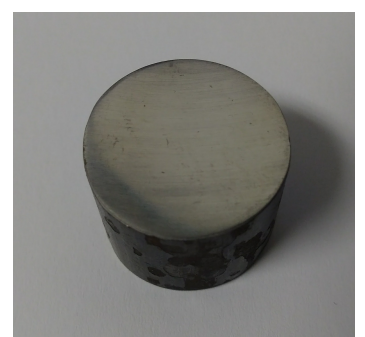

Amostra No.5

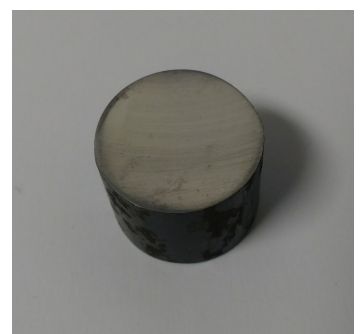

Amostra No.8

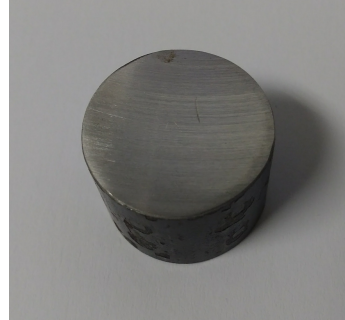

Amostra No.3

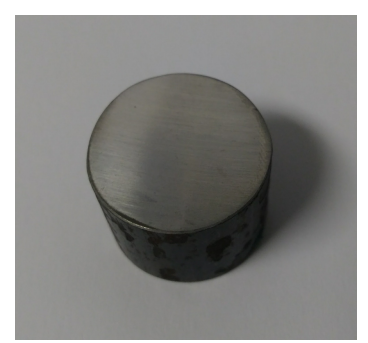

Amostra N.6

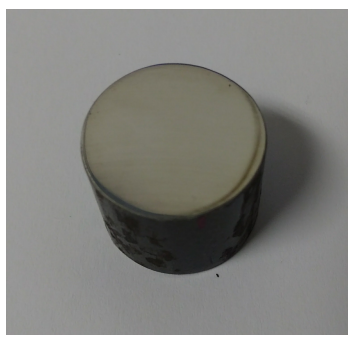

Amostra No.9

Figura 5.11 - Amostras após preparação metalográfica.

- Polimento

O polimento foi executado apenas para a mostra No. 10. Com panos especiais colados em pratos giratórios, a amostra passou por três tamanhos de grão de pasta de diamante, 6, 3 e $1 \mu m$ respectivamente. A amostra foi refrigerada com a utilização de álcool. O acabamento da amostra N.10 se apresenta na Figura. 5.12.

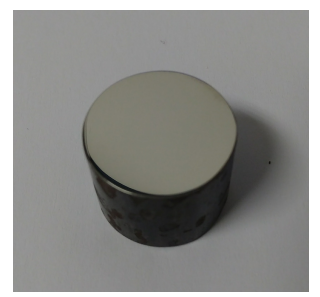

Figura 5.12 - Amostra No.10 após processo de polido. 
- Ataque químico

O ataque químico foi realizado pela imersão da amostra durante um período de três (3) segundos em Nital (ácido nítrico e álcool). Após o ataque químico foi passada por água para retirar o ácido da superfície, secada e guardada num saco plástico para evitar a oxidação da mesma.

\subsection{Execução das medições.}

Para cada uma das amostras do Aço 1010 foram realizadas três (3) medições em regiões da superfície das amostras escolhidas de forma aleatória, como se apresenta na Figura. 5.13.

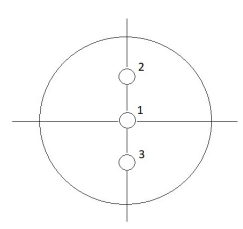

Amostra No.1

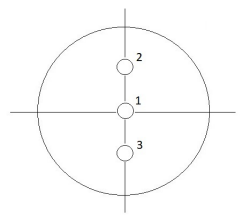

Amostra No.6

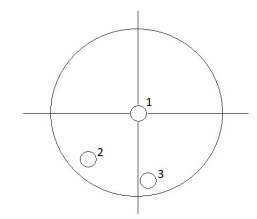

Amostra No.2
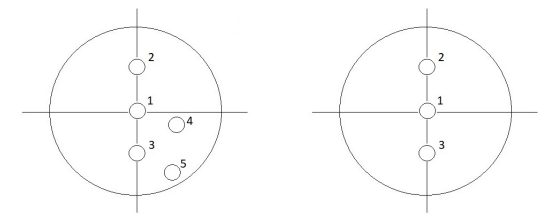

Amostra No.7 Amostra No.8

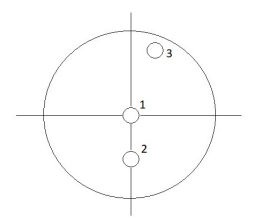

Amostra No.4

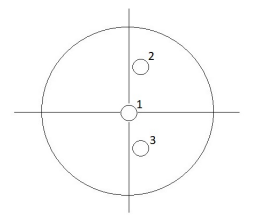

Amostra No.9 Amostra No.10

Figura 5.13 - Regiões onde foram realizadas as medições de Ra.

Cada amostra foi colocada na configuração experimental, Figura. 4.3. Para cada região da amostra foram capturados três (3) hologramas e o processamento dos hologramas para a reconstrução da imagem foi realizado da mesma forma que nas amostras embutidas.

\subsection{Algoritmo e metodologia para medição da Ra}

Para medir a rugosidade superficial Ra, a imagem original se traduz com uma matriz que se encontra entre os valores $[0,255]$ pixels. Esta imagem é convertida a valores reais, com magnitude $(\mu m)$, definindo assim a escala, segundo o algoritmo apresentado no Apêndice A. Na imagem 3D, se traça uma linha que alcança valores desde $x$ a $x_{m}$, ao qual é subtraído o valor médio para centrar os resultados no eixo zero. 
A partir dos valores calculados, se convertem as diferenças de fases $\Delta \varphi_{i}$ em alturas ou distâncias, para isso utiliza-se a relação de fase e o caminho óptico $\delta_{n}$ :

$$
\Delta \varphi_{i}=\frac{2 \pi}{\lambda} \delta_{n}=\frac{2 \pi}{\lambda} 2 h_{i} \Rightarrow h_{i}=\frac{\lambda}{4 \pi} \Delta \varphi_{i}
$$

Desta forma o valor da diferença de fase $\Delta \varphi_{i}$ em pixel $(i)$ corresponde uma altura $h_{i}$. Foi considerado o índice de refração do meio igual a 1 por estar o objeto no ar. $\mathrm{O}$ valor $2 h_{i}$ aparece por ser o esquema de reflexão, com o mesmo caminho $h_{i}$ em uma direção e na contrária depois da reflexão no objeto. Este processo é realizado através do algoritmo introduzido no programa Holodig, utilizando a Equação. 5.2 onde, o valor de Ra vai ser igual à somatória dos valores absolutos das intensidades trasladadas ao eixo zero, dividido pela longitude da reta traçada na imagem, conforme se observa no algoritmo no Apêndice A.

Com a imagem reconstruída e o programa calibrado vamos à opção "Profile" e traçamos uma linha na área da amostra. Podem ser traçadas várias linhas para uma mesma imagem, sendo que para cada uma delas o valor da rugosidade aparece na janela principal do Matlab, como se apresenta na Figura. 5.14 e Figura. 5.15.

Por cada região da imagem reconstruída foram realizadas nove (9) medições de Ra, com um total de 27 (vinte e sete) medidas por amostra.

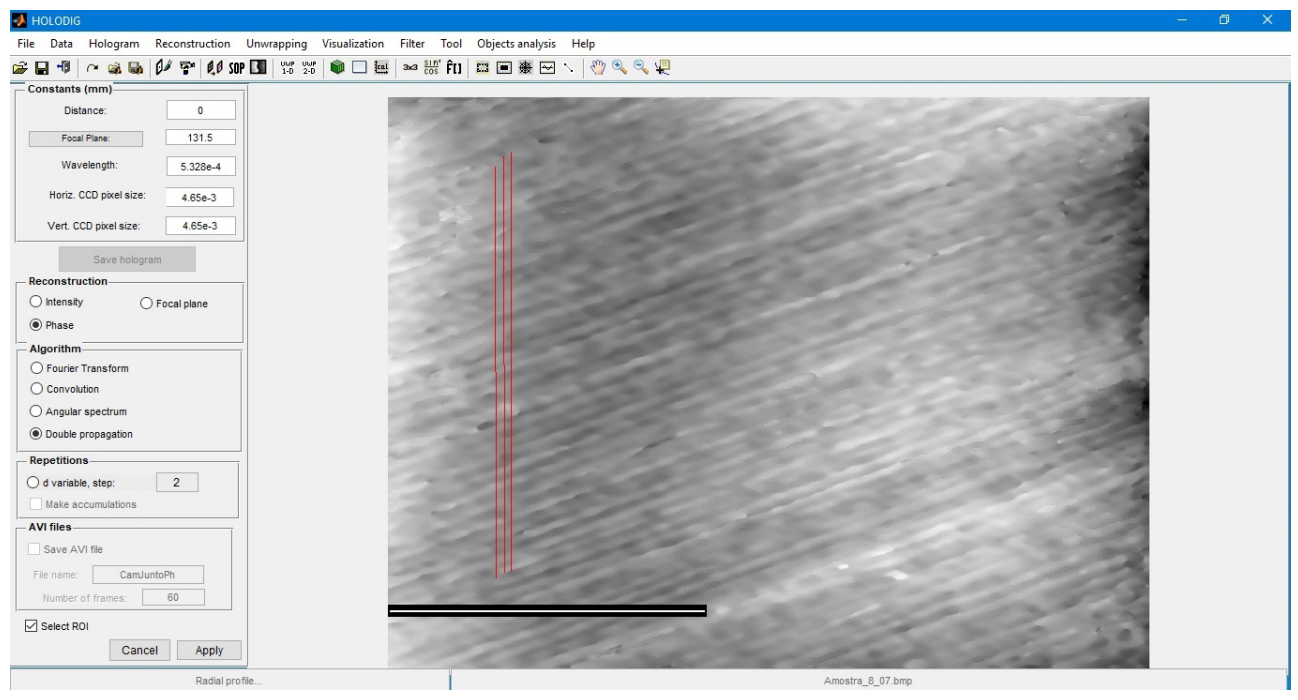

Figura 5.14 - Várias medições de Ra para uma região de uma amostra.

Os resultados obtidos, na Figura. 5.15, representam em ordem por colunas, a quantidade de medições, a longitude da linha traçada e o valor da Ra para essa linha. 


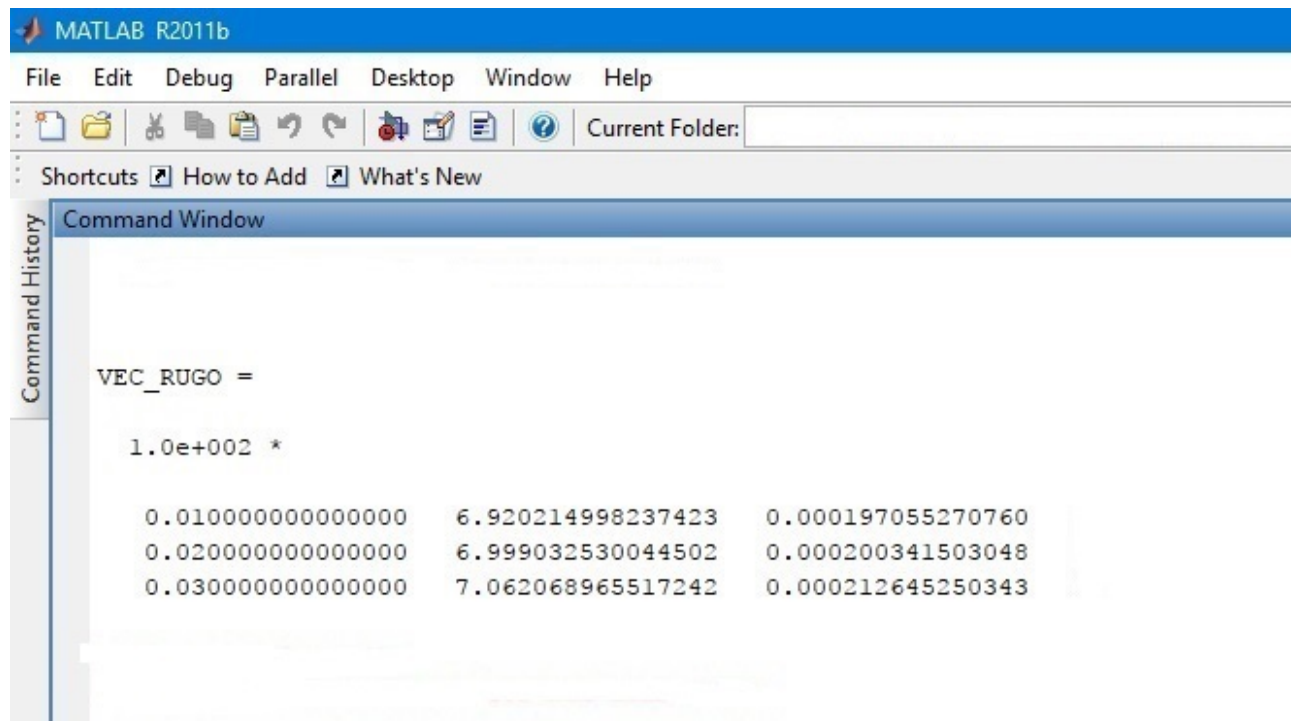

Figura 5.15 - Resultados de Ra obtidos.

Em sequência com a medição realizada o programa foi projetado para gerar um arquivo que contém os valores obtidos em cada medição. Este arquivo permite além de guardar os resultados, sua exportação para outros programas, por exemplo, o Excel, onde se realizou a análise da rugosidade superficial através de gráficos e tabelas.

Para validar a metodologia aqui proposta, após realizar a captura dos hologramas, o processo de reconstrução da imagem e obtenção dos diferentes valores de rugosidade superficial para cada amostra, cada uma delas foram analisadas em um perfilômetro óptico 3D sem contato nodelo CCI-MP.

\subsection{Perfilômetro óptico 3D sem contato modelo CCI MP.}

O perfilômetro possui um sistema de medição por interferometria óptica confocal, permitindo a medição de acabamento superficial 3D e espessura de camadas dentro de um campo de $300 \mathrm{~nm}$ a 1,5 $\mathrm{m}$ com uma resolução de 0,1 Angstrom.

O instrumento combina campo, resolução, precisão e repetitividade em qualquer tipo de peça; desde uma superfície muito rugosa até um acabamento polido. O sistema possui um processo automático de detecção de superfície que elimina os ajustes manuais para encontrar as franjas de luz na peça, além do ajuste automático de campo vertical baseado na superfície a medir. O algoritmo de coerência está patenteado pela Taylor Hobson e proporciona uma resolução sub-angstrom independentemente do campo de varredura. 


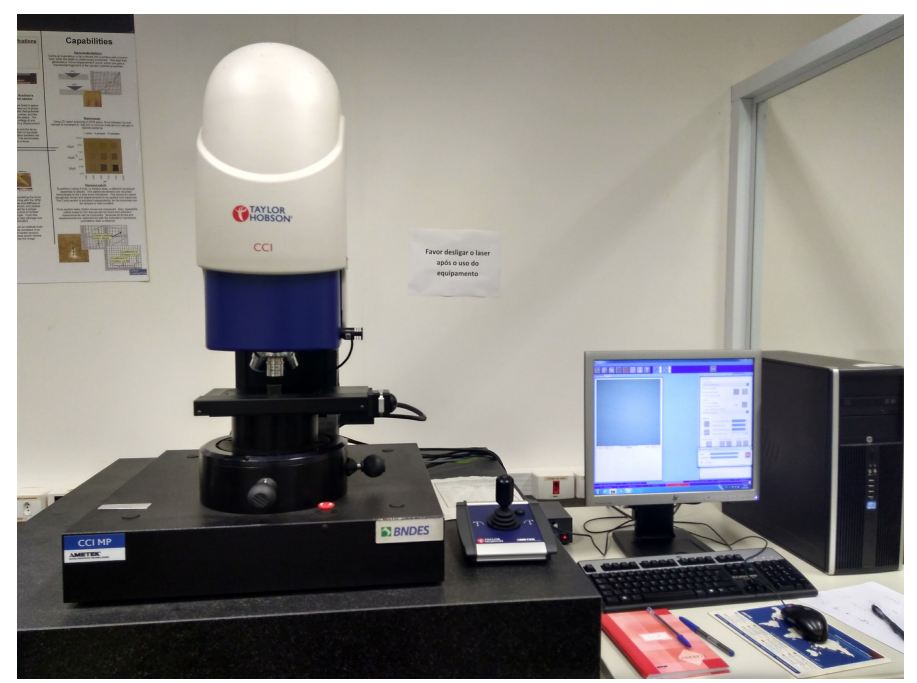

Figura 5.16 - Perfilômetro óptico 3D sem contato modelo CCI MP

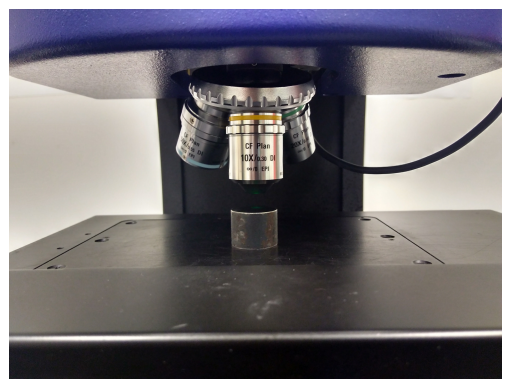

Figura 5.17 - Exemplo de medição com uma amostra de Aço 1010.

As amostras foram colocadas na plataforma do CCI e as medições foram realizadas nas regiões descritas na Figura. 5.13. Os resultados foram gravados e armazenados em arquivo pdf, um por cada medição.

\subsection{Resultados da análise da rugosidade superficial.}

Para cada amostra de aço 1010 que passaram pelo processo de desbaste com diferentes granulometrias, foram obtidos três (3) hologramas por região. A partir destes obtiveram-se as imagens de contraste de fase em 3D que nos oferecem uma visão da superfície de cada amostra a um nível da ordem das micras $(\mu \mathrm{m})$, como se apresenta desde a Figura. ?? à Figura. ??. Também pode ser observado nestas figuras o processo de desbaste abrasivo das superfícies através de lixas de diferente granulometria. 


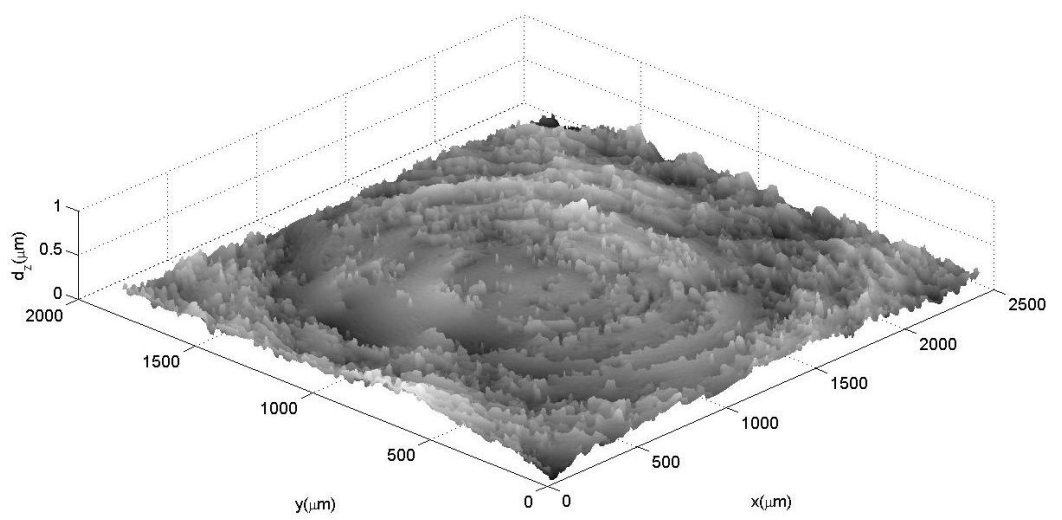

Figura 5.18 - Imagem reconstruída em 3D da Amostra No.1 Região 1.

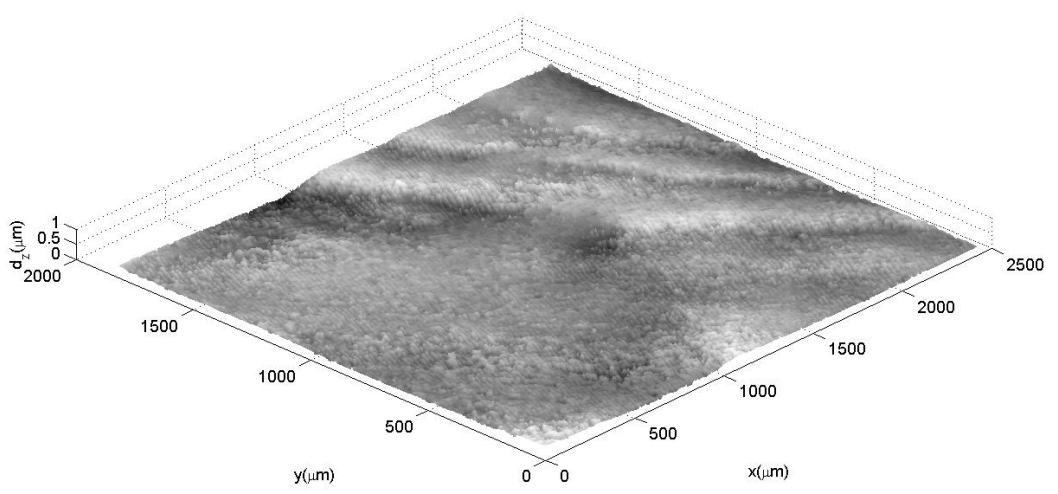

Figura 5.19 - Imagem reconstruída em 3D da Amostra No.1 Região 2.

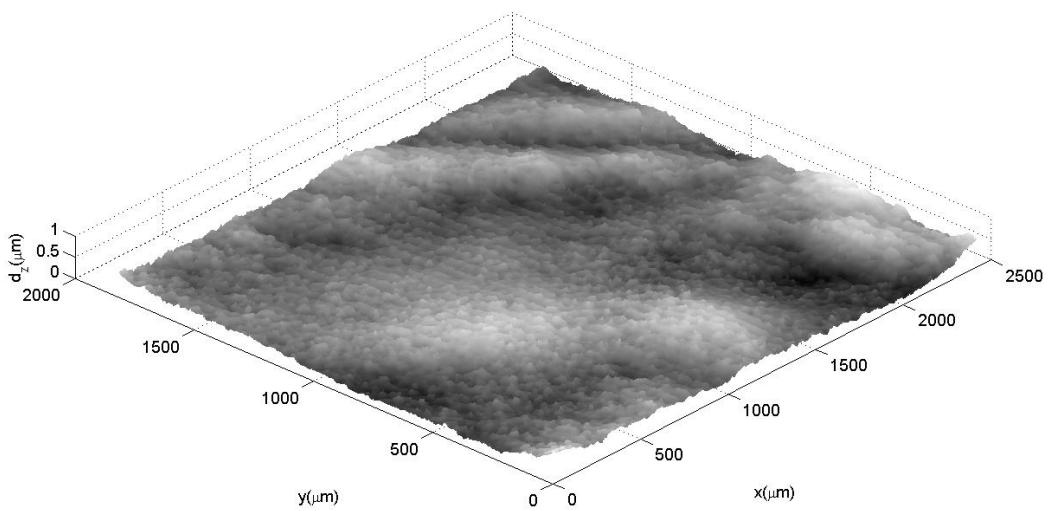

Figura 5.20 - Imagem reconstruída em 3D da Amostra No.1 Região 3. 


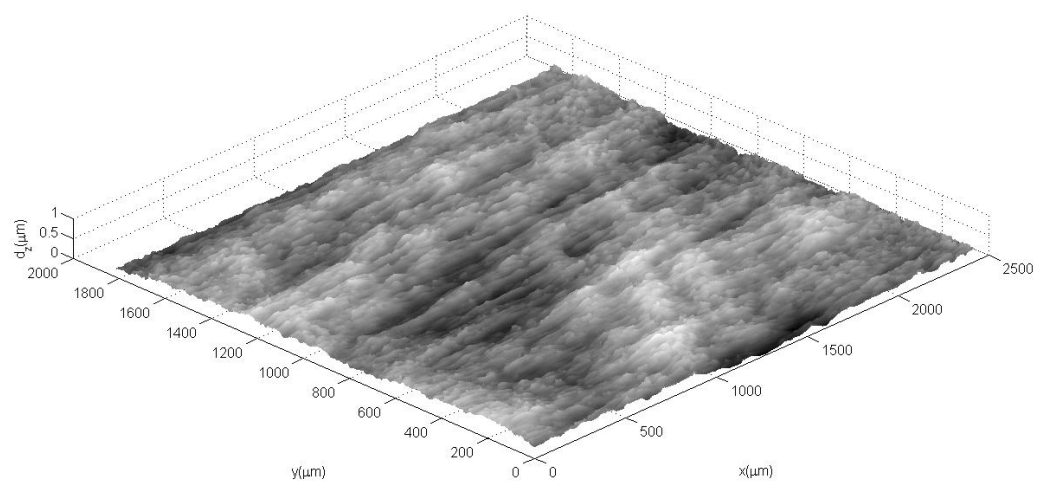

Figura 5.21 - Imagem reconstruída em 3D da Amostra No.2 Região 1.

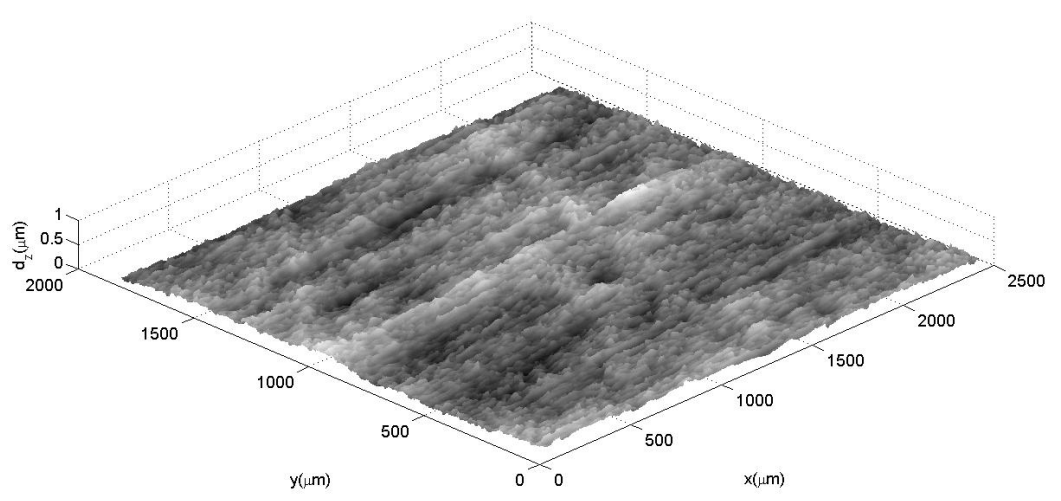

Figura 5.22 - Imagem reconstruída em 3D da Amostra No.2 Região 2.

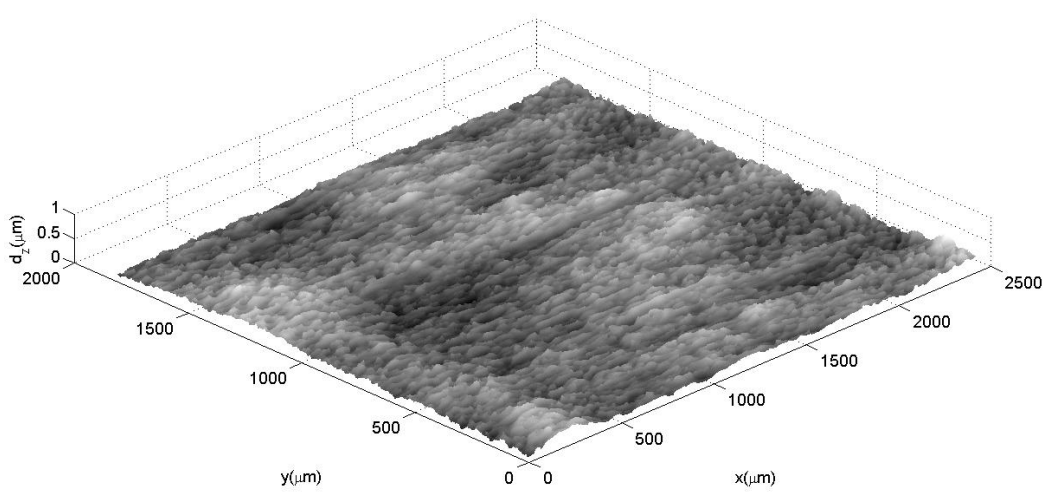

Figura 5.23 - Imagem reconstruída em 3D da Amostra No.2 Região 3. 


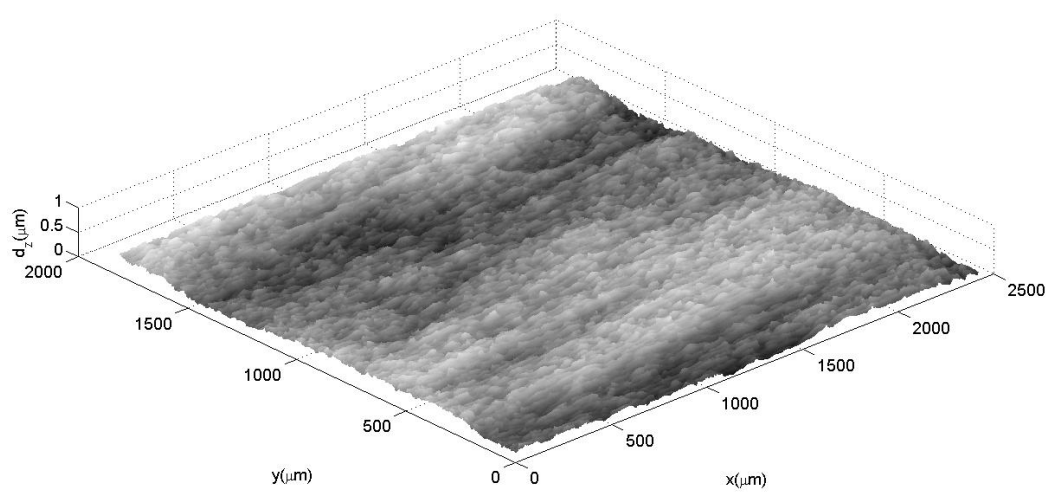

Figura 5.24 - Imagem reconstruída em 3D da Amostra No.3 Região 1.

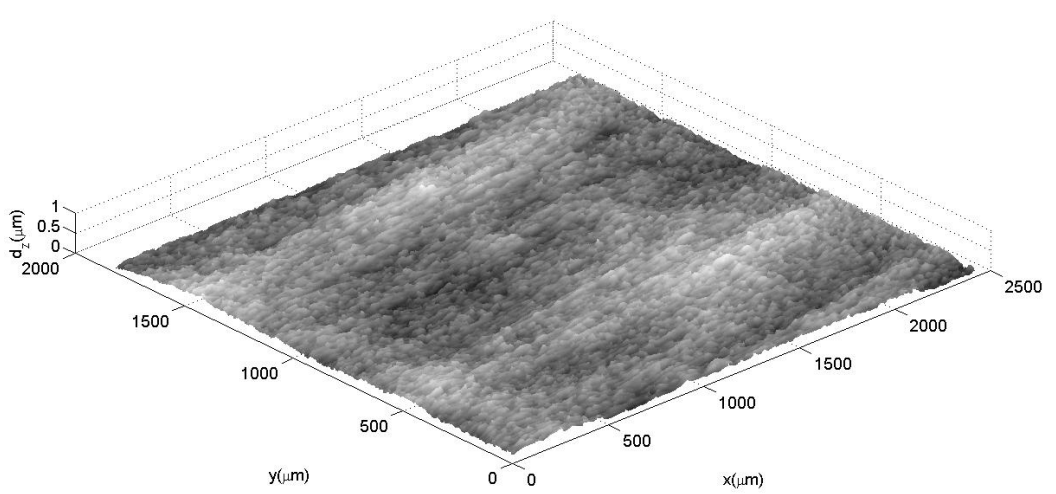

Figura 5.25 - Imagem reconstruída em 3D da Amostra No.3 Região 2.

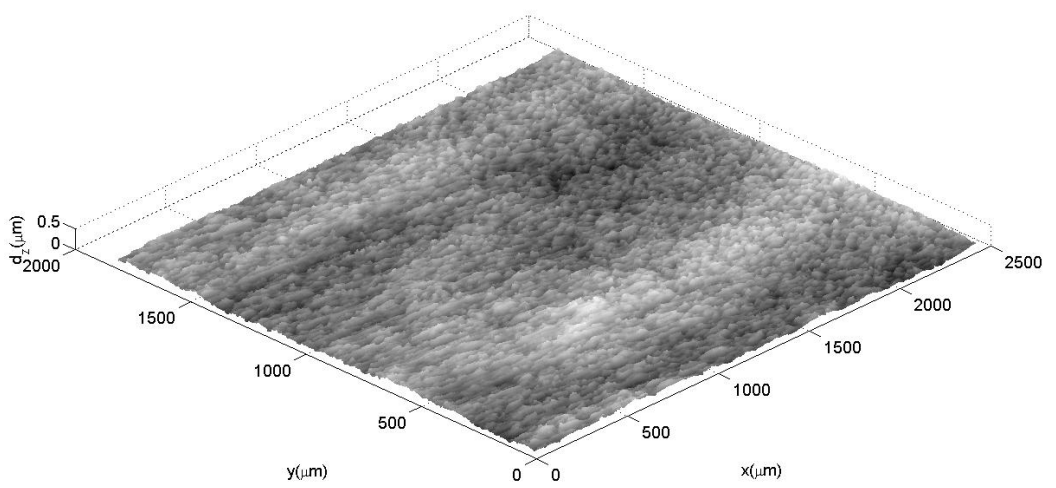

Figura 5.26 - Imagem reconstruída em 3D da Amostra No.3 Região 3. 


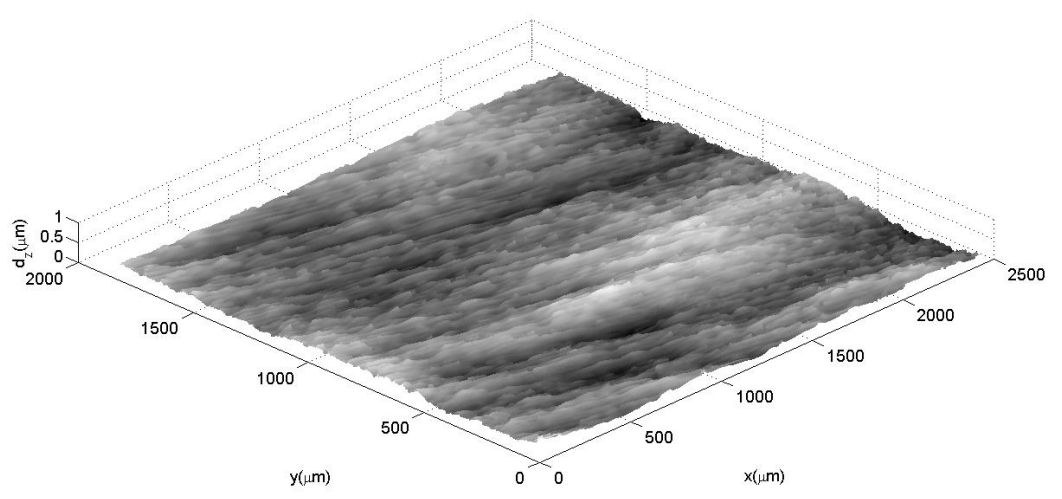

Figura 5.27 - Imagem reconstruída em 3D da Amostra No.4 Região 1.

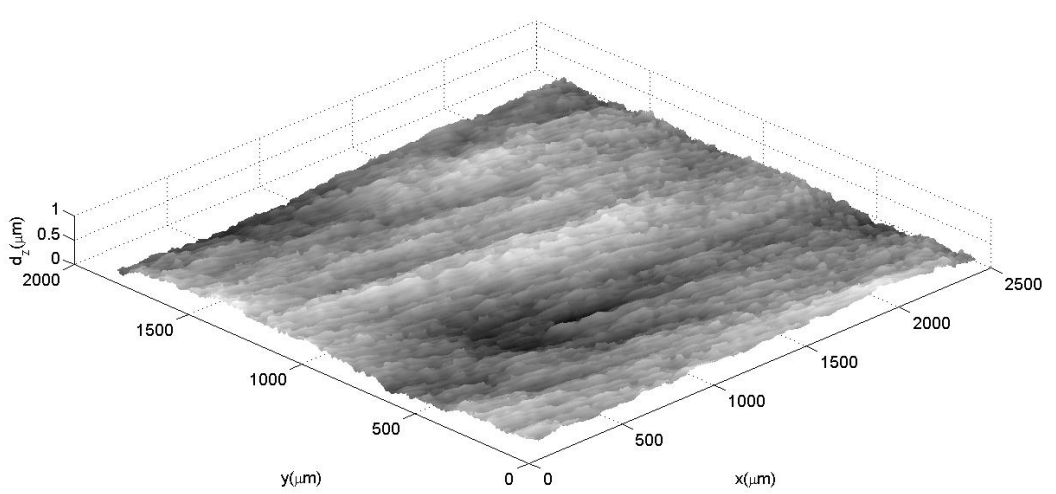

Figura 5.28 - Imagem reconstruída em 3D da Amostra No.4 Região 2.

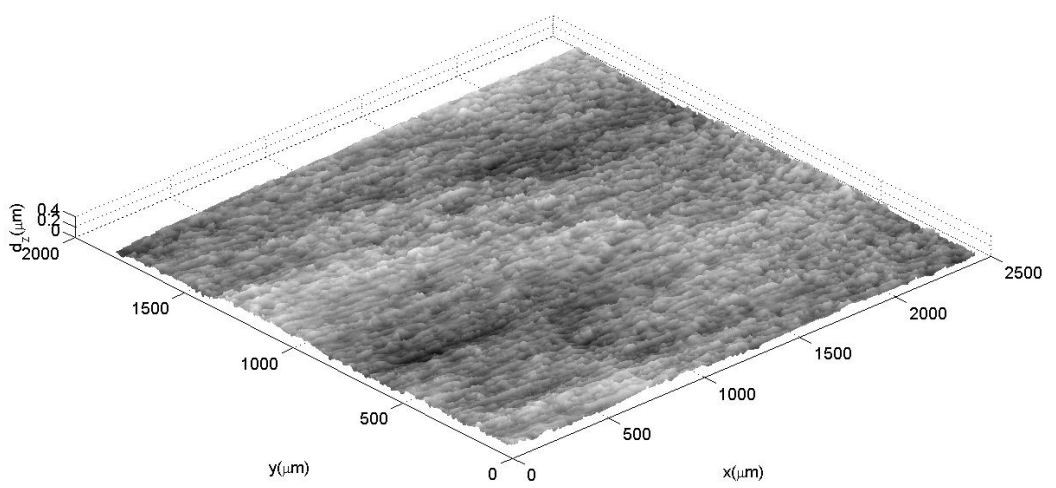

Figura 5.29 - Imagem reconstruída em 3D da Amostra No.4 Região 3. 


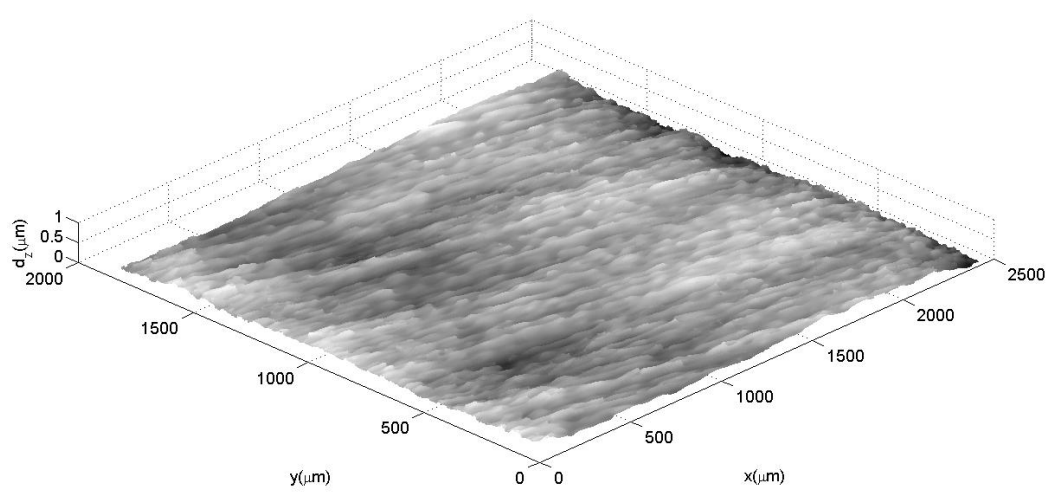

Figura 5.30 - Imagem reconstruída em 3D da Amostra No.5 Região 1.

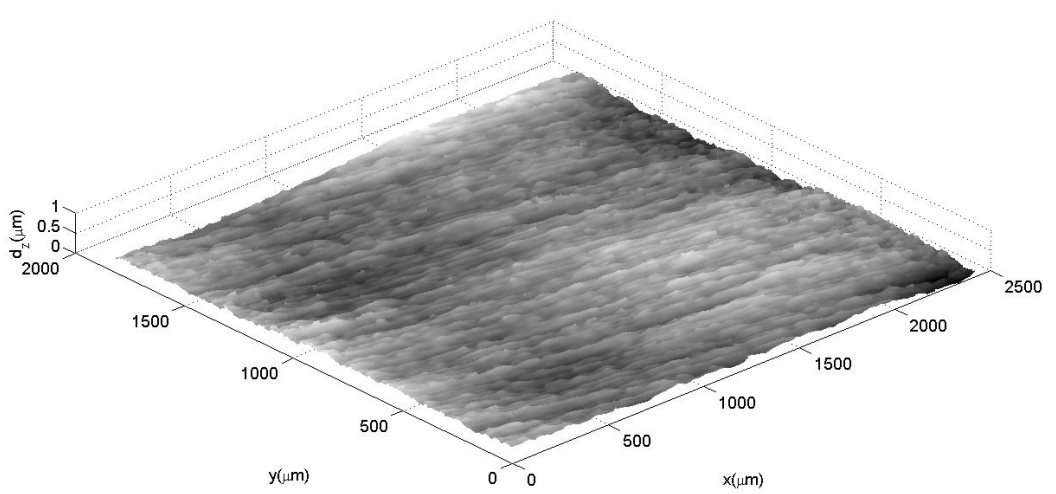

Figura 5.31 - Imagem reconstruída em 3D da Amostra No.5 Região 2.

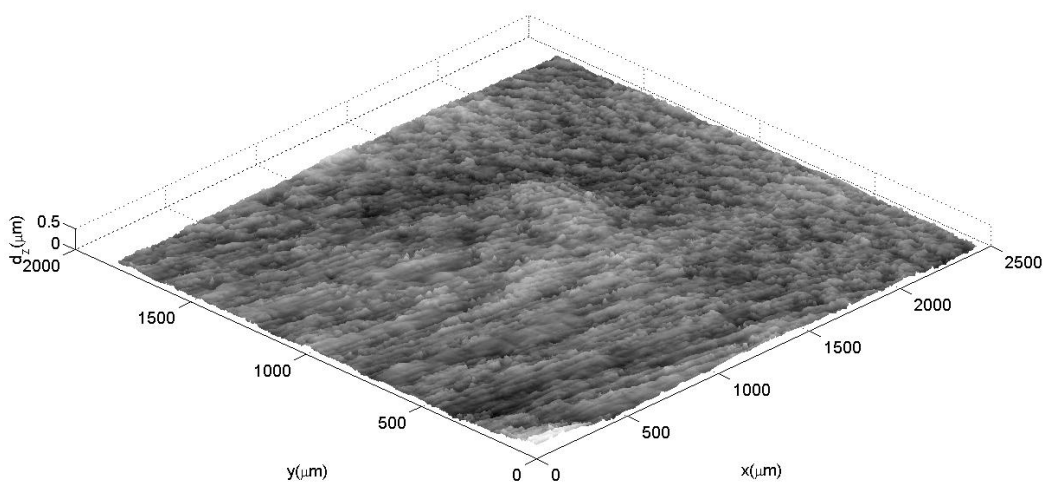

Figura 5.32 - Imagem reconstruída em 3D da Amostra No.5 Região 3. 


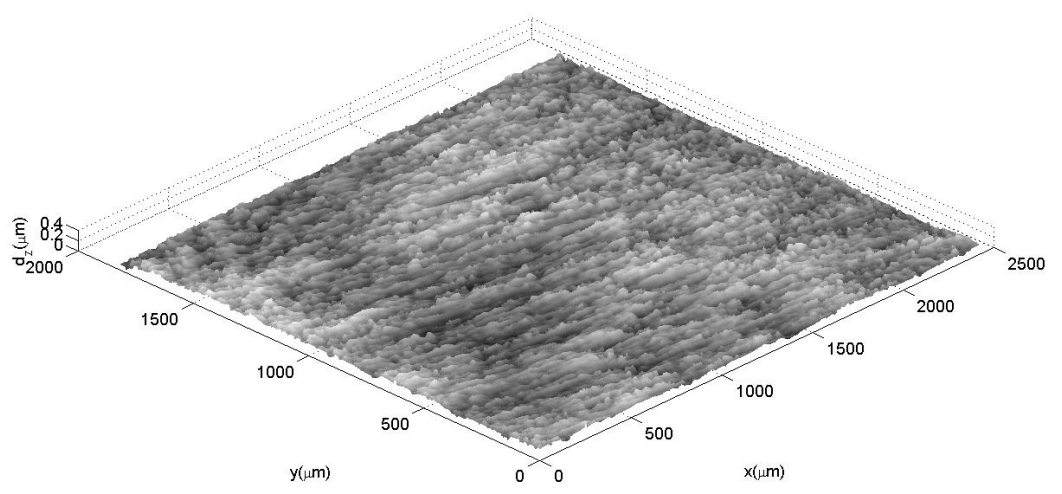

Figura 5.33 - Imagem reconstruída em 3D da Amostra No.6 Região 1.

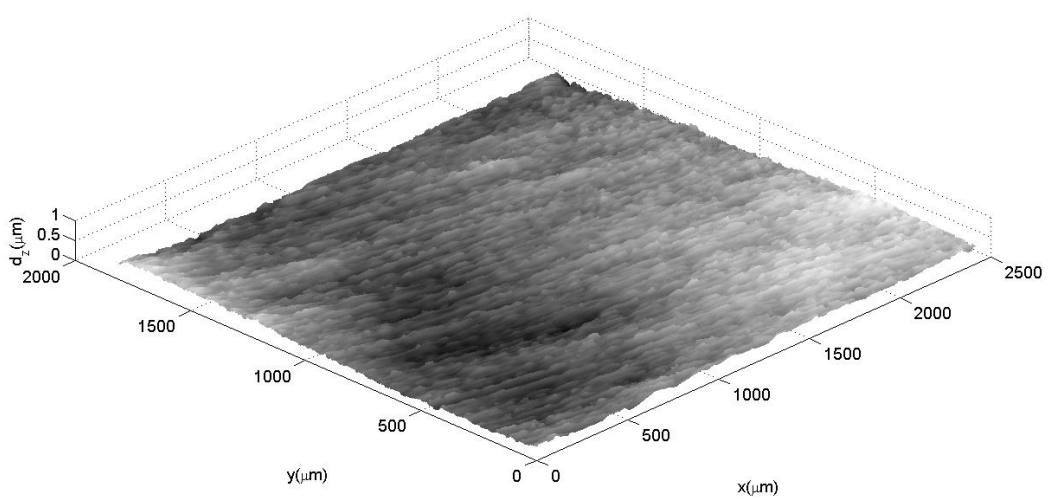

Figura 5.34 - Imagem reconstruída em 3D da Amostra No.6 Região 2.

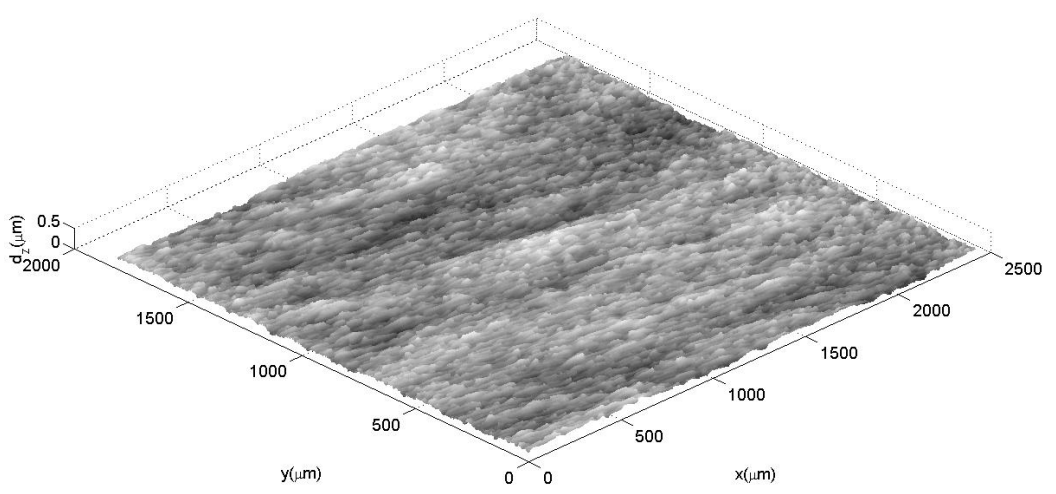

Figura 5.35 - Imagem reconstruída em 3D da Amostra No.6 Região 3. 


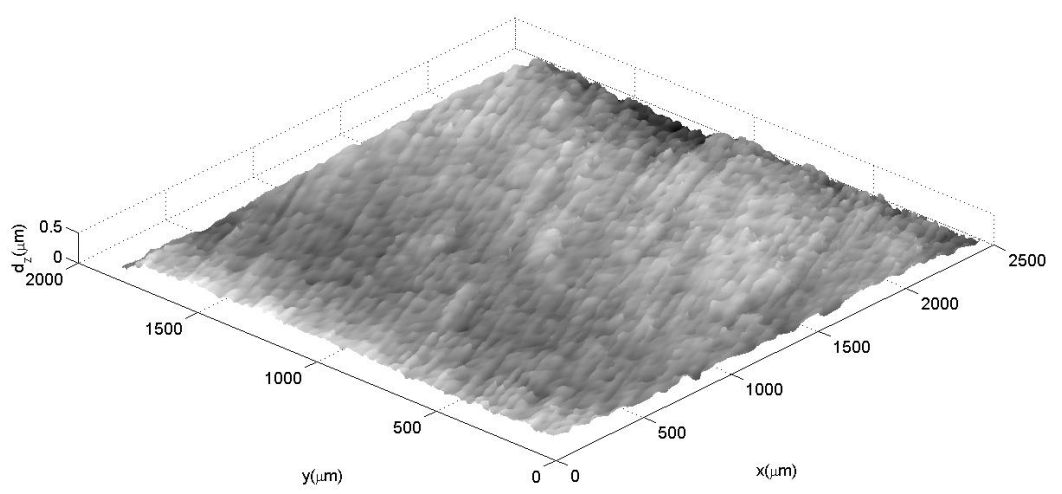

Figura 5.36 - Imagem reconstruída em 3D da Amostra No.7 Região 1.

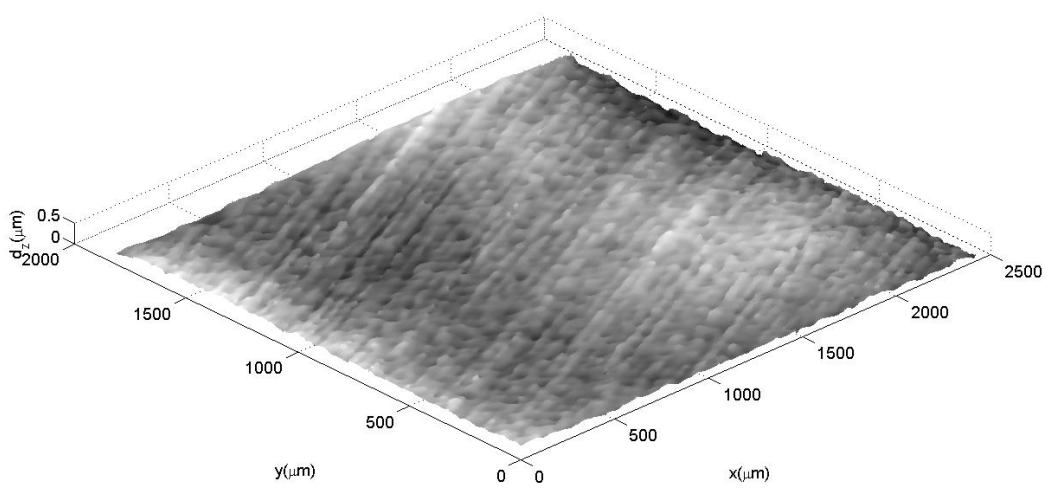

Figura 5.37 - Imagem reconstruída em 3D da Amostra No.7 Região 2.

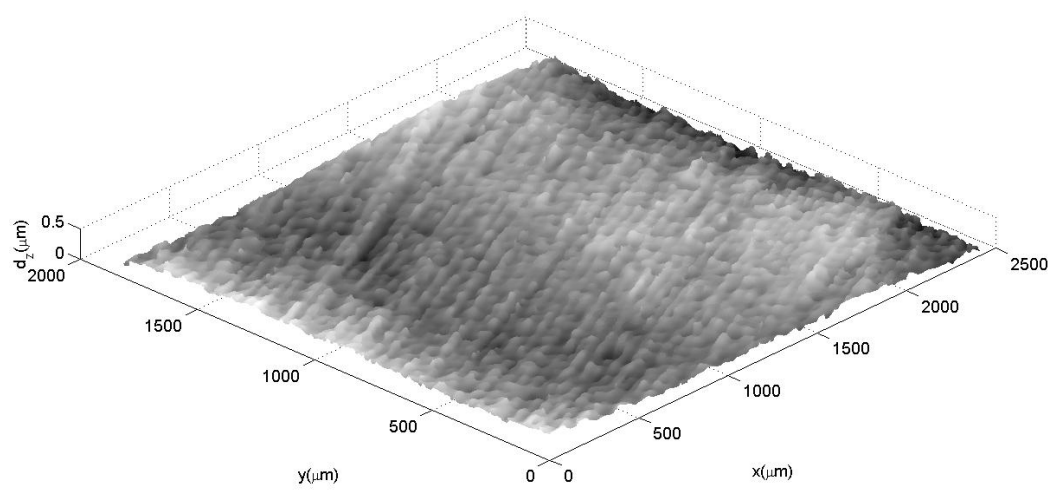

Figura 5.38 - Imagem reconstruída em 3D da Amostra No.7 Região 3. 


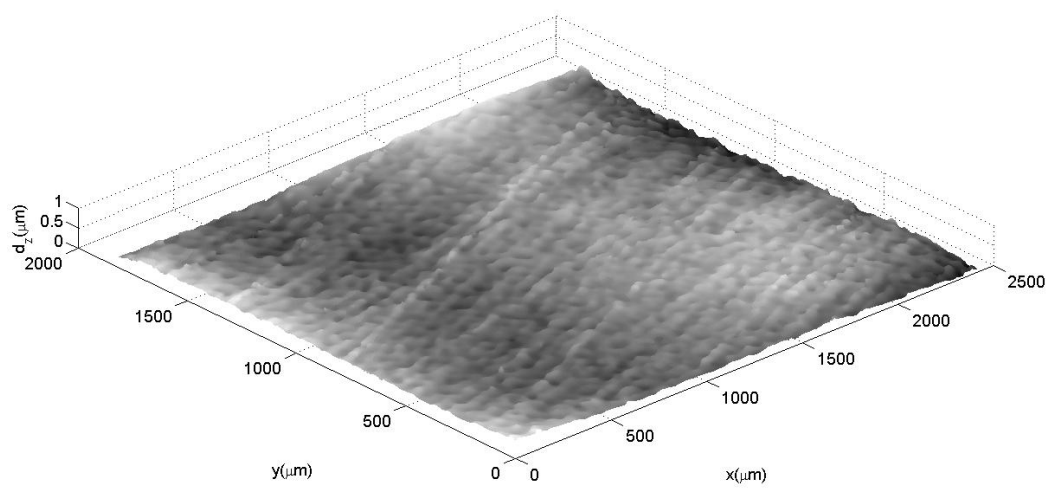

Figura 5.39 - Imagem reconstruída em 3D da Amostra No.8 Região 1.

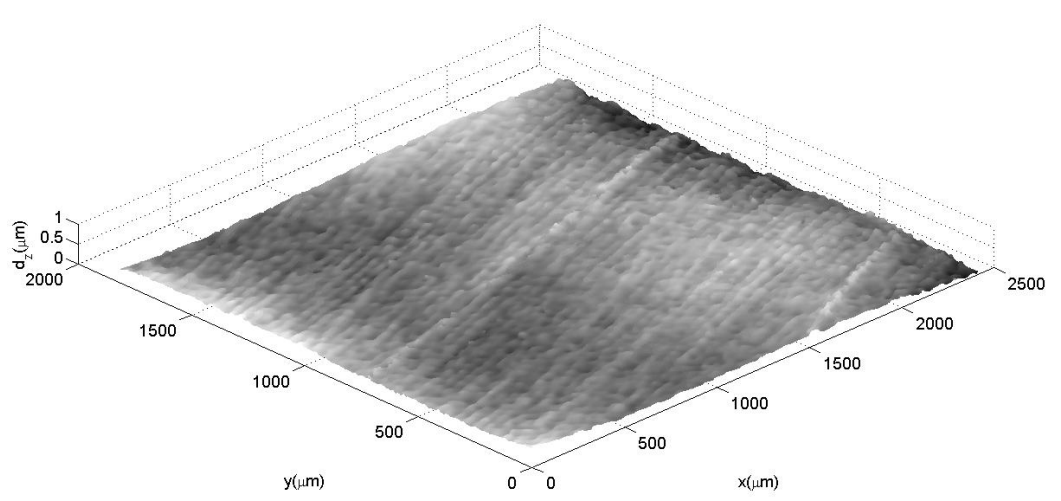

Figura 5.40 - Imagem reconstruída em 3D da Amostra No.8 Região 2.

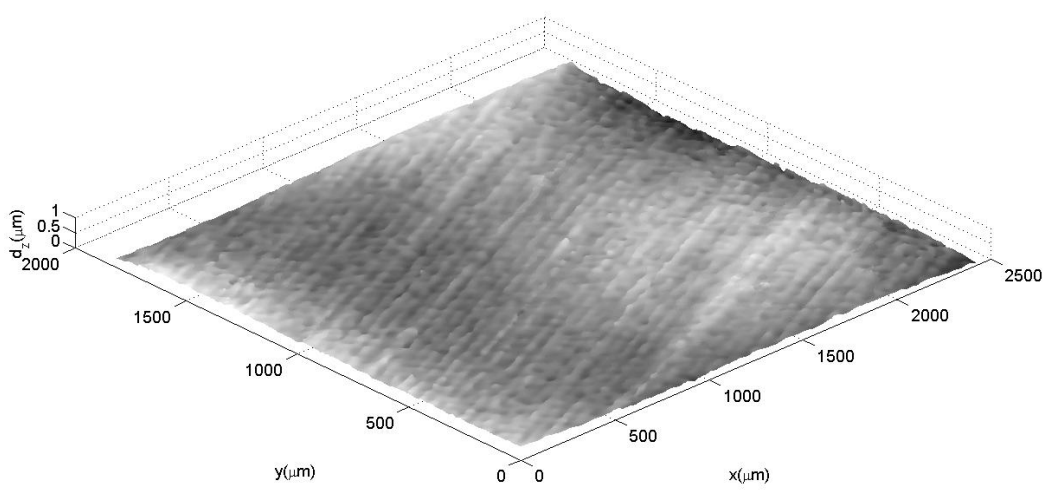

Figura 5.41 - Imagem reconstruída em 3D da Amostra No.8 Região 3. 


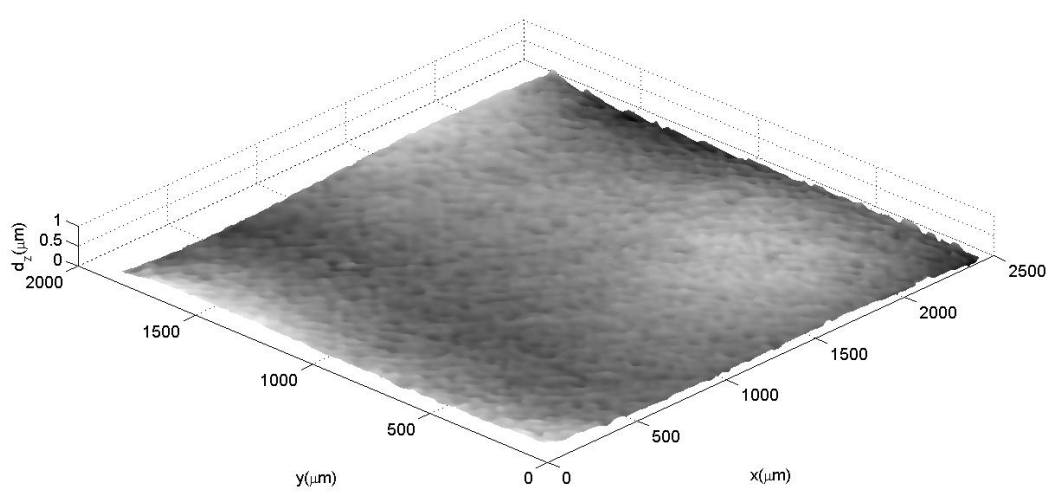

Figura 5.42 - Imagem reconstruída em 3D da Amostra No.9 Região 1.

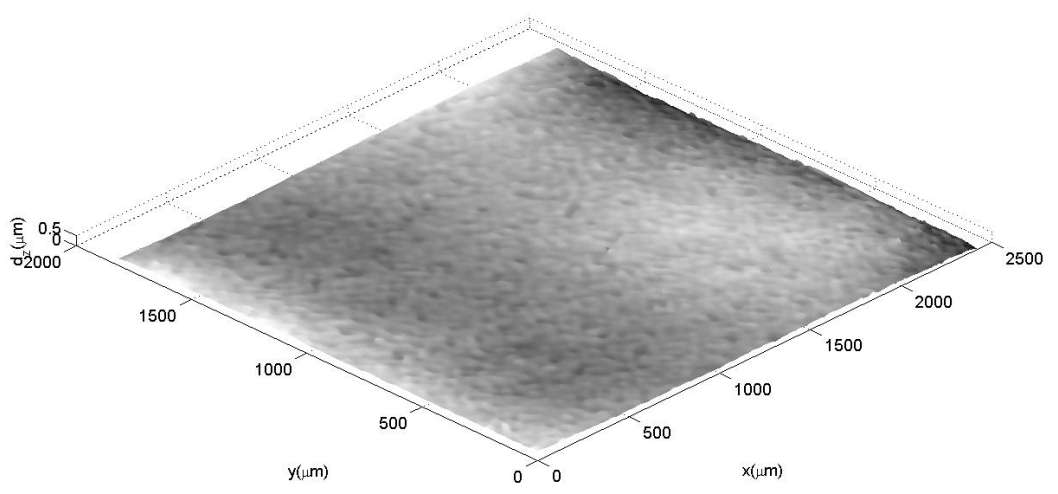

Figura 5.43 - Imagem reconstruída em 3D da Amostra No.9 Região 2.

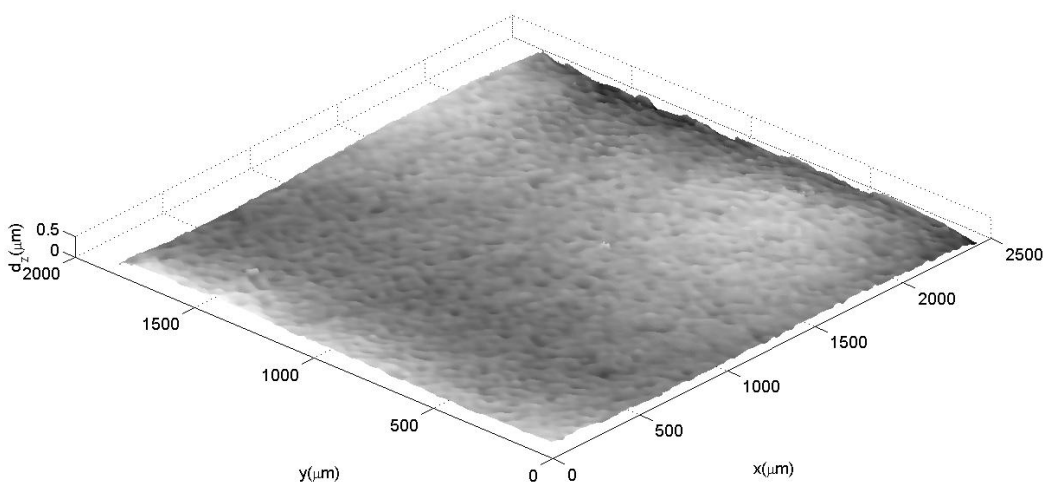

Figura 5.44 - Imagem reconstruída em 3D da Amostra No.9 Região 3. 


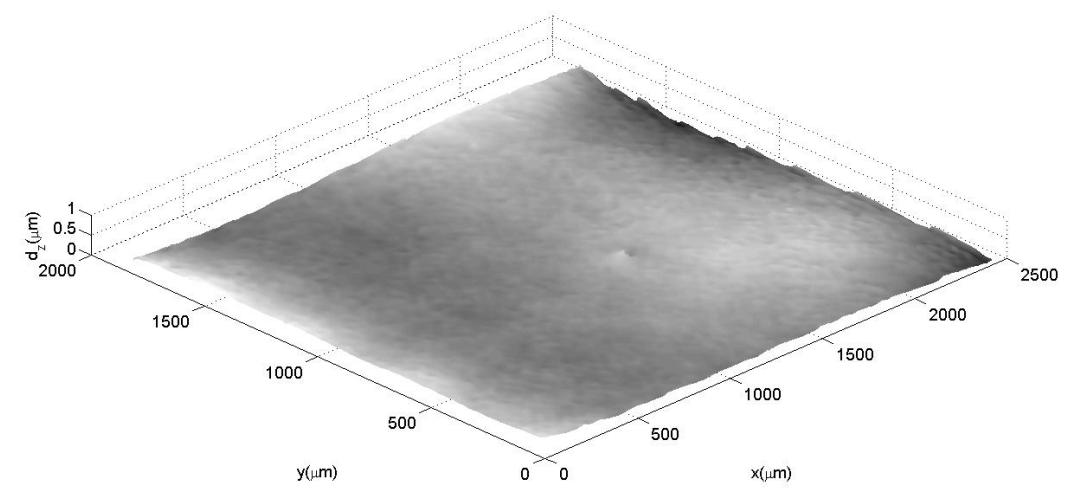

Figura 5.45 - Imagem reconstruída em 3D da Amostra No.10 Região 1.

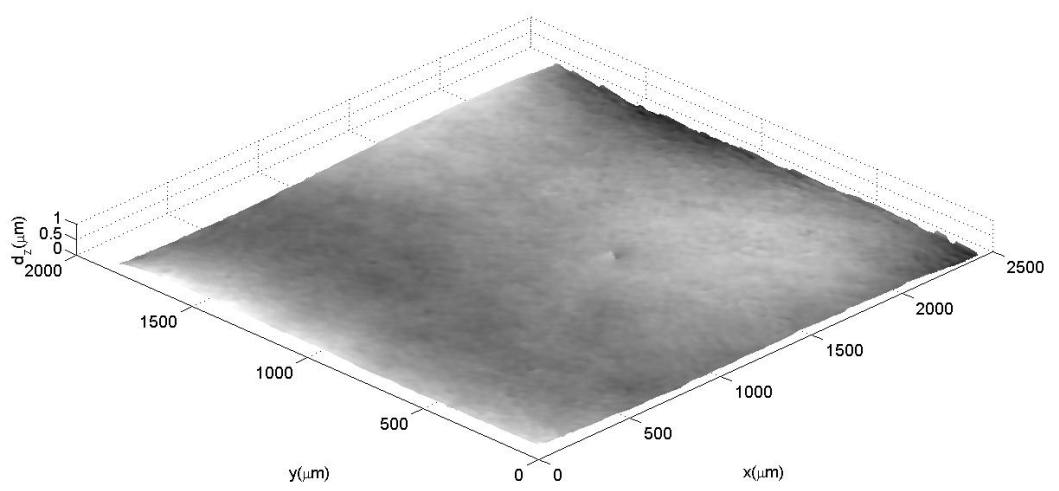

Figura 5.46 - Imagem reconstruída em 3D da Amostra No.10 Região 2.

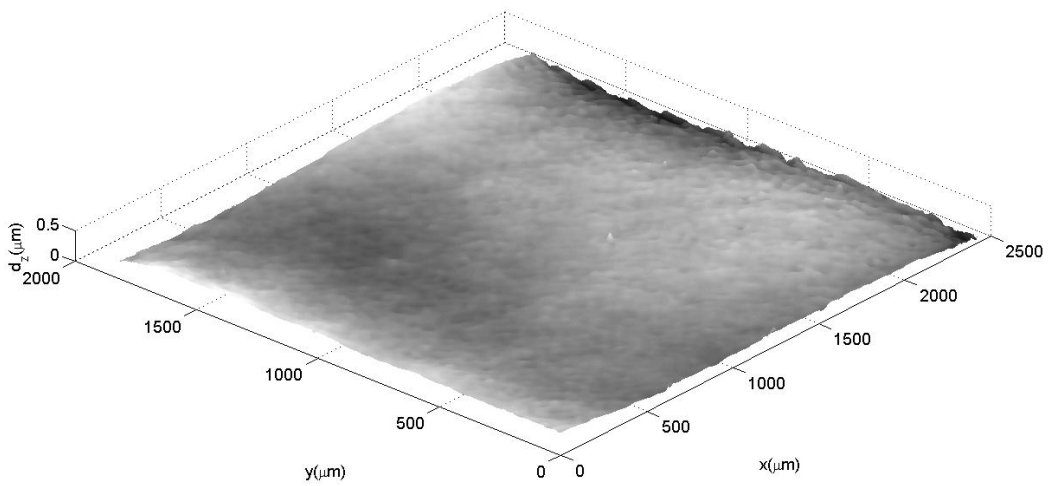

Figura 5.47 - Imagem reconstruída em 3D da Amostra No.10 Região 3. 
A amostra 1 apresenta uma superfície com mais irregularidades, por não passar pelo processo de desbaste, e a amostra No.10 possui uma superfície onde as irregularidades são imperceptíveis ao olho humano por apresentar a menor rugosidade superficial de todos os corpos de prova. As imagens das superfícies para cada amostra e suas regiões, obtidas através do Perfilômetro óptico 3D sem contato modelo CCI-MP, encontram-se na Figura. B.1 até a Figura. B.90 no Apêndice B.

Os resultados da rugosidade superficial Ra obtidos pelo método holográfico com a metodologia proposta e os resultados obtidos através do Perfilômetro óptico 3D sem contato modelo CCI-MP, são apresentados na Tabela. 5.6. Como parâmetro de entrada têm o número de grau da lixa utilizado e como parâmetro de saída a rugosidade superficial. Os valores tabelados por amostra correspondem à soma dos valores médios das suas respectivas regiões. Os resultados por região da metodologia proposta, encontram-se desde a Tabela $\mathrm{C} 1$ até a Tabela $\mathrm{C} 10$ do Apêndice C. Os valores individuais por região de Ra $(\mu m)$ do CCI, encontram-se no Apêndice B.

Tabela 5.6 - Valores da Rugosidade Superficial.

\begin{tabular}{cccc}
\hline Lixa & Ammostra & $\begin{array}{c}\text { Holodig } \\
\text { Ra }[\mu m]\end{array}$ & $\begin{array}{c}\text { CCI } \\
\text { Ra }[\mu m]\end{array}$ \\
\hline- & 1 & 1,1367 & 1,1377 \\
\hline 180 & 2 & 0,1093 & 0,1083 \\
\hline 240 & 3 & 0,1893 & 0,1855 \\
\hline 360 & 4 & 0,0687 & 0,0678 \\
\hline 600 & 5 & 0,0424 & 0,0427 \\
\hline 1200 & 6 & 0,0822 & 0,0779 \\
\hline 1500 & 7 & 0,0245 & 0,0225 \\
\hline 2000 & 8 & 0,0246 & 0,0211 \\
\hline 2500 & 9 & 0,0060 & 0,0062 \\
\hline Polido & 10 & 0,0057 & 0,0059 \\
\hline
\end{tabular}

Os resultados obtidos através do Perfilômetro óptico 3D sem contato modelo CCI-MP são similares aos obtidos pela técnica holográfica, validando assim a metodologia e o arranjo aqui proposto.

A partir dos resultados adquiridos através do programa Holodig foram obtidos os diferentes gráficos do perfil da superfície de cada amostra e suas regiões correspondentes. No primeiro gráfico da Figura. 5.48 aparecem os perfis das amostras No.1, No.6, No.8 e No.10 respectivamente. A diferença dos valores da rugosidade superficial fica em evidencia para os diferentes tipos de lixas utilizadas. 


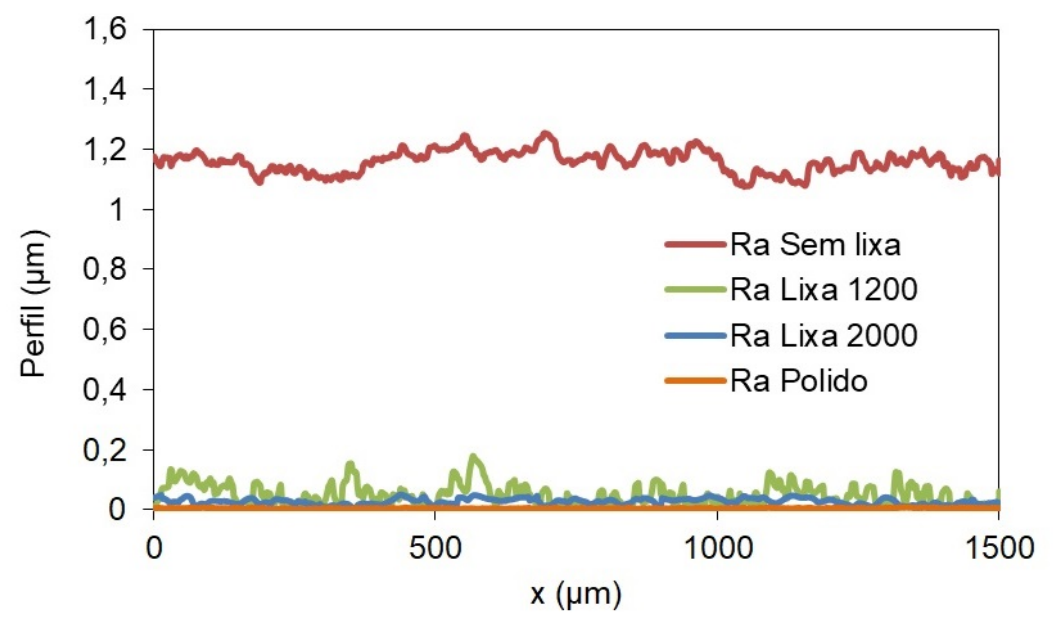

Figura 5.48 - Comportamento da rugosidade Ra segundo o tipo da lixa utilizado por amostra.

O gráfico da Figura. 5.49 com escala reduzida a valores pequenos mostra como a distância entre os picos e os vales da rugosidade superficial diminui para cada amostra segundo o número da lixa utilizada no processo de desbaste abrasivo.

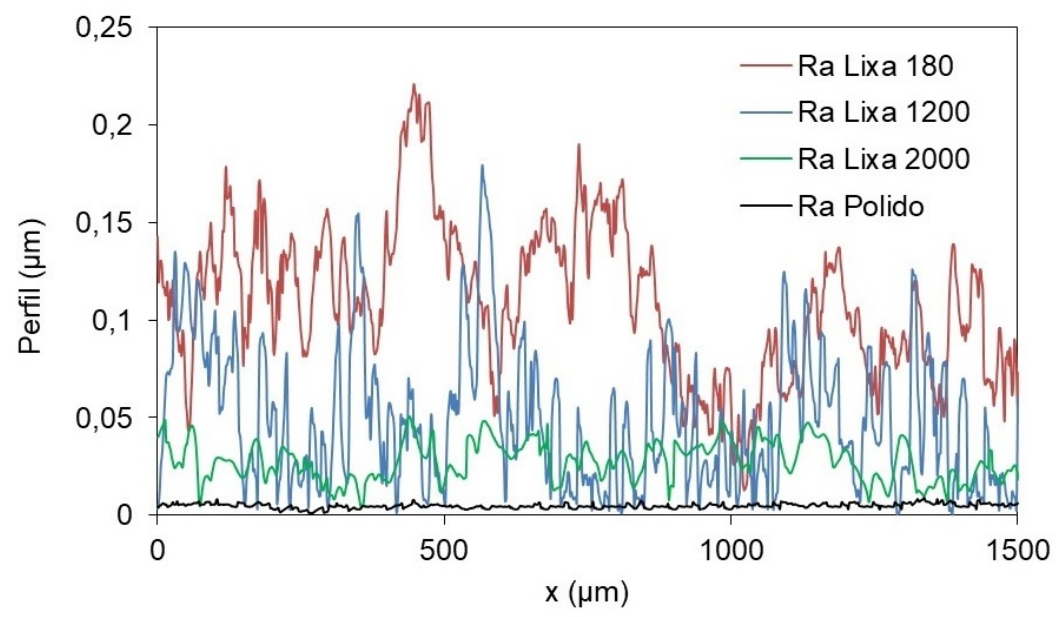

Figura 5.49 - Variação dos picos e vales da Ra segundo o número da lixa.

\subsection{Análise Estatística.}

Análise estatística entre os resultados obtidos através da metodologia proposta trabalho utilizando microscopia holográfica digital (DHM) e o perfilômetro óptico sem contato 3D modelo CCI-MP (CCI).

Nesta análise procura-se comprovar a semelhança que existe para a determinação de Ra através da metodologia proposta utilizando microscopia holográfica digital e o 
perfilômetro óptico 3D sem contato modelo CCI-MP. Os dados de entrada para esta análise encontram-se na Tabela. D.3 no Apêndice D. Na Tabela. 5.7 apresentam-se vários valores estatísticos para cada um dos dois métodos utilizados para encontrar se existem diferenças ou semelhanças significativas.

Tabela 5.7 - Estatística resumida

\begin{tabular}{lccccc}
\hline & Contagem & Média & $\begin{array}{c}\text { Coeficiente } \\
\text { de variação } \\
{[\%]}\end{array}$ & Mín. & Máx. \\
\hline CCI & 30 & 0,1667 & 200,17 & 0,0046 & 1,1920 \\
\hline DHM & 30 & 0,1694 & 196,31 & 0,0047 & 1,1910 \\
\hline Total & 60 & 0,1681 & 196,54 & 0,0046 & 1,1920 \\
\hline
\end{tabular}

A tabela ANOVA decompõe a variância dos dados em dois componentes: um componente entre grupos (DHM e CCI) e outro componente dentro do grupo (DHM) e (CCI). A relação F, que neste caso é igual a 0,00099254, é uma proporção da estimativa entre grupos para a estimativa dentro do grupo. Uma vez que o valor $\mathrm{P}$ do teste $\mathrm{F}$ é maior ou igual a 0,05, não há diferença estatisticamente significativa entre as médias das duas variáveis no nível de confiança de 95,0\%.

Tabela 5.8 - Anova

\begin{tabular}{lccccc}
\hline \multicolumn{1}{c}{ Fonte } & $\begin{array}{c}\text { Soma dos } \\
\text { quadrados }\end{array}$ & Df & $\begin{array}{c}\text { Quadrado } \\
\text { médio }\end{array}$ & F-Razão & P-Valor \\
\hline Entre grupos & 0,00011 & 1 & 0,00011 & 0,00 & 0,9750 \\
\hline Dentro dos grupos & 6,44214 & 58 & 0,11107 & & \\
\hline Total (Corr.) & 6,44225 & 59 & & & \\
\hline
\end{tabular}

A Figura. 5.50 apresenta o gráfico da dispersão dos resultados experimentais da rugosidade superficial, obtidos através da metodologia proposta de microscopia holográfica digital (DHM) e os resultados obtidos a partir do perfilômetro óptico 3D sem contato modelo CCI-MP (CCI). 


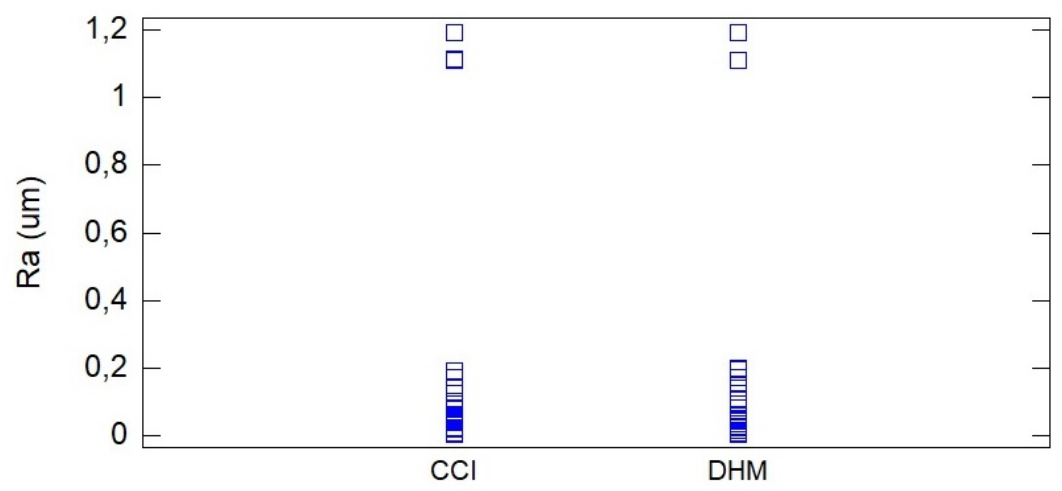

Figura 5.50 - Gráfico da dispersão de Ra obtidos através dos dois métodos.

O diagrama de extremos e quartis da Figura. 5.51 representa a variação dos resultados por meio de quartis. Os valores da Ra para cada método utilizado se identifica através das caixas que representam onde se encontra a maior concentração. Assim estão localizadas a mediana e os valores extremos.

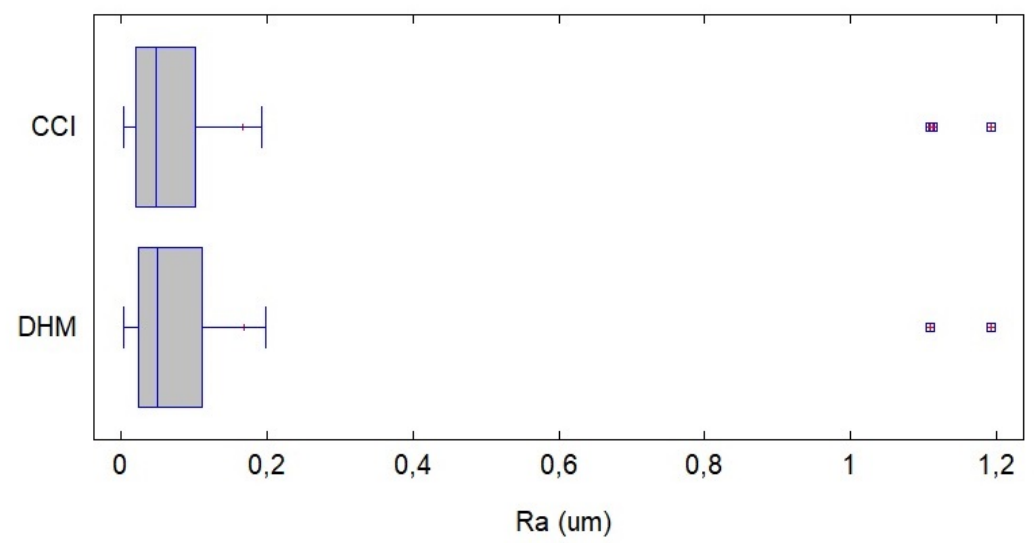

Figura 5.51 - Diagrama de extremos e quartis de DHM e CCI.

Na Tabela. 5.9 se mostra a média para DHM e CCI. Também mostra o erro padrão de cada média, que é uma medida da sua variabilidade na amostragem. O erro padrão é formado dividindo o desvio padrão combinado pela raiz quadrada do número de observações em cada nível. A tabela também exibe um intervalo em torno de cada média. Os intervalos exibidos atualmente são baseados no procedimento de menor diferença significativa (LSD) de Fisher. Eles são construídos de tal forma que, se dois meios forem iguais, seus intervalos se sobrepõem a 95,0 \% do tempo. 
Tabela 5.9 - Tabela das Médias com 95,0 \% de intervalos LSD

\begin{tabular}{cccccc}
\hline & Contagem & Média & $\begin{array}{c}\text { Erro padrão } \\
(\text { em conjunto })\end{array}$ & Limite inferior & Limite superior \\
\hline CCI & 30 & 0,1667 & 0,060 & 0,0806 & 0,2528 \\
\hline DHM & 30 & 0,1694 & 0,060 & 0,0833 & 0,2556 \\
\hline Total & 60 & 0,1681 & & & \\
\hline
\end{tabular}

A análise exibida na Tabela. 5.10 testa a hipótese nula de que os desvios padrão dentro de cada uma das duas variáveis, DHM e CCI, são iguais. De particular interesse é o valor P. Uma vez que o valor P é maior ou igual a 0,05, não há diferença estatisticamente significativa entre os desvios-padrão num nível de confiança de 95,0\%. Sendo que o P-Valor é de 0,99, pode-se afirmar que não existe diferença estatisticamente significativa entre os resultados obtidos a través da metodologia proposta neste trabalho que utiliza microscopia holográfica digital (DHM) para a determinação da Ra e os resultados obtidos a través do perfilômetro óptico 3D sem contato modelo CCI-MP (CCI).

Tabela 5.10 - Verificação da Variação

\begin{tabular}{ccc}
\hline & Teste & P-Valor \\
\hline Levene & 0,00013 & 0,99077 \\
\hline
\end{tabular}

Para definir o modelo que se ajusta aos valores obtidos através da DHM e o CCI foi realizada uma análise de regressão simples. Para esta análise se definem as variáveis como aparecem a seguir.

Variável Dependente: CCI

Variável Independente: DHM

A Tabela. D.4 do Apêndice D mostra os resultados da montagem de vários modelos curvilíneos aos dados. Dos modelos instalados, o modelo de duplo quadrado produz o valor R-Quadrado mais alto com 99,99 \%. Este é o modelo atualmente selecionado.

Duplo-quadrado: $Y=\sqrt{\left(a+b \cdot X^{2}\right)}$ 
Tabela 5.11 - Coeficientes

\begin{tabular}{ccccc}
\hline Parâmetro & $\begin{array}{c}\text { Estimativa dos } \\
\text { mínimos } \\
\text { quadrados }\end{array}$ & Erro padrão & T estatístico & P-Valor \\
\hline Intercepto & $-0,00045$ & 0,00040 & $-1,12$ & 0,2705 \\
\hline Declive & 1,00197 & 0,00099 & 1007,24 & 0,0000 \\
\hline
\end{tabular}

Tabela 5.12 - Análise de Variância

\begin{tabular}{cccccc}
\hline Fonte & $\begin{array}{c}\text { Soma dos } \\
\text { quadrados }\end{array}$ & Df & $\begin{array}{c}\text { Quadrado } \\
\text { médio }\end{array}$ & F-Valor & P-Valor \\
\hline Modelo & 4,51360 & 1 & 4,513600 & 1014522,94 & 0,0000 \\
\hline Resíduo & 0,00012 & 28 & 0,000004 & 0,0000 & \\
\hline Total (corr.) & 4,51372 & 29 & & & \\
\hline
\end{tabular}

Coeficiente de correlação $=0,99$

R-quadrado $=99,99 \%$

Erro padrão da Estimativa. = 0,002

Erro absoluto médio $=0,001$

A avaliação apresenta os resultados da montagem de um modelo duplo quadrado para descrever a relação entre CCI e DHM. A equação do modelo ajustado é:

$$
C C I=\sqrt{\left(-0,000458697+1,00197 \cdot D H M^{2}\right)}
$$

Uma vez que o valor P na tabela ANOVA é inferior a 0,05, existe uma relação estatisticamente significativa entre CCI e DHM num nível de confiança de 95,0 \%.

A estatística de R-Quadrado indica que o modelo conforme ajustado explica 99,9972 \% da variabilidade em CCI. O coeficiente de correlação é igual a 0,999986, indicando uma relação relativamente forte entre as variáveis. O erro padrão da estimativa mostra o desvio padrão dos resíduos em 0,002. Esse valor pode ser usado para construir limites de previsão para novas observações. O erro absoluto médio (MAE) de 0,001 é o valor médio dos resíduos. 


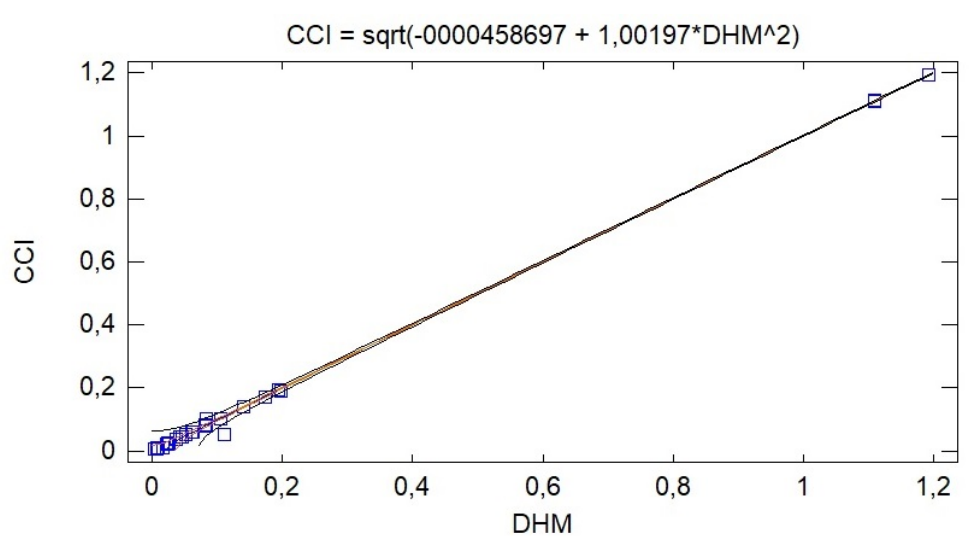

Figura 5.52 - Modelo ajustado

Análise estatística entre os valores da rugosidade superficial (Ra) obtidos através da metodologia proposta utilizando microscopia holográfica digital (DHM) e sua relação com o processo ou número de grau da lixa utilizada.

Para determinar se o processo de desbaste abrasivo tem uma influencia representativa sob a rugosidade superficial ( $\mathrm{Ra}$ ) se realiza uma análise estatística a partir da análise da variância.

Tabela 5.13 - Código na análise estatística.

\begin{tabular}{cc} 
Amostra & Fator \\
\hline 1 & Usinagem \\
\hline 2 & 180 \\
\hline 3 & 240 \\
\hline 4 & 360 \\
\hline 5 & 600 \\
\hline 6 & 1200 \\
\hline 7 & 1500 \\
\hline 8 & 2000 \\
\hline 9 & 2500 \\
\hline 10 & Polido \\
\hline
\end{tabular}

A análise da variância permite constatar a hipótese nula de que as médias das populações são iguais, frente à hipótese alternativa de que pelo menos uma destas populações difere das outras enquanto ao seu valor esperado. Este contraste é fundamental quando precisa-se 
comparar os resultados da rugosidade superficial Ra em relação à variável dependente ou de interesse.

As variáveis chamadas de "Processo ou número de lixa" ou "fator", correspondem ao acabamento da amostra segundo a Tabela. 5.13.

Os nove (9) valores da rugosidade superficial foram escolhidos aleatoriamente por amostra.

A análise de variância ANOVA realizada foi do tipo simples, onde a variável dependente e independente foram tomadas da seguinte maneira:

Variável dependente: Ra

Fator: Processo ou número da lixa

Número de observações: 9

Número de níveis: 10

Tabela 5.14 - Estatísticas resumidas da Ra.

\begin{tabular}{cccccccc}
\hline $\begin{array}{c}\text { Processo ou } \\
\text { número de lixa }\end{array}$ & Contagem & Média & $\begin{array}{c}\text { Desvío } \\
\text { Padrão }\end{array}$ & $\begin{array}{c}\text { Coeficiente } \\
\text { Variação }(\%)\end{array}$ & Mín. & Máx. & $\begin{array}{c}\text { Erro } \\
\text { Padrão }\end{array}$ \\
\hline Usinagem & 9 & 1,1390 & 0,0416 & 3,65 & 1,0910 & 1,1970 & 0,0138 \\
\hline 180 & 9 & 0,1155 & 0,0193 & 16,72 & 0,0916 & 0,1427 & 0,0064 \\
\hline 240 & 9 & 0,1879 & 0,0092 & 4,91 & 0,1726 & 0,1985 & 0,0030 \\
\hline 360 & 9 & 0,0683 & 0,0102 & 15,01 & 0,0596 & 0,0830 & 0,0034 \\
\hline 600 & 9 & 0,0420 & 0,0047 & 11,22 & 0,0357 & 0,0481 & 0,0015 \\
\hline 1200 & 9 & 0,0631 & 0,0152 & 24,18 & 0,0512 & 0,0875 & 0,0050 \\
\hline 1500 & 9 & 0,0250 & 0,0033 & 13,30 & 0,0202 & 0,0276 & 0,0011 \\
\hline 2000 & 9 & 0,0239 & 0,0025 & 10,46 & 0,0184 & 0,0276 & 0,0008 \\
\hline 2500 & 9 & 0,0086 & 0,0004 & 5,32 & 0,0082 & 0,0094 & 0,0001 \\
\hline Polido & 9 & 0,0055 & 0,0015 & 27,16 & 0,0042 & 0,0079 & 0,0005 \\
\hline Total & 90 & 0,1679 & 0,3301 & 196,60 & 0,0042 & 1,1970 & 0,0348 \\
\hline
\end{tabular}

Esta tabela apresenta vários valores estatísticos de Ra para cada um dos 10 níveis do processo ou número da lixa. A análise unidirecional da variância está destinada principalmente a comparar as médias dos diferentes níveis, que aqui se enumeram na coluna da Média.

Na Tabela. 5.15 aparece a relação da Assimetria, o que permite descrever a forma como os dados tendem a se reunir em correspondência com a frequência com que se encontram dentro da distribuição. A Kurtosis mede o grau de acuidade ou achatamento da distribuição em relação à distribuição normal. 
Tabela 5.15 - Assimetria e Kurtosis.

\begin{tabular}{ccc}
\hline $\begin{array}{c}\text { Processo ou } \\
\text { número de lixa }\end{array}$ & $\begin{array}{c}\text { Assimetria } \\
\text { Padrão }\end{array}$ & $\begin{array}{c}\text { Kurtosis } \\
\text { Padrão }\end{array}$ \\
\hline Usinagem & 0,47 & $-1,16$ \\
\hline 180 & 0,60 & $-0,96$ \\
\hline 240 & $-0,57$ & $-0,82$ \\
\hline 360 & 0,99 & $-1,02$ \\
\hline 600 & $-0,55$ & $-0,93$ \\
\hline 1200 & 1,04 & $-0,89$ \\
\hline 1500 & $-0,58$ & $-1,00$ \\
\hline 2000 & $-1,33$ & 1,76 \\
\hline 2500 & 1,01 & $-0,54$ \\
\hline Polido & 0,98 & $-0,94$ \\
\hline Total & 10,03 & 9,86 \\
\hline
\end{tabular}

A Tabela. 5.16 decompõe a variância da rugosidade Ra em dois componentes: um componente entre grupos e outro componente dentro dos grupos. F-razão, que é igual a 4174,87, neste caso, é uma proporção da estimativa entre grupos para a estimativa dentro dos grupos. Uma vez que a P-valor do teste $\mathrm{F}$ é inferior a 0,05, existe uma diferença estatisticamente significativa entre a média Ra de um nível de Processo ou número de lixa para outro, com um nível de confiança de 95,0\%.

Tabela 5.16 - ANOVA para Ra por Processo ou número de lixa.

\begin{tabular}{llllll}
\hline Fonte & $\begin{array}{l}\text { Soma dos } \\
\text { quadrados }\end{array}$ & Df & $\begin{array}{l}\text { Quadrado } \\
\text { Médio }\end{array}$ & F-razão & P-valor \\
\hline $\begin{array}{l}\text { Entre os } \\
\text { grupos }\end{array}$ & 9,68 & 9 & 1,0757 & 4174,87 & 0,0000 \\
\hline $\begin{array}{l}\text { Dentro dos } \\
\text { grupos }\end{array}$ & 0,02 & 80 & 0,0002 & & \\
\hline Total (Corr.) & 9,70 & 89 & 0 & & \\
\hline
\end{tabular}

A Figura. 5.53 apresenta o gráfico de dispersão por nível dos resultados experimentais da Rugosidade Superficial obtida através da metodologia proposta. No gráfico pode-se observar como uma variável afeta à outra. 


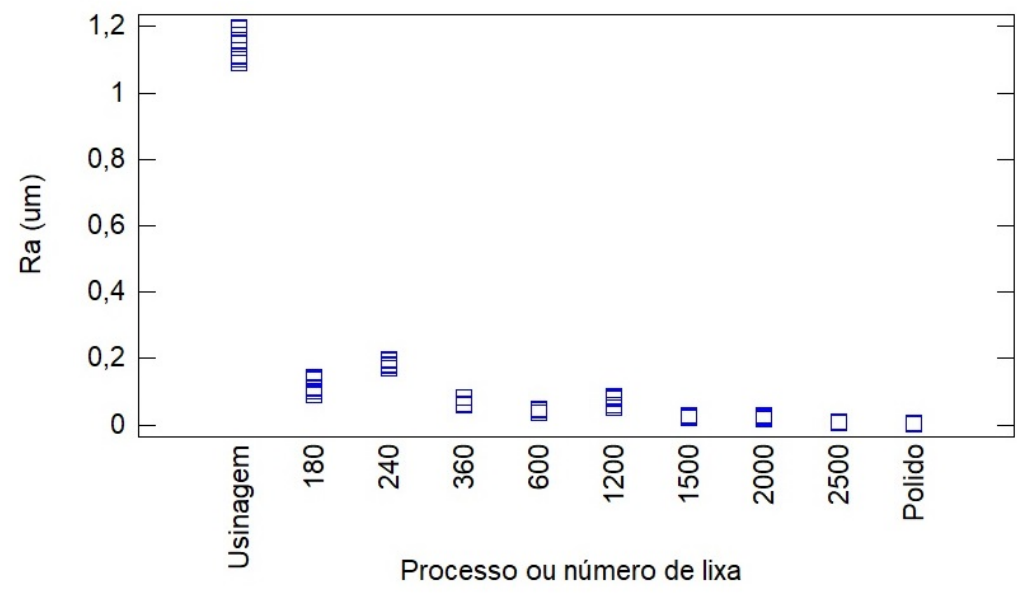

Figura 5.53 - Gráfico da Dispersão por Nível.

O diagrama de extremos e quartis da Figura. 5.54 representa a variação dos resultados por médio de quartis. Na variação dos valores nos processos ou número de lixa se identifica onde estão localizados $50 \%$ dos valores mais prováveis, a mediana e os valores extremos. Os espaços entre as diferentes partes da caixa indicam o grau de dispersão e a obliquidade nos valores da rugosidade superficial e sua variação através dos diferentes níveis.

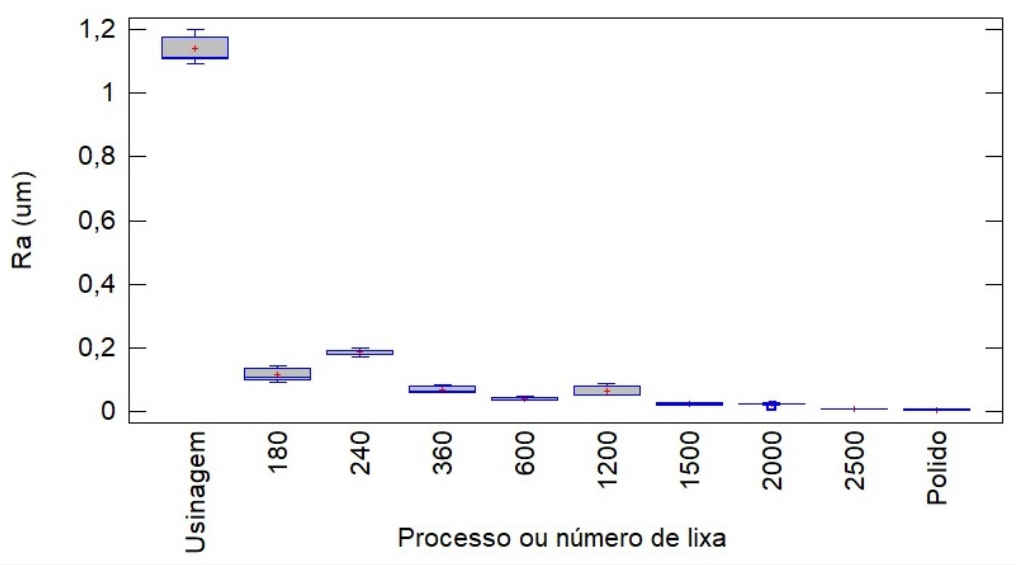

Figura 5.54 - Diagrama de extremos e quartis.

No Apêndice D uma análise de múltiplos testes de intervalo da rugosidade superficial e o processo ou número de lixa utilizado sao apresentados. Nesta análise se evidencia a influencia entre os próprios processos e números de lixa, destacando que quase todos os parâmetros possuem uma grande influência no resultado da rugosidade superficial. 
Por outro lado numa análise de regressão simples ou ajuste linear encontramos um modelo matemático para aproximar a relação de dependência entre a variável dependente e a variável independente expressado a seguir.

Regressão Simples: Ra vs. Processo ou número de lixa.

Variável dependente: Ra.

Variável independente: Processo ou número de lixa.

Raiz quadrada-Y recíproco-X modelo: $Y=(a+b / X)^{2}$

Tabela 5.17 - Coeficientes

\begin{tabular}{lcccc}
\hline Parâmetro & $\begin{array}{c}\text { Estimativa dos } \\
\text { mínimos } \\
\text { quadrados }\end{array}$ & Erro Padrão & T-Estatístico & P-Valor \\
\hline Intercepto & 0,0072 & 0,0113 & 0,6391 & 0,5244 \\
\hline Declive & 1,0111 & 0,0289 & 34,9326 & 0,0000 \\
\hline
\end{tabular}

Tabela 5.18 - Análise de Variância

\begin{tabular}{lccccc}
\hline \multicolumn{1}{c}{ Fonte } & $\begin{array}{c}\text { Soma dos } \\
\text { quadrados }\end{array}$ & Df & $\begin{array}{c}\text { Quadrado } \\
\text { médio }\end{array}$ & F-Razão & P-Valor \\
\hline Modelo & 6,3670 & 1 & 6,3670 & 1220,29 & 0,0000 \\
\hline Residual & 0,4591 & 88 & 0,0052 & & \\
\hline Total (Corr.) & 6,8226 & 89 & & & \\
\hline
\end{tabular}

Coeficiente de correlação $=0,96$.

R-quadrado $=93,27 \%$.

R-quadrado (ajustado para d.f.) $=93,20 \%$.

Erro padrão do Est. = 0,072.

Erro absoluto médio $=0,050$. 
Estatística de Durbin-Watson $=0,45(\mathrm{P}=0,0000)$.

Lag1 autocorrelação residual $=0,77$.

A avaliação amostra os resultados da montagem de um modelo de raiz quadrada-Y recíproco-X para descrever a relação entre Ra e o processo ou número da lixa (PL). A equação do modelo ajustado é:

$$
R a=(0,0072839+1,01118 / \mathrm{PL})^{2} .
$$

Uma vez que o valor P na tabela ANOVA é inferior a 0,05 , existe uma relação estatisticamente significativa entre Ra e processo ou número de lixa no nível de confiança de $95,0 \%$.

A estatística de R-Quadrado indica que o modelo conforme ajustado explica 93,27 \% da variabilidade em Ra. O coeficiente de correlação é igual a 0,96, indicando uma relação relativamente forte entre as variáveis. O erro padrão da estimativa mostra que o desvio padrão dos resíduos é de 0,07. Esse valor pode ser usado para construir limites de previsão para novas observações.

O erro absoluto médio (MAE) de 0,05 é o valor médio dos resíduos. A estatística Durbin-Watson (DW) testa os resíduos para determinar se existe uma correlação significativa com base na ordem em que eles ocorrem em seu arquivo de dados. Uma vez que o valor P é inferior a 0,05, há uma indicação de correlação serial no nível de confiança de $95,0 \%$.

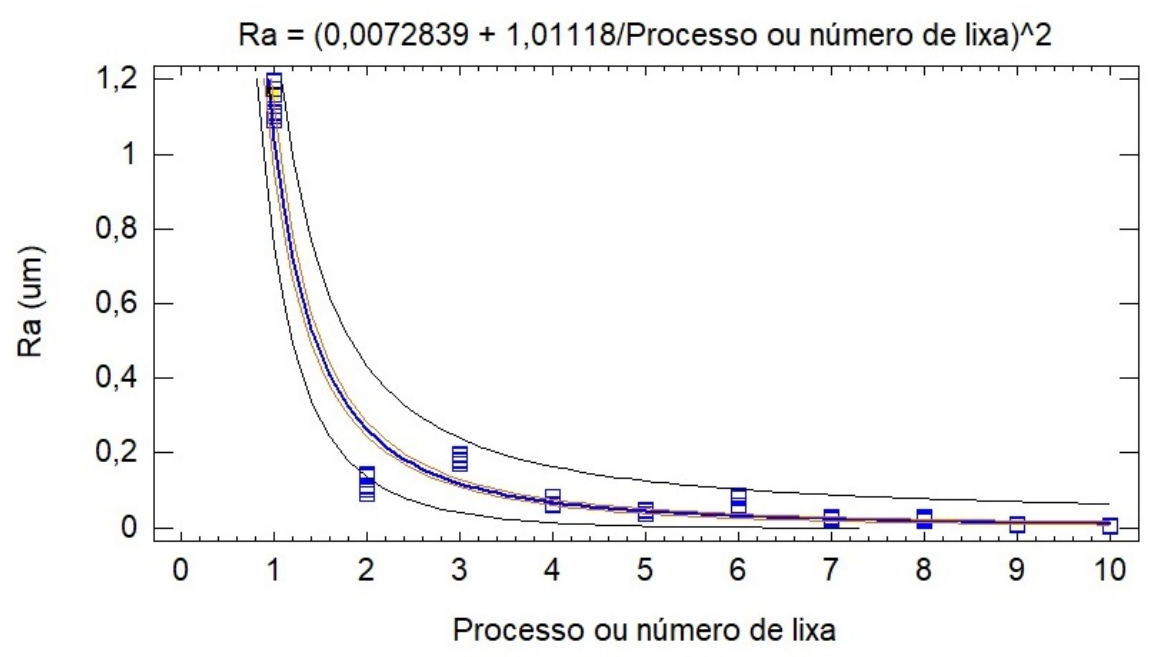

Figura 5.55 - Modelo ajustado. 


\section{Conclusões e Recomendações}

No presente trabalho se realizou o projeto e a montagem de uma instalação de microscopia holográfica digital por reflexão, utilizando objetos de contorno definido. O arranjo com base no esquema de um interferômetro de Michelson permitiu a obtenção dos hologramas dos mesmos e a reconstrução numérica das imagens através do programa Holodig, que por sua vez, foi preparado para realizar uma análise dimensional destes objetos. A obtenção de parâmetros como comprimento, largura e dimensões de características específicas ou defeitos da superfície são realizados de forma simples e rápida. As medições repetidas no programa ImageJ apresentaram resultados semelhantes ao do programa Holodig, validando assim os resultados aqui obtidos.

A técnica proposta utilizando um único holograma permitiu determinar a rugosidade superficial nas amostras de aço 1010.

O algoritmo desenhado para a reconstrução numérica das imagens permitiu através das diferenças de contaste de fase em 3D, medir a rugosidade superficial das amostras de uma forma rápida e simples. A nova técnica utilizando microscopia holográfica digital por reflexão permite obter resultados nos três eixos, a partir da imagem de contraste de fase reconstruída, fornecendo assim, a obtenção de uma maior quantidade de informação da superfície que a obtida através dos métodos convencionais.

Os resultados obtidos através do perfilômetro óptico 3D sem contacto confirmam a existência da fidelidade dos resultados da nova técnica.

A análise estatística realizada comparando ambas as técnicas indica que não há diferença significativa entre a os resultados obtidos utilizando a técnica holográfica e o perfilômetro. O modelo matemático ajusta os valores da DHM e o CCI, assim como a equação que define a relação entre ambos.

A outra análise estatística realizada para determinar a influência do processo ou número de lixa sobre a rugosidade superficial revela que existe diferença estatisticamente significativa entre a média de ambas variáveis. A equação do modelo ajustado explica a variabilidade da Ra.

A técnica proposta consegue realizar medições de uma maneira rápida e precisa. Os elementos necessários para o seu desenvolvimento são simples, o que faz dela uma boa proposta como alternativa para medir rugosidade superficial e controle dimensional de objetos.

Pela qualidade da técnica, recomenda-se sua adaptação futura para realizar medições fora do laboratório, mediante o desenvolvimento de um cabeçote que contenha os elementos necessários. 


\section{Referências}

ABDELSALAM, D.; BAEK, B. J.; KIM, D. Influence of the collimation of the reference wave in off-axis digital holography. Optik - International Journal for Light and Electron Optics, v. 123, n. 16, p. $1469-1473,2012$.

ALVAREZ, A. A. Análise e modelagem da delaminação de materiais compósitos no processo de furação. Tese (Doutorado), 2015.

BENTON, S. (Ed.). White Light Transmission/Reflection Holographic Image. [S.1.: s.n.], 1976.

BERND, J. Digital Image Processing. [S.1.]: Springer, 2005. ISBN 9783540240358.

COCHRAN, G. New method of making fresnel transforms with incoherent light. . Opt. Soc. Am., v. 56, p. 1513, 1966.

COLOMB., T.; CUCHE, E.; DAHLGREN, P.; MARIAN, A. M.; MONTFORT, F.; DEPEURSINGE, C. D.; MARQUET, P.; MAGISTRETTI, P. J. 3d imaging of surfaces and cells by numerical reconstruction of wavefronts in digital holography applied to transmission and reflection m icroscopy. I n : 2002 I EEE I NTERNATIONAL SYMPOSIUM ON BIOMEDICAL IMAGING, PROCEEDINGS. [S.l.]: IEEE, 2002. p. 773-776. ISBN 0-7803-7584-X.

CUCHE, E.; MARQUET, P.; DEPEURSINGE, C. Simultaneous amplitude-contrast and quantitative phase-contrast microscopy by numerical reconstruction of fresnel off-axis holograms. Appl. Opt., OSA, v. 38, n. 34, p. 6994-7001, Dec 1999.

CUCHE, E.; MARQUET, P.; DEPEURSINGE, C. Aperture apodization using cubic spline interpolation :application in digital holographic microscopy. Optics Communications, n. 182, p. 59-69, 2000.

DAVIM, J. P.; RUBIO, J. C.; ABRAO, A. A novel approach based on digital image analysis to evaluate the delamination factor after drilling composite laminates. Composites Science and Technology, v. 67, n. 9, p. 1939-1945, 2007. ISSN 0266-3538.

DEPEURSINGE, C.; CUCHE, E.; MARQUET, P.; COLOMB, T.; DAHLGREN, P.; MARIAN, A.; MONTFORT, F.; MAGISTRETTI, P. Digital holography applied to microscopy. In: PRACTICAL HOLOGRAPHY XVI AND HOLOGRAPHIC MATERIALS VIII. [S.l.]: SPIE-INT SOC OPTICAL ENGINEERING, 2002. 4659, p. 30-34. ISBN 0-8194-4399-9. ISSN 0277-786X.

DOMINGUEZ C.; HERAS, J. P. V. Ij-opencv: Combining imagej and opencv for processing images in biomedicine. Computers in Biology and Medicine, v. 84, p. 189 - 194, 2017. ISSN 0010-4825. 
FERRARO, P.; NICOLA, S. D.; FINIZIO, A.; COPPOLA, G.; GRILLI, S.; MAGRO, C.; PIERATTINI, G. Compensation of the inherent wave front curvature in digital holographic coherent microscopy for quantitative phase-contrast imaging. Appl. Opt., OSA, v. 42, n. 11, p. 1938-1946, Apr 2003.

FOLEY, J. D.; DAM, A. van; FEINER, S. K.; HUGHES, J. F. Computer Graphics: Principles and Practice in C. 2. ed. [S.1.]: Addison-Wesley Professional, 1996. ISBN 978-0201848403.

GABOR, D. Microscopy by reconstructed wavefronts. Proc. Roy. Soc. A197, n. 154, 1949.

GESUALDI, M. R. R.; BRITO, I. V.; RICARDO, J.; PALACIOS, F. F.; MURAMATSU, M.; VALIN, J. Photorefractive digital holographic microscopy applied in microstructures analysis. Optics Comunications, v. 286, p. 103-110, 2013.

GHIGLIA, D. C.; MASTIN, G. A.; ROMERO, L. A. Cellular-automata method for phase unwrapping. J. Opt. Soc. Am., v. 4, n. 1, p. 267-280, 1987.

GILlES, J.-F.; SANTOS, M. D.; BOUDIER, T.; BOLTE, S.; HECK, N. D. An imagej tool for object-based 3d co-localization and distance analysis. methods. Image Processing for Biologists., v. 115, p. 55 - 64, 2017. ISSN 1046-2023.

GONZALEZ, R. C.; WOODS, R. E. Digital Image Processing. 2. ed. [S.l.: s.n.], 2002. ISBN 10: 0201180758.

GONZÁLEZ, C. G.; VÁZQUEZ, J. R. Z. Metrologia. [S.l.: s.n.], 1995. ISBN 9701003705 .

HALLIDAY, D.; RESNICK, R.; WALKER, J. Fundamentals of Physics. 10. ed. [S.l.]: Wiley, 2013. 1440 p.

JUNIOR, R. B. D. R. F. Introdução a microscopia holográfica digital. 2014.

KREIS, T. Handbook of Holographic Interferometry: Optical and Digital Methods. [S.l.: s.n.], 2005.

LEITH, E.; UPATNIEKS, J. Reconstructed wavefronts and communication theory. J. Opt. Soc. Am., v. 53, p. 1123-1130, 1962.

LEITH, E.; UPATNIEKS, J. Wavefront reconstruction with continous-tone objects. $J$. Opt. Soc. Am., v. 53, p. 1377-1381, 1963.

LEITH, E.; UPATNIEKS, J. Wavefront reconstruction with diffused illumination of three-dimensional objects. J. Opt. Soc. Am., v. 54(11), p. 1295-1301, 1964.

LIANG, H.; CID, M. G.; CUCU, R. G.; DOBRE, G. M.; PODOLEANU, A. G.; PEDRO, J.; SAUNDERS, D. En-face optical coherence tomography - a novel application of non-invasive imaging to art conservation. Opt. Express, OSA, v. 13, n. 16, p. 6133-6144, Aug 2005. 
LOPEZ, M. Microscopia Holográfica Digital Aplicada na Análise de Tecidos Biológicos. Tese (Doutorado), 2012.

MATRECANO, M.; MICCIO, L.; PERSANO, A.; QUARANTA, F.; SICILIANO, P.; FERRARO, P. Automatic digital filtering for the accuracy improving of a digital holographic measurement system. SPIE-INT SOC OPTICAL ENGINEERING, 9132, 2014 .

MONTEIRO, J. Métodos de Interferometria para Inspecção Não Destrutiva. Tese (Doutorado), 2012.

PAGLIARULO, V.; RUSSO, T.; MICCIO, L.; FERRARO, P. Numerical tools for the characterization of microelectromechanical systems by digital holographic microscopy. JOURNAL OF MICRO-NANOLITHOGRAPHY MEMS AND MOEMS, SPIE-SOC PHOTO-OPTICAL INSTRUMENTATION ENGINEERS, 14, n. 4, OCT 2015.

PALACIOS, F.; FONT, O.; RICARDO, J.; PALACIOS, G.; MURAMATSU, M.; SOGA, D.; PALACIOS, D.; VALIN, J.; MONROY, F. Alternative reconstruction method and object analysis in digital holographic microscopy. In: Advanced holography -Metrology and imaging. [S.l.]: Intech, 2011. ISBN 9789533077291.

PALACIOS, F.; GONÇALVES, E.; RICARDO, J.; VALIN, J. L. Adaptive filter to improve the performance of phase-unwrapping in digital holography. Optics Communications, v. 238, p. 245 - 251, 2004.

PAWLEY, J. B. Handbook of Biological Confocal Microscopy. [S.l.: s.n.], 2006. ISBN 9780387259215.

PETERS, P. J. Incoherent holograms with mercury light source. Appl. Phys. lett., n. 8, p. 209-210, 1966.

PIEDRAHITA-QUINTERO P.; GARCIA-SUCERQUIA, J. Off-axis digital holography simulation in imagej. Optik - International Journal for Light and Electron Optics, v. 140,

p. $626-633,2017$. ISSN 0030-4026. .

SANG, X.; YU, C.; YU, M.; HSU, D. Applications of digital holography to measurements and optical characterization. Optical Engineering, v. 50, n. 9, p. 091311-091311-8, 2011.

SCHNARS, U.; JUPTNER, W. irect recording of holograms by a ccd target and numerical reconstruction. Applied Optics, v. 33(2), p. 179-181, 1994.

SCHNARS, U. A. K.; JUPTNER, W. Digital recording and numerical reconstruction of holograms: Reduction of the spatial frequency spectrum. Optical Engineering, v. 35(4), p. 977-982, 1996.

SOILLE, P. Morphological phase unwrapping. Optics and Laser in Engineering, v. 4, n.32, p. 339 - 354, 1999. 
SOKOLOV, P.; BELOUSOV, M.; BONDAREV, S.; ZHOURAVLEVA, G.; KASYANENKO, N. Fibrilj: Imagej plugin for fibrils' diameter and persistence length determination. Computer Physics Communications, v. 214, p. 199 - 206, 2017. ISSN 0010-4655.

TAVIO, I.; VELOZ, R.; CALZADO, L. S.; ROQUE, G. P. Ventajas de la microscopia holográfica digital para el estudio de muestras biológicas. Scielo, v. 21, p. 74 - 82, 012017.

VÁZQUEZ, A. B. "holografÍa: Generalidades". fundamentos de Óptica para ingeniería informática. Servicio de Publicaciones de la Universidad de Alicante, 1996.

WALBORN, S. Interferência da luz, arte e computação. Ciência e Cultura, v. 67, p. 38 -43, 09 2015. ISSN 0009-6725.

ZHANG, H.; TAN, Q.; JIN, G. Holographic display system of a three-dimensional image with distortion-free magnification and zero-order elimination. Optical Engineering, v. 51, n. 7, p. 075801, 2012. 
Apêndices 


\section{APÊNDICE A - Algoritmo para o cálculo da rugosidade superficial Ra.}

A seguir se apresenta o algoritmo introduzido no programa Holodig para o cálculo da rugosidade superficial, a partir da imagem de contraste de fase 3D. 


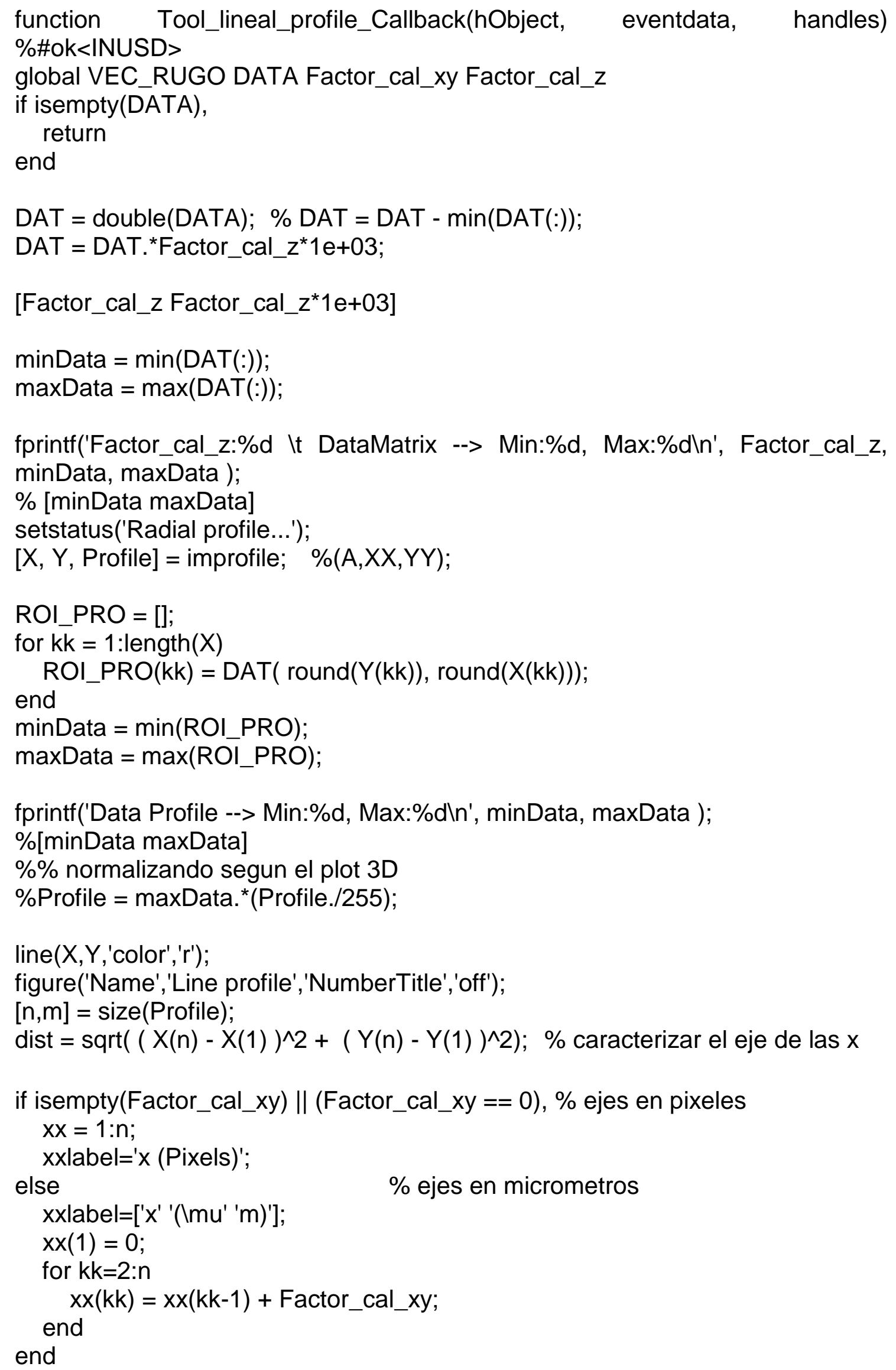


\%plot(xx,ROI_PRO,'color','black');

plot(xx,ROI_PRO - mean(ROI_PRO),'color','black');

xlabel(xxlabel)

ylabel('Profile')

[rugReal, mnDst, stdDst] = getRugosidad(ROI_PRO);

nMeasures = size (VEC_RUGO, 1);

newRog $=\operatorname{sum}\left(\operatorname{abs}\left(\mathrm{ROI} \_\mathrm{PRO}\right)\right) . /($ dist*Factor_cal_xy);

VEC_RUGO(nMeasures+1,:) = [nM̄easures+1 dist rugReal rugReal./Factor_cal_xy newRog]

setstatus('Ready'); 


\section{APÊNDICE B - Resultados da rugosidade superficial do Perfilometro óptico 3D sem contacto CCI.}

A seguir se apresentam os datos obtidos das medições realizadas através do CCI. 


\section{PROFILE EXTRACTION}

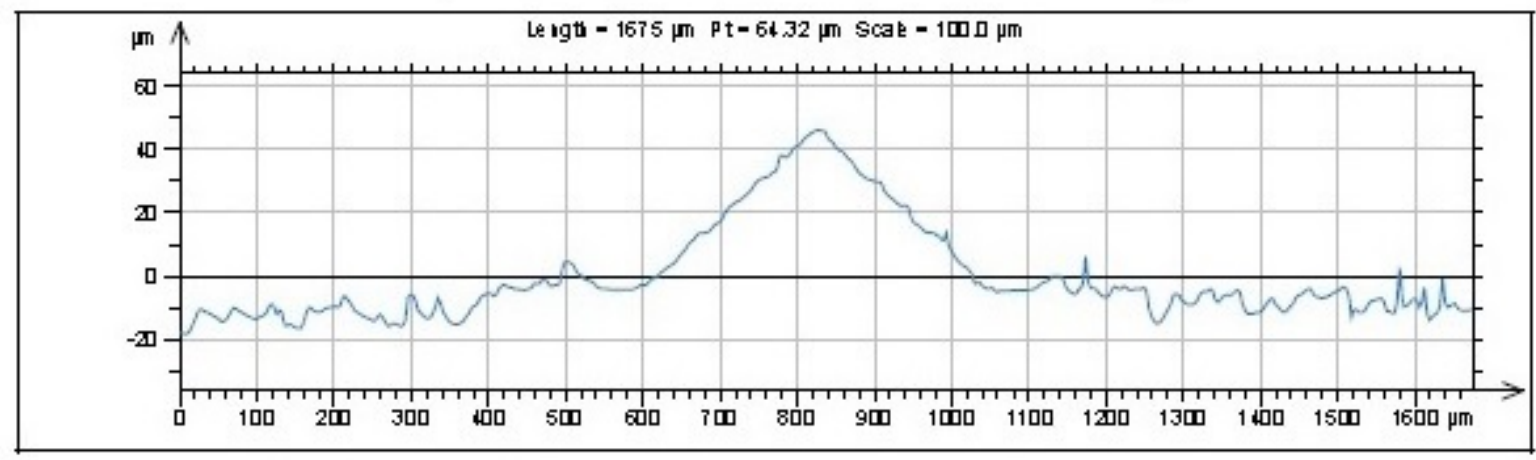

Figura B.1 - Amostra 1 Região 1 Perfil da Superfície.

\begin{tabular}{|c|c|c|}
\hline \multicolumn{3}{|l|}{ ISO 4287 } \\
\multicolumn{3}{|l|}{ Amplitude parameters - R ou } \\
\hline Rp & 3.299 & $\mu m$ \\
\hline Ru & 2.159 & $\mu m$ \\
\hline Rz & 5.457 & $\mu m$ \\
\hline Ro & 4.872 & $\mu m$ \\
\hline R.t & 15.62 & $\mu m$ \\
\hline Ra & 1.109 & $\mu m$ \\
\hline Rq & 1.407 & $\mu m$ \\
\hline Rsk & 0.6088 & \\
\hline Rku & 3.623 & \\
\hline
\end{tabular}

Figura B.2 - Relação dos parâmetros obtidos da Amostra 1 Região 1.

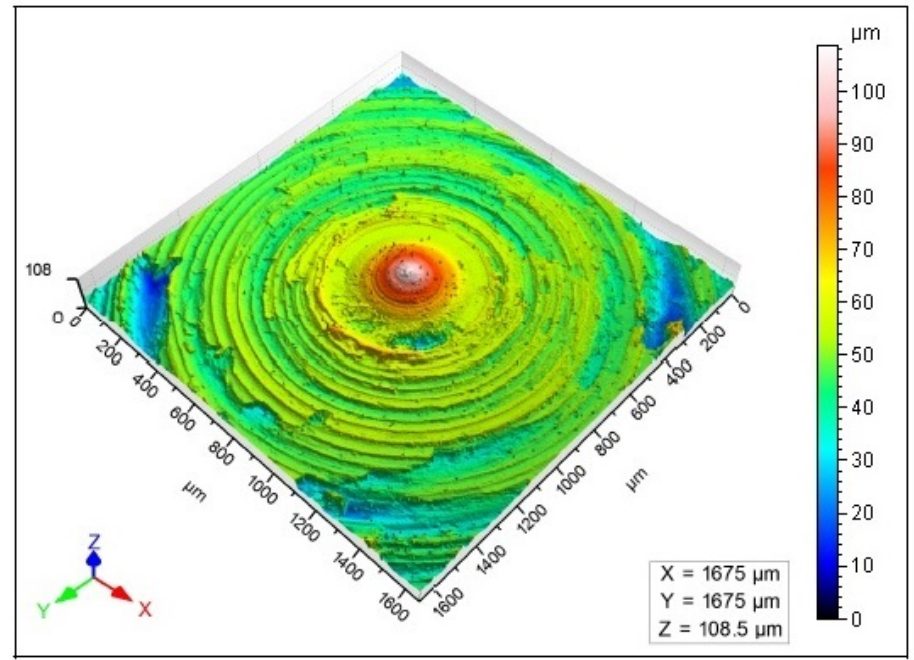

Figura B.3 - Amostra 1 Região 1 Resultados em 3D. 


\section{PROFILE EXTRACTION}

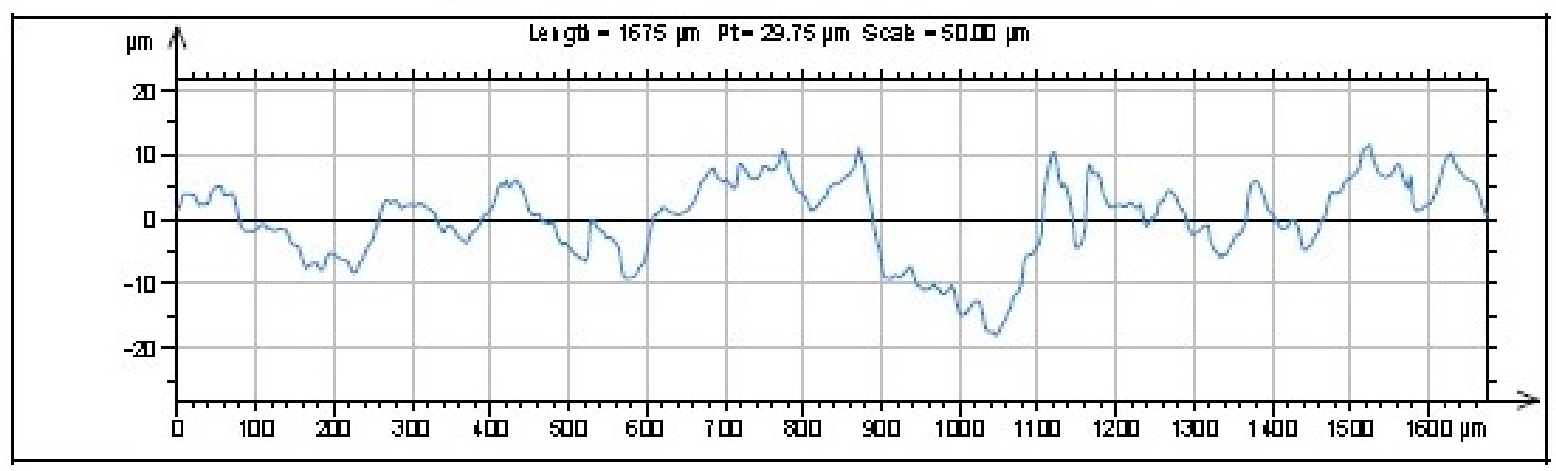

Figura B.4 - Amostra 1 Região 2 Perfil da Superfície.

\begin{tabular}{|c|c|c|}
\hline \multicolumn{3}{|c|}{1504287} \\
\hline \multicolumn{3}{|c|}{ Amplitude parameters - Rou } \\
\hline Fp & 2.618 & $\mu \mathrm{m}$ \\
\hline Rv & 2.248 & $\mu m$ \\
\hline $\mathrm{F} z$ & 4.866 & $\mu m$ \\
\hline $\mathrm{Roc}$ & 3.535 & $\mu \mathrm{m}$ \\
\hline Rit & 11.61 & $\mu m$ \\
\hline $\mathrm{Ra}$ & 1.112 & $\mu m$ \\
\hline Rog & 1.357 & $\mu m$ \\
\hline Rsk & 0.1771 & \\
\hline Ritas & 2.474 & \\
\hline
\end{tabular}

Figura B.5 - Relação dos parâmetros obtidos da Amostra 1 Região 2.

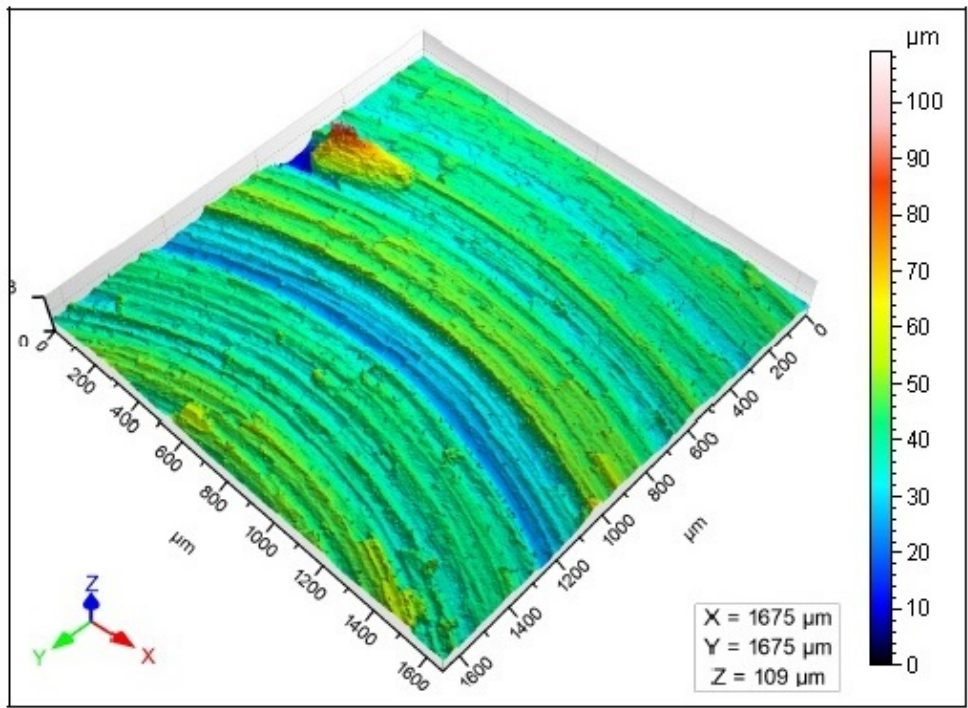

Figura B.6 - Amostra 1 Região 2 Resultados em 3D. 


\section{PROFILF EXTRACTION}

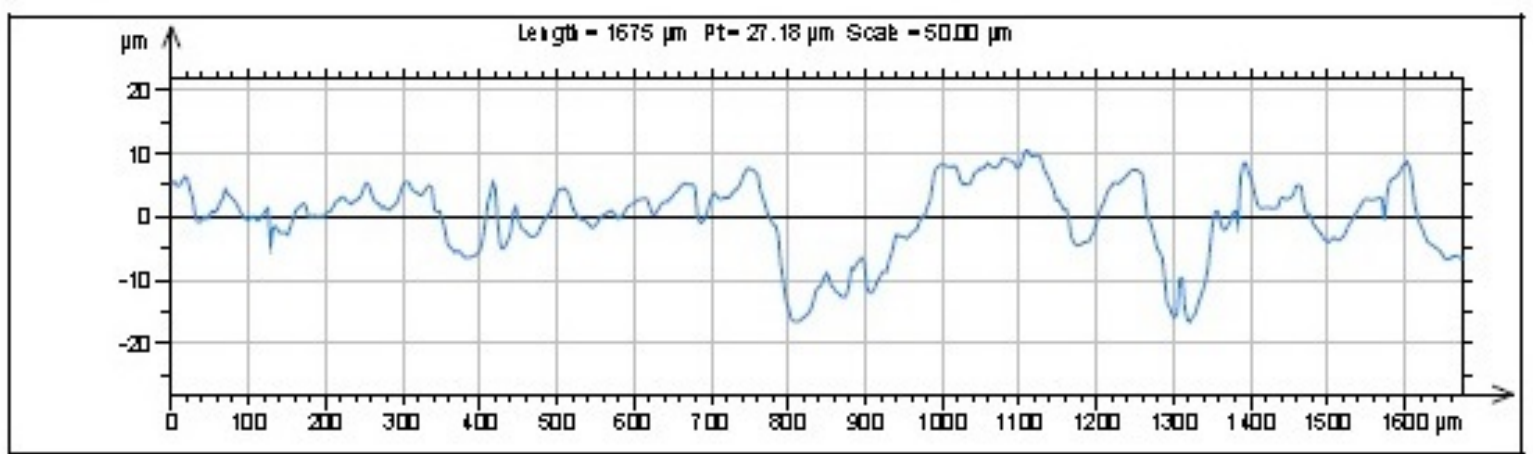

Figura B.7 - Amostra 1 Região 3 Perfil da Superfície.

\begin{tabular}{|c|c|c|}
\hline \multicolumn{3}{|c|}{ ISO 4287} \\
\hline \multicolumn{3}{|c|}{ Amplitude parameters - Rou } \\
\hline Fp & 2.870 & $\mu m$ \\
\hline Ru & 2.527 & $\mu m$ \\
\hline $\mathrm{Rz}$ & 5.397 & $\mu m$ \\
\hline $\mathrm{Roc}$ & 4.352 & $\mu m$ \\
\hline $\mathrm{Ft}_{\mathrm{t}}$ & 10.74 & $\mu m$ \\
\hline $\mathrm{Ra}$ & 1.192 & $\mu m$ \\
\hline Fig & 1.460 & $\mu m$ \\
\hline Rsk & 0.3250 & \\
\hline Rita & 2.613 & \\
\hline
\end{tabular}

Figura B.8 - Relação dos parâmetros obtidos da Amostra 1 Região 3.

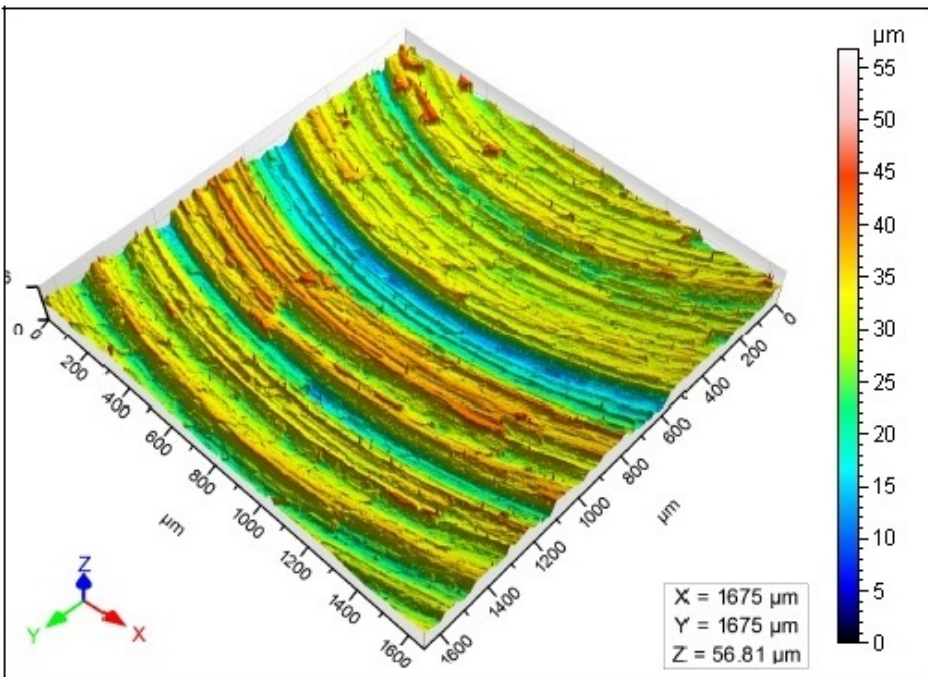

Figura B.9 - Amostra 1 Região 3 Resultados em 3D. 


\section{PROFILE EXTRACT ION}

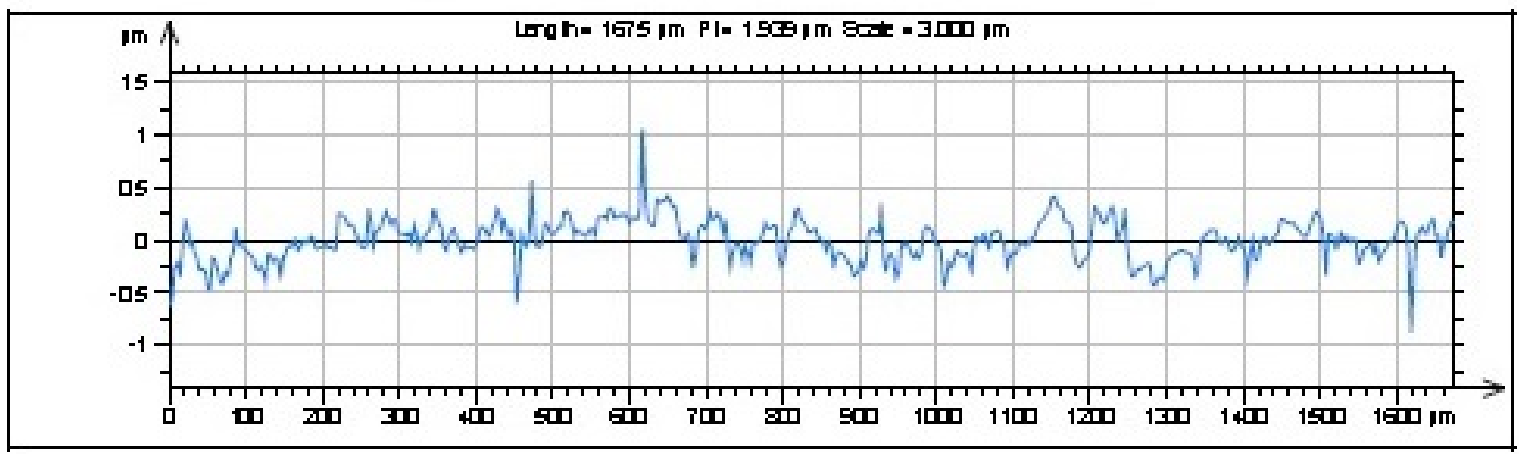

Figura B.10 - Amostra 2 Região 1 Perfil da Superfície.

\begin{tabular}{|c|c|c|}
\hline \multicolumn{3}{|c|}{1504287} \\
\hline \multicolumn{3}{|c|}{ Ampitude paramete rs - Rois } \\
\hline P & 0.2503 & $\mu m$ \\
\hline RV & Q.3ण0 & $\mu m$ \\
\hline$R 2$ & 0.550 & $\mu m$ \\
\hline 踚 & 0.3210 & $\mu \pi$ \\
\hline Rt & $1 \square 11$ & $\mu \mathrm{m}$ \\
\hline Pit & 0.1016 & $\mu m$ \\
\hline 问 & 0.1313 & $\mu m$ \\
\hline RII & -03232 & \\
\hline PिU & 3.791 & \\
\hline
\end{tabular}

Figura B.11 - Relação dos parâmetros obtidos da Amostra 2 Região 1.

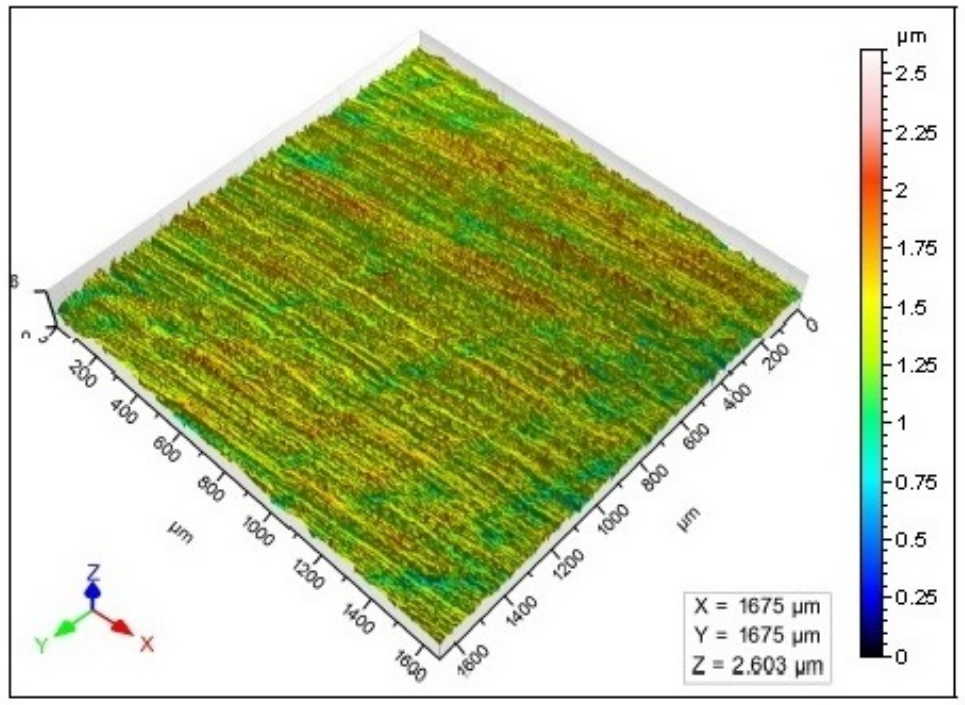

Figura B.12 - Amostra 2 Região 1 Resultados em 3D. 


\section{PROFILE EXTRACTION}

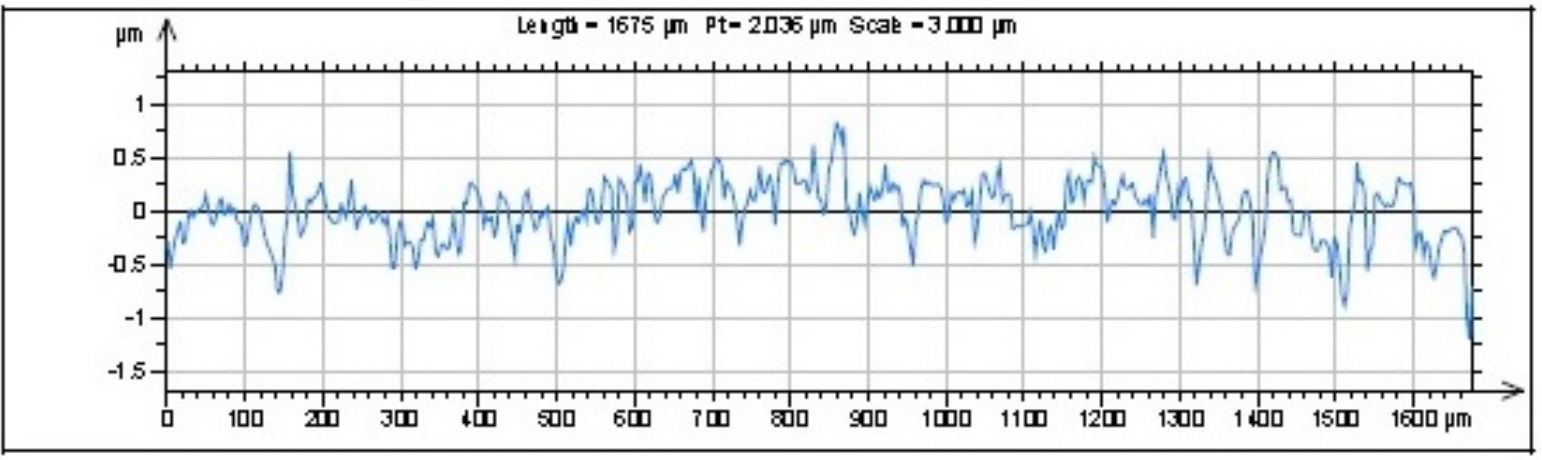

Figura B.13 - Amostra 2 Região 2 Perfil da Superfície.

\begin{tabular}{|c|c|c|}
\hline \multicolumn{3}{|c|}{ ISO 4287} \\
\hline \multicolumn{3}{|c|}{ Amplitude parameters - Rous } \\
\hline $\mathrm{Fp}$ & 03233 & $\mu m$ \\
\hline Rv & 0,3951 & $\mu m$ \\
\hline Rz & 0.7183 & $\mu \mathrm{m}$ \\
\hline $\mathrm{Ric}$ & 0.4466 & $\mu \mathrm{m}$ \\
\hline Fit & 1332 & $\mu m$ \\
\hline $\mathrm{Ra}$ & 0.1409 & $\mu \mathrm{m}$ \\
\hline Rig & 0.1773 & $\mu m$ \\
\hline Rsk & -0.3532 & \\
\hline Ritas & 3.107 & \\
\hline
\end{tabular}

Figura B.14 - Relação dos parâmetros obtidos da Amostra 2 Região 2.

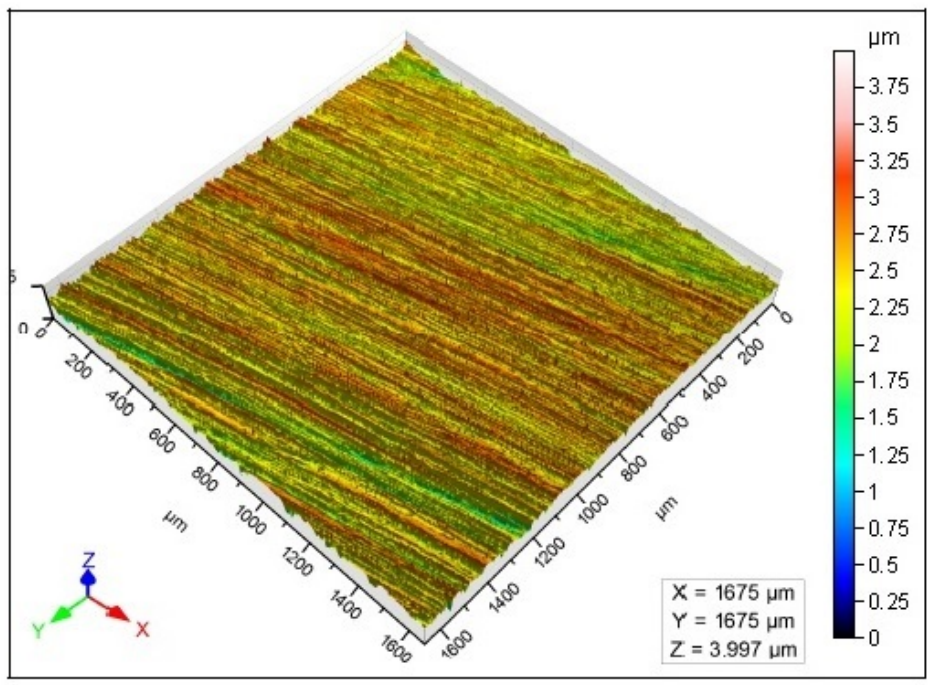

Figura B.15 - Amostra 2 Região 2 Resultados em 3D. 


\section{PROFILF EXTRACTION}

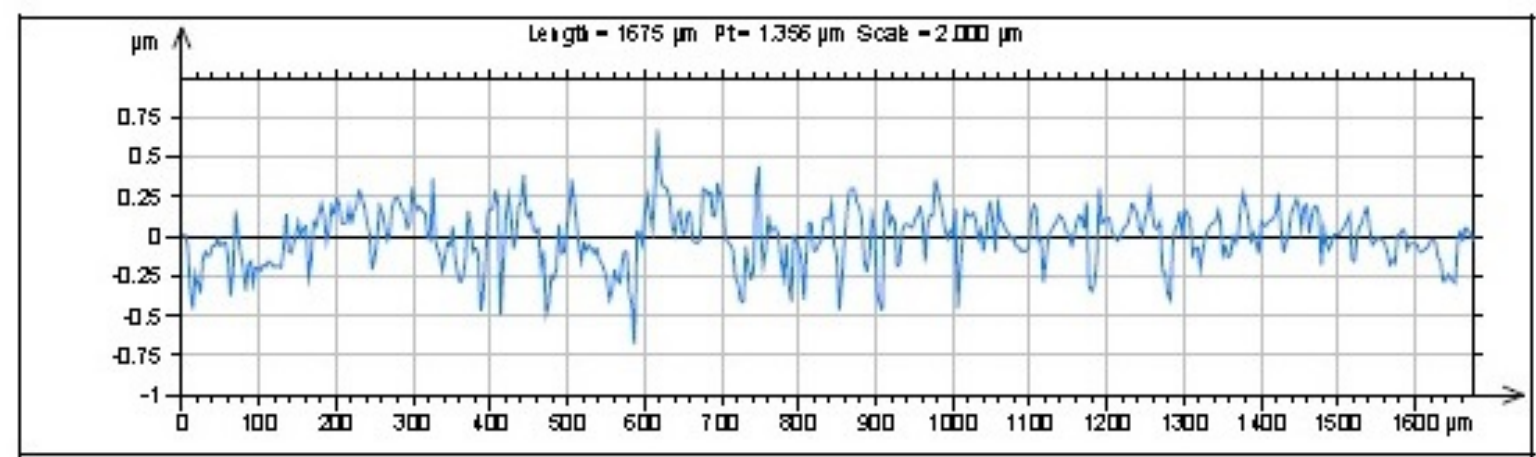

Figura B.16 - Amostra 2 Região 3 Perfil da Superfície.

\begin{tabular}{|c|c|c|}
\hline \multicolumn{3}{|c|}{ ISO 4287} \\
\hline \multicolumn{3}{|c|}{ Amplitude parameters - Roug } \\
\hline Fp & 02548 & $\mu m$ \\
\hline Ru & 0.3083 & $\mu m$ \\
\hline Rzz & 05631 & $\mu m$ \\
\hline $\mathrm{Ric}$ & 0,3332 & $\mu m$ \\
\hline Ft & 1013 & $\mu m$ \\
\hline $\mathrm{Rà}$ & 0.1024 & $\mu m$ \\
\hline Rig & 0.1321 & $\mu m$ \\
\hline Rsk & -03242 & \\
\hline Ritas & 3.796 & \\
\hline
\end{tabular}

Figura B.17 - Relação dos parâmetros obtidos da Amostra 2 Região 3.

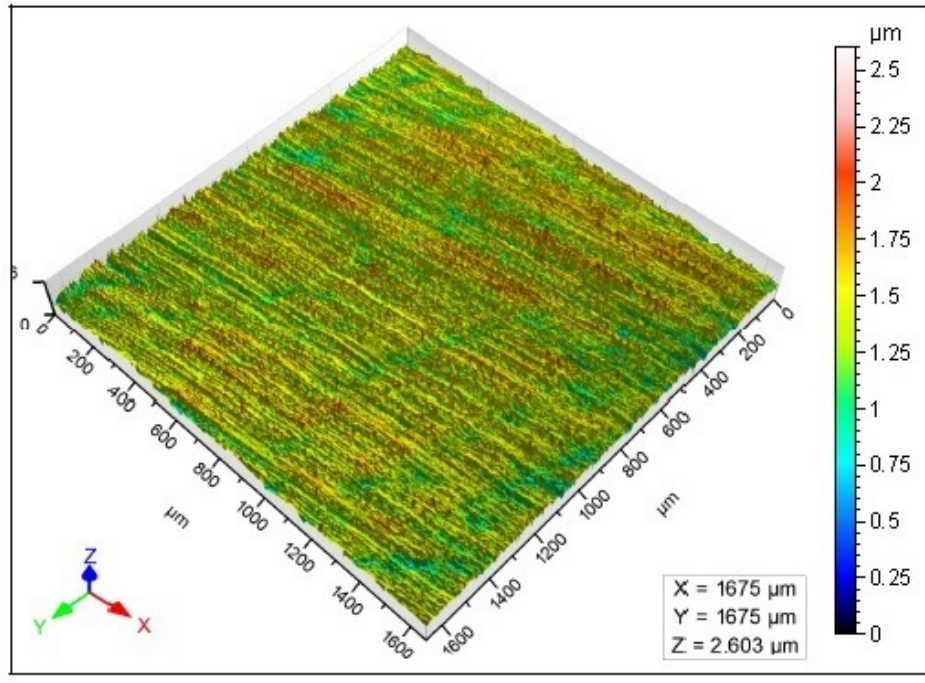

Figura B.18 - Amostra 2 Região 3 Resultados em 3D. 


\section{PROFILF EXTRACTION}

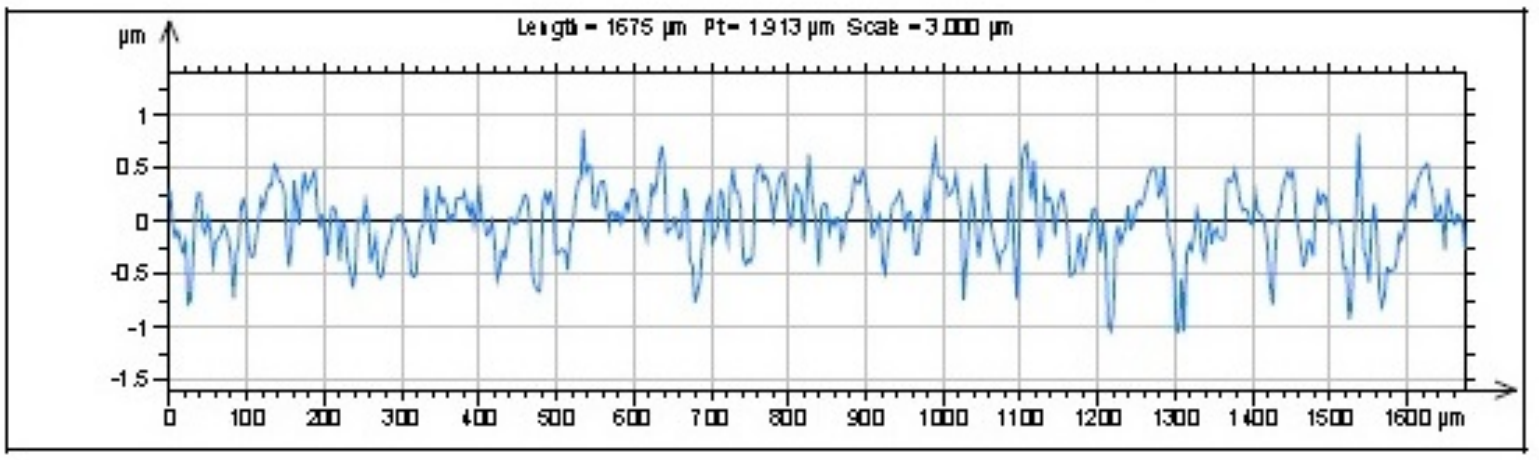

Figura B.19 - Amostra 3 Região 1 Perfil da Superfície.

\begin{tabular}{|c|c|c|}
\hline \multicolumn{3}{|c|}{ ISO 4287} \\
\hline \multicolumn{3}{|c|}{ Amplitude parameters - Roug } \\
\hline Fp & 0.4327 & $\mu m$ \\
\hline $\mathrm{R}$ & 0.5457 & $\mu m$ \\
\hline Fz & 09784 & $\mu \mathrm{m}$ \\
\hline Ric & 0.6033 & $\mu m$ \\
\hline Ft & 1827 & $\mu \mathrm{m}$ \\
\hline $\mathrm{Ra}$ & 0.1921 & $\mu \mathrm{m}$ \\
\hline Rig & 02413 & $\mu \mathrm{m}$ \\
\hline Rsk & -0.3723 & \\
\hline Ritas & 3243 & \\
\hline
\end{tabular}

Figura B.20 - Relação dos parâmetros obtidos da Amostra 3 Região 1.

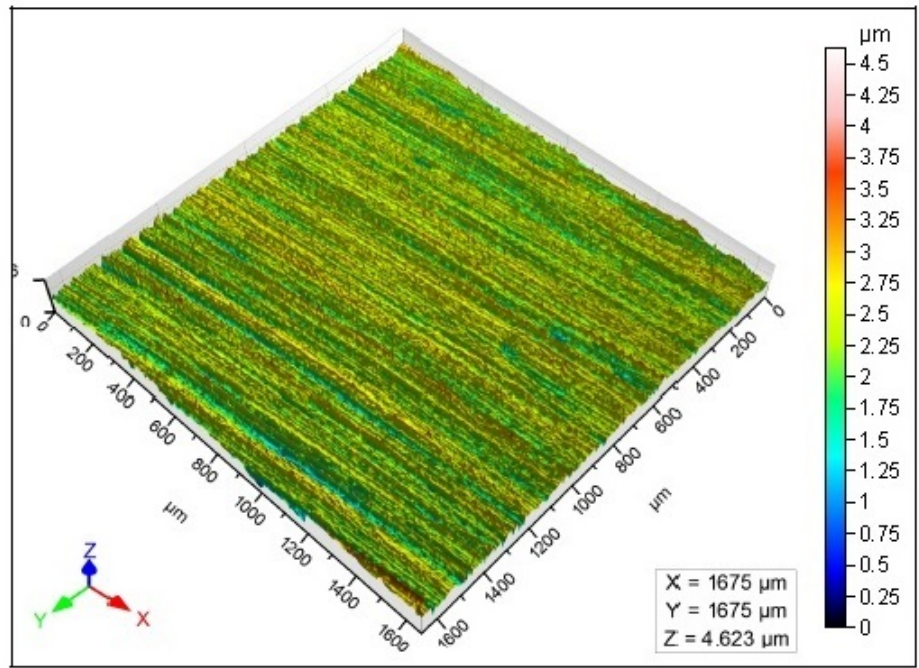

Figura B.21 - Amostra 3 Região 1 Resultados em 3D. 


\section{PROFILE EXTRACTION}

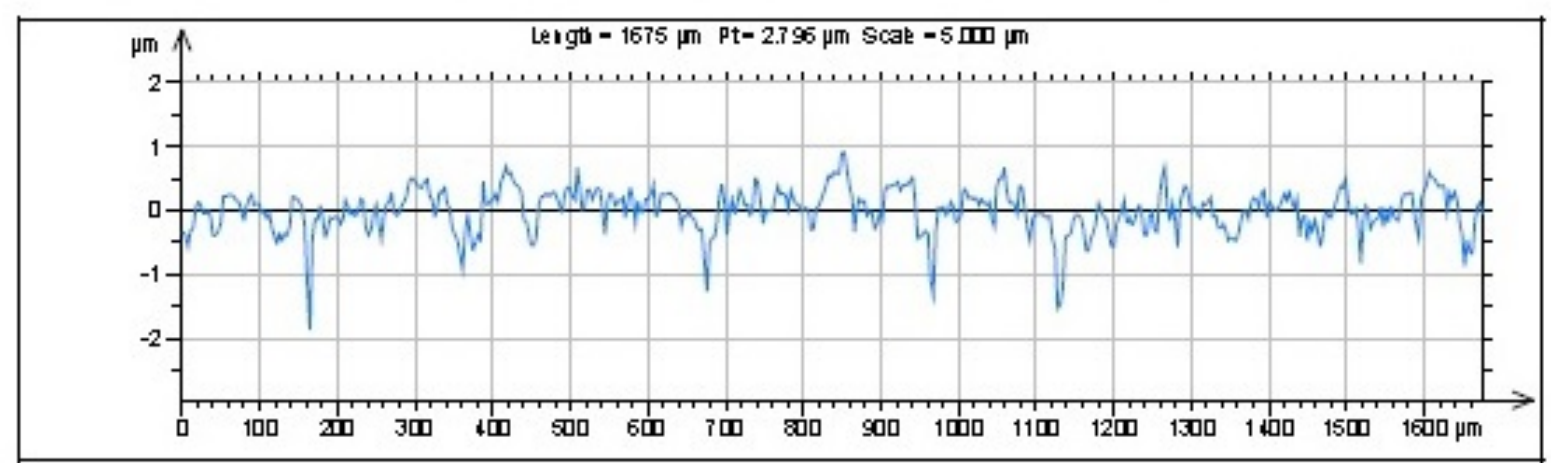

Figura B.22 - Amostra 3 Região 2 Perfil da Superfície.

\begin{tabular}{|c|c|c|}
\hline \multicolumn{3}{|c|}{ ISO 4287} \\
\hline \multicolumn{3}{|c|}{ Amplitude parameters - Roug } \\
\hline $\mathrm{Fp}$ & 03712 & $\mu m$ \\
\hline Rv & 0.5778 & $\mu \mathrm{m}$ \\
\hline $\mathrm{Rz}$ & 0940 & $\mu m$ \\
\hline $\mathrm{Ric}$ & 0.5749 & $\mu m$ \\
\hline $\mathrm{Ft}_{\mathrm{t}}$ & 2.141 & $\mu m$ \\
\hline Rà & 0.1722 & $\mu m$ \\
\hline Rig & 02242 & $\mu m$ \\
\hline Rsk & -0.6629 & \\
\hline Ritus & 3.544 & \\
\hline
\end{tabular}

Figura B.23 - Relação dos parâmetros obtidos da Amostra 3 Região 2.

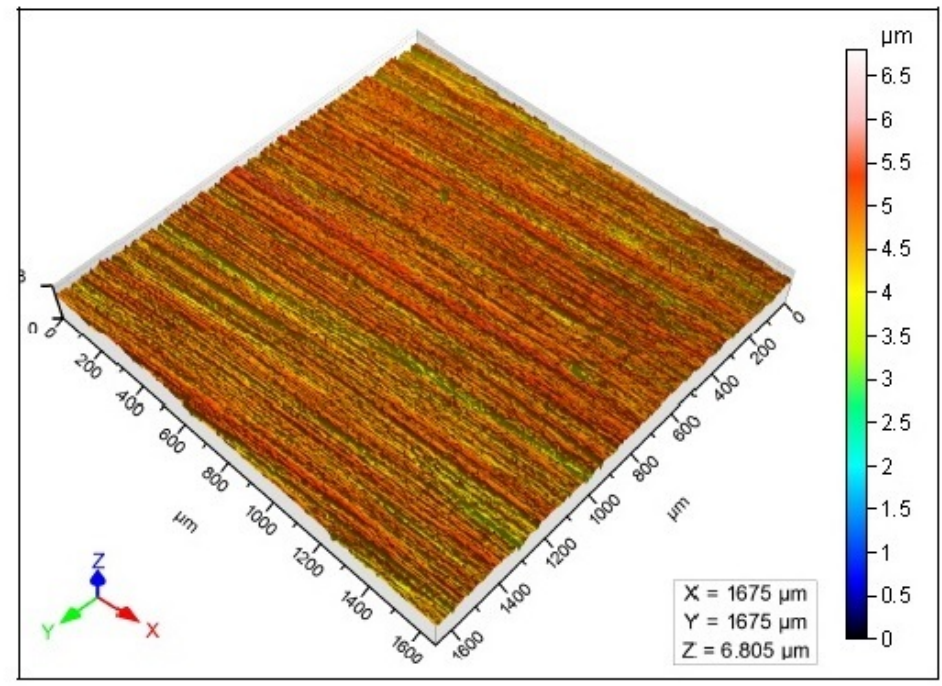

Figura B.24 - Amostra 3 Região 2 Resultados em 3D. 


\section{PROFILF EXTRACTIOH}

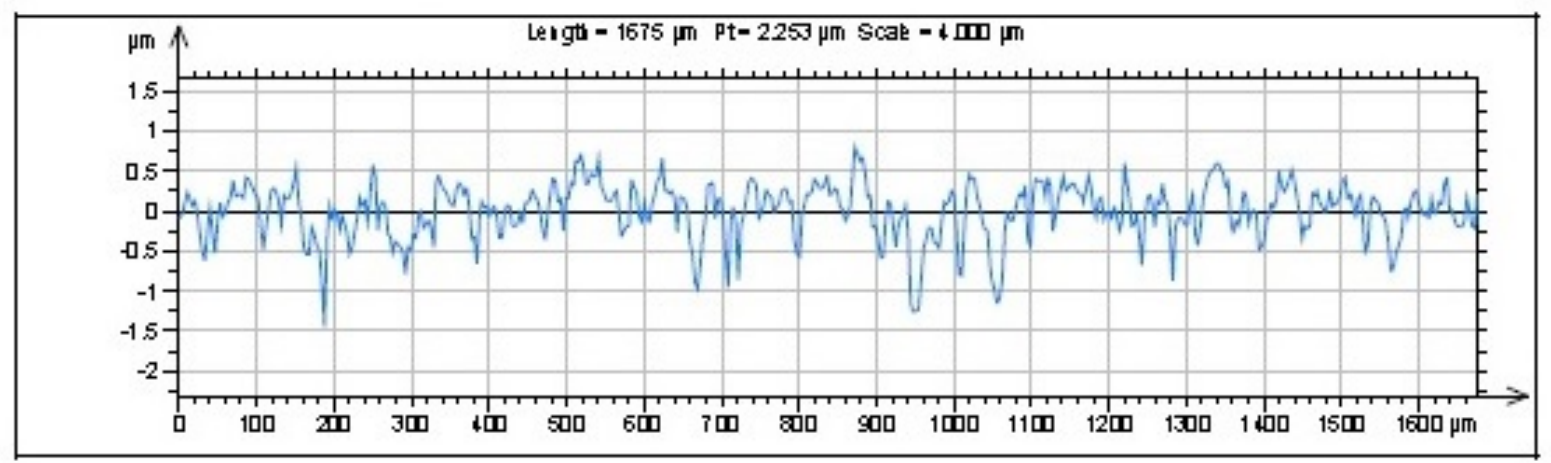

Figura B.25 - Amostra 3 Região 3 Perfil da Superfície.

\begin{tabular}{|c|c|c|}
\hline \multicolumn{3}{|c|}{ ISO 4287} \\
\hline \multicolumn{3}{|c|}{ Amplitude parameters - Roug } \\
\hline Fp & 03809 & $\mu m$ \\
\hline $\mathrm{Rv}$ & 0.5530 & $\mu m$ \\
\hline Fiz & 09339 & $\mu m$ \\
\hline Ric & 0.6085 & $\mu m$ \\
\hline Ft & 1.642 & $\mu m$ \\
\hline $\mathrm{Ri}$ & 0.1923 & $\mu m$ \\
\hline Rig & 02399 & $\mu m$ \\
\hline Rsk & -0.6168 & \\
\hline Ritas & 3079 & \\
\hline
\end{tabular}

Figura B.26 - Relação dos parâmetros obtidos da Amostra 3 Região 3.

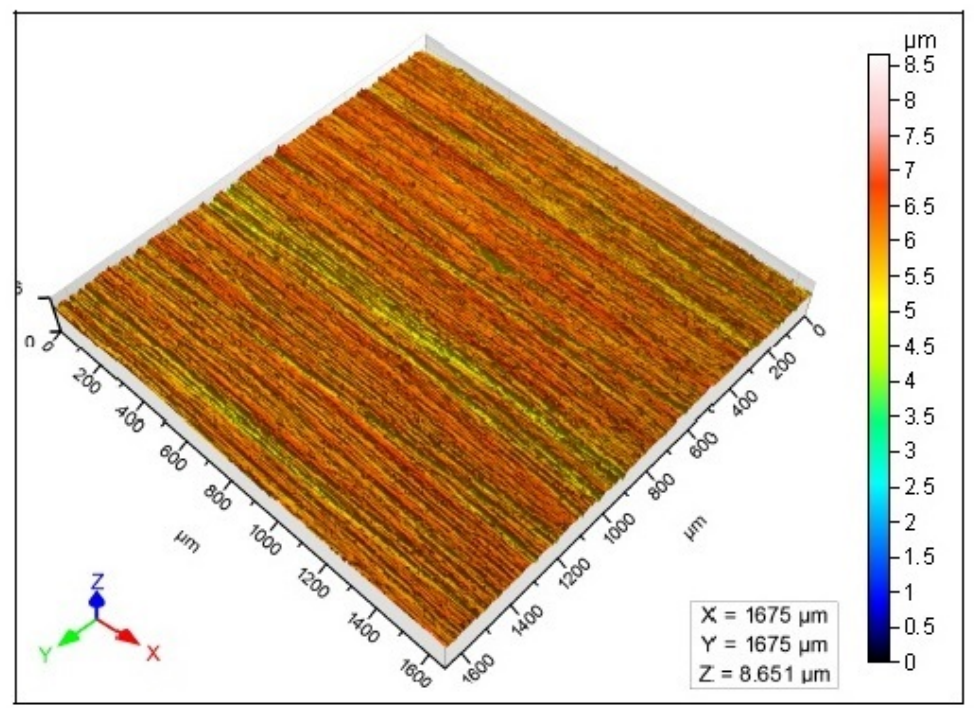

Figura B.27 - Amostra 3 Região 3 Resultados em 3D. 
PROFILE EXTRACTION

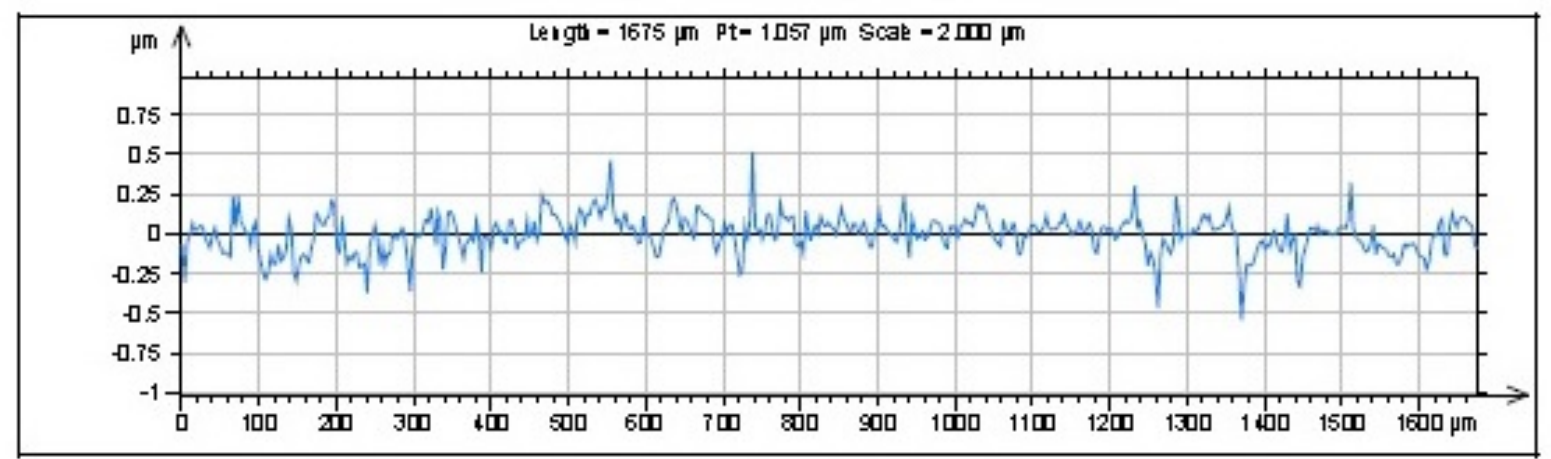

Figura B.28 - Amostra 4 Região 1 Perfil da Superfície.

\begin{tabular}{|c|c|c|}
\hline \multicolumn{3}{|c|}{ ISO 4287} \\
\hline \multicolumn{3}{|c|}{ Amplitude parameters - Roug } \\
\hline Fp & 0.1892 & $\mu m$ \\
\hline Rv & 0.1832 & $\mu m$ \\
\hline Fzz & 0.3724 & $\mu \mathrm{m}$ \\
\hline $\mathrm{Rc}$ & 02153 & $\mu \mathrm{m}$ \\
\hline Ft & 0.8793 & $\mu m$ \\
\hline $\mathrm{Rà}$ & 006094 & $\mu m$ \\
\hline Rig & 008236 & $\mu \mathrm{m}$ \\
\hline Risk & 006501 & \\
\hline Ritu & 4675 & \\
\hline
\end{tabular}

Figura B.29 - Relação dos parâmetros obtidos da Amostra 4 Região 1.

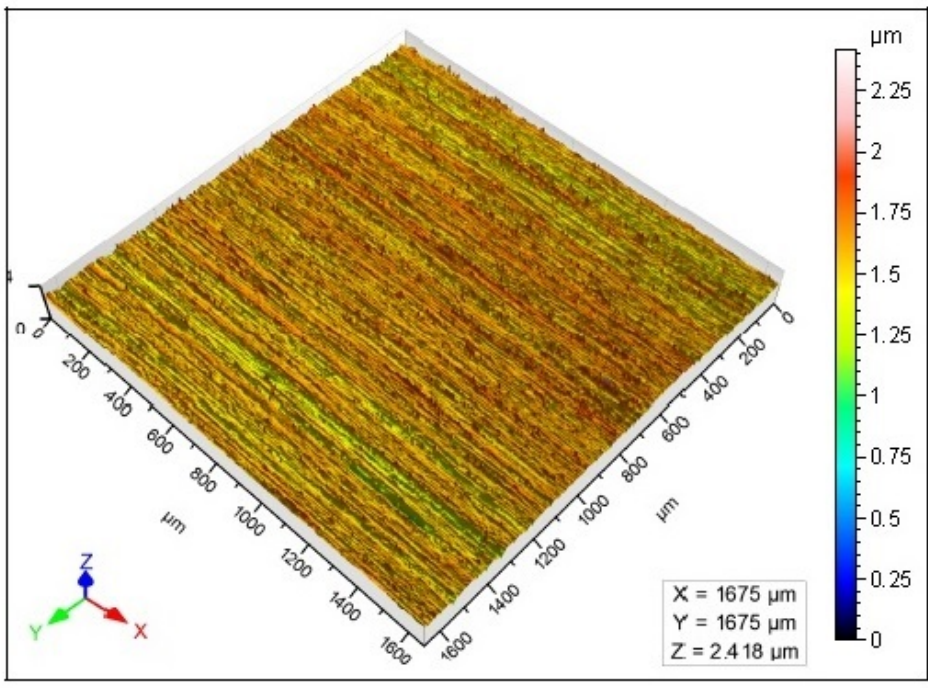

Figura B.30 - Amostra 4 Região 1 Resultados em 3D. 


\section{PROFILE EXTRACTION}

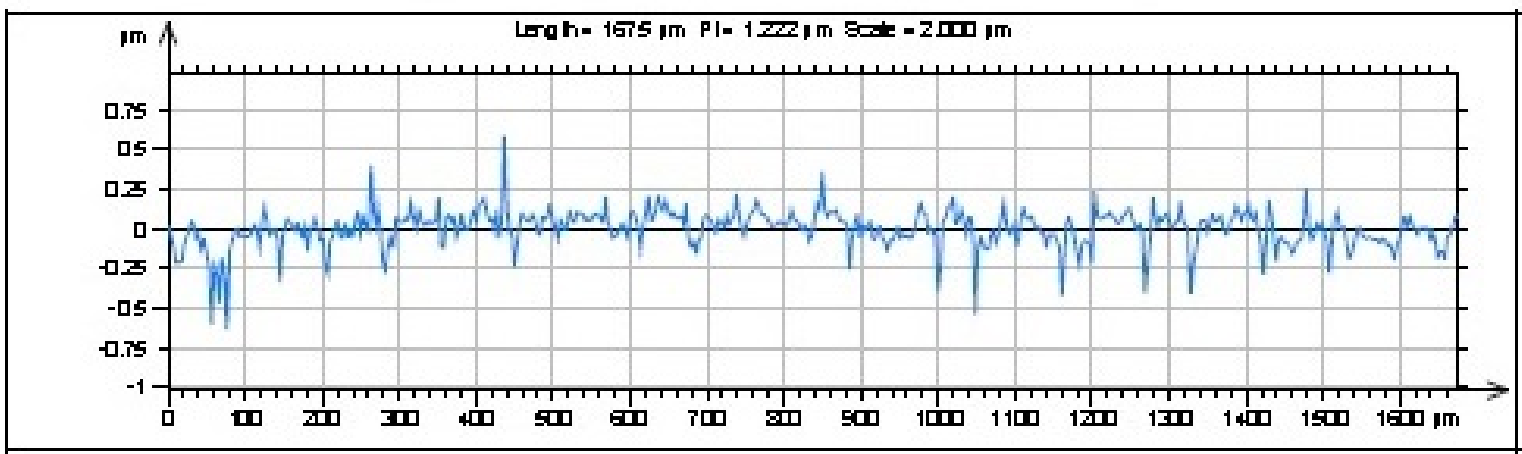

Figura B.31 - Amostra 4 Região 2 Perfil da Superfície.

\begin{tabular}{|c|c|c|}
\hline \multicolumn{3}{|c|}{ ISO 4287} \\
\hline \multicolumn{3}{|c|}{ Ampitude parame te rs - Roig } \\
\hline 中 & 0.1965 & $\mu \mathrm{m}$ \\
\hline Rv & $02 \downarrow 21$ & $\mu \mathrm{m}$ \\
\hline$R z$ & 0.1385 & $\mu m$ \\
\hline Bz & 02241 & $\mu m$ \\
\hline Rt & 09686 & $\mu \mathrm{m}$ \\
\hline 成 & 006129 & $\mu \mathrm{m}$ \\
\hline 网 & 008927 & $\mu \mathrm{m}$ \\
\hline RIM & $-\square 3866$ & \\
\hline PU士 & 535 & \\
\hline
\end{tabular}

Figura B.32 - Relação dos parâmetros obtidos da Amostra 4 Região 2.

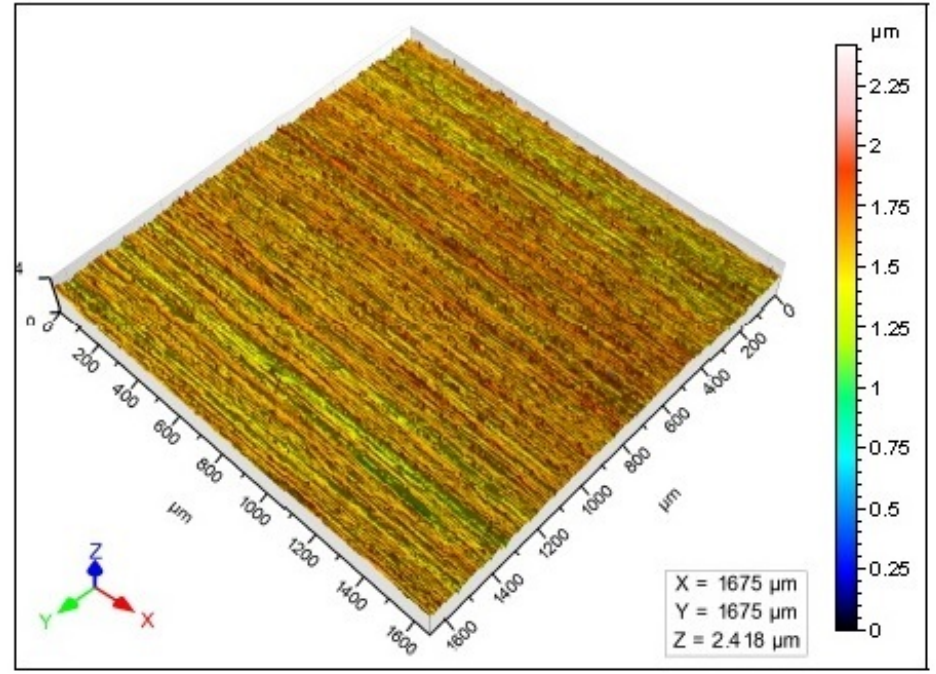

Figura B.33 - Amostra 4 Região 2 Resultados em 3D. 


\section{PROFILE EXTRACTION}

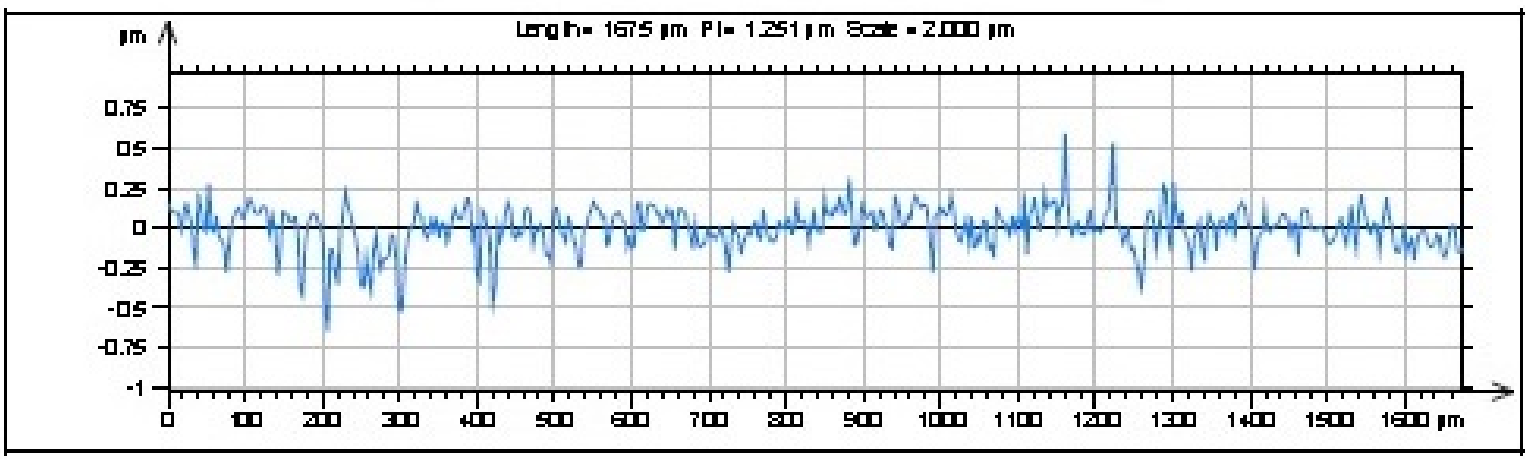

Figura B.34 - Amostra 4 Região 3 Perfil da Superfície.

\begin{tabular}{|c|c|c|}
\hline \multicolumn{3}{|l|}{ ISO 4287 } \\
\multicolumn{3}{|c|}{ Amplitude par ameters - Roug } \\
\hline Rp & 0.2078 & $\mu m$ \\
\hline Rv & 0.2468 & $\mu m$ \\
\hline Rzz & 0.4546 & $\mu m$ \\
\hline Ric & 0.2567 & $\mu m$ \\
\hline R.t & 0.9547 & $\mu m$ \\
\hline Rì & 0.08133 & $\mu m$ \\
\hline Rq & 0.1064 & $\mu m$ \\
\hline Rsk & -02857 & \\
\hline Rku & 3882 \\
\hline
\end{tabular}

Figura B.35 - Relação dos parâmetros obtidos da Amostra 4 Região 3.

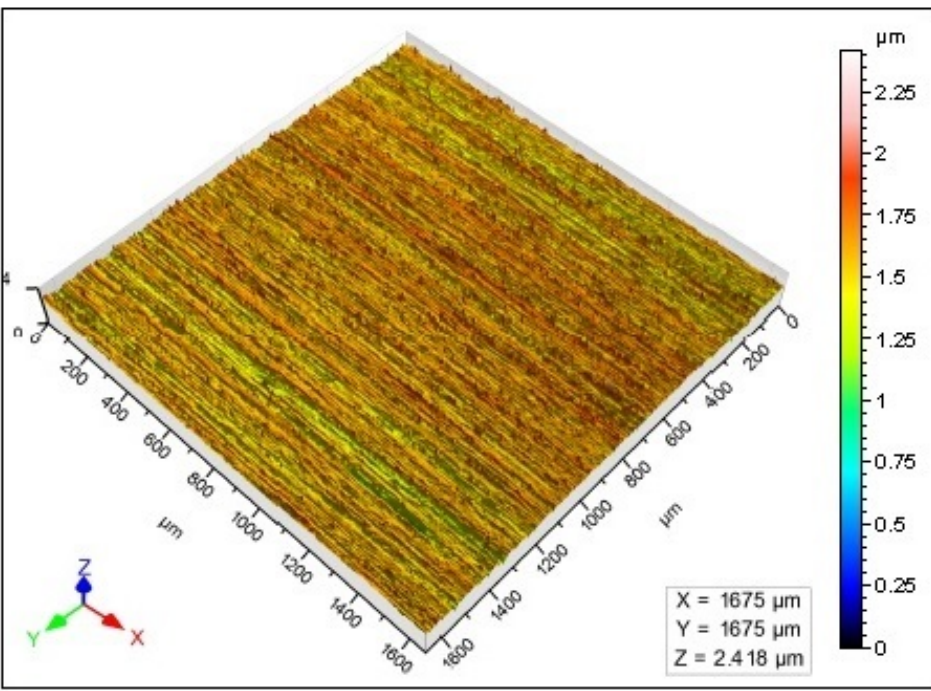

Figura B.36 - Amostra 4 Região 3 Resultados em 3D. 


\section{PROFILF EXTRACTION}

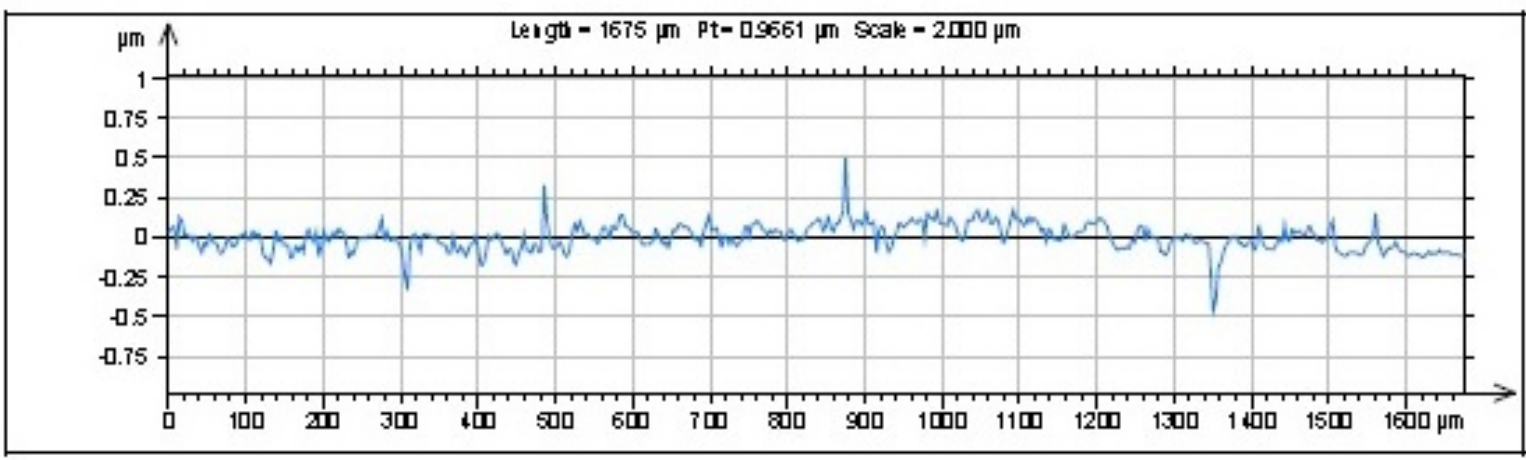

Figura B.37 - Amostra 5 Região 1 Perfil da Superfície.

\begin{tabular}{|c|c|c|}
\hline \multicolumn{3}{|c|}{ ISO 4287} \\
\hline \multicolumn{3}{|c|}{ Amplitude parameters - Roug } \\
\hline$F_{p}$ & 0.1174 & $\mu m$ \\
\hline $\mathrm{Rov}$ & 0.1065 & $\mu m$ \\
\hline $\mathrm{Fz}$ & 02238 & $\mu m$ \\
\hline $\mathrm{Ric}$ & 0.14002 & $\mu m$ \\
\hline Fit & 0.6801 & $\mu m$ \\
\hline $\mathrm{Ra}$ & 003815 & $\mu m$ \\
\hline Rig & 005242 & $\mu m$ \\
\hline Risk & 0.1684 & \\
\hline Ritas & 4.771 & \\
\hline
\end{tabular}

Figura B.38 - Relação dos parâmetros obtidos da Amostra 5 Região 1.

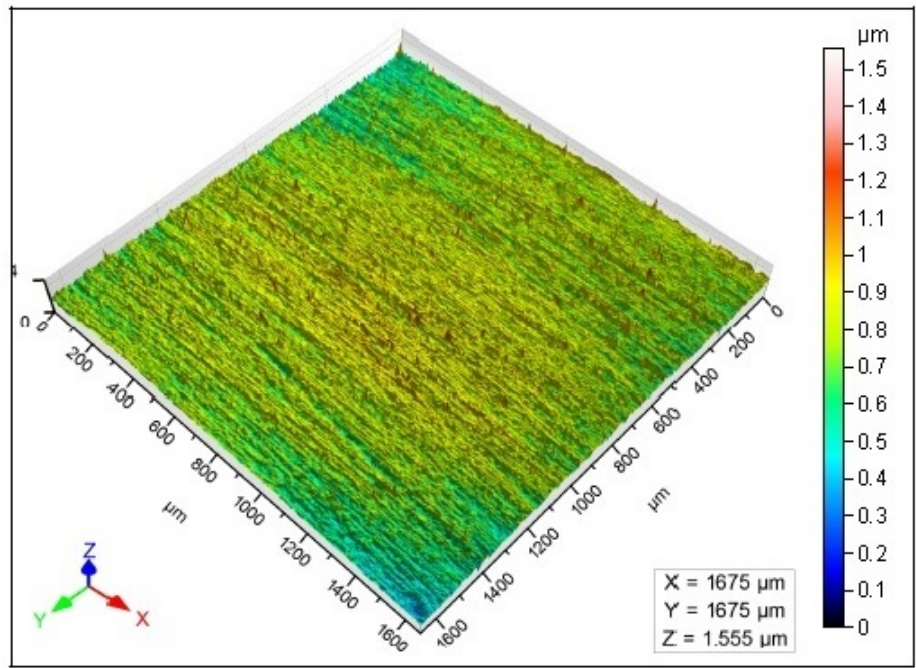

Figura B.39 - Amostra 5 Região 1 Resultados em 3D. 


\section{PROFILF EXTRACTION}

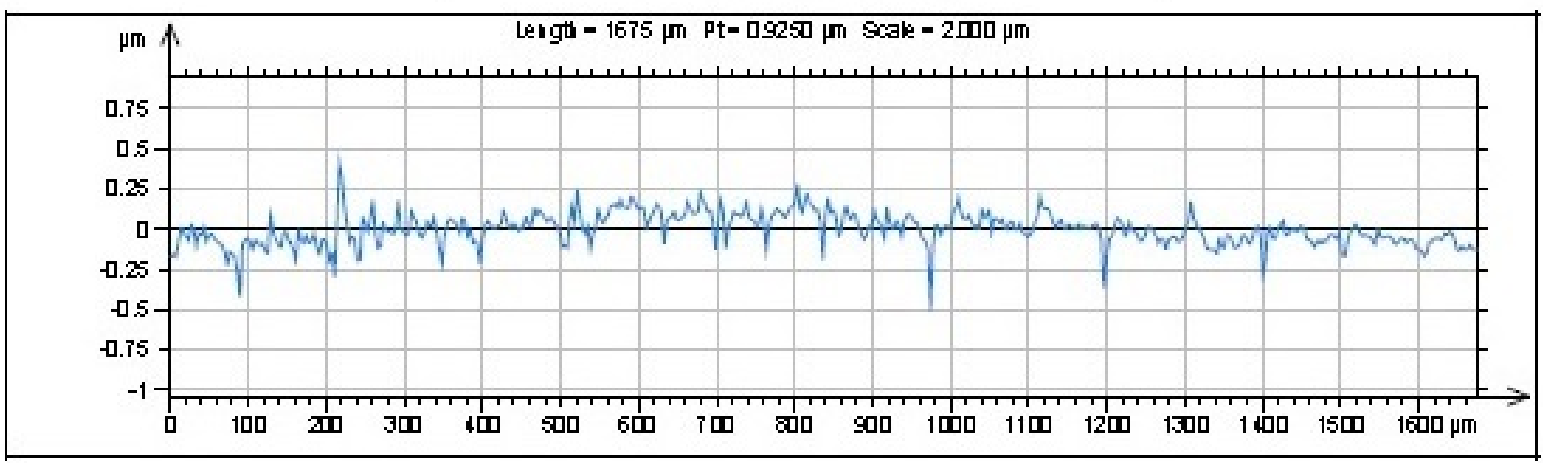

Figura B.40 - Amostra 5 Região 2 Perfil da Superfície.

\begin{tabular}{|c|c|c|}
\hline \multicolumn{3}{|c|}{ ISO 4287} \\
\hline \multicolumn{3}{|c|}{ Amplitude parameters - Roug } \\
\hline Fp & 0.1266 & $\mu m$ \\
\hline Rv & 0.1807 & $\mu m$ \\
\hline Fzz & 03073 & $\mu m$ \\
\hline $\mathrm{Roc}$ & 0.1603 & $\mu m$ \\
\hline Fit & 08497 & $\mu m$ \\
\hline $\mathrm{Ra}$ & 004593 & $\mu m$ \\
\hline Rig & 006471 & $\mu m$ \\
\hline Rsk & -0.7107 & \\
\hline Ritu & 5.597 & \\
\hline
\end{tabular}

Figura B.41 - Relação dos parâmetros obtidos da Amostra 5 Região 2.

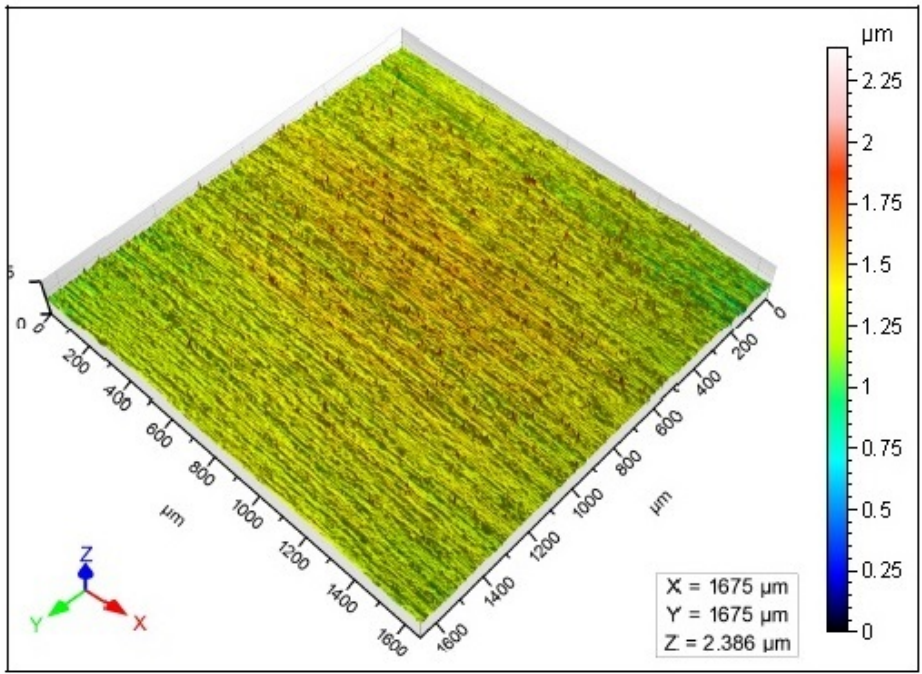

Figura B.42 - Amostra 5 Região 2 Resultados em 3D. 


\section{PROFILE EXTRACTION}

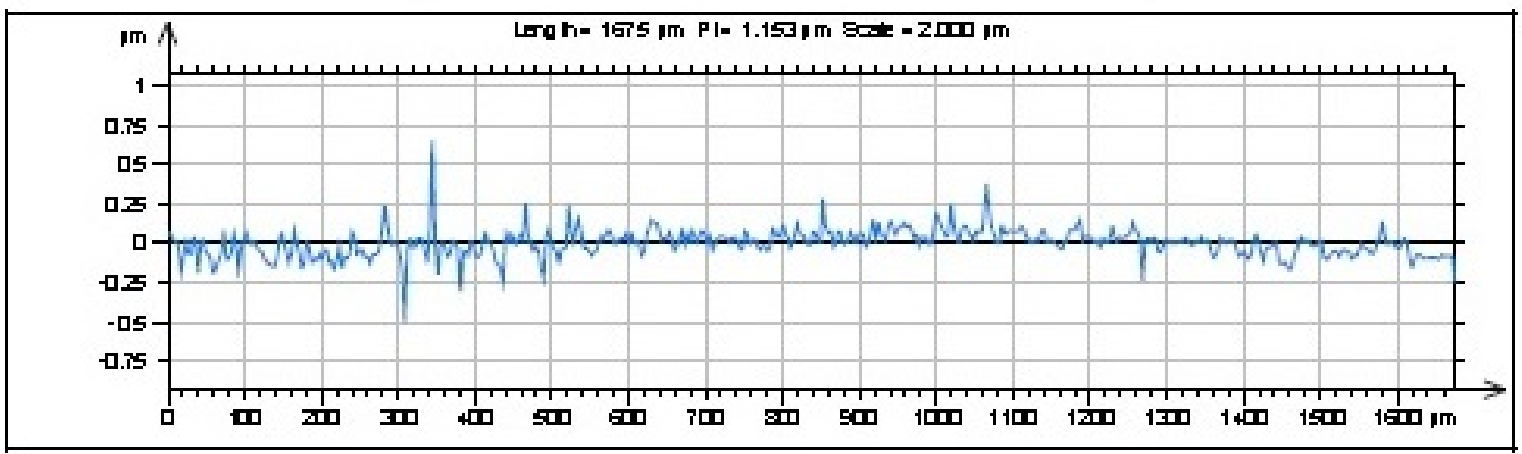

Figura B.43 - Amostra 5 Região 3 Perfil da Superfície.

\begin{tabular}{|c|c|c|}
\hline \multicolumn{3}{|c|}{ ISO 4287} \\
\hline \multicolumn{3}{|c|}{ Amplitude $p$ ar ameters - R oug } \\
\hline$R_{p}$ & 0.1555 & $\mu m$ \\
\hline Rv & 0.1245 & $\mu m$ \\
\hline $\mathrm{Rz}$ & 0.2800 & $\mu m$ \\
\hline $\mathrm{Ric}$ & 0.1591 & $\mu m$ \\
\hline Rit & 1060 & $\mu m$ \\
\hline $\mathrm{Ra}$ & 004412 & $\mu m$ \\
\hline $\mathrm{Rq}$ & 006049 & $\mu m$ \\
\hline Rsk & 0.2690 & \\
\hline Rku & 4596 & \\
\hline
\end{tabular}

Figura B.44 - Relação dos parâmetros obtidos da Amostra 5 Região 3.

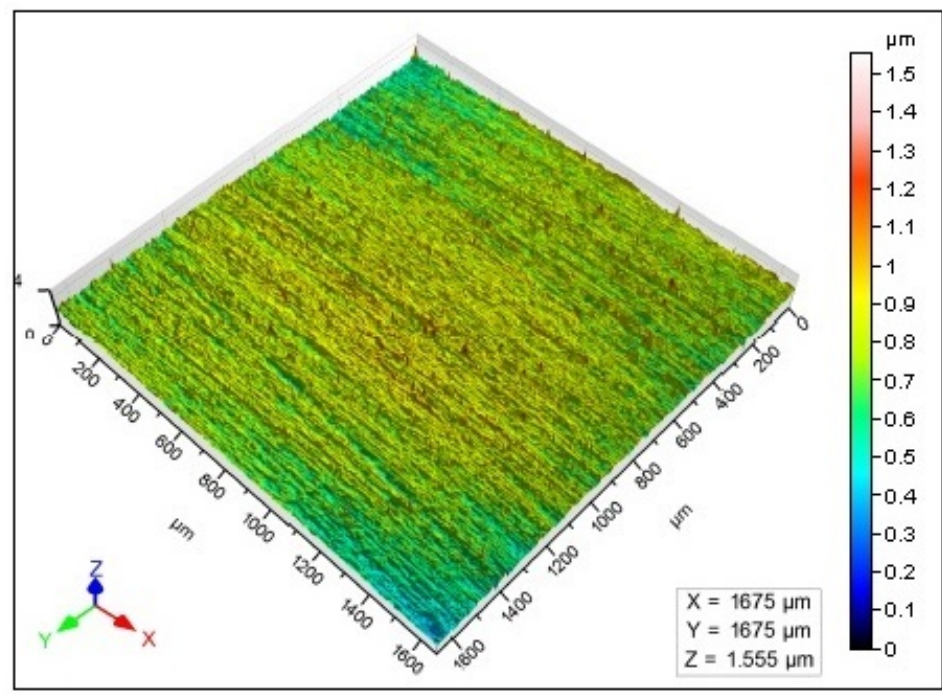

Figura B.45 - Amostra 5 Região 3 Resultados em 3D. 


\section{PROFILF EXTRACTION}

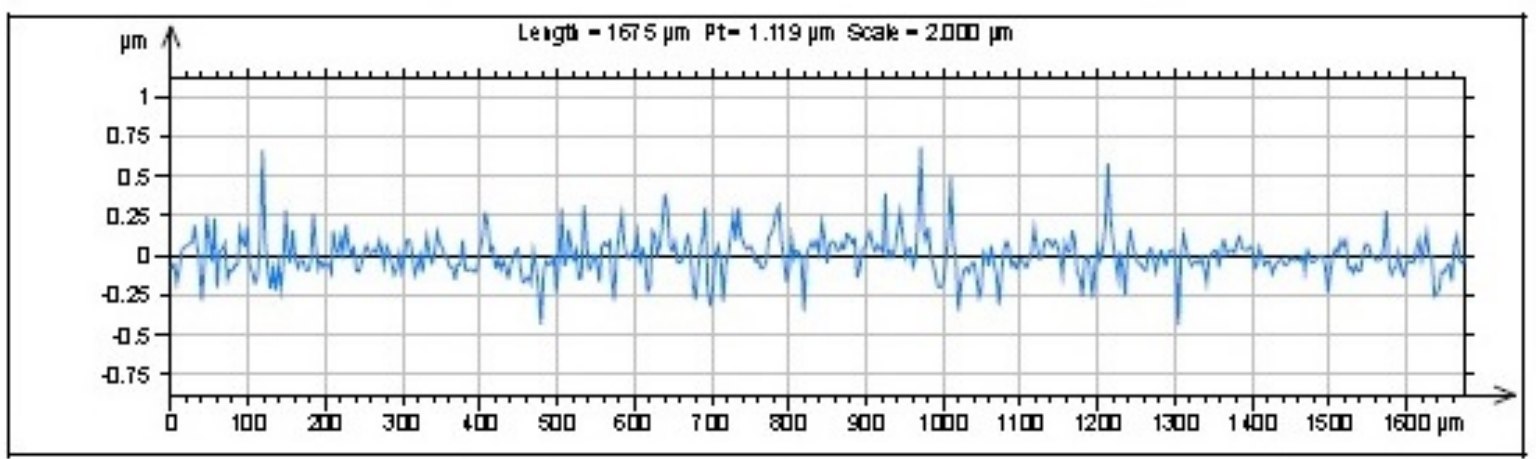

Figura B.46 - Amostra 6 Região 1 Perfil da Superfície.

\begin{tabular}{|c|c|c|}
\hline \multicolumn{3}{|c|}{ ISO 4287} \\
\hline \multicolumn{3}{|c|}{ Amplitude parameters - Roug } \\
\hline Fp & 02841 & $\mu m$ \\
\hline Rv & 02283 & $\mu m$ \\
\hline Rzz & 0.5123 & $\mu m$ \\
\hline $\mathrm{Ric}$ & 02661 & $\mu m$ \\
\hline Ft & 1051 & $\mu m$ \\
\hline $\mathrm{Ra}$ & 008056 & $\mu m$ \\
\hline Rig & 0.1099 & $\mu m$ \\
\hline$R \leq k$ & 02093 & \\
\hline Rita & 4.793 & \\
\hline
\end{tabular}

Figura B.47 - Relação dos parâmetros obtidos da Amostra 6 Região 1.

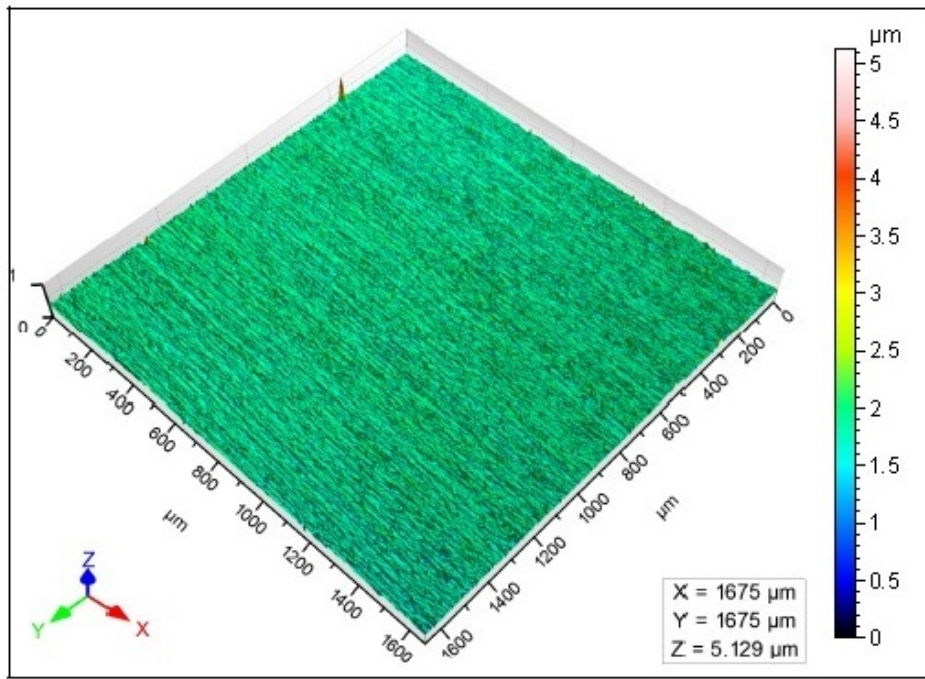

Figura B.48 - Amostra 6 Região 1 Resultados em 3D. 


\section{PROFILE EXTRACTION}

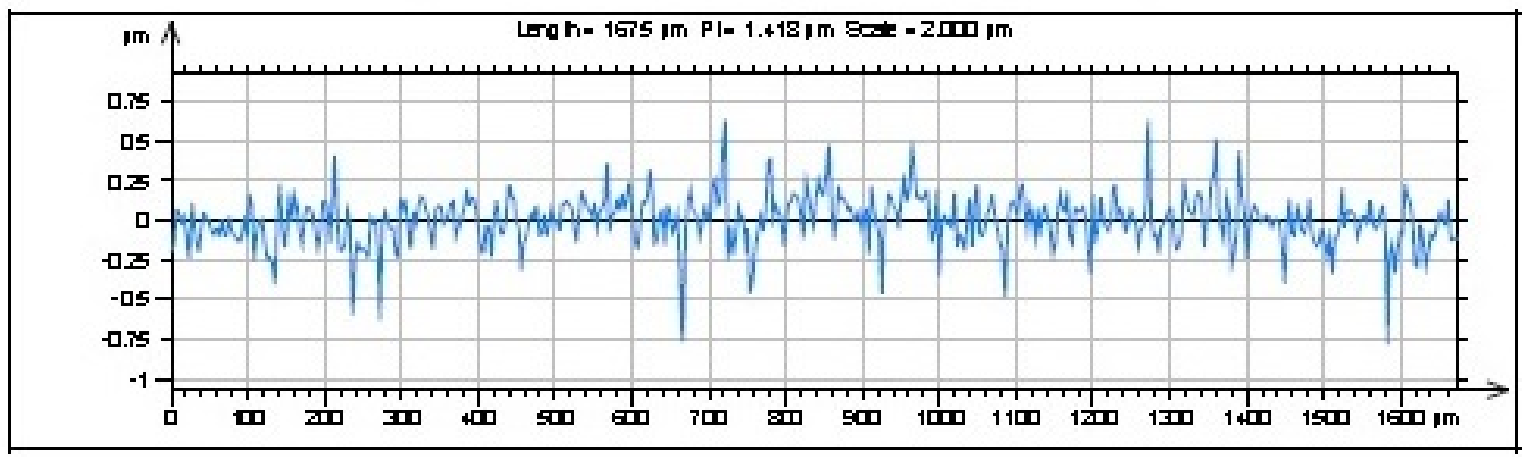

Figura B.49 - Amostra 6 Região 2 Perfil da Superfície.

\begin{tabular}{|c|c|c|}
\hline \multicolumn{3}{|l|}{ ISO 4287 } \\
\multicolumn{3}{|l|}{ Amplitude par ameters - Rou! } \\
\hline Rp & 0.1571 & $\mu \mathrm{m}$ \\
\hline $\mathrm{R} v$ & 0.1625 & $\mu \mathrm{m}$ \\
\hline $\mathrm{Rz}$ & 0.3200 & $\mu \mathrm{m}$ \\
\hline $\mathrm{Rc}$ & 0.1773 & $\mu \mathrm{m}$ \\
\hline $\mathrm{R} t$ & 0.5700 & $\mu \mathrm{m}$ \\
\hline $\mathrm{Ra}$ & 0.05260 & $\mu \mathrm{m}$ \\
\hline $\mathrm{Rq}$ & 0.07017 & $\mu \mathrm{m}$ \\
\hline Rsk & -0.1610 & \\
\hline Rku & 3830 & \\
\hline
\end{tabular}

Figura B.50 - Relação dos parâmetros obtidos da Amostra 6 Região 2.

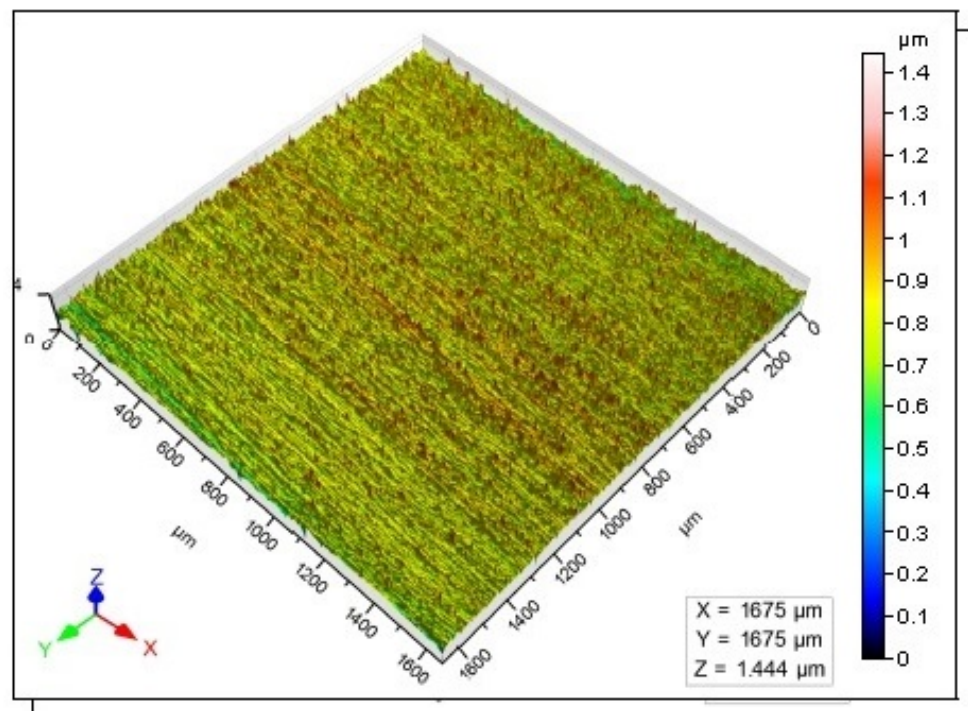

Figura B.51 - Amostra 6 Região 2 Resultados em 3D. 
PROFILF EXTRACTION

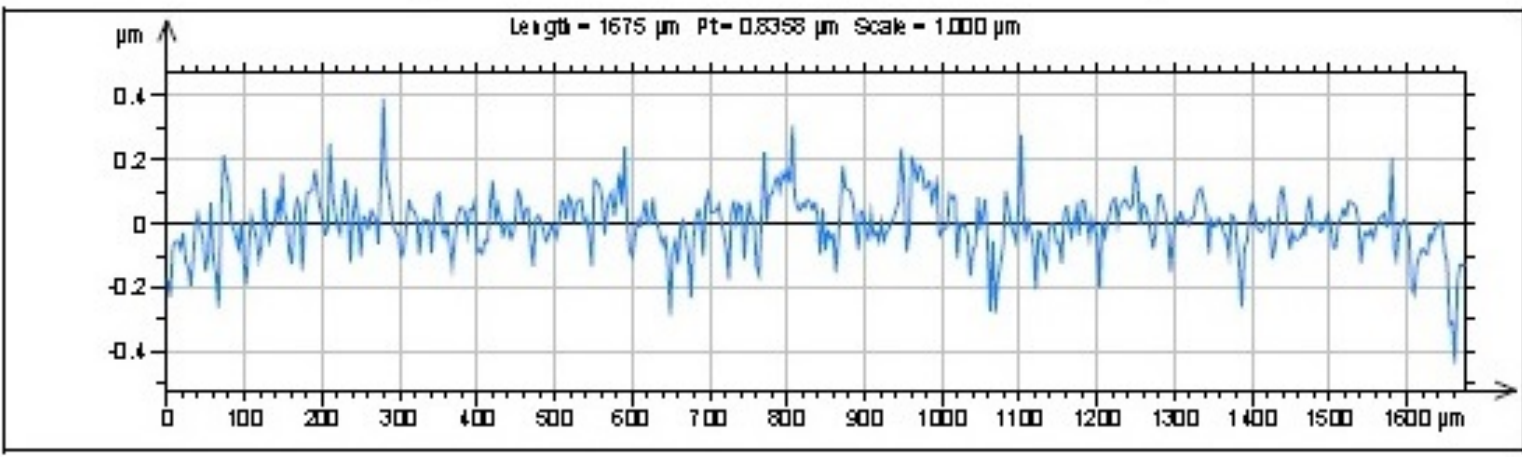

Figura B.52 - Amostra 6 Região 3 Perfil da Superfície.

\begin{tabular}{|c|c|c|}
\hline \multicolumn{3}{|c|}{ ISO 4287} \\
\hline \multicolumn{3}{|c|}{ Amplitude parameters - Roug } \\
\hline$F$ & 0.1568 & $\mu \mathrm{m}$ \\
\hline Ru & 0.1623 & $\mu \mathrm{m}$ \\
\hline Fzz & 03190 & $\mu \mathrm{m}$ \\
\hline $\mathrm{Ric}$ & 0.1770 & $\mu m$ \\
\hline Ft & 0.5697 & $\mu \mathrm{m}$ \\
\hline $\mathrm{Ra}$ & 005249 & $\mu \mathrm{m}$ \\
\hline Rig & 007014 & $\mu \mathrm{m}$ \\
\hline Risk & -0.1608 & \\
\hline Rita & 3827 & \\
\hline
\end{tabular}

Figura B.53 - Relação dos parâmetros obtidos da Amostra 6 Região 3.

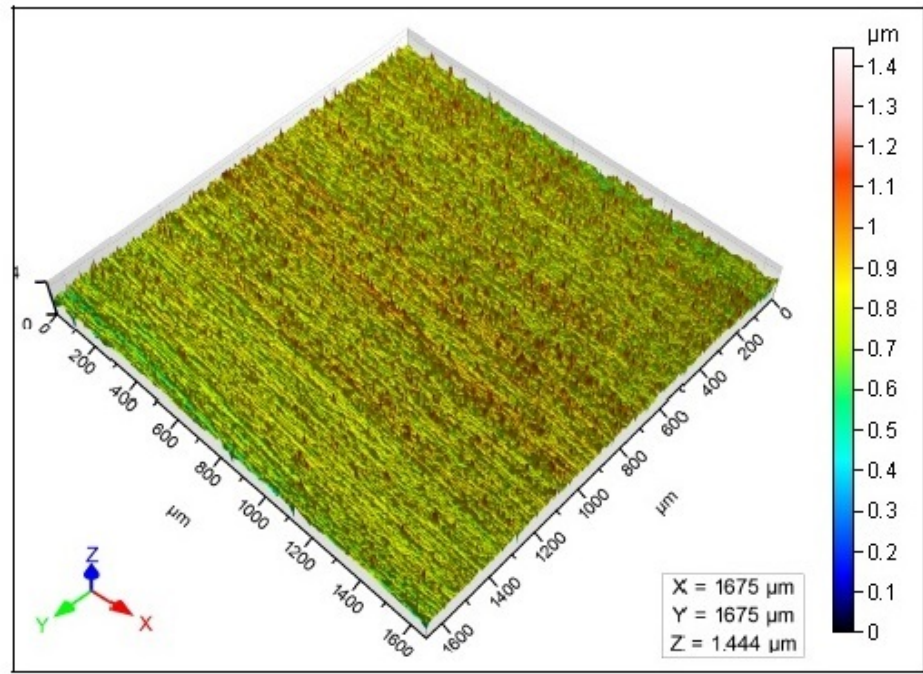

Figura B.54 - Amostra 6 Região 3 Resultados em 3D. 


\section{PROFILF EXTRACTION}

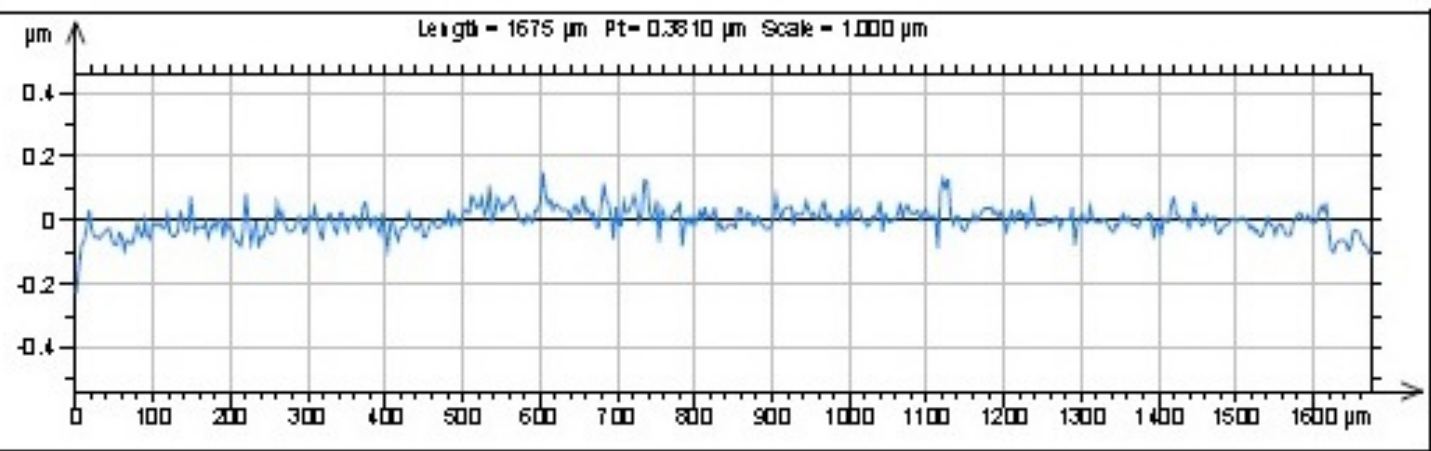

Figura B.55 - Amostra 7 Região 1 Perfil da Superfície.

\begin{tabular}{|c|c|c|}
\hline \multicolumn{3}{|l|}{ ISO 4287 } \\
\multicolumn{3}{|l|}{ Amplitude parameters - Rough } \\
\hline Rp & 00690 & $\mu \mathrm{m}$ \\
\hline Rv & 006313 & $\mu \mathrm{m}$ \\
\hline Rz & 0.1221 & $\mu \mathrm{m}$ \\
\hline Rc & 007067 & $\mu \mathrm{m}$ \\
\hline Rt & 02482 & $\mu \mathrm{m}$ \\
\hline Ra & 00271 & $\mu \mathrm{m}$ \\
\hline Rq & 002716 & $\mu \mathrm{m}$ \\
\hline Risk & 0.4577 & \\
\hline Fku & 3.781 & \\
\hline
\end{tabular}

Figura B.56 - Relação dos parâmetros obtidos da Amostra 7 Região 1.

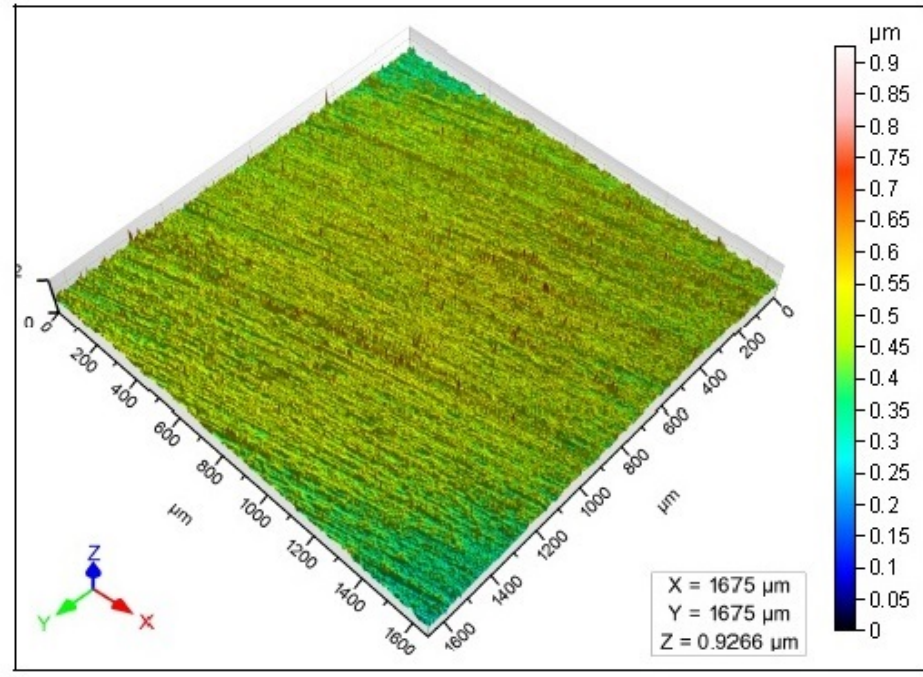

Figura B.57 - Amostra 7 Região 1 Resultados em 3D. 


\section{PROFILE EXTRACTION}

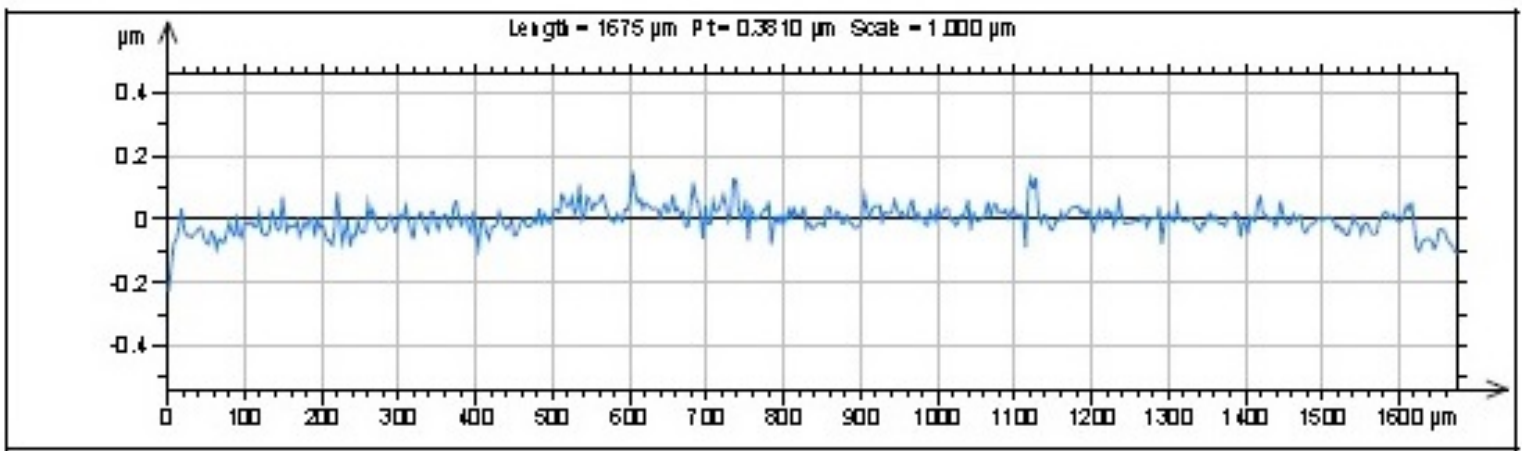

Figura B.58 - Amostra 7 Região 2 Perfil da Superfície.

\begin{tabular}{|c|c|c|}
\hline \multicolumn{3}{|c|}{1504287} \\
\hline \multicolumn{3}{|c|}{ Amplitude parameters - Rougl } \\
\hline Fp & 00587 & $\mu \mathrm{m}$ \\
\hline Ru & 005423 & $\mu \mathrm{m}$ \\
\hline Bzz & 0.1221 & $\mu \mathrm{m}$ \\
\hline $\mathrm{Re}$ & 006157 & $\mu \mathrm{m}$ \\
\hline R.t & 02492 & $\mu \mathrm{m}$ \\
\hline Ra & 002452 & $\mu \mathrm{m}$ \\
\hline Rig & 002576 & $\mu \mathrm{m}$ \\
\hline Risk & 0.1647 & \\
\hline Fku & 3.590 & \\
\hline
\end{tabular}

Figura B.59 - Relação dos parâmetros obtidos da Amostra 7 Região 2.

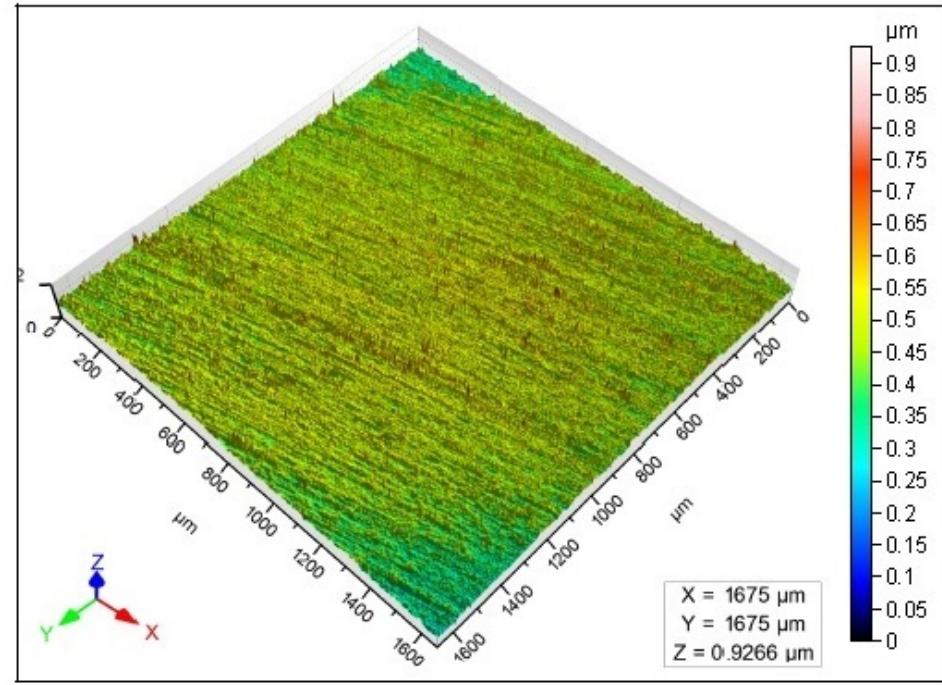

Figura B.60 - Amostra 7 Região 2 Resultados em 3D. 
PROFILE EXTRACTION

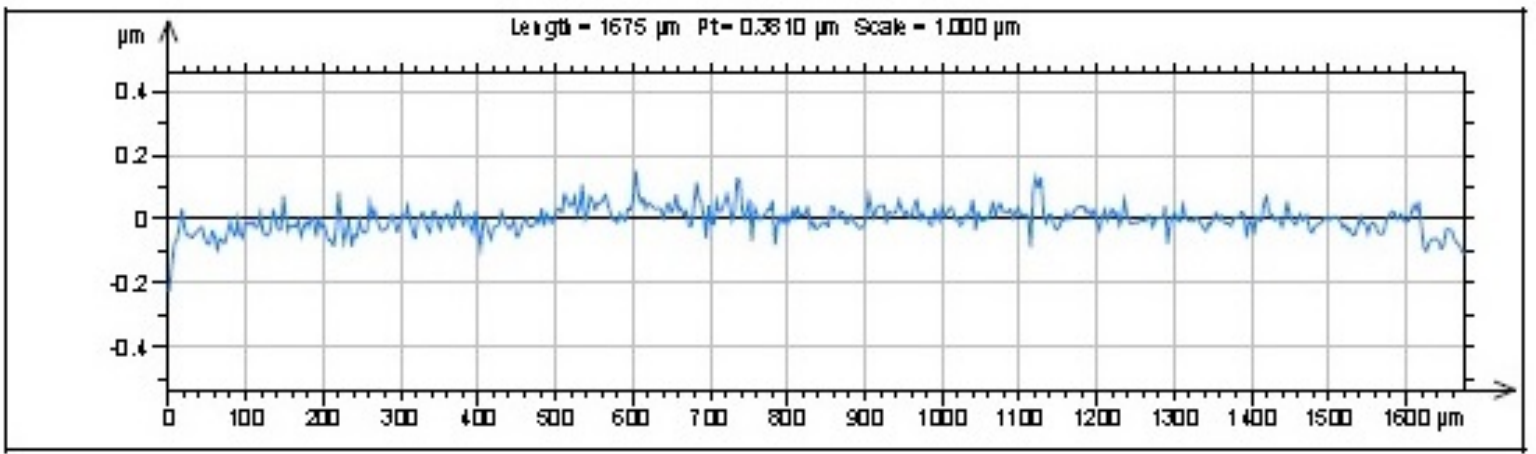

Figura B.61 - Amostra 7 Região 3 Perfil da Superfície.

\begin{tabular}{|c|c|c|}
\hline \multicolumn{3}{|c|}{ ISO 4287} \\
\hline \multicolumn{3}{|c|}{ Amplitude parameters - Roug } \\
\hline Fp & 00590 & $\mu m$ \\
\hline Rv & 005313 & $\mu m$ \\
\hline Rzz & 0.1121 & $\mu m$ \\
\hline $\mathrm{Ric}$ & 006067 & $\mu \mathrm{m}$ \\
\hline Fit & 02382 & $\mu m$ \\
\hline $\mathrm{Ra}$ & 002012 & $\mu m$ \\
\hline $\mathrm{Rog}$ & 002616 & $\mu \mathrm{m}$ \\
\hline $\mathrm{R}: \mathrm{k}$ & 0.1577 & \\
\hline Ritas & 3581 & \\
\hline
\end{tabular}

Figura B.62 - Relação dos parâmetros obtidos da Amostra 7 Região 3.

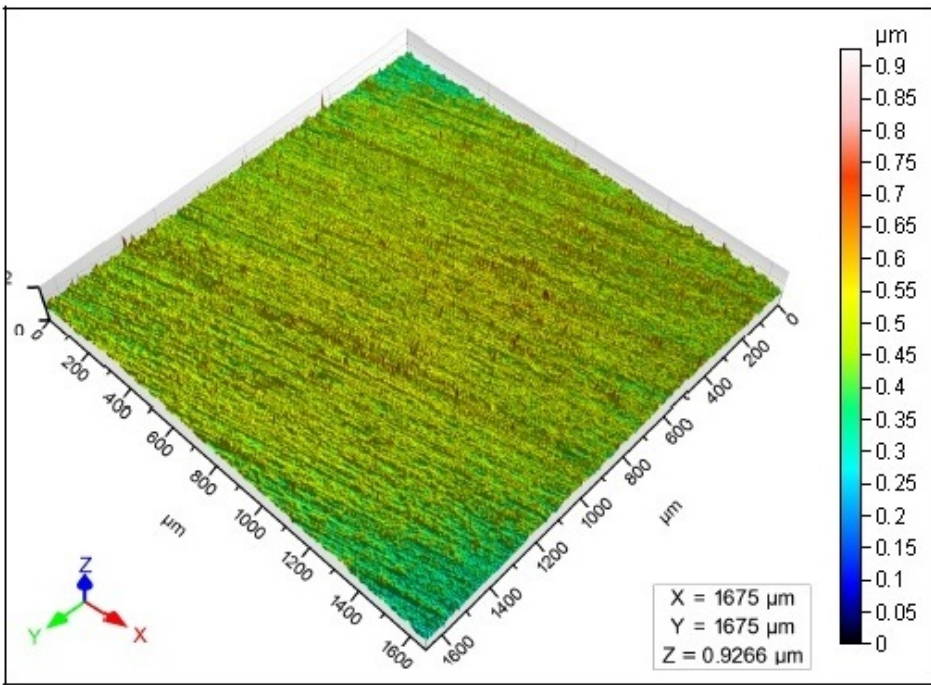

Figura B.63 - Amostra 7 Região 3 Resultados em 3D. 


\section{PROFILE EXTRACTIOH}

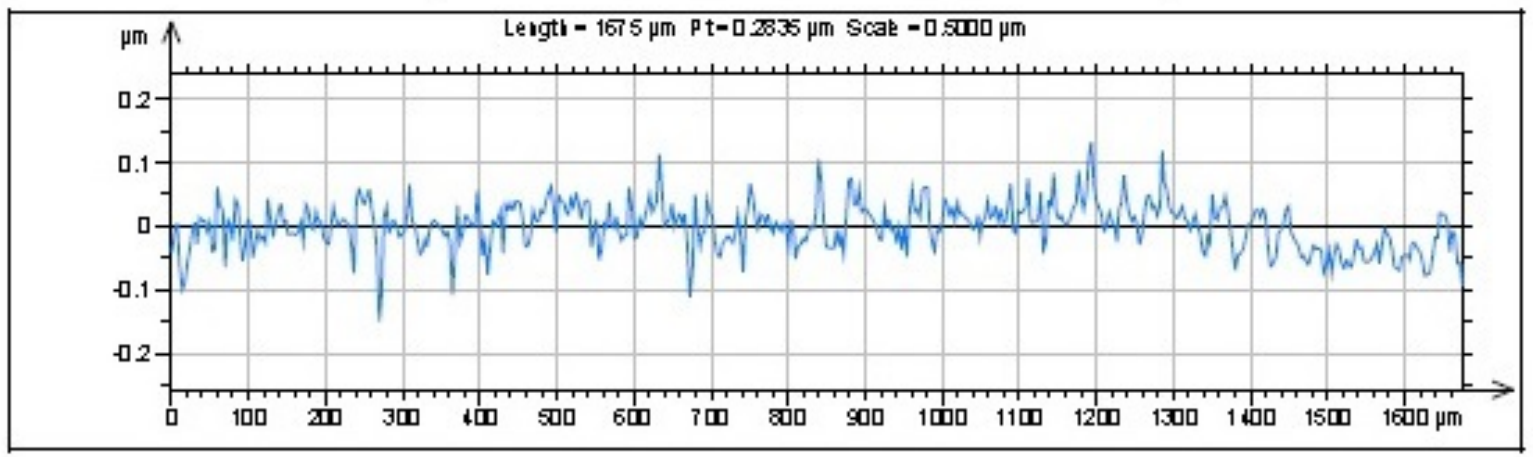

Figura B.64 - Amostra 8 Região 1 Perfil da Superfície.

\begin{tabular}{|c|c|c|}
\hline \multicolumn{3}{|c|}{ ISO 4287} \\
\hline \multicolumn{3}{|c|}{ Amplitude parameters - Roug } \\
\hline Fp & 005556 & $\mu \mathrm{m}$ \\
\hline $\mathrm{Rov}$ & 005356 & $\mu \mathrm{m}$ \\
\hline $\mathrm{Fz}$ & 0.1091 & $\mu \mathrm{m}$ \\
\hline Ric & 00690 & $\mu \mathrm{m}$ \\
\hline$F_{t}$ & 02365 & $\mu \mathrm{m}$ \\
\hline Ra & 002003 & $\mu \mathrm{m}$ \\
\hline Fig & 002631 & $\mu \mathrm{m}$ \\
\hline Risk & 0.1240 & \\
\hline Rive & 3360 & \\
\hline
\end{tabular}

Figura B.65 - Relação dos parâmetros obtidos da Amostra 8 Região 1.

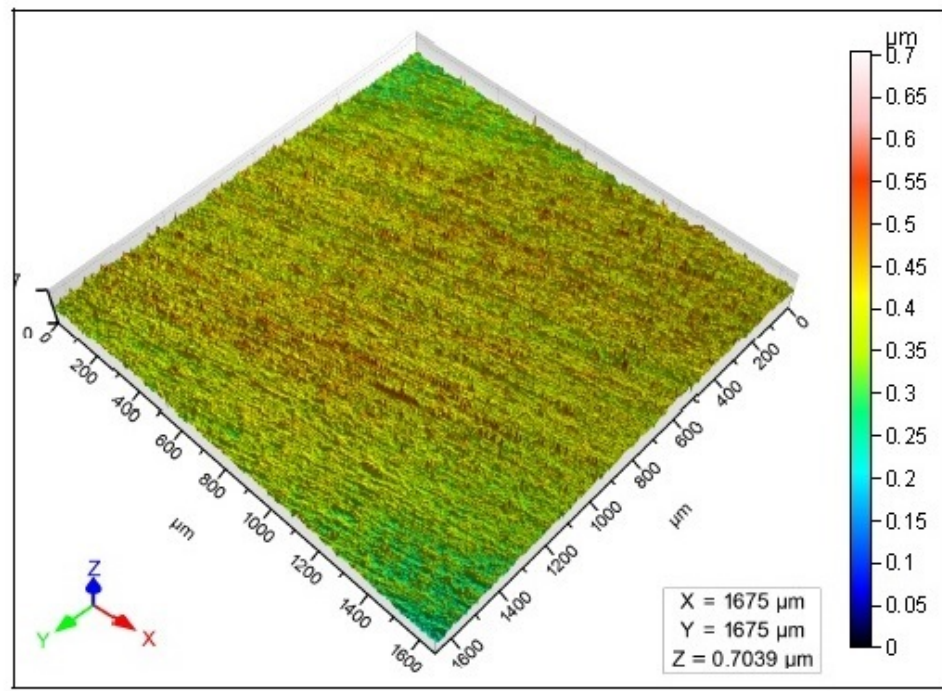

Figura B.66 - Amostra 8 Região 1 Resultados em 3D. 


\section{PROFILF EXTRACTION}

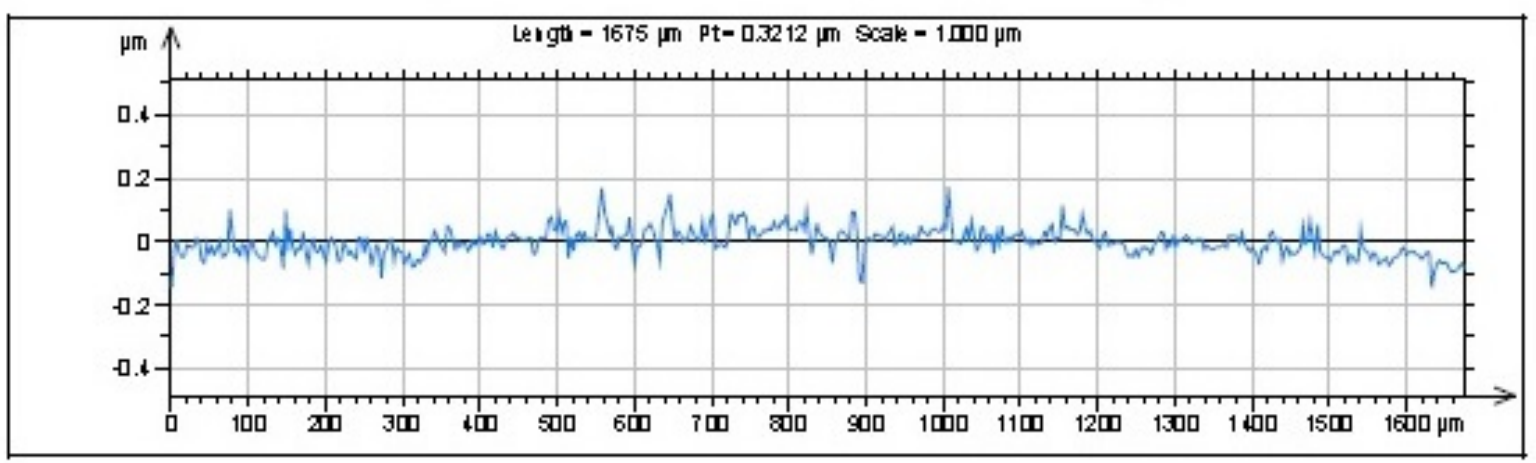

Figura B.67 - Amostra 8 Região 2 Perfil da Superfície.

\begin{tabular}{|ccc|}
\hline \multicolumn{3}{|l|}{ ISO 4287 } \\
Amplitude parameters - Roug \\
\hline $\mathrm{F} \mathrm{p}$ & 006855 & $\mu \mathrm{m}$ \\
\hline $\mathrm{Rv}$ & 005137 & $\mu \mathrm{m}$ \\
\hline $\mathrm{Rz}$ & 0.1199 & $\mu \mathrm{m}$ \\
\hline $\mathrm{Rc}$ & 006632 & $\mu \mathrm{m}$ \\
\hline $\mathrm{F}$ & 02573 & $\mu \mathrm{m}$ \\
\hline $\mathrm{Ra}$ & 002115 & $\mu \mathrm{m}$ \\
\hline $\mathrm{Rq}$ & 002772 & $\mu \mathrm{m}$ \\
\hline $\mathrm{Rsk}$ & 0.4887 & \\
\hline $\mathrm{R} k \mathrm{k}$ & 3817 & \\
\hline
\end{tabular}

Figura B.68 - Relação dos parâmetros obtidos da Amostra 8 Região 2.

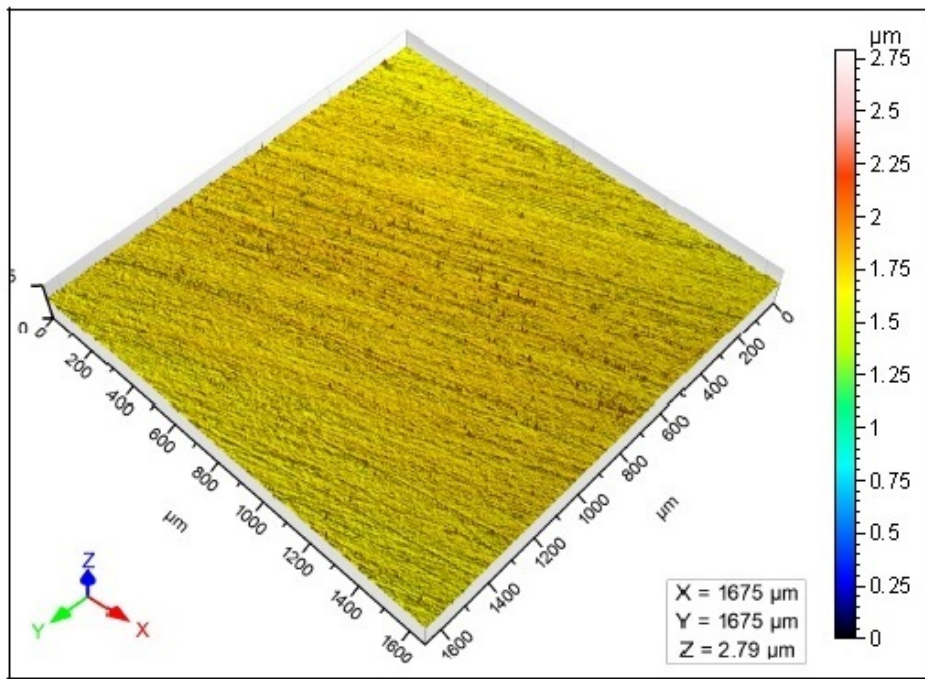

Figura B.69 - Amostra 8 Região 2 Resultados em 3D. 


\section{PROFILE EXTRACTION}

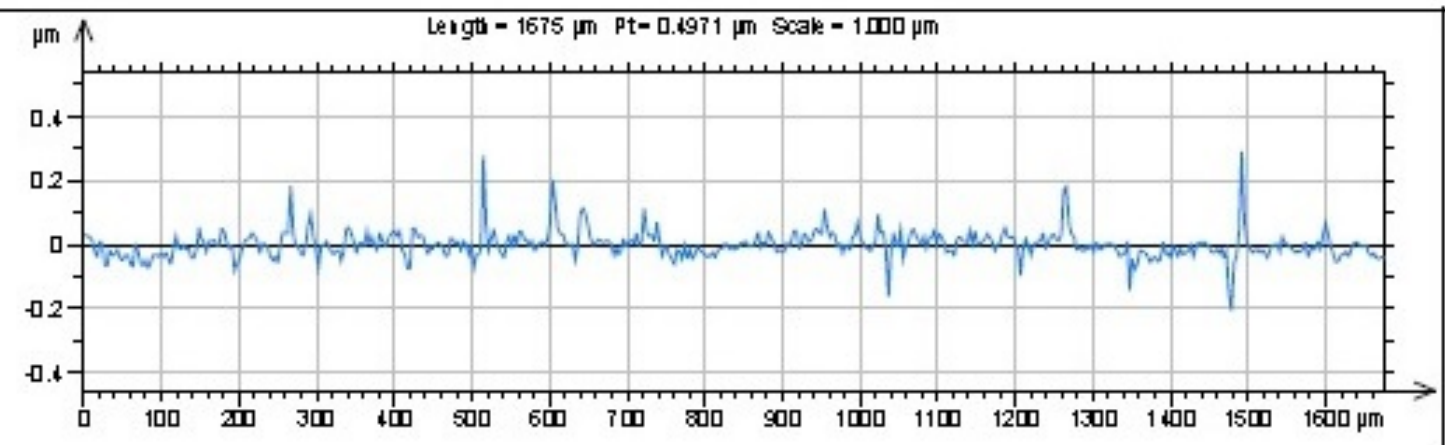

Figura B.70 - Amostra 8 Região 3 Perfil da Superfície.

\begin{tabular}{|c|c|c|}
\hline \multicolumn{3}{|c|}{ ISO 4287} \\
\hline \multicolumn{3}{|c|}{ Amplitude parameters - Roug } \\
\hline $\mathrm{Fp}$ & 009056 & $\mu m$ \\
\hline $\mathrm{R} v$ & 006749 & $\mu m$ \\
\hline Rz & 0.1580 & $\mu \mathrm{m}$ \\
\hline $\mathrm{Ric}$ & 007677 & $\mu m$ \\
\hline Fit & 0.4674 & $\mu \mathrm{m}$ \\
\hline Ra & 002239 & $\mu m$ \\
\hline $\mathrm{Rq}$ & 003263 & $\mu \mathrm{m}$ \\
\hline Rsk & 0.4000 & \\
\hline Ritas & 5.781 & \\
\hline
\end{tabular}

Figura B.71 - Relação dos parâmetros obtidos da Amostra 8 Região 3.

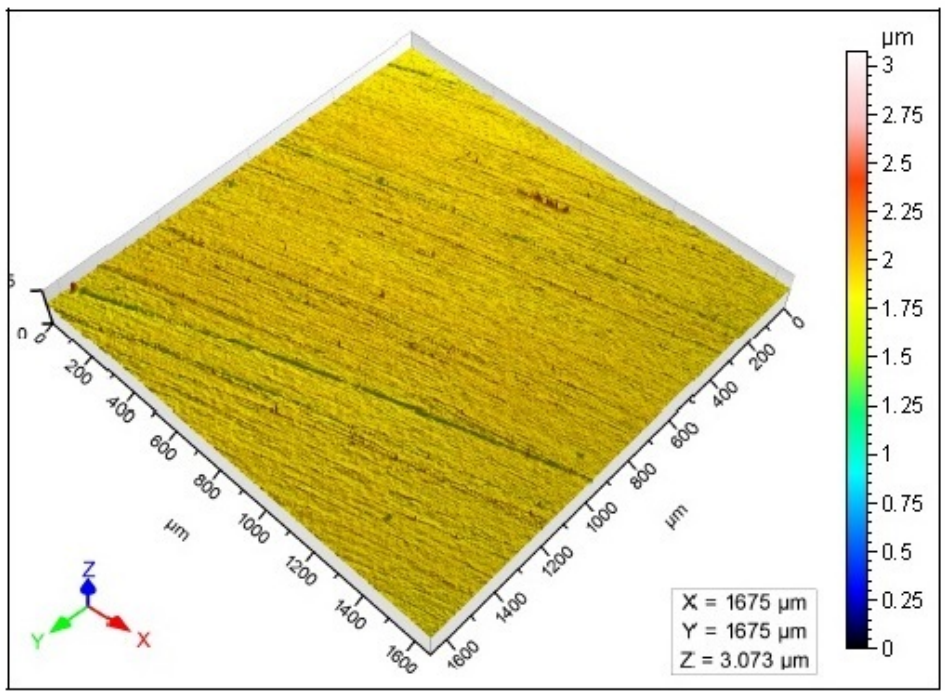

Figura B.72 - Amostra 8 Região 3 Resultados em 3D. 
PROFILE EXTRACTION

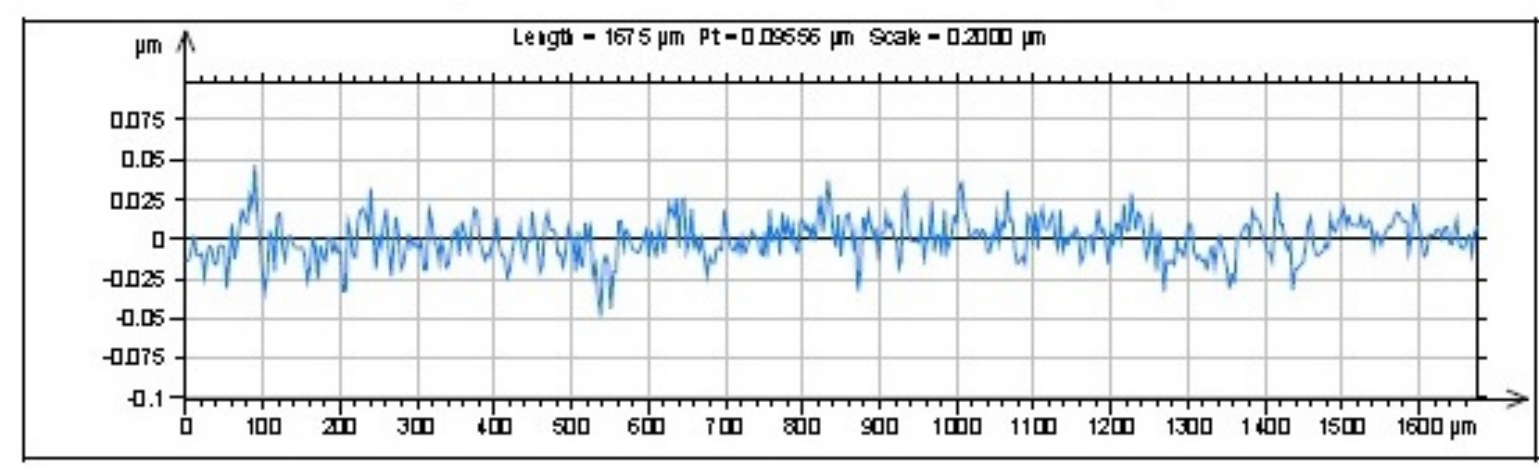

Figura B.73 - Amostra 9 Região 1 Perfil da Superfície.

\begin{tabular}{|c|c|c|}
\hline \multicolumn{3}{|c|}{ ISO 4287} \\
\hline \multicolumn{3}{|c|}{ Amplitude parameters - Rough } \\
\hline Fp & 002204 & $\mu m$ \\
\hline Ru & 002028 & $\mu \mathrm{m}$ \\
\hline $\mathrm{F} z$ & 004233 & $\mu \mathrm{m}$ \\
\hline $\mathrm{Rec}$ & 002407 & $\mu m$ \\
\hline Fut & 007234 & $\mu m$ \\
\hline $\mathrm{Ra}$ & 0.008345 & $\mu \mathrm{m}$ \\
\hline Rig & 001045 & $\mu \mathrm{m}$ \\
\hline Risk & 008134 & \\
\hline Rita & 2.839 & \\
\hline
\end{tabular}

Figura B.74 - Relação dos parâmetros obtidos da Amostra 9 Região 1.

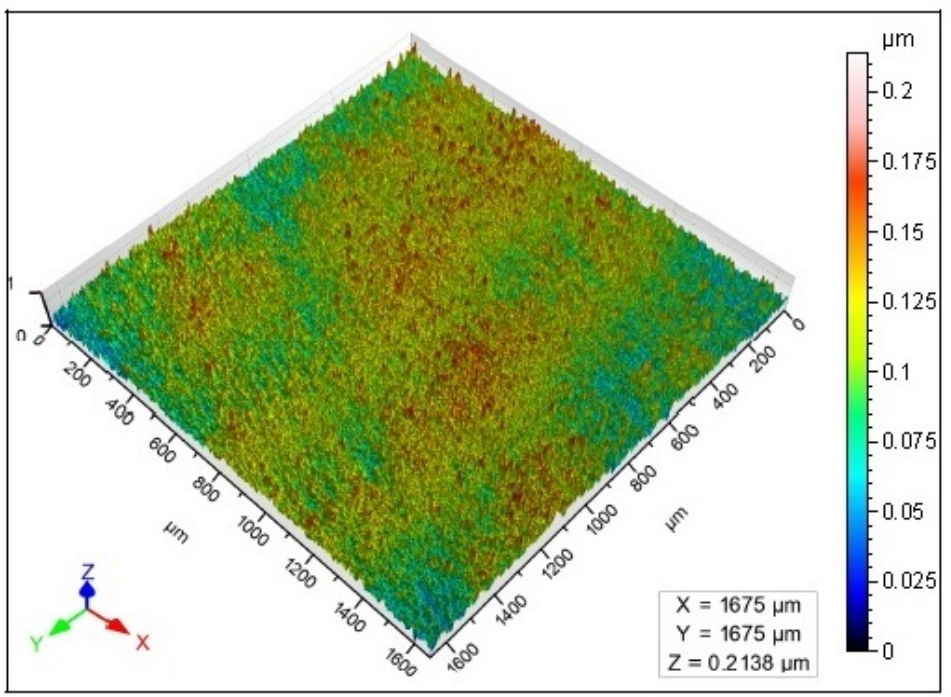

Figura B.75 - Amostra 9 Região 1 Resultados em 3D. 
PROFILE EXTRACTION

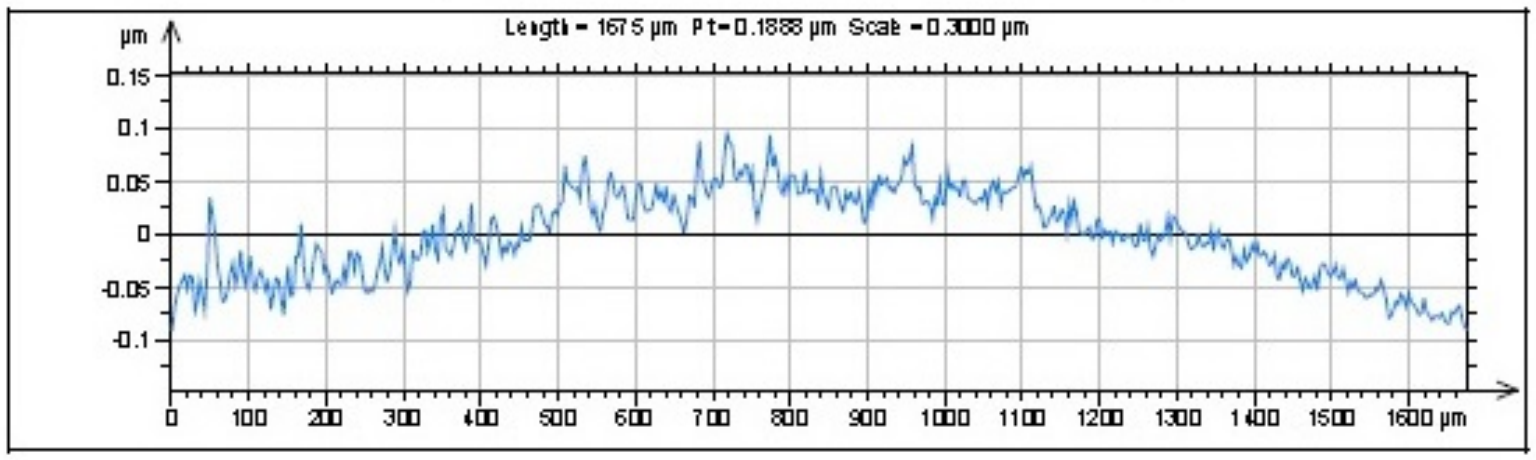

Figura B.76 - Amostra 9 Região 2 Perfil da Superfície.

\begin{tabular}{|c|c|c|}
\hline \multicolumn{3}{|c|}{ ISO 4287} \\
\hline \multicolumn{3}{|c|}{ Amplitude parameters - Rough } \\
\hline Fp & 002656 & $\mu \mathrm{m}$ \\
\hline $\mathrm{Rv}$ & 002157 & $\mu \mathrm{m}$ \\
\hline $\mathrm{Fz}$ & 004813 & $\mu m$ \\
\hline Roc & 002834 & $\mu m$ \\
\hline Ft & 0.1030 & $\mu m$ \\
\hline $\mathrm{Ra}$ & 0.009391 & $\mu m$ \\
\hline Rig & 001181 & $\mu \mathrm{m}$ \\
\hline Rsk & 02550 & \\
\hline Ritas & 2.805 & \\
\hline
\end{tabular}

Figura B.77 - Relação dos parâmetros obtidos da Amostra 9 Região 2.

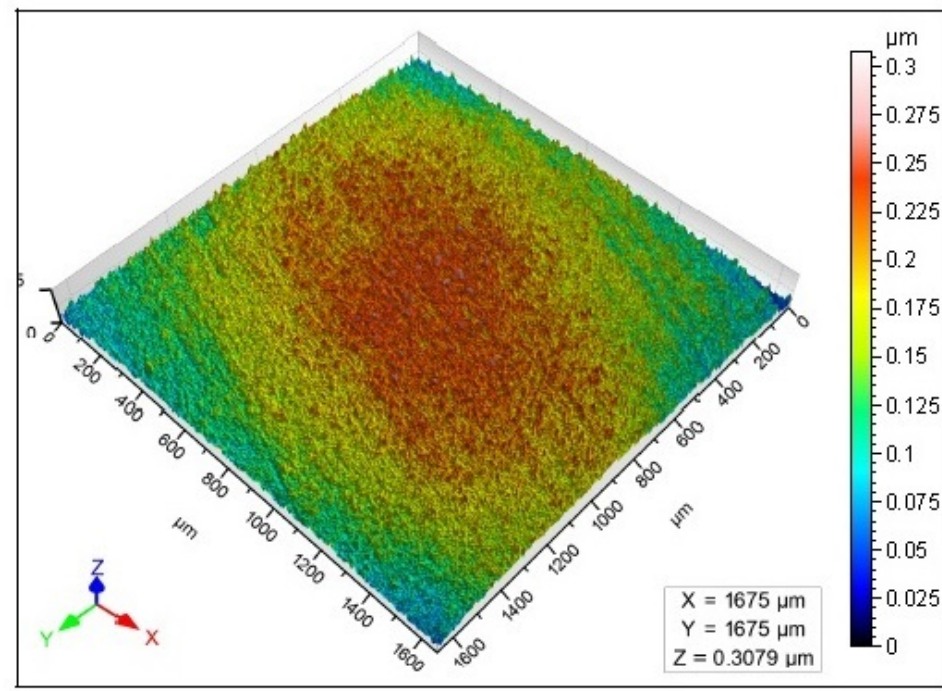

Figura B.78 - Amostra 9 Região 2 Resultados em 3D. 


\section{PROFILE EXTRACT ION}

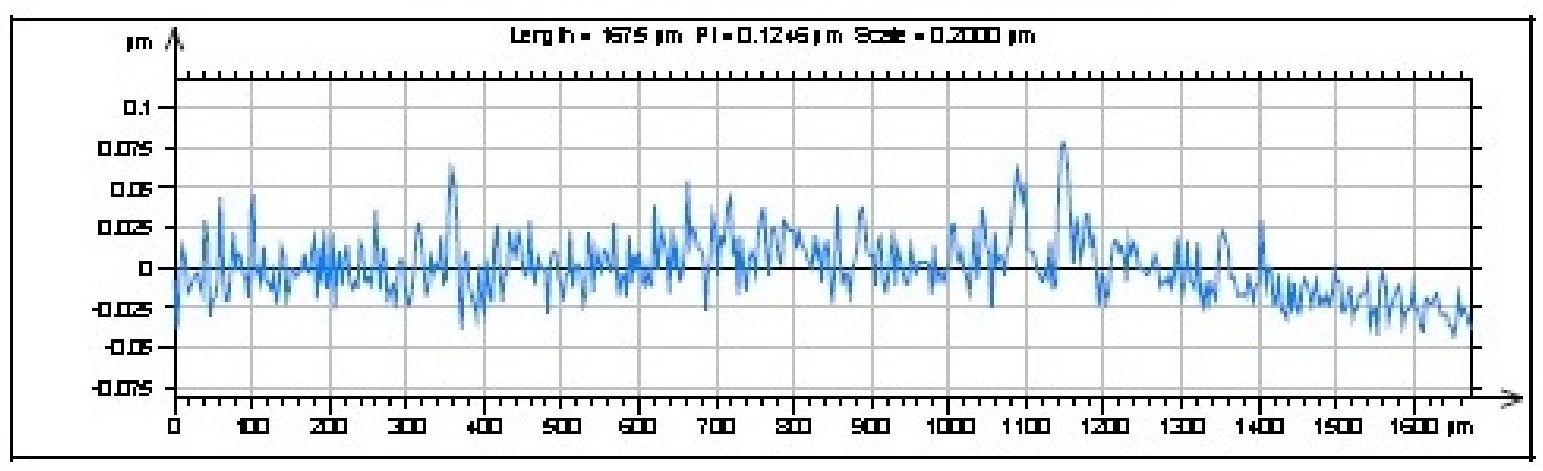

Figura B.79 - Amostra 9 Região 3 Perfil da Superfície.

\begin{tabular}{|c|c|c|}
\hline \multicolumn{3}{|c|}{ ISO 4287} \\
\hline \multicolumn{3}{|c|}{ Amplitude $p$ arameters - Roug } \\
\hline $\mathrm{Rp}$ & 002206 & $\mu m$ \\
\hline Rv & 002030 & $\mu \mathrm{m}$ \\
\hline Rzz & 004235 & $\mu \mathrm{m}$ \\
\hline $\mathrm{Ric}$ & 002409 & $\mu \mathrm{m}$ \\
\hline Rt & 007237 & $\mu \mathrm{m}$ \\
\hline $\mathrm{Ra}$ & 0.008348 & $\mu m$ \\
\hline $\mathrm{Rq}$ & 001047 & $\mu m$ \\
\hline Rsk & 0.08137 & \\
\hline Rku & 2840 & \\
\hline
\end{tabular}

Figura B.80 - Relação dos parâmetros obtidos da Amostra 9 Região 3.

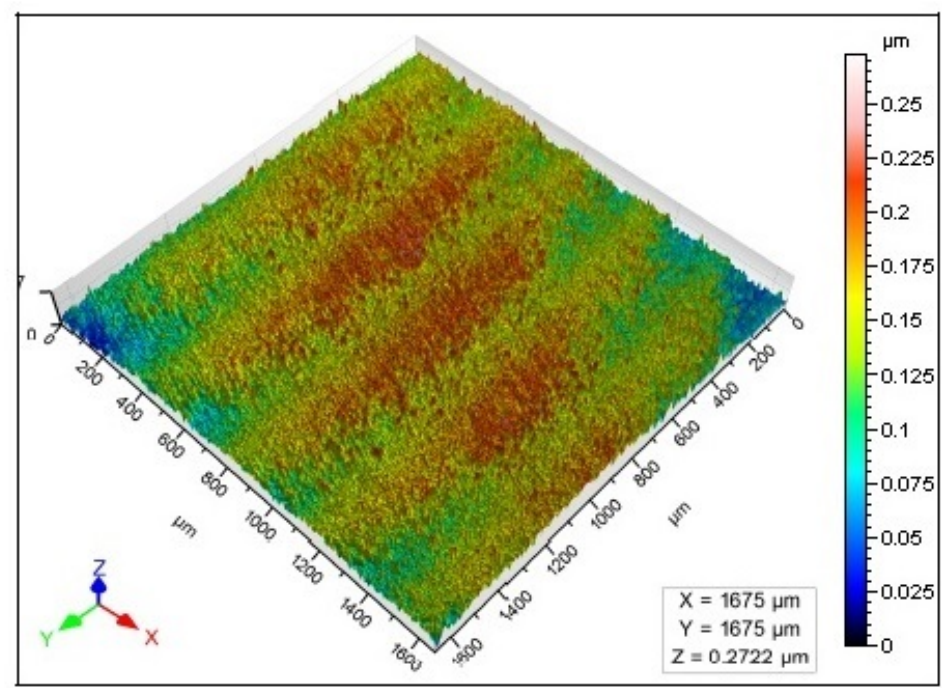

Figura B.81 - Amostra 9 Região 3 Resultados em 3D. 
PROFILE EXTRACTION

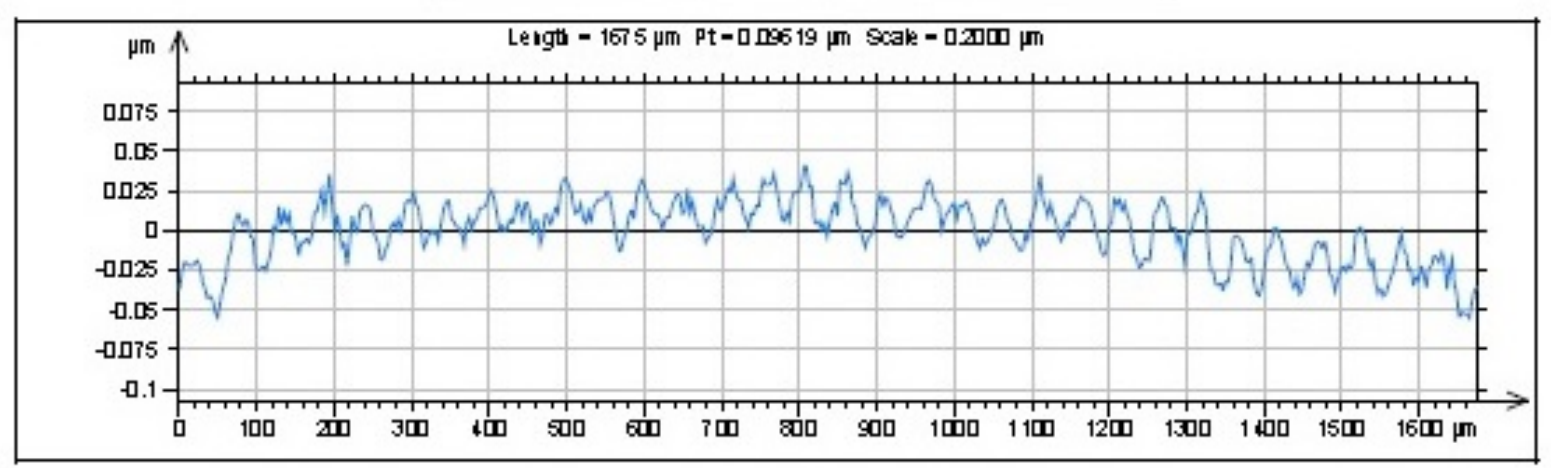

Figura B.82 - Amostra 10 Região 1 Perfil da Superfície.

\begin{tabular}{|c|c|c|}
\hline \multicolumn{3}{|c|}{ ISO 4287} \\
\hline \multicolumn{3}{|c|}{ Amplitude parameters - Rough } \\
\hline Fp & 001625 & $\mu \mathrm{m}$ \\
\hline Rv & 001624 & $\mu m$ \\
\hline Fzz & 003319 & $\mu \mathrm{m}$ \\
\hline $\mathrm{Ric}$ & 002438 & $\mu m$ \\
\hline Ft & 004903 & $\mu \mathrm{m}$ \\
\hline $\mathrm{R}_{\mathrm{a}}$ & 0.007713 & $\mu \mathrm{m}$ \\
\hline Rig & 0.009142 & $\mu \mathrm{m}$ \\
\hline Rsk & 006783 & \\
\hline Ritu & 2211 & \\
\hline
\end{tabular}

Figura B.83 - Relação dos parâmetros obtidos da Amostra 10 Região 1.

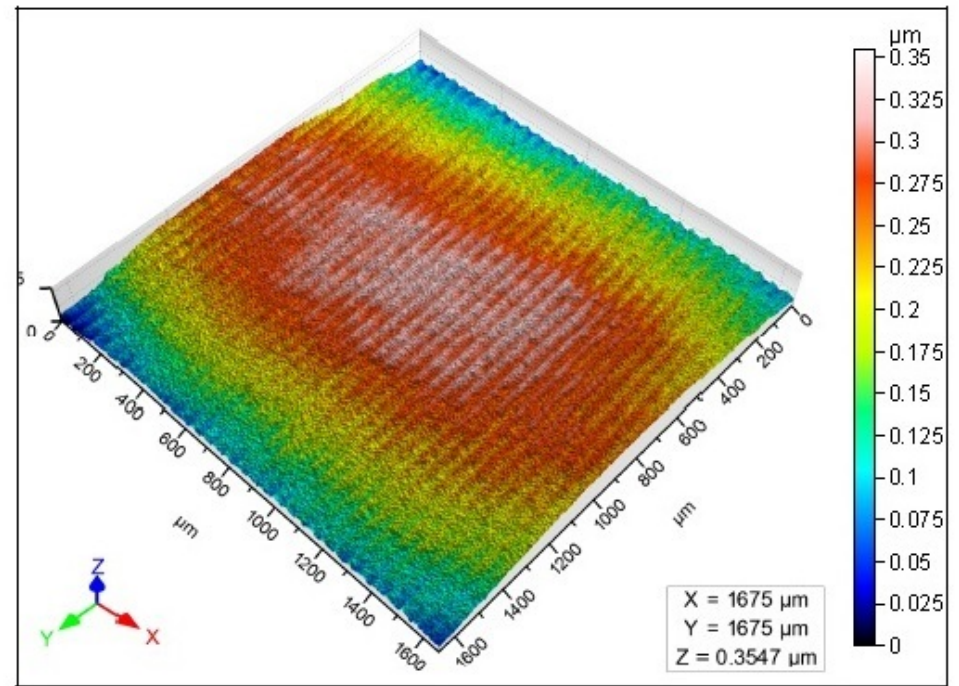

Figura B.84 - Amostra 10 Região 1 Resultados em 3D. 


\section{PROFILE EXTRACTION}

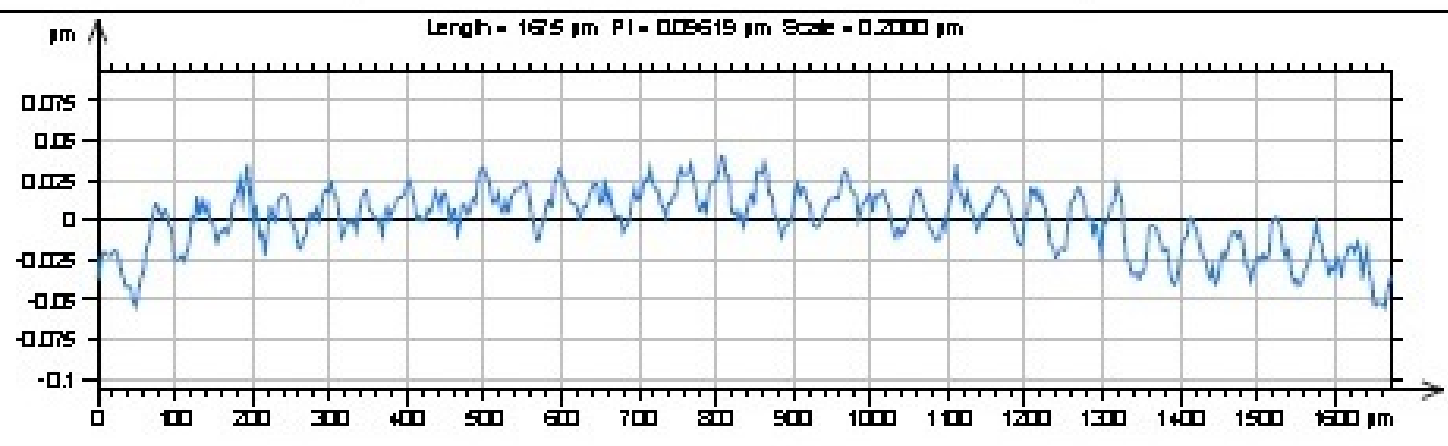

Figura B.85 - Amostra 10 Região 2 Perfil da Superfície.

\begin{tabular}{|c|cc|}
\hline \multicolumn{3}{|l|}{ ISO 4287} \\
Amplitude $p$ ar ameters - R ough \\
\hline Rp & 0.01096 & $\mu m$ \\
\hline Rv & 0.01025 & $\mu m$ \\
\hline Rz & 0.02119 & $\mu m$ \\
\hline Ro & 0.01446 & $\mu m$ \\
\hline Rt & 0.03159 & $\mu m$ \\
\hline Ra & 0.004671 & $\mu m$ \\
\hline Rq & 0.005723 & $\mu m$ \\
\hline Rsk & 0.1193 & \\
\hline Rku & 2350 \\
\hline
\end{tabular}

Figura B.86 - Relação dos parâmetros obtidos da Amostra 10 Região 2.

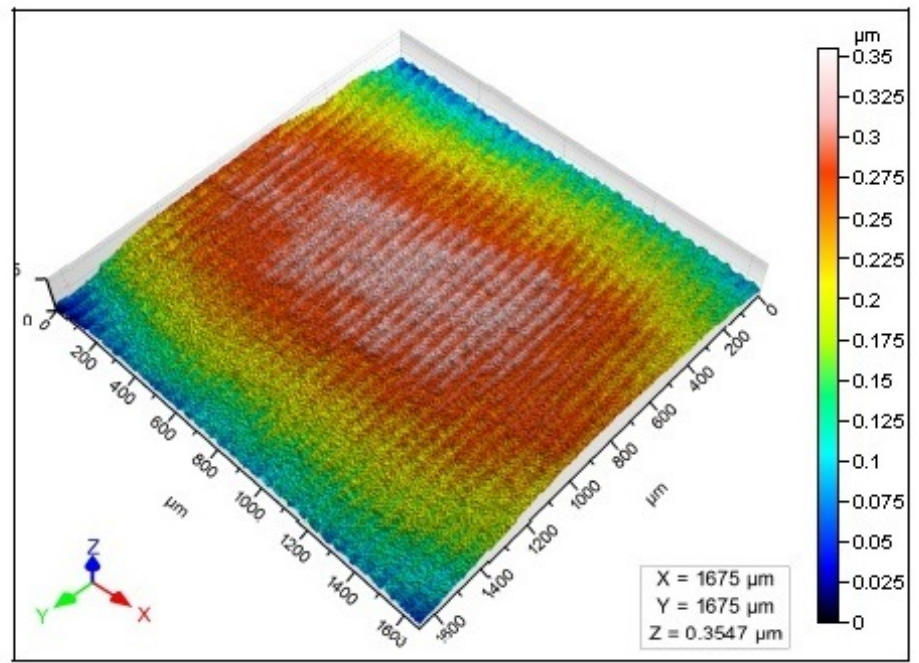

Figura B.87 - Amostra 10 Região 2 Resultados em 3D. 


\section{PROFILE EXTRACTION}

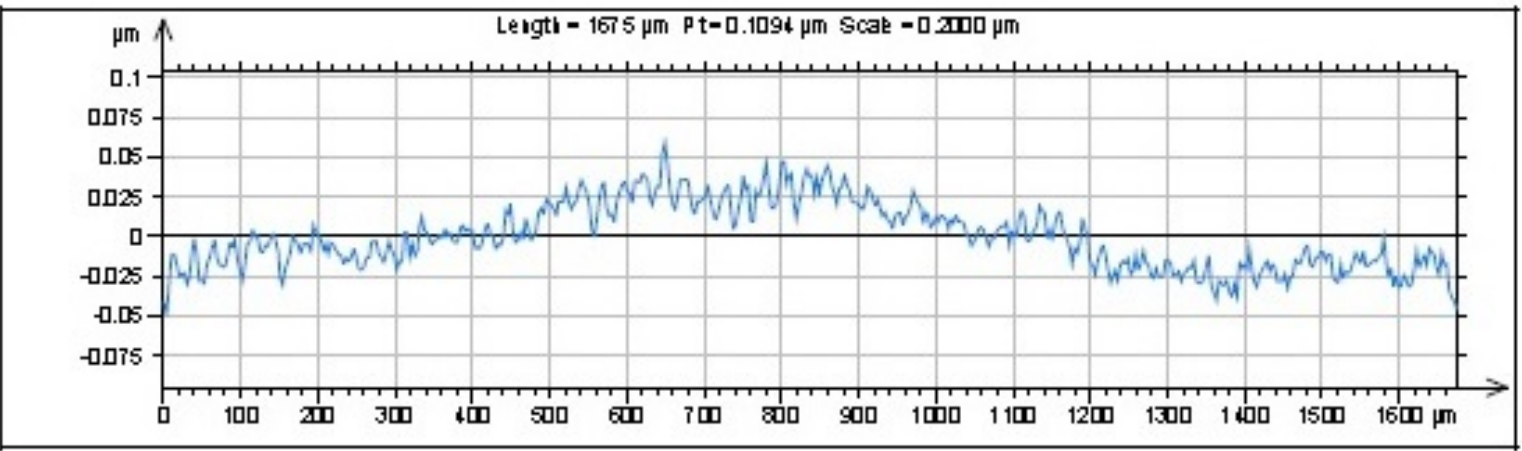

Figura B.88 - Amostra 10 Região 3 Perfil da Superfície.

\begin{tabular}{|c|c|c|}
\hline \multicolumn{3}{|c|}{ ISO 4287} \\
\hline \multicolumn{3}{|c|}{ Amplitude parameters - Rough } \\
\hline Fp & 001343 & $\mu m$ \\
\hline Rv & 001258 & $\mu m$ \\
\hline Fzz & 002601 & $\mu m$ \\
\hline Ric & 001766 & $\mu m$ \\
\hline Fit & 004538 & $\mu m$ \\
\hline $\mathrm{Ra}$ & 0.005532 & $\mu m$ \\
\hline Rig & 0.006713 & $\mu m$ \\
\hline Rsk & 008596 & \\
\hline Ritas & 2.526 & \\
\hline
\end{tabular}

Figura B.89 - Relação dos parâmetros obtidos da Amostra 10 Região 3.

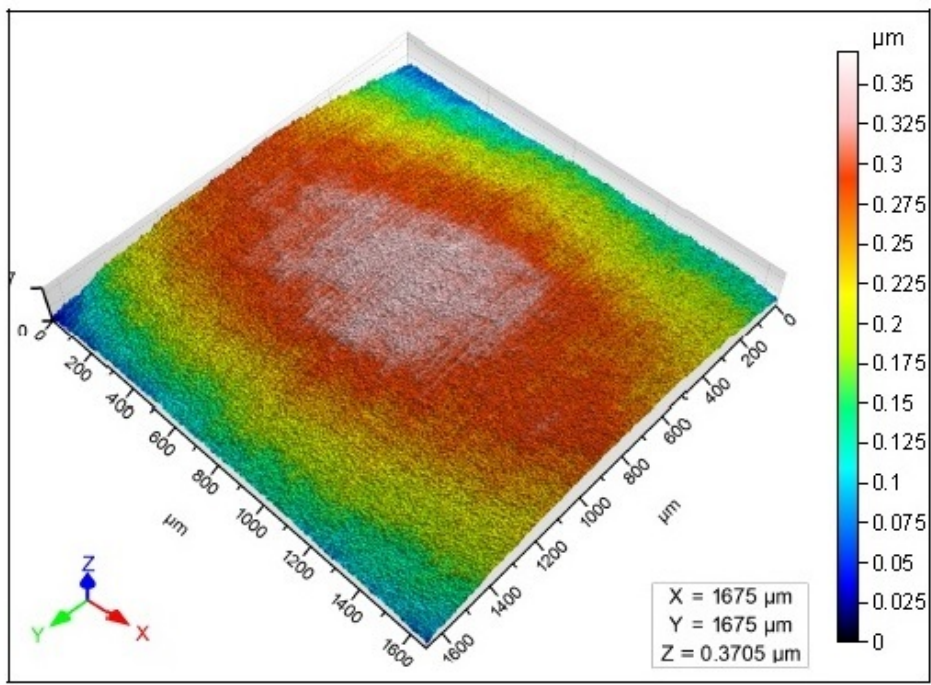

Figura B.90 - Amostra 10 Região 3 Resultados em 3D. 


\section{APÊNDICE C - Resultados dos valores da (Ra) por amostras e suas respectivas regiões.}

Tabela C.1 - Resultados de Ra da Amostra 1.

\begin{tabular}{cc}
\hline \multicolumn{2}{c}{ Região 1} \\
\hline $\mathrm{N}$ & $\mathrm{Ra}$ \\
\hline 1 & 1,1000 \\
\hline 2 & 1,1020 \\
\hline 3 & 1,1130 \\
\hline 4 & 1,1080 \\
\hline 5 & 1,1070 \\
\hline 6 & 1,1120 \\
\hline 7 & 1,1150 \\
\hline 8 & 1,1240 \\
\hline 9 & 1,0970 \\
\hline média & 1,1087 \\
\hline
\end{tabular}

\begin{tabular}{cc}
\hline \multicolumn{2}{c}{ Região 2} \\
\hline $\mathrm{N}$ & $\mathrm{Ra}$ \\
\hline 1 & 1,1130 \\
\hline 2 & 1,1130 \\
\hline 3 & 1,0910 \\
\hline 4 & 1,1600 \\
\hline 5 & 1,0930 \\
\hline 6 & 1,0720 \\
\hline 7 & 1,1180 \\
\hline 8 & 1,1280 \\
\hline 9 & 1,0980 \\
\hline média & 1,1096 \\
\hline
\end{tabular}

\begin{tabular}{cc}
\hline \multicolumn{2}{c}{ Região 3} \\
\hline $\mathrm{N}$ & $\mathrm{Ra}$ \\
\hline 1 & 1,1920 \\
\hline 2 & 1,1970 \\
\hline 3 & 1,1750 \\
\hline 4 & 1,1980 \\
\hline 5 & 1,1880 \\
\hline 6 & 1,1990 \\
\hline 7 & 1,1880 \\
\hline 8 & 1,2080 \\
\hline 9 & 1,1810 \\
\hline média & 1,1918 \\
\hline
\end{tabular}

Tabela C.2 - Resultados de Ra da Amostra 2.

\begin{tabular}{cc}
\hline \multicolumn{2}{c}{ Região 1} \\
\hline $\mathrm{N}$ & $\mathrm{Ra}$ \\
\hline 1 & 0,0802 \\
\hline 2 & 0,0796 \\
\hline 3 & 0,0853 \\
\hline 4 & 0,0851 \\
\hline 5 & 0,0810 \\
\hline 6 & 0,0793 \\
\hline 7 & 0,0851 \\
\hline 8 & 0,0887 \\
\hline 9 & 0,0796 \\
\hline média & 0,0826 \\
\hline
\end{tabular}

\begin{tabular}{cc}
\hline \multicolumn{2}{c}{ Região 2} \\
\hline $\mathrm{N}$ & $\mathrm{Ra}$ \\
\hline 1 & 0,1401 \\
\hline 2 & 0,1427 \\
\hline 3 & 0,1367 \\
\hline 4 & 0,1424 \\
\hline 5 & 0,1420 \\
\hline 6 & 0,1365 \\
\hline 7 & 0,1398 \\
\hline 8 & 0,1407 \\
\hline 9 & 0,1406 \\
\hline média & 0,1402 \\
\hline
\end{tabular}

\begin{tabular}{cc}
\hline \multicolumn{2}{c}{ Região 3} \\
\hline $\mathrm{N}$ & $\mathrm{Ra}$ \\
\hline 1 & 0,1144 \\
\hline 2 & 0,1099 \\
\hline 3 & 0,0916 \\
\hline 4 & 0,0999 \\
\hline 5 & 0,1028 \\
\hline 6 & 0,1082 \\
\hline 7 & 0,1066 \\
\hline 8 & 0,1069 \\
\hline 9 & 0,1053 \\
\hline média & 0,1051 \\
\hline
\end{tabular}


Tabela C.3 - Resultados de Ra da Amostra 3.

\begin{tabular}{cc}
\hline \multicolumn{2}{c}{ Região 1} \\
\hline $\mathrm{N}$ & $\mathrm{Ra}$ \\
\hline 1 & 0,1971 \\
\hline 2 & 0,1985 \\
\hline 3 & 0,1927 \\
\hline 4 & 0,2043 \\
\hline 5 & 0,1977 \\
\hline 6 & 0,1953 \\
\hline 7 & 0,1996 \\
\hline 8 & 0,1925 \\
\hline 9 & 0,2000 \\
\hline média & 0,1989 \\
\hline
\end{tabular}

\begin{tabular}{cc}
\hline \multicolumn{2}{c}{ Região 2} \\
\hline $\mathrm{N}$ & $\mathrm{Ra}$ \\
\hline 1 & 0,1798 \\
\hline 2 & 0,1797 \\
\hline 3 & 0,1726 \\
\hline 4 & 0,1704 \\
\hline 5 & 0,1733 \\
\hline 6 & 0,1724 \\
\hline 7 & 0,1698 \\
\hline 8 & 0,1735 \\
\hline 9 & 0,1765 \\
\hline média & 0,1742 \\
\hline
\end{tabular}

\begin{tabular}{cc}
\hline \multicolumn{2}{c}{ Região 3} \\
\hline $\mathrm{N}$ & $\mathrm{Ra}$ \\
\hline 1 & 0,1831 \\
\hline 2 & 0,1940 \\
\hline 3 & 0,1938 \\
\hline 4 & 0,1948 \\
\hline 5 & 0,1974 \\
\hline 6 & 0,1082 \\
\hline 7 & 0,2024 \\
\hline 8 & 0,1970 \\
\hline 9 & 0,1942 \\
\hline média & 0,1947 \\
\hline
\end{tabular}

Tabela C.4 - Resultados de Ra da Amostra 4.

\begin{tabular}{cc}
\hline \multicolumn{2}{c}{ Região 1} \\
\hline $\mathrm{N}$ & $\mathrm{Ra}$ \\
\hline 1 & 0,0635 \\
\hline 2 & 0,0596 \\
\hline 3 & 0,0610 \\
\hline 4 & 0,0607 \\
\hline 5 & 0,0639 \\
\hline 6 & 0,0627 \\
\hline 7 & 0,0793 \\
\hline 8 & 0,0598 \\
\hline 9 & 0,0588 \\
\hline média & 0,0608 \\
\hline
\end{tabular}

\begin{tabular}{cc}
\hline \multicolumn{2}{c}{ Região 2} \\
\hline $\mathrm{N}$ & $\mathrm{Ra}$ \\
\hline 1 & 0,0634 \\
\hline 2 & 0,0594 \\
\hline 3 & 0,0606 \\
\hline 4 & 0,0591 \\
\hline 5 & 0,0671 \\
\hline 6 & 0,0633 \\
\hline 7 & 0,0684 \\
\hline 8 & 0,0581 \\
\hline 9 & 0,0678 \\
\hline média & 0,0631 \\
\hline
\end{tabular}

\begin{tabular}{cc}
\hline \multicolumn{2}{c}{ Região 3} \\
\hline $\mathrm{N}$ & $\mathrm{Ra}$ \\
\hline 1 & 0,0795 \\
\hline 2 & 0,0814 \\
\hline 3 & 0,0830 \\
\hline 4 & 0,0812 \\
\hline 5 & 0,0862 \\
\hline 6 & 0,0793 \\
\hline 7 & 0,0889 \\
\hline 8 & 0,0810 \\
\hline 9 & 0,0785 \\
\hline média & 0,0821
\end{tabular}


Tabela C.5 - Resultados de Ra da Amostra 5.

\begin{tabular}{cc}
\hline \multicolumn{2}{c}{ Região 1} \\
\hline $\mathrm{N}$ & $\mathrm{Ra}$ \\
\hline 1 & 0,0359 \\
\hline 2 & 0,0367 \\
\hline 3 & 0,0357 \\
\hline 4 & 0,0335 \\
\hline 5 & 0,0363 \\
\hline 6 & 0,0377 \\
\hline 7 & 0,0389 \\
\hline 8 & 0,0351 \\
\hline 9 & 0,0385 \\
\hline média & 0,0365 \\
\hline
\end{tabular}

\begin{tabular}{cc}
\hline \multicolumn{2}{c}{ Região 2} \\
\hline $\mathrm{N}$ & $\mathrm{Ra}$ \\
\hline 1 & 0,0451 \\
\hline 2 & 0,0481 \\
\hline 3 & 0,0464 \\
\hline 4 & 0,0482 \\
\hline 5 & 0,0460 \\
\hline 6 & 0,0489 \\
\hline 7 & 0,0451 \\
\hline 8 & 0,0466 \\
\hline 9 & 0,0463 \\
\hline média & 0,0468
\end{tabular}

\begin{tabular}{cc}
\hline \multicolumn{2}{c}{ Região 3} \\
\hline $\mathrm{N}$ & $\mathrm{Ra}$ \\
\hline 1 & 0,0448 \\
\hline 2 & 0,0400 \\
\hline 3 & 0,0424 \\
\hline 4 & 0,0429 \\
\hline 5 & 0,0434 \\
\hline 6 & 0,0469 \\
\hline 7 & 0,0424 \\
\hline 8 & 0,0444 \\
\hline 9 & 0,0458 \\
\hline média & 0,0437 \\
\hline
\end{tabular}

Tabela C.6 - Resultados de Ra da Amostra 6.

\begin{tabular}{cc}
\hline \multicolumn{2}{c}{ Região 1} \\
\hline $\mathrm{N}$ & $\mathrm{Ra}$ \\
\hline 1 & 0,0811 \\
\hline 2 & 0,0810 \\
\hline 3 & 0,0876 \\
\hline 4 & 0,0830 \\
\hline 5 & 0,0843 \\
\hline 6 & 0,0821 \\
\hline 7 & 0,0847 \\
\hline 8 & 0,0810 \\
\hline 9 & 0,0821 \\
\hline média & 0,0830 \\
\hline
\end{tabular}

\begin{tabular}{cc}
\hline \multicolumn{2}{c}{ Região 2} \\
\hline $\mathrm{N}$ & $\mathrm{Ra}$ \\
\hline 1 & 0,0561 \\
\hline 2 & 0,0523 \\
\hline 3 & 0,0540 \\
\hline 4 & 0,0544 \\
\hline 5 & 0,0543 \\
\hline 6 & 0,0580 \\
\hline 7 & 0,0571 \\
\hline 8 & 0,0572 \\
\hline 9 & 0,0555 \\
\hline média & 0,0554 \\
\hline
\end{tabular}

\begin{tabular}{cc}
\hline \multicolumn{2}{c}{ Região 3} \\
\hline $\mathrm{N}$ & $\mathrm{Ra}$ \\
\hline 1 & 0,0519 \\
\hline 2 & 0,0529 \\
\hline 3 & 0,0520 \\
\hline 4 & 0,0553 \\
\hline 5 & 0,0533 \\
\hline 6 & 0,0523 \\
\hline 7 & 0,0507 \\
\hline 8 & 0,0521 \\
\hline 9 & 0,0535 \\
\hline média & 0,0527 \\
\hline
\end{tabular}


Tabela C.7 - Resultados de Ra da Amostra 7.

\begin{tabular}{cc}
\hline \multicolumn{2}{c}{ Região 1} \\
\hline $\mathrm{N}$ & $\mathrm{Ra}$ \\
\hline 1 & 0,0202 \\
\hline 2 & 0,0207 \\
\hline 3 & 0,0216 \\
\hline 4 & 0,0205 \\
\hline 5 & 0,0223 \\
\hline 6 & 0,0234 \\
\hline 7 & 0,0226 \\
\hline 8 & 0,0242 \\
\hline 9 & 0,0270 \\
\hline média & 0,0225 \\
\hline
\end{tabular}

\begin{tabular}{cc}
\hline \multicolumn{2}{c}{ Região 2} \\
\hline $\mathrm{N}$ & $\mathrm{Ra}$ \\
\hline 1 & 0,0272 \\
\hline 2 & 0,0262 \\
\hline 3 & 0,0285 \\
\hline 4 & 0,0233 \\
\hline 5 & 0,0222 \\
\hline 6 & 0,0217 \\
\hline 7 & 0,0229 \\
\hline 8 & 0,0279 \\
\hline 9 & 0,0205 \\
\hline média & 0,0245 \\
\hline
\end{tabular}

\begin{tabular}{cc}
\hline \multicolumn{2}{c}{ Região 3} \\
\hline $\mathrm{N}$ & $\mathrm{Ra}$ \\
\hline 1 & 0,0271 \\
\hline 2 & 0,0246 \\
\hline 3 & 0,0284 \\
\hline 4 & 0,0278 \\
\hline 5 & 0,0269 \\
\hline 6 & 0,0249 \\
\hline 7 & 0,0245 \\
\hline 8 & 0,0250 \\
\hline 9 & 0,0276 \\
\hline média & 0,0263 \\
\hline
\end{tabular}

Tabela C.8 - Resultados de Ra da Amostra 8.

\begin{tabular}{cc}
\hline \multicolumn{2}{c}{ Região 1} \\
\hline $\mathrm{N}$ & $\mathrm{Ra}$ \\
\hline 1 & 0,0240 \\
\hline 2 & 0,0232 \\
\hline 3 & 0,0253 \\
\hline 4 & 0,0240 \\
\hline 5 & 0,0262 \\
\hline 6 & 0,0295 \\
\hline 7 & 0,0241 \\
\hline 8 & 0,0232 \\
\hline 9 & 0,0249 \\
\hline média & 0,0249 \\
\hline
\end{tabular}

\begin{tabular}{cc}
\hline \multicolumn{2}{c}{ Região 2} \\
\hline $\mathrm{N}$ & $\mathrm{Ra}$ \\
\hline 1 & 0,0247 \\
\hline 2 & 0,0237 \\
\hline 3 & 0,0276 \\
\hline 4 & 0,0258 \\
\hline 5 & 0,0260 \\
\hline 6 & 0,0255 \\
\hline 7 & 0,0237 \\
\hline 8 & 0,0227 \\
\hline 9 & 0,0241 \\
\hline média & 0,0249 \\
\hline
\end{tabular}

\begin{tabular}{cc}
\hline \multicolumn{2}{c}{ Região 3} \\
\hline $\mathrm{N}$ & $\mathrm{Ra}$ \\
\hline 1 & 0,0253 \\
\hline 2 & 0,0227 \\
\hline 3 & 0,0184 \\
\hline 4 & 0,0247 \\
\hline 5 & 0,0251 \\
\hline 6 & 0,0272 \\
\hline 7 & 0,0227 \\
\hline 8 & 0,0240 \\
\hline 9 & 0,0244 \\
\hline média & 0,0238 \\
\hline
\end{tabular}


Tabela C.9 - Resultados de Ra da Amostra 9.

\begin{tabular}{cc}
\hline \multicolumn{2}{c}{ Região 1} \\
\hline $\mathrm{N}$ & $\mathrm{Ra}$ \\
\hline 1 & 0,0086 \\
\hline 2 & 0,0083 \\
\hline 3 & 0,0083 \\
\hline 4 & 0,0088 \\
\hline 5 & 0,0088 \\
\hline 6 & 0,0088 \\
\hline 7 & 0,0085 \\
\hline 8 & 0,0079 \\
\hline 9 & 0,0087 \\
\hline média & 0,0085 \\
\hline
\end{tabular}

\begin{tabular}{cc}
\hline \multicolumn{2}{c}{ Região 2} \\
\hline $\mathrm{N}$ & $\mathrm{Ra}$ \\
\hline 1 & 0,0090 \\
\hline 2 & 0,0092 \\
\hline 3 & 0,0094 \\
\hline 4 & 0,0091 \\
\hline 5 & 0,0092 \\
\hline 6 & 0,0090 \\
\hline 7 & 0,0090 \\
\hline 8 & 0,0090 \\
\hline 9 & 0,0090 \\
\hline média & 0,0091 \\
\hline
\end{tabular}

\begin{tabular}{cc}
\hline \multicolumn{2}{c}{ Região 3} \\
\hline $\mathrm{N}$ & $\mathrm{Ra}$ \\
\hline 1 & 0,0184 \\
\hline 2 & 0,0164 \\
\hline 3 & 0,0148 \\
\hline 4 & 0,0151 \\
\hline 5 & 0,0192 \\
\hline 6 & 0,0153 \\
\hline 7 & 0,0151 \\
\hline 8 & 0,0197 \\
\hline 9 & 0,0159 \\
\hline média & 0,0167 \\
\hline
\end{tabular}

Tabela C.10 - Resultados de Ra da Amostra 10.

\begin{tabular}{cc}
\hline \multicolumn{2}{c}{ Região 1} \\
\hline $\mathrm{N}$ & $\mathrm{Ra}$ \\
\hline 1 & 0,0079 \\
\hline 2 & 0,0075 \\
\hline 3 & 0,0073 \\
\hline 4 & 0,0078 \\
\hline 5 & 0,0075 \\
\hline 6 & 0,0076 \\
\hline 7 & 0,0072 \\
\hline 8 & 0,0077 \\
\hline 9 & 0,0072 \\
\hline média & 0,0075 \\
\hline
\end{tabular}

\begin{tabular}{cc}
\hline \multicolumn{2}{c}{ Região 2} \\
\hline $\mathrm{N}$ & $\mathrm{Ra}$ \\
\hline 1 & 0,0042 \\
\hline 2 & 0,0045 \\
\hline 3 & 0,0043 \\
\hline 4 & 0,0048 \\
\hline 5 & 0,0045 \\
\hline 6 & 0,0046 \\
\hline 7 & 0,0042 \\
\hline 8 & 0,0040 \\
\hline 9 & 0,0041 \\
\hline média & 0,0047 \\
\hline
\end{tabular}

\begin{tabular}{cc}
\hline \multicolumn{2}{c}{ Região 3} \\
\hline $\mathrm{N}$ & $\mathrm{Ra}$ \\
\hline 1 & 0,0047 \\
\hline 2 & 0,0048 \\
\hline 3 & 0,0049 \\
\hline 4 & 0,0045 \\
\hline 5 & 0,0049 \\
\hline 6 & 0,0048 \\
\hline 7 & 0,0047 \\
\hline 8 & 0,0047 \\
\hline 9 & 0,0047 \\
\hline média & 0,0048 \\
\hline
\end{tabular}




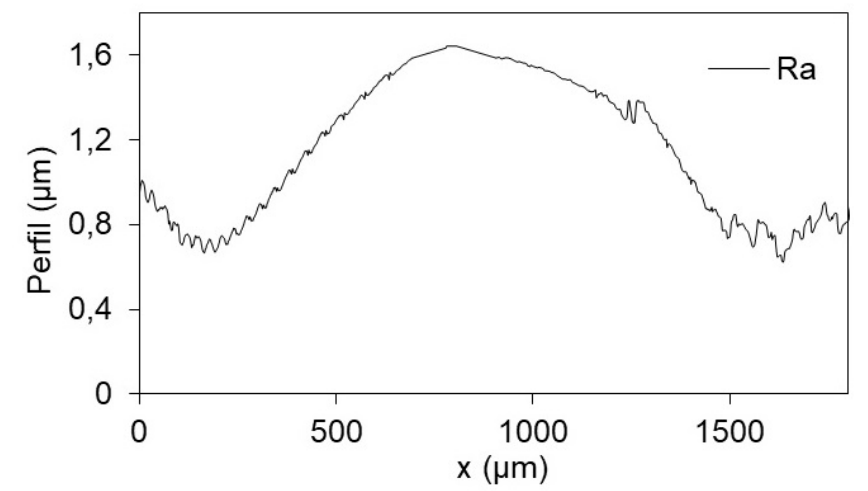

Figura C.1 - Rugosidade superficial Amostra 1 Região 1.

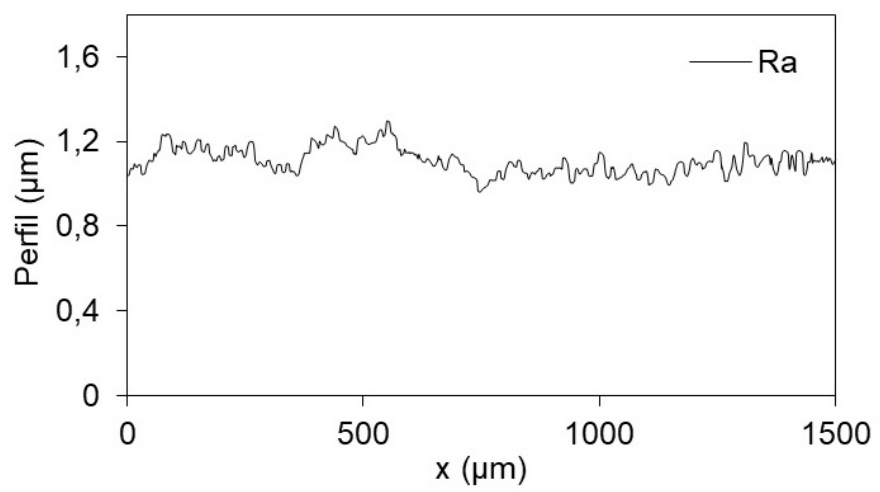

Figura C.2 - Rugosidade superficial Amostra 1 Região 2.

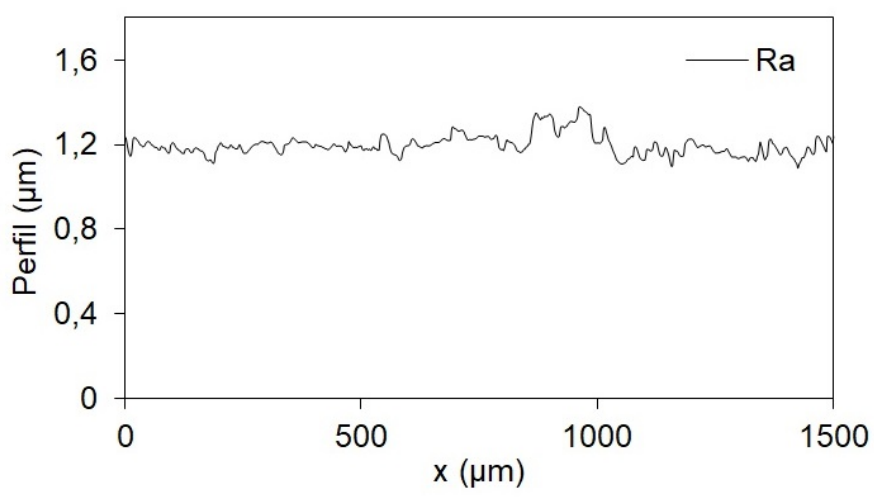

Figura C.3 - Rugosidade superficial Amostra 1 Região 3. 


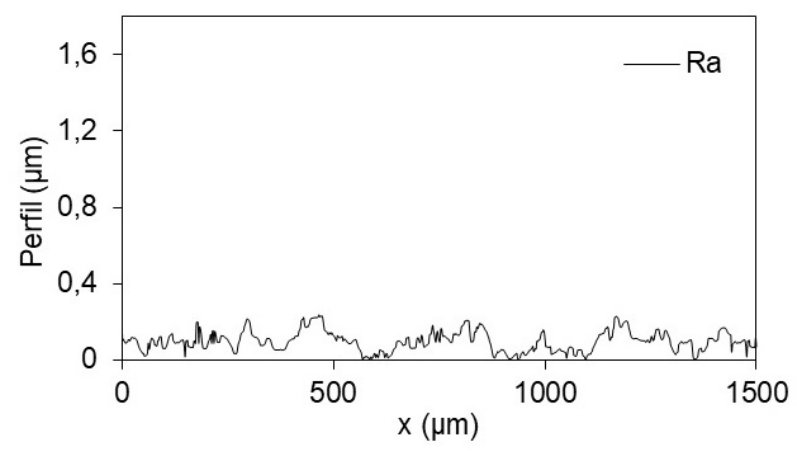

Figura C.4 - Rugosidade superficial Amostra 2 Região 1.

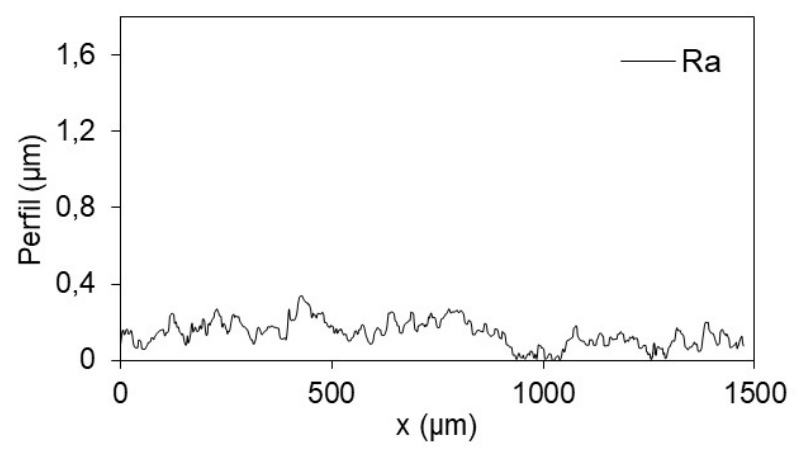

Figura C.5 - Rugosidade superficial Amostra 2 Região 2.

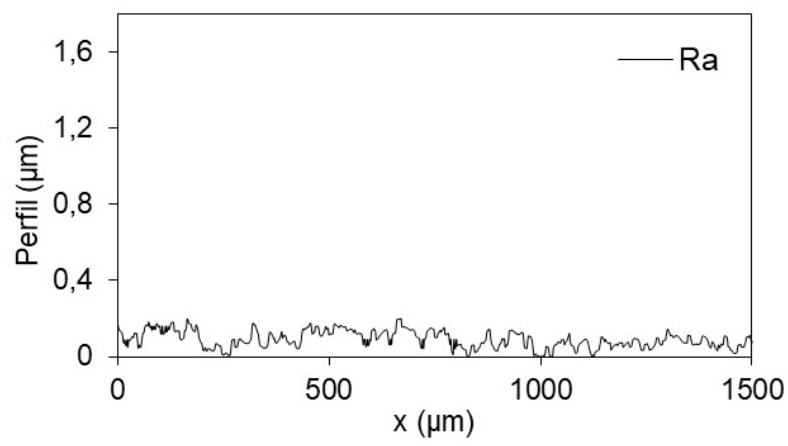

Figura C.6 - Rugosidade superficial Amostra 2 Região 3. 


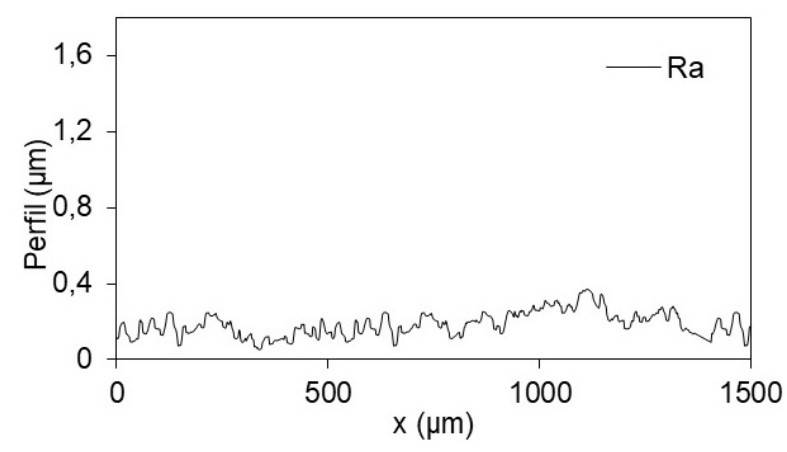

Figura C.7 - Rugosidade superficial Amostra 3 Região 1.

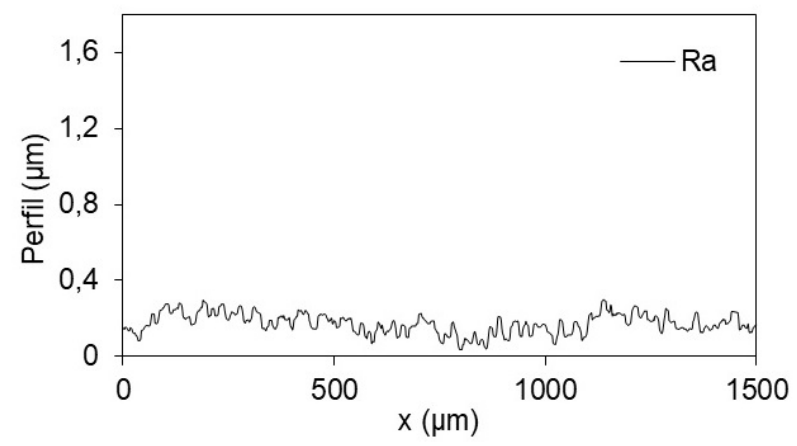

Figura C.8 - Rugosidade superficial Amostra 3 Região 2.

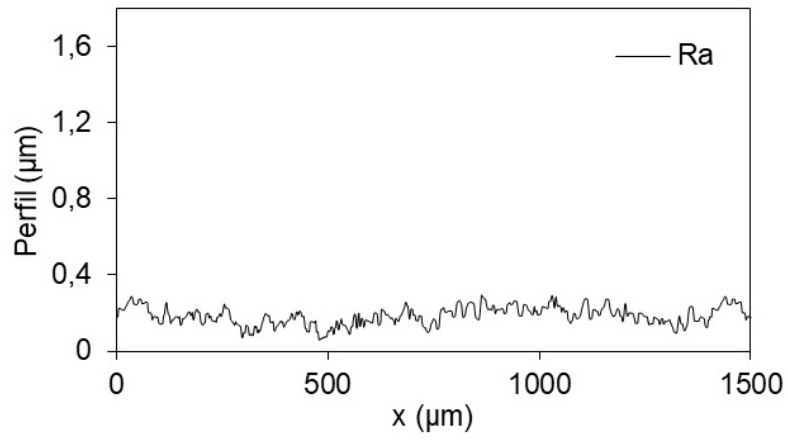

Figura C.9 - Rugosidade superficial Amostra 3 Região 3. 


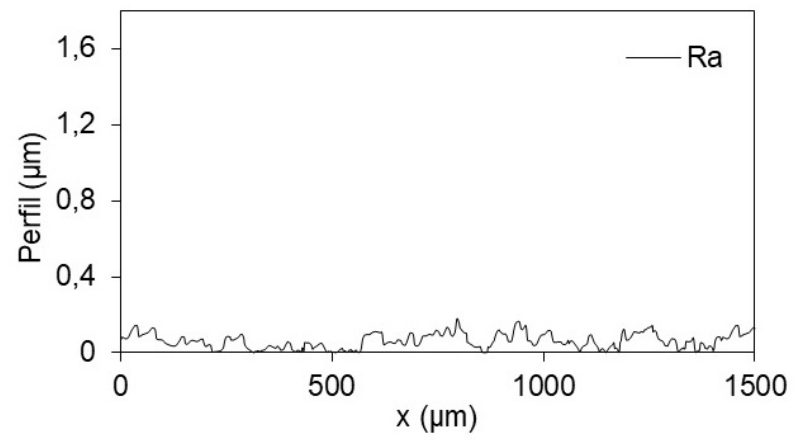

Figura C.10 - Rugosidade superficial Amostra 4 Região 1.

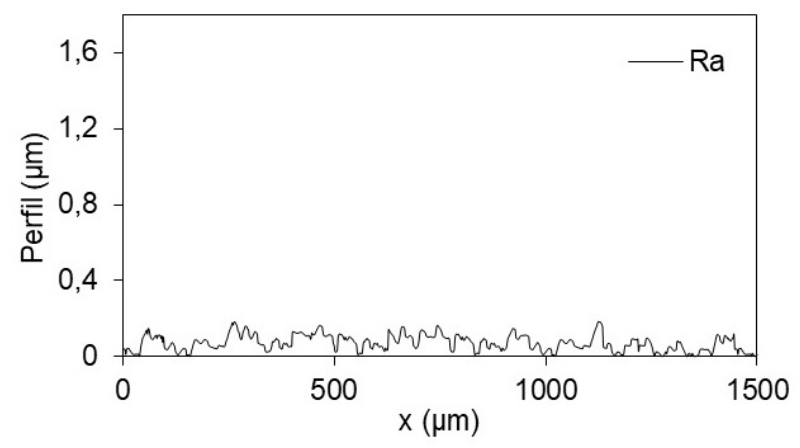

Figura C.11 - Rugosidade superficial Amostra 4 Região 2.

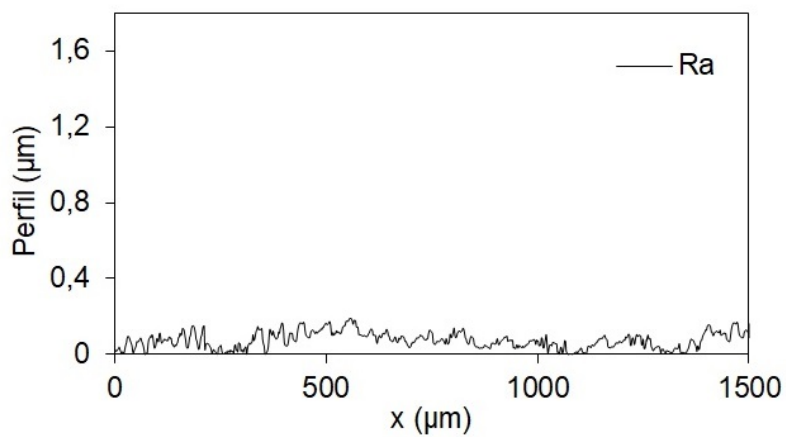

Figura C.12 - Rugosidade superficial Amostra 4 Região 3. 


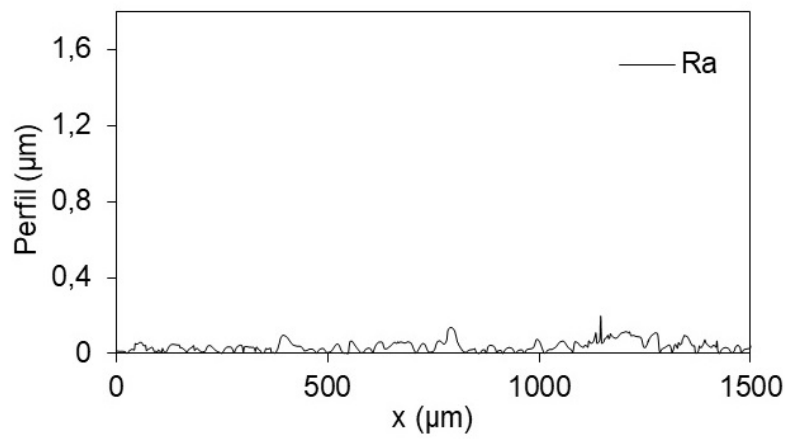

Figura C.13 - Rugosidade superficial Amostra 5 Região 1.

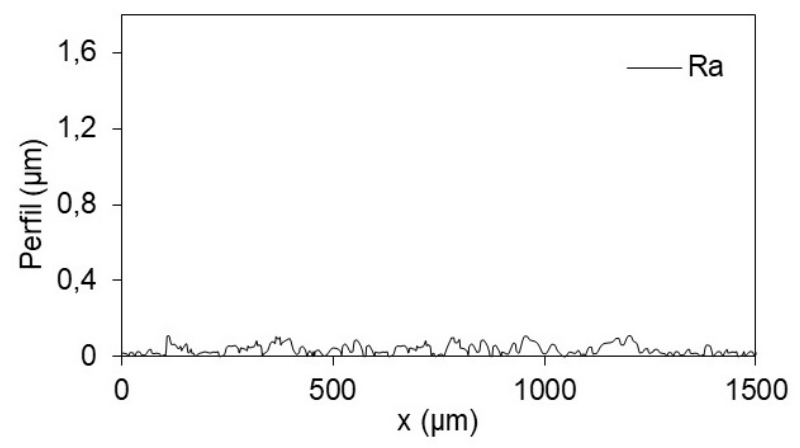

Figura C.14 - Rugosidade superficial Amostra 5 Região 2.

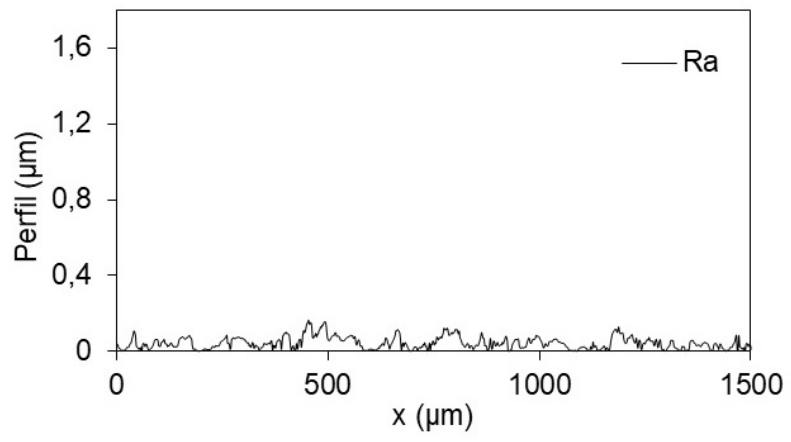

Figura C.15 - Rugosidade superficial Amostra 5 Região 3. 


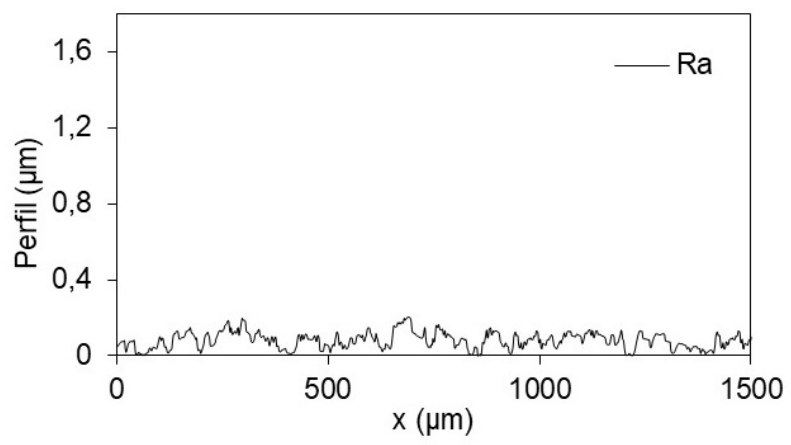

Figura C.16 - Rugosidade superficial Amostra 6 Região 1.

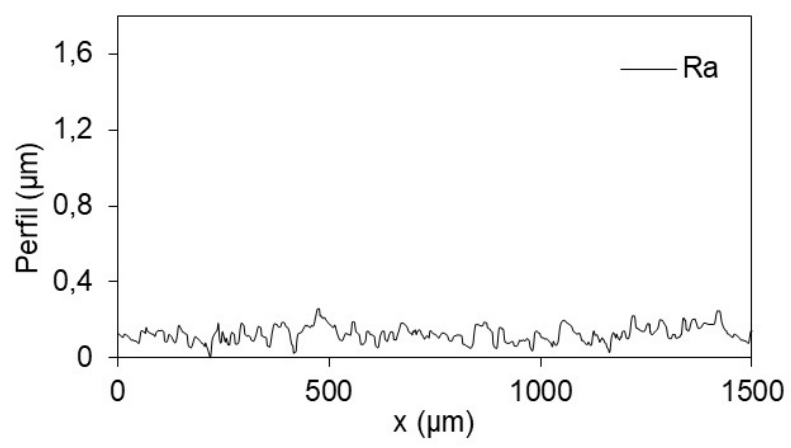

Figura C.17 - Rugosidade superficial Amostra 6 Região 2.

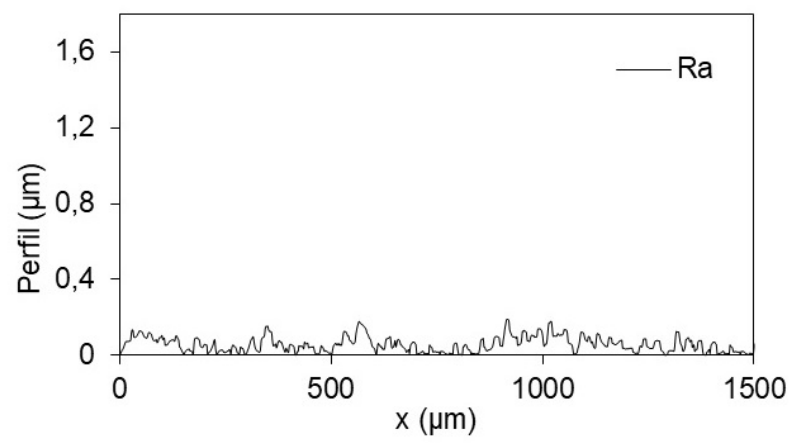

Figura C.18 - Rugosidade superficial Amostra 6 Região 3. 


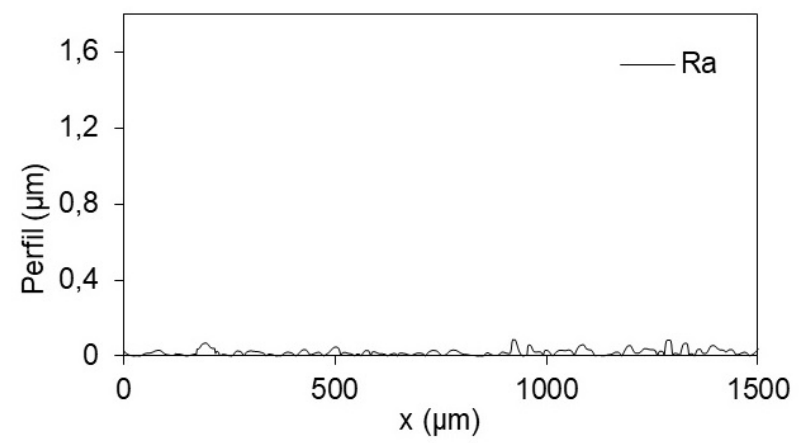

Figura C.19 - Rugosidade superficial Amostra 7 Região 1.

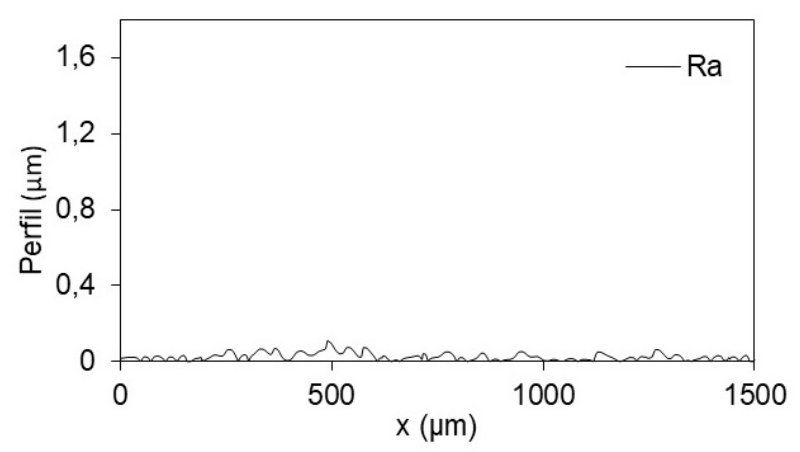

Figura C.20 - Rugosidade superficial Amostra 7 Região 2.

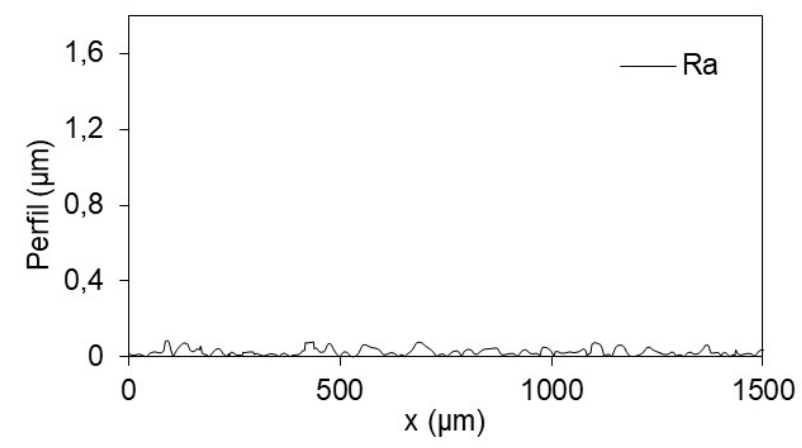

Figura C.21 - Rugosidade superficial Amostra 7 Região 3. 


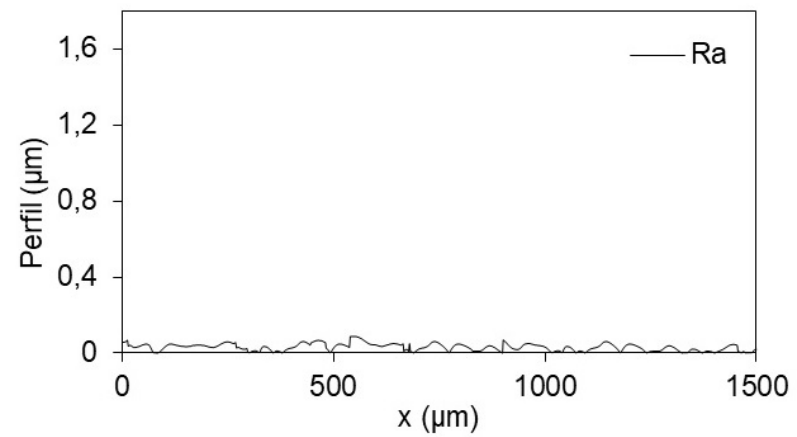

Figura C.22 - Rugosidade superficial Amostra 8 Região 1.

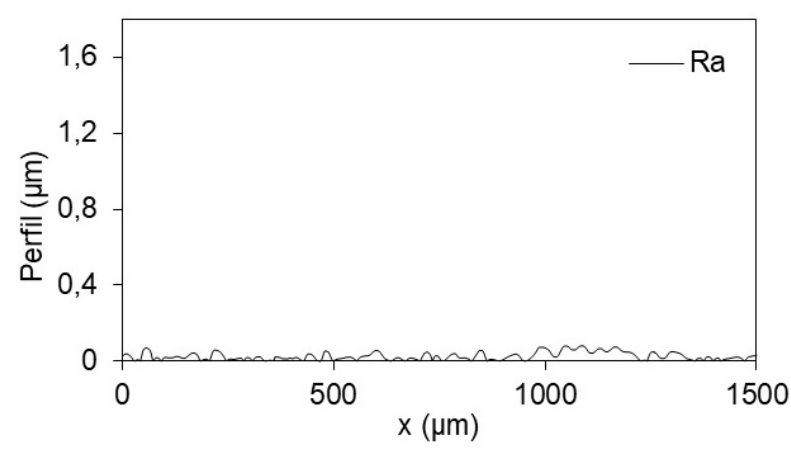

Figura C.23 - Rugosidade superficial Amostra 8 Região 2.

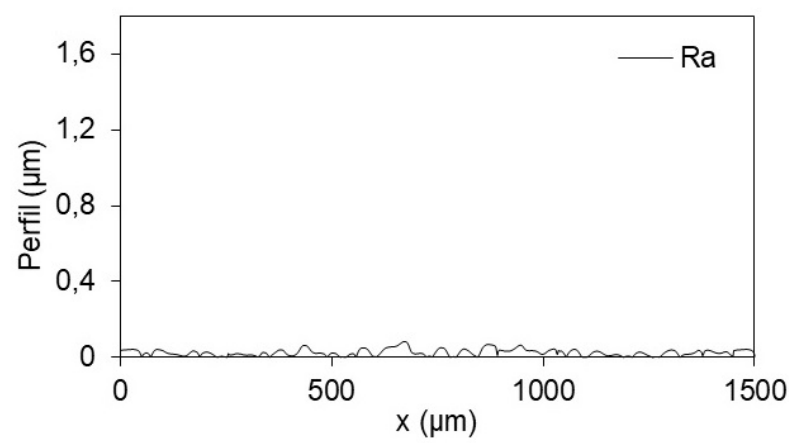

Figura C.24 - Rugosidade superficial Amostra 8 Região 3. 


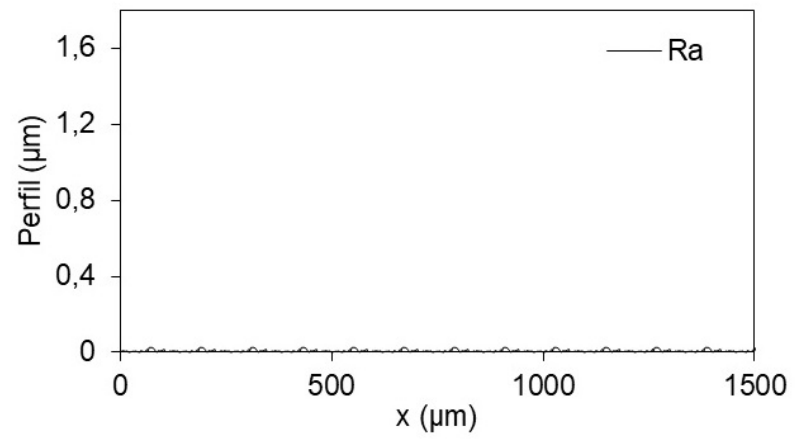

Figura C.25 - Rugosidade superficial Amostra 9 Região 1.

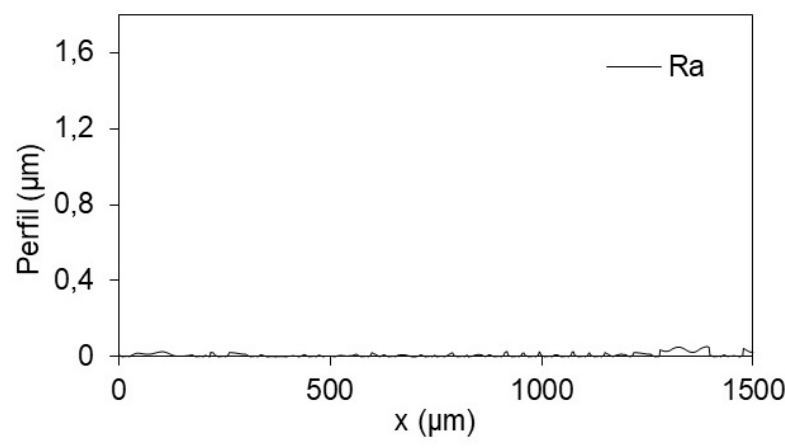

Figura C.26 - Rugosidade superficial Amostra 9 Região 2.

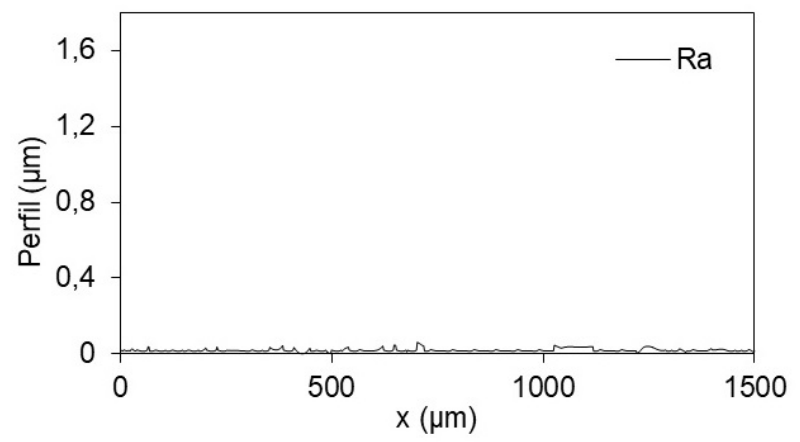

Figura C.27 - Rugosidade superficial Amostra 9 Região 3. 


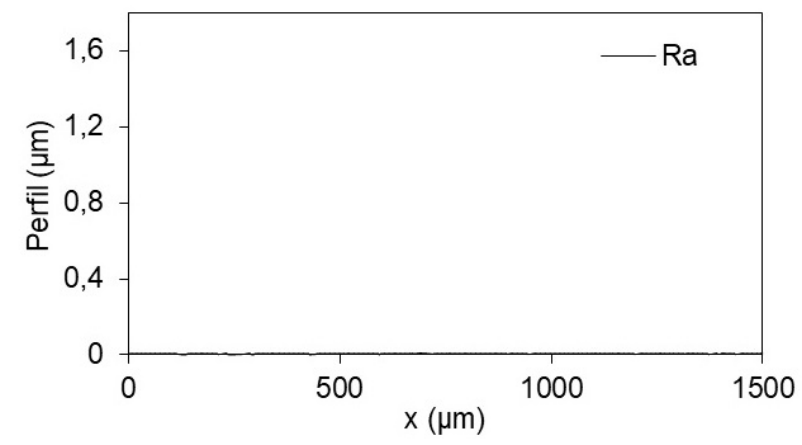

Figura C.28 - Rugosidade superficial Amostra 10 Região 1.

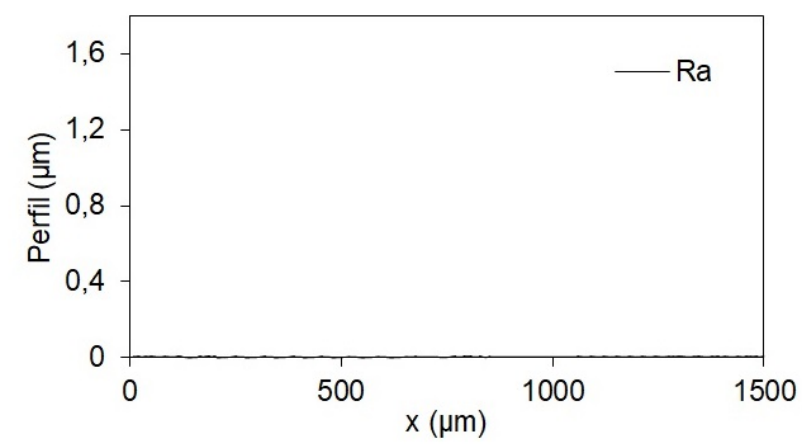

Figura C.29 - Rugosidade superficial Amostra 10 Região 2.

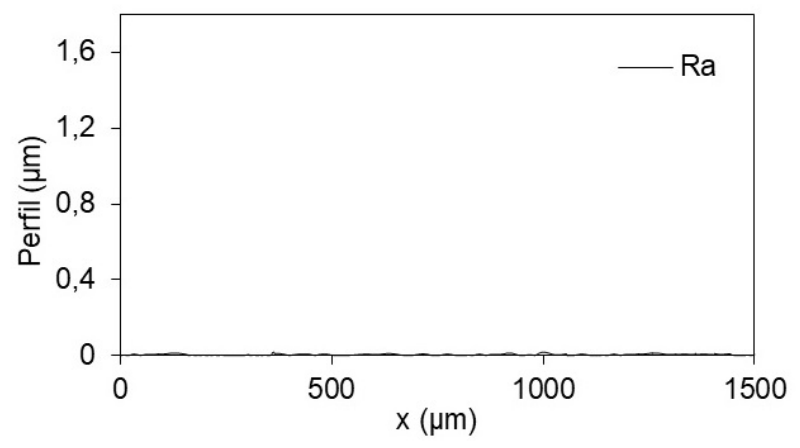

Figura C.30 - Rugosidade superficial Amostra 10 Região 3. 


\section{APÊNDICE D - Resultados da Análise Estatística.}

Na Tabela. D.1, 7 grupos homogêneos são identificados usando colunas de X. Dentro de cada coluna, os níveis que contêm X formam um grupo de meios dentro dos quais não há diferenças estatisticamente significativas. O método atualmente utilizado para discriminar entre os meios. A Tabela. D.2 e D.3 aplica um procedimento de comparação múltipla para determinar quais os meios que são significativamente diferentes dos outros. A metade inferior da saída mostra a diferença estimada entre cada par de meios. Um asterisco foi colocado ao lado de 42 pares, indicando que esses pares apresentam diferenças estatisticamente significativas com um nível de confiança de 95,0 \% é o procedimento de menor diferença significativa (LSD) de Fisher.

Tabela D.1 - Método: 95,0 \% LSD.

\begin{tabular}{cccc}
\hline Nivel & Contagem & Média & Grupos Hologêneos \\
\hline 10 & 9 & 0,005 & $\mathrm{X}$ \\
\hline 9 & 9 & 0,008 & $\mathrm{X}$ \\
\hline 8 & 9 & 0,02 & $\mathrm{X}$ \\
\hline 7 & 9 & 0,02 & $\mathrm{X}$ \\
\hline 5 & 9 & 0,04 & $\mathrm{X}$ \\
\hline 6 & 9 & 0,06 & $\mathrm{X}$ \\
\hline 4 & 9 & 0,06 & $\mathrm{X}$ \\
\hline 2 & 9 & 0,11 & $\mathrm{X}$ \\
\hline 3 & 9 & 0,18 & $\mathrm{X}$ \\
\hline 1 & 9 & 1,13 & $\mathrm{X}$ \\
\hline
\end{tabular}


Tabela D.2 - Testes de alcance múltiplo para Ra por Processo ou número de lixa.

\begin{tabular}{|c|c|c|c|}
\hline Contraste & Sig. & Diferência & +/- Limites \\
\hline $1-2$ & * & 1,02 & 0,015 \\
\hline $1-3$ & $*$ & 0,95 & 0,015 \\
\hline $1-4$ & $*$ & 1,07 & 0,015 \\
\hline $1-5$ & $*$ & 1,09 & 0,0173286 \\
\hline $1-6$ & $*$ & 1,07 & 0,0173286 \\
\hline $1-7$ & * & 1,11 & 0,0173286 \\
\hline $1-8$ & $*$ & 1,11 & 0,0173286 \\
\hline $1-9$ & $*$ & 1,13 & 0,0173286 \\
\hline $1-10$ & $*$ & 1,13 & 0,0173286 \\
\hline $2-3$ & * & $-0,07$ & 0,0173286 \\
\hline $2-4$ & * & 0,04 & 0,0173286 \\
\hline $2-5$ & * & 0,07 & 0,0173286 \\
\hline $2-6$ & * & 0,05 & 0,0173286 \\
\hline $2-7$ & $*$ & 0,09 & 0,0173286 \\
\hline $2-8$ & $*$ & 0,09 & 0,0173286 \\
\hline $2-9$ & $*$ & 0,10 & 0,0173286 \\
\hline $2-10$ & $*$ & 0,10 & 0,0173286 \\
\hline $3-4$ & $*$ & 0,11 & 0,0173286 \\
\hline $3-5$ & $*$ & 0,14 & 0,0173286 \\
\hline $3-6$ & $*$ & 0,12 & 0,0173286 \\
\hline $3-7$ & $*$ & 0,16 & 0,0173286 \\
\hline $3-8$ & * & 0,16 & 0,0173286 \\
\hline $3-9$ & $*$ & 0,17 & 0,0173286 \\
\hline $3-10$ & * & 0,18 & 0,0173286 \\
\hline $4-5$ & $*$ & 0,02 & 0,0173286 \\
\hline $4-6$ & $*$ & 0,005 & 0,0173286 \\
\hline $4-7$ & $*$ & 0,04 & 0,0173286 \\
\hline $4-8$ & $*$ & 0,04 & 0,0173286 \\
\hline $4-9$ & $*$ & 0,05 & 0,0173286 \\
\hline $4-10$ & $*$ & 0,06 & 0,0173286 \\
\hline $5-6$ & $*$ & $-0,021$ & 0,0173286 \\
\hline $5-7$ & $*$ & 0,017 & 0,0173286 \\
\hline $5-8$ & $*$ & 0,018 & 0,0173286 \\
\hline $5-9$ & $*$ & 0,033 & 0,0173286 \\
\hline $5-10$ & $*$ & 0,036 & 0,0173286 \\
\hline
\end{tabular}


Tabela D.3 - Testes de alcance múltiplo para Ra por Processo ou número de lixa.

\begin{tabular}{lccc}
\hline Contraste & Sig. & Diferência & $+/$ - Limites \\
\hline $6-7$ & $*$ & 0,038 & 0,0173286 \\
\hline $6-8$ & $*$ & 0,039 & 0,0173286 \\
\hline $6-9$ & $*$ & 0,054 & 0,0173286 \\
\hline $6-10$ & $*$ & 0,057 & 0,0173286 \\
\hline $7-8$ & $*$ & 0,001 & 0,0173286 \\
\hline $7-9$ & $*$ & 0,016 & 0,0173286 \\
\hline $7-10$ & $*$ & 0,019 & 0,0173286 \\
\hline $8-9$ & $*$ & 0,015 & 0,0173286 \\
\hline $8-10$ & $*$ & 0,018 & 0,0173286 \\
\hline $9-10$ & $*$ & 0,003 & 0,0173286 \\
\hline
\end{tabular}

* Denota diferença estatisticamente significante.

Análise estatística entre os resultados obtidos através da metodologia proposta neste trabalho utilizando Microscopia Holográfica Digital (MHD) e o Perfilometro óptico sem contacto 3D (CCI).

Dados de entrada: 
Tabela D.4 - Resultados da Ra $(\mu m)$

\begin{tabular}{|c|c|c|}
\hline Amostra & $\begin{array}{c}\text { Sistema } \\
\text { MHD }\end{array}$ & $\mathrm{CCI}$ \\
\hline 1 & 1,10867 & 1,10900 \\
\hline 1 & 1,10956 & 1,11200 \\
\hline 1 & 1,19178 & 1,19200 \\
\hline 2 & 0,08265 & 0,10160 \\
\hline 2 & 0,14018 & 0,14090 \\
\hline 2 & 0,10508 & 0,10240 \\
\hline 3 & 0,19889 & 0,19210 \\
\hline 3 & 0,17423 & 0,17220 \\
\hline 3 & 0,19467 & 0,19230 \\
\hline 4 & 0,06089 & 0,06090 \\
\hline 4 & 0,06310 & 0,06129 \\
\hline 4 & 0,08217 & 0,08130 \\
\hline 5 & 0,03653 & 0,03810 \\
\hline 5 & 0,04680 & 0,04590 \\
\hline 5 & 0,04372 & 0,04410 \\
\hline 6 & 0,08298 & 0,08050 \\
\hline 6 & 0,11104 & 0,05260 \\
\hline 6 & 0,05272 & 0,05240 \\
\hline 7 & 0,02256 & 0,02271 \\
\hline 7 & 0,02453 & 0,02452 \\
\hline 7 & 0,02637 & 0,02012 \\
\hline 8 & 0,02496 & 0,02000 \\
\hline 8 & 0,02491 & 0,02110 \\
\hline 8 & 0,02388 & 0,02230 \\
\hline 9 & 0,00856 & 0,00830 \\
\hline 9 & 0,00914 & 0,00930 \\
\hline 9 & 0,01670 & 0,00835 \\
\hline 10 & 0,00756 & 0,00480 \\
\hline 10 & 0,00476 & 0,00460 \\
\hline 10 & 0,00480 & 0,00550 \\
\hline
\end{tabular}


Tabela D.5 - Cpmparação de modelos alternativos

\begin{tabular}{lcc}
\hline Modelo & Correlação & R-Quadrado $(\%)$ \\
\hline Double squared & 1,0000 & 100,00 \\
\hline Linear & 0,9994 & 99,88 \\
\hline Double square root & 0,9971 & 99,43 \\
\hline Multiplicative & 0,9906 & 98,12 \\
\hline Squared-Y & 0,9899 & 98,00 \\
\hline Squared-X & 0,9895 & 97,90 \\
\hline Square root-X & 0,9717 & 94,41 \\
\hline Square root-Y & 0,9707 & 94,22 \\
\hline Double reciprocal & 0,9533 & 90,88 \\
\hline Squared-Y square root-X & 0,9316 & 86,78 \\
\hline Square root-Y squared-X & 0,9310 & 86,68 \\
\hline Logarithmic-Y square root-X & 0,9079 & 82,44 \\
\hline Square root-Y logarithmic-X & 0,9072 & 82,29 \\
\hline Exponential & 0,7958 & 63,33 \\
\hline Logarithmic-X & 0,7944 & 63,11 \\
\hline S-curve model & $-0,7860$ & 61,78 \\
\hline Reciprocal-Y logarithmic-X & $-0,7638$ & 58,34 \\
\hline Logarithmic-Y squared-X & 0,7179 & 51,53 \\
\hline Squared-Y logarithmic-X & 0,7142 & 51,01 \\
\hline Square root-Y reciprocal-X & $-0,5163$ & 26,66 \\
\hline Reciprocal-X & $-0,3526$ & 12,43 \\
\hline Squared-Y reciprocal-X & $-0,2688$ & \\
\hline Reciprocal-Y squared-X & $-0,2618$ & \\
\hline Reciprocal-Y & $<$ sem ajuste & \\
\hline Reciprocal-Y square root-X & $<$ sem ajuste & \\
\hline Logistic & $<$ sem ajuste & \\
\hline Log probit & $<$ sem ajuste & \\
\hline
\end{tabular}

